

\section{LIBRARY OF CONGRESS,}

Chap........ Copyright No.. Shelf $57 \neq+6$ Shell...79

UNITED STATES OF AMERICA. 






\section{VETERINARY HOMEOPATHY}

IN ITS APPLICATION TO THE

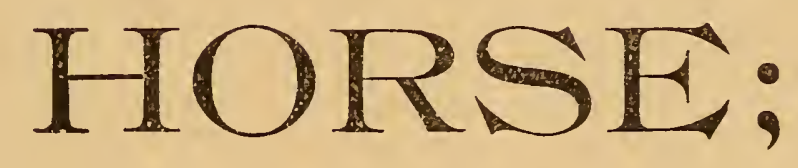

INCLUDING A CODE OF COMMON

\section{SUGGESTIVE SYMPTOMS,}

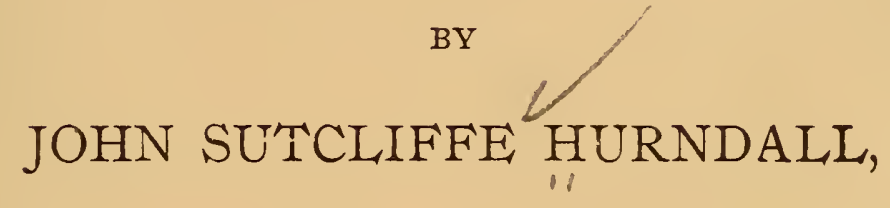

Member of the Royal College of Veterinary Surgeons, England.

PHIIAADELPHIA:

$$
29015-B^{2}-1
$$

BOERICKE \& TAFEL.

I 896 . 


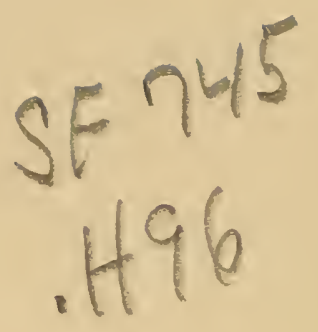

COPYRIGHTED, I896,

BOERICKE \& TAEL.

T. B. \& H. B. COCHRAN, PRINTERS, LANCASTER, PA.

$12-13348$ 


\section{CONTENTS.}

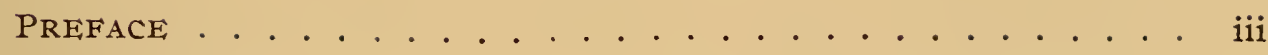

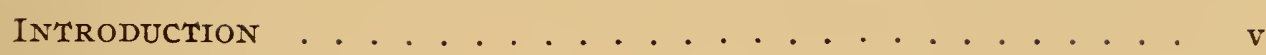

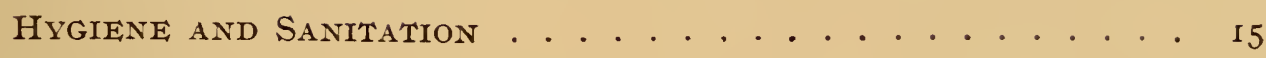

DIAGNosis . . . . . . . . . . . . . . 2I

STRENGTH OF DRUGS AND THE DOSE ............... 34

ARRANGEMENT OF DISEASES $\ldots \ldots \ldots \ldots \ldots$

General Diseases . . . . . . . . . . . . . . . 45

Simple Fever . . . . . . . . . . . . . . . 45

Bilious Fever . . . . . . . . . . . . 46

Strangles . . . . . . . . . . . . . . . 47

Influenza . . . . . . . . . . . . . . 50

Erysipelas . . . . . . . . . . . . . . ${ }_{58}$

Glanders and Farcy .............. 6I

Anthrax . . . . . . . . . . . . 72

Rheumatism. . . . . . . . . . . . 77

BLOOD POISONING. . . . . . . . . . . . . . . 82

Pyæmia, Septicamia . . . . . . . . . . . . 82

Rabies . . . . . . . . . . . . . . . . 85

Weed, Lymphangitis . . . . . . . . . . . . . 87

Purpurea Hæmorrhica . . . . . . . . . . . . . . . . 92

DISEASES OF PARTS AND ORgans INCLUdED IN THE RESPIRATORY

TRACT . . . . . . . . . . . . . . . . 95

Common Cold . . . . . . . . . . . . . . 96

Nasal Gleet . . . . . . . . . . . . . . . . . . . 97

Laryngitis . . . . . . . . . . . . . IOI

Roaring . . . . . . . . . . . . . . 103

THE LUNGS . . . . . . . . . . . . . . . . . . . . IO9

Bronchitis . . . . . . . . . . . . IIO

Congestion of the Lungs . . . . . . . . . . . II5

Pleuro-pneumonia . . . . . . . . . . . 115 
CONTENTS.

Broncho-pneumonia . . . . . . . . . . II5

Pneumonia . . . . . . . . . . . . . II6

Pleurisy . . . . . . . . . . . . . I23

Asthma-Broken Wind . . . . . . . . . . . I26

Newmarket Fever . . . . . . . . . . . . I29

DISEASES OF THE CIRCULATORY SYSTEM . . . . . . . I I32

Palpitation ................ . . 136

Enlargement or Dilations of the Heart ......... $\mathrm{I}_{3} \mathrm{~S}$

Carditis, Endocarditis, Valvulitis, ......... . I40

Fatty Degeneration of the Heart . . . . . . . . . . 146

Arteries . . . . . . . . . . . . . . . . 146

Phlebitis-Inflammation of the Veins . . . . . . . . I47

Hiccough, Spasm of Diaphragm . . . . . . . . I 48

DISEASES OF DIGESTIVE SYSTEM. . . . . . . . . . . I49

The Teeth . . . . . . . . . . . . . . $\mathrm{I}_{52}$

Lampas . . . . . . . . . . . . . . . . I54

Glossitis-Inflammation of the Tongue . . . . . . . I56

Parotitis-Inflammation of the Parotid Glands . . . . . . . I57

Pharyngitis-Inflammation of Pharynx . . . . . . . . I59

Sore Throat . . . . . . . . . . . . . . I59

Esophagus, Gullet. . . . . . . . . . . . . I6I

Gastritis-Inflammation of Stomach . . . . . . . I62

Indigestion, Dyspepsia . . . . . . . . . . . I67

Rupture of the Stomach . . . . . . . . . . I70

The Intestines . . . . . . . . . . . . . . . . I74

Intestinal Obstruction . . . . . . . . . . I76

Colic . . . . . . . . . . . . . . . . I 183

Rupture of Intestinal Walls . . . . . . . . . . . I88

Enteretis-Inflammation of the Intestines . . . . . . . I90

Dysentery . . . . . . . . . . . . . . . I92

Prolapsus Ani . . . . . . . . . . . . . . . . . . I94

Peritonitis . . . . . . . . . . . . . . I95

Acites, Dropsy . . . . . . . . . . . . . I97

Constipation . . . . . . . . . . . . . . I98

Diarrhœa ... . . . . . . . . . . . 205

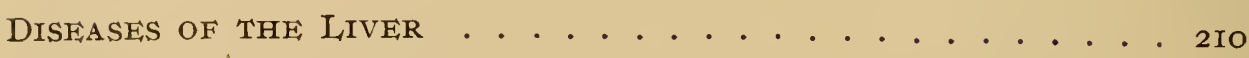

Congestion of the Liver . . . . . . . . . . . 2 II

Diseases OF THE URINARY and Generative ORganc . . . . 214 


\section{CONTENTS.}

Congestion of Kidneys, Renal Congestion . . . . . . . . 217

Nephritis: Inflammation of Kidneys . . . . . . . . 2 I9

Diabetes ................. . . 223

Cystitis: Inflammation of the Bladder. . . . . . . . 225

Azoturia . . . . . . . . . . . . . . . 227

Occasional Diseases of the Urinary Organs . . . . . . 229

PARTURITION . . . . . . . . . . . . . . . . 233

Before, During and After the Act . . . . . . . . . 233

Retention of the Fœtal Membranes . . . . . . . . . 237

After-birth .................. 237

Hæmorrhage or Flooding . . . . . . . . . . . 238

Diseased Conditions Incidental to Parturition . . . . . . . . 240

Vaginitis: Inflammation of Vagina . . . . . . . . . 24I

Metretis: Inflammation of the Womb . . . . . . . . 242

Mammitis: Inflammation of the Udder . . . . . . . 244

Sore Teats . . . . . . . . . . . . . . 246

The Foal . . . . . . . . . . . . . . 246

Arthritis ................ . . . 248

Abortion and Premature Birth .......... . 250

THE NeRvous SYSTEM . . . . . . . . . . . . 260

Meningitis. Cerebritis: Inflammation of the Brain . . . . 266

Cerebro-Spinal Meningitis ............ . 268

Tetanus-Lock-jaw . . . . . . . . . . 27I

Chorea ................ . . 275

Paralysis . . . . . . . . . . . . 276

LAMENESS . . . . . . . . . . . . . . . . . . . . 278

SPRAINS OF Tendons, Ligaments AND MUScles ...... . 28I

DISEASES OF THE EYE . . . . . . . . . . . . 304

Occasional Diseases. . . . . . . . . . . . . 310

DISHASES OF THE SKIN . . . . . . . . . . . 312

INTERnai PARASITES . . . . . . . . . . . . . 320

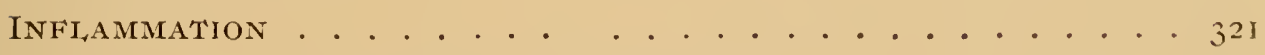

Conf of Common Suggestive Symptoms. . . . . . . 327

GeNERAL INDEX . . . . . . . . . . . . . 337 



\section{PREFACE.}

The object I have tried to keep before me while preparing this book, has been to furnish, in concise and, so far as possible, unconventional language, information that will enable those who have the charge of horses to discover what ails the animal when signs of illness or incapacity for work are observed; and further how to treat a patient under such conditions. I make no claim for the production of a scientific work; but I am attempting to cater to those who have no acquaintance either with medicine or disease but who at the same time are thrown upon their own resources when their equine charges fall ill. I am informed that over large districts of the United States of America, the services of a qualified Veterinary Surgeon are not available simply because there is not one resident within a reasonable distance; I hope that in such districts, especially, this book will prove of considerable service. It has been my aim to treat of common and oft-recurring ailments and in my descriptions I have sought to express myself in the everyday language of the stable.

If in the opinion of some it should seem that I am chargeable with prolixity and that many phrases are oft repeated, I must ask one and all to remember that I am writing for the million, among many of whom, educational advantages may possibly not have been of the highest order; to make clear to such as these, the full meaning of all I desire to convey, has, as it seems to me, rendered the frequent repetition of phraseology an absolute necessity.

Conventional terms appear much oftener than I could have desired, but to avoid these simply means to leave many ailments untouched; I have therefore sought to obviate the objection which may possibly be raised to their introduction by a very full Index to which reference can always be made to insure a simpler understanding of the meaning.

With a view to render it comparatively easy to discover a given ailments, I have prepared a list of prominent suggestive symp- 
toms, such as are common to the observation of any man who is qualified to undertake the responsibility of managing or superintending a stable; and in juxtaposition therewith, the names of the various diseases in which these symptoms occur; on a careful perusal of this portion of the work it will be observed that quite a large proportion of these symptoms occur in a number of different diseases, and, perhaps, it may strike some persons that, after all, the list of suggestive symptoms is not much help; but my advice is, that when a horse appears unwell, a note should be made of all the chief symptoms observable; thereafter refer to the list, and the disease which covers the greater number of symptoms should be studied in order to determine if the case in hand answers to the fuller description therein contained. The number of remedies prescribed in the body of the work is considerable, and under some special forms of disease circumstances demand reference to various remedies; the careful comparative study of the "suggestive symptoms" with those symptoms which indicate the selection of a given drug under specific conditions, will be found extremely useful as it will result in conveying a lasting impression upon the mind that will render the practice of recognizing symptoms much easier on future occasions.

I sincerely hope that as these "suggestive symptoms" become thoroughly impressed upon the minds of those who do me the honor to consult this work, the simpler will the task of recognizing disorder become from time to time; and that the object I had in view when I undertook this work will be fully realized and ultimately prove a boon to many a man who is thrown entirely upon his own resources in the management and treatment of his horses.

J. Sutcliffe Hurndali, M. R. C. V. S., Sussex Villas, Kensington, London, July, 1895. 


\section{INTRODUCTION.}

For every work that is worth the doing, a good reason may, if necessary, be assigned, for how can a good work exist without a reasonable cause! It may not be absolutely necessary to advance a reason for the production of the present work on "Veterinary Homœopathy in its Application to the Horse." Nevertheless it is to be hoped that it will not detract from its usefulness if an attempt is made to explain why the production of such a work should have been entertained.

During the last two decades the science of Physiology, which purports to treat of the body in a state of health, and the science of Pathology, which, in like manner, treats of the bodily functions in a state of disease, have respectively made rapid advances both as regards discovery and application; but, apart from those who practice Homœopathy, little or no advance has been made in the science of Therapeutics, which is the science of curing disease; this may seem an unwarrantably dogmatic assertion, but it has been so frequently admitted by leaders of the medical profession to be a lamentable fact, that any one who has a practical acquaintance with the "better way," may well be pardoned for referring to so weak a spot in the armour of the general orthodox practitioner. In view of the fact that a very large majority of the medical practitioners of the world, and for the sake of comparison to all intents and purposes, all the Veterinary Practitioners, remain faithful to the old system of medicine, which, since Homœopathy sprung into existence has been termed Allopathy, the practical and intelligent layman naturally asks the question as to what is the distinction between these two systems; and in many instances it is not before either he or some dearly belored friend has been snatched from the jaws of death by means of the medical system known as Homœopathy after all that could be done by means of the old-fashioned system of allopathy has been tried and failed, that serious attention has been given to the subject and even then it is 
admired and relied upon, in ninety-nine cases out of a hundred, because, notwithstanding the antiquity of the old system, the new has done what the old failed to realize and the man accepts the truth of Homœopathy and believes in it because through it his life or that of his friend was saved.

It is quite true that Homœopathy has done what Allopathy has failed to do, and it is impossible to assign an intelligible reason for the non-acceptance of the principles of Homœopathy among so large a proportion of the medical and Veterinary professions, the real fact, stated in plain unvarnished language is, that for some unaccountable reason, the word Homœopathy and the name of Hahnemann, its discoverer and founder, are like the proverbial red rag to a bull, to members of these professions; the bull without thought, reason or compunction on seeing a red rag tosses and does his best to destroy it; this is very much like the action of the medical profession towards Homœopathy; a rational person would naturally conclude that on hearing of what Homœopathy could do and had done, the medical profession, whose first duty it is to save life and ameliorate suffering, would hail with joy and thanksgiving any discovery that promised well to realize so desirable an object; and that, without loss of time, it would fearlessly and honestly investigate the facts and prove them for itself; it is acknowledged that by no means an inconsiderable number has adopted this course, with the result that so far as is known publicly not one single member of the allopathic professions ever undertook the serious investigation of Homœopathy with a conscientious determination to learn the truth, the whole truth and nothing but the truth who did not accept the principle as his guide in the future. This is a fact worthy the serious consideration of every practical layman, and from it he may without difficulty draw his own deductions as to the reason why so few, as compared with the fuil roll of medical practitioners and Veterinarians in the world have adopted Hahnemann's golden rule, as their own; true, America has shown a splendid example and she has done more to foster the growth and development of this glorious, life-saving principle than any country in the world, and she includes among the alumni of her famous medical colleges a sufficiently influential number of the loyal followers of Hahnemann who are a power in the States; still, as compared with the vast 
army of allopathists they are but feeble folk numerically. The position which homøopathists occupy would seem to furnish a sufficiently valid reason for the production of a practical manual that shall serve as a guide to laymen, especially those located in districts which lie very distant from the centres where the professional veterinarian is established, and that without reference to the fact that the system offers advantages far and away superior to the old fashioned practice chiefly in vogue among the general run of veterinary surgeons. It is of the first importance that all whom it concerns should enjoy an intelligent appreciation of the difference between Homœopathy and Allopathy; and in the first place with a view to explain the matter, it may be safely averred that whereas Allopathy means, etymologically, treating by opposites, Homœopathy is treating by likes. At first sight it looks as though Allopathy had, from a rational standpoint, the best of the argument, but as we proceed we shall discover that Allopathy furnishes no guiding principle in the selection of drugs, whereas the foundation of Homœopathy is based upon its one guiding principle "likes may be cured by likes" and but for this the whole superstructure would tumble to pieces, " -in fact there would be no superstructure. Let us attempt in a few simple words to clear up the objections to the old-fashioned allopathic method of prescribing; it has already been said that allopathists have no principle or law to guide them in selecting drugs for the cure of diseases, and remarkable as this may seem to those not practically acquainted with medicine, it is an undeniable fact; it has also been stated that allopathists pretend to prescribe and treat disease by opposites, that is to say they endeavor to find a drug or method of treatment which is contrary or opposed to the patient's symptoms, or disease; for instance, if an animal or man is constipated, administer a purge or laxative; if loose in the bowels administer an astringent, and so on; at first sight this appears a very rational line of procedure; but inquire a little further; how are you to find out the contrary or opposite of a toothache, a stomachache, a sore throat, sickness, inflammation of the lungs, bronchitis, inflanmation of the kidneys, and so on to the end of the chapter; the fact is you cannot do anything of the sort, and it will be clear to the perception of any practical mind, that failing this, the allopathists' method has 10 guiding principle about it. The same objec- 
tion arises when you examine the plan allopathists adopt of treating diseases from knowledge gained through the study of pathology, which is the science that deals with the changes that go on in the various organs of the body, and the tissue or material of which those organs consist; for instance, consider what changes take place under certain conditions in the liver and the lungs; without any scientific knowledge, any man who has been in a Knacker's yard and seen these organs exposed to view could easily tell that very considerable changes had taken place in the tissue if only guided by the color and texture of these organs when diseased as compared with those recognized as in a healthy or normal condition; well! how can a contrary or opposite in the form of a drug be found to these diseased conditions? Knowledge, such as allopathists have, can only be obtained by experimenting on patients, and this many of them not only admit, but boast is their method of prescribing; experience and experiment are very forcible and effective words and sound well to the mind not specially trained in medicine, but they may be badly applied, and mislead the unwary, and so they have done, and still are doing; but it is the duty and the privilege of those who have studied the principles of Homcopathy to show to all intelligent people who are willing to learn, that there is a rule or guiding principle, based on scientific principles, as unerring in its application as any of the great and acknowledged laws of nature by which the Veterinarian and medical man may determine what drug to administer in the thousand and one ailments to which man and beast are daily falling victims; to the practical layman, who looks at the matter from a common sense point of view, and whose mind is not biased by any old traditions, the system, which can give a welldefined reason for its regular course of action, must assuredly commend itself. Now, for the better understanding of the matter let us ask the question "What is Homœopathy?" Many persons are under the impression that this word is associated only with the administration of small, and in some cases infinitesimal, doses; that the drugs are generally prepared in the form of globules or pilules and are devoid of nauseous taste; but it must please be distinctly understood that these are erroneous conceptions of the meaning of Homœopathy; there is not a vestige of truth in the idea, and the reason why it became so prevalent 
can only be due to the fact that few persons have ever troubled themselves to investigate and find out the truth concerning the system; they have satisfied themselves with the result of the practice of Homœopathy either in their own experience or that of an intimate friend, and there the matter has ended, but to aroid any misunderstanding let it be distinctly understood the matter of the dose is one of experience only and has nothing to do with the principle; this alone depends upon a law based on the relationship which exists between a given drug and the symptoms it is capable of producing on a healthy subject and the symptoms which present themselves in a subject when affected by disease. The various strengths of drugs as defined in the Homœopathic Pharmacopœia and the very precise methods of their preparation are the results of extensive practice after Hahnemann introduced the Law of selection to public notice, and it is very necessary that they should be observed and adopted, for there is no doubt that very frequently the drug which is homøopathically selected and administered in its crude form not only fails to do good but actually does harm by intensifying and rendering more acute the very condition it is intended to alleviate; further the methods of preparation, which Hahnemann laid down for the guidance of the Pharmaceutical Druggists should be conscientiously observed, as there is no doubt, whatever some Practitioners may say to the contrary, that the succussion or shaking of the tinctures and the persistent trituration with the pestle and mortar of the powders brings out in some mysterious way the active power of the drug, without which it is absolutely ineffectual and useless, and to the absence of these precautions are traceable the failure and disappointment which unfortunately will crop up in homœopathic practice; there is a great tendency in the present day to ignore the value of what are called high attenuations, simply because the practitioners who attribute little importance to the value of highly potentized drugs appear incapable of appreciating the fact that in this condition they are more (under certain conditions) effective than in the crude state; the fact that they are so,--these learned gentlemen notwithstanding, - has been proved among the lower animals very frequently.

But to return to the main subject, viz. the Law which constitutes the principle of Homœopathy: it does not call for the ex- 
ercise of much imagination to understand that given a healthy subject, whether among the human race or the lower animals, and you administer a 1non-poisonous dose of Arsenic, Mercury, Strychnine, Aconite, Belladonna or any other drug, whether it belongs to the mineral, vegetable, or animal worlds, you will in all probability be able to observe the result, which result will make itself known by certain symptoms either experienced by the subject in the way of sensation or noticeable to the eye of anyone looking on; for instance, if a person takes sufficient Belladonna to produce the ordinary effects of this drug on the healthy, both kinds of symptoms will present themselves: first the subjective, or symptoms of sensation experienced by the person, namely, a sore throat, headache and fever; second, a symptom observable to the eye of one looking on, namely, a scarlet rash on the skin; this is an objective symptom. Now these subjective and objective symptoms, namely, fever, headache, sore throat and scarlet rash furnish a picture of the symptoms experienced by one who is the subject of scarlet fever. Belladonna therefore is the remedy according to Hahnemann's law of drug selection for scarlet fever, and so clinical or bedside experience has proved it to be, times out of number; but in the practical application of this law there is a pitfall into which many persons fall when attempting to put it to the test, and not a few of these failures could be found among members of the medical and veterinary professions, what wonder, therefore, if a layman makes a mistake! The pitfall consists in taking one, two, three or more symptoms while two or three others that may be present were overlooked or ignored; Hahnemann states that the totality-which means the whole of them, not leaving even one out-of the symptoms, either patent to the naked eye, or experienced or felt by the patient, must be included to enable the doctor to properly select the remedy for the case before him; by way of illustration take scarlet fever and Belladonna already referred to; a person might easily be the subject of fever and have a headache and sore throat, but if there was 110 bright scarlet rash on the skin depend upon it he was suffering from something other than scarlet fever; in which case the fever, headache and sore throat would not point to Belladonna as a suitable remedy; provided, always, that those three symptoms formed the totality of the symptoms of the case. With these facts 
before the reader it will be quite clear that to select a drug for a case of disease or illness requires close observation, especially among the lower animals who cannot give expression to their feelings by word of mouth; at the same time anyone constantly among animals, who is endowed with quick perception, can soon learn much from the dumb show often most intelligently displayed by these creatures that shall lead to quite as correct an estimate of their sensations as can be learned from the higher order of creation who by word of mouth not infrequently mislead by incorrect or wilfully untrue statements. It will now be seen that the homœopathic law, "Likes may be cured by likes," has a scientific foundation, inasmuch as it furnishes a means for and a guide in the choice of a medicine, and for this reason alone it should commend itself to every man of ordinary intelligence. There is no diffculty in finding suitable remedies, inasmuch as Hahnemann and a considerable number of his followers in more recent times have tested the action of a very large proportion of the drugs now in. cluded in the pharmacopœia upon themselves when in health, and these have been recorded in various books which are now kept for reference; of necessity the study calls for a retentive memory backed up by indomitable perseverance before anything like an adequate understanding of the subject can be arrived at; but to render the present work of practical use to the horse owner who desires to treat his own animals a summary of the principal symptoms in many of the more common ailments will be prepared, so that reference may the more readily be made to that portion of the book which deals with diseases under their recognized headings, and the special remedies will be indicated; in this manner it is hoped to compensate the layman for his want of technical knowledge and experience, and in this way assist those who by reason of locality are unable to avail themselves of professional advice. Let us now examine the position arrived at; it is an acknowledged fact among those who content themselves with prescribing drugs as the allopathist does, that EXPERIENCE is the sheet anchor on which they rely; let us assume that a certain man or a certain animal was the subject of an illness, which the allopathic practioner described in his professional phraseology as "Pneumonia," which in plain language means "inflammation of the lungs;" a certain course of treatment was adopted in this case and the result, together witl 
the name of the drug or drugs used, has been handed down to future generations of practitioners; the patient recovered, hence when other cases of Pneumonia crop up the allopathist falis back upon the system of treatment which he finds recorded as above; and so the thing has gone on for ages; but not one of those who have acted on this line could give any scientific reason for the use of the drug or drugs referred to, and more often than not disappointment has resulted and the patient has died. An effort has been made to give loud-sounding names, based on the science known as pathology, to every form of disease, and in each of the many diseases recognized the same course of procedure has been adopted; one man has tried one thing for a given disease and succeeded; another has experimented on some other drug with equally good results, and so on ad infinitum, and each in their turn published their experience in some book or journal until the medical professions have become fairly bewildered with the numerous prescriptions for various diseases; but this very fact should convince that some other method than an experience based on the uncertain foundation of guess work is called for; you may give names to such as Pneumonia, Bronchitis, Pleurisy and the like, and for professional descriptive purposes these names may serve a useful purpose; but there never were two cases of Pneumonia, or Bronchitis, or Pleurisy, or any other form of disease, recognized by name, that were exactly alike; some symptoms occur in one case that do not present themselves in another, and the presence of one or more symptoms in one case that are absent in another are quite sufficient to account for the failure of a certain line of treatment that was perhaps marvellously successful in another that had preceded it; the allopathic practitioner places no value upon the totality of the symptoms; in other words, he generalizes, but is not sufficiently precise.

This is where Homœopathy steps in and furnishes a definite mode of procedure; it does not ignore any symptoms; nay more, it not only includes the aggregate or totality of the symptoms presented at the time by the patient, but takes into consideration any symptoms experienced or that may have been observed in the previous history of the case; and comparing all these as a whole, with the symptoms that drugs are capable of producing in the healthy body as a whole, a correct selection of a drug for a given 
ailment may be made on the principle or law that likes may be cured by likes; as before stated, given several cases of Pneumonia, Bronchitis, or Pleurisy, no two cases will present an exactly similar totality of symptoms, therefore, though generally speaking, the names given to these diseases may be useful, they do not furnish any reliable data whereupon a doctor may select a remedy; every case must be taken as it is found and the guide for the selection of the drug must be the aggregate of the symptoms presented; in conclusion the law of healing (Therapeutic Law) includes two classes of symptoms: First.-The symptoms outwardly exhibited and inwardly felt by the patient. Second.-The symptoms produced in a healthy subject by a drug; provided always that the symptoms which the drug produces are similar to those of the patient, under which circumstances the former will relieve and remove the latter. So far our aim has been to make clear the system of medicine in accordance with which the ailments of a patient may be cured through the instrumentality of a remedy in the form of drugs; but it must be distinctly understood that as with the human subject, so, and indeed more also, with horses it frequently happens that circumstances calling for very careful attention arise in which the science of treating animals by means of drugs (therapeutics) will not meet the case adequately, or, indeed, at all; for instance, a horse meets with an injury due to an unavoidable accident, or he has his foot severely pricked while being shod; again, you may own a mare that is with foal, which, by reason of its having got into an unnatural position cannot be born without assistance; these are cases calling for operative surgery; and while it is not at all improbable that the condition of the patient may be such, as a consequence of these circumstances to require the administration of drugs by way of assistance, the difficulties could not be got over by drugs alone; operative surgery here would be the chief factor in the course of treatment; therefore it must not be imagined that cases such as these calling for mechanical interference can be cured by the administration of drugs only. Again, there are certain diseases which owe their origin to parasites, which are found both in the body and upon it externally; for the removal of these chemical or mechanical means must be adopted; for the destruction of these animal or vegetable organisms the homœopathic law is not applicable, though there is 
very little doubt that so far as internal parasites are affected much can be done to render the places of their abode in the organism an unsuitable habitation, by which is meant that the intestines when they harbor parasites are not in a healthy condition and consequently favor the production of parasitic germs, and that by the administration of suitable remedies they may be restored to a healthy condition and as a result rendered unfavorable to the production and development of parasites; thus far drugs may be useful, but it cannot be said that under such circumstances the homœopathic law is brought into practice; that is to say, in the sense of curing a disease by drugs alone; the parasites have to be destroyed, hence the process is a chemical one and not a therapeutic. Although many of these methods of treatment do not come within the possible knowledge of a layman, it has been deemed necessary to clearly point them out lest a misconception should arise that all diseases can be cured by drugs alone; there are limits in the application of the homœopathic law of cure, and it is desirable that this should be clearly understood, otherwise discredit will be brought upon the principle and great disappointment experienced by persons who may be attempting an impossibility. Although this attempt at expounding the tenets of the homœopathic faith has been made, the author feels he has but feebly realized the objects aimed at; the difficulties have rather been enhanced by reason of the necessity laid upon him by the publishers to avoid, as much as possible, technical professional terms; still it is hoped that this introductory chapter will not be without interest and utility, in so far as those who desire to avail themselves of the work may be able to comprehend the difference between the man who has a principle to guide him in the selection of a drug for any given ailment, and he who simply does so by guess work on the off chance that a cure may be hit upon. 


\title{
HYGIENE AND SANITATION
}

\author{
OR PRINCIPLES TO BE OBSERVED FOR THE PRESER- \\ VATION OF HEALTH.
}

The old-fashioned adage that "prevention is better than cure," cannot be more usefully brought into practice than in its application to the health of the horse and other domestic animals; for so long as a horse enjoys immunity from disease, so much more valuable is he to his owner, as no time is lost in the due fulfillment of his daily duties, to say nothing of the absence of anxiety and trouble on the owner's or stableman's minds and parts, by reason of attention and expense involved during a bout of sickness; therefore it will not be out of place to devote a special chapter to the careful consideration of how to keep a horse in health so far as ordinary precautions avail.

One of the first and most important matters for consideration is the construction of the stable; few, if any, architects seem able to grasp the first principles of ventilation, or, if acquainted with them, rarely carry them into practice; free circulation of pure air combined with a complete freedom from cold draughts is an absolutely essential feature of a healthy stable; many horses, especially those kept for racing, hunting, trotting and carriage work, are kept in elaborately built stables in which a high temperature is maintained by keeping the inlets to fresh air tightly closed, and that without any provision for its ingress other than passes throngh the windows or doors. Places no better provided with ventilation than this are egregiously faulty; horses kept for sport and private convenience, especially the former, are, without doubt, rendered peculiarly susceptible to disease, particularly diseases affecting the respiratory organs, by the mistake of keeping them in an unnaturally high temperature; it is quite possible to keep a horse sufficiently warm to fulfill the exigencies of training for racing and liunting and 
carriage work, and still to maintain an equable temperature combined with a free circulation of pure air, but to do this windorws and doors must not be relied upon. Windorvs are intended for the admission of light and doors for the passing in and out of the inhabitants. Fresh air must have a means of ingress, and foul air a means of egress peculiar to each, and that altogether separate and distinct from doors and windorvs; the requirements may best be provided in the following manner: The walls of the stable should be from fourteen to eighteen inches thick, and the inside should be either plastered or faced with glazed bricks, about twelve inches above the level of the ground outside. A longitudinal channel should be left in the centre of the wall about four and a half inches wide and nine inches deep, and on a level with this channel, both inside and out, perforated bricks should be laid alternately; that is to say, the outside perforated bricks should not be directly opposite those inside, but alternate with them. The object of this is, of course, patent to any one, viz., to prevent direct ingress of the fresh air, and so obviate a draught, at the same time insuring a constant, continuous and gentle diffusion over the whole building; it is no less important to provide for the due escape of foul air as for the admission of fresh, and to this end nothing can exceed in value an open roof with louvre boards running the whole length of the stable; there is, however, one important objection to an open roof, namely, the exposure to cold in winter and heat in summer; but this may be obviated by having a ceiling placed at the same angle as the roof, but about a foot from it, with a large central shaft and side exits under the eaves of the ceiling in the wall. This, of course, does not act so well as the open roof, but it guards the occupants of the stable from the extremes of temperature. By observing these precautions a perfect ventilation is assured.

Next to ventilation comes drainage, which in residential houses is not easy to perfect, but in stables it is a simple matter; given a reasonable fall and surface drains are all that is required within. the building; each stall or loose box should have a central channel towards which the superficial area of the floor should slope in both directions, and this central channel should empty itself into a. main channel running in the longitudinal direction of the building, which in its turn should be discharged into an underground 
drain, but this should be so arranged that the point of discharge should be situated at least six feet from the outer wall of the stable; taking for granted that the floor of the stable is pared with a suitable material that is impervious to moisture, a free sluicing of water will ensure cleanliness and the due washing away of all excrementitious material.

Ventilation and drainage being secured as near perfection as possible, it is very important to the well being of horses that they be abundantly supplied with light, and if you cannot do better than windows in the walls, let them be arranged high up; but better than all are the vertical lights obtained from the roof; but even these are not without their objection lest the sun's rays should rest too fully upon the horses at midday; this, horvever, may be obviated by having the louvre boards replaced by glass in the same form, and if the glass be ground or fluted the rays of the sun will be broken so as not to rest directly on the inmates of the stable. A good light is absolutely essential, not only for the sake of general health, but especially for the preservation of the eyesight.

As it is of the first importance to the health of the horse that he should not be exposed to damp, a precaution which is only too often overlooked, it is very necessary that the site and aspect of the stable should be carefully and properly arranged; nothing, of course, beats a good gravel soil, but if the locality does not enjoy the advantage of this kind of soil, then the place should be well drained to a depth of three or four feet, and the floor of the stable should be raised at least one foot from the level of the ground and allowed to rest upon a concrete base. In the cases of horses trained for racing, hunting and trotting, with whom a perfectly sound condition of the respiratory organs is an essential point, the adoption of open fireplaces is a great advantage, not so much in use for the sake of ensuring warmth, as to keep the stable dry and to render the ventilation more perfect, as well to maintain an even temperature during the night; of course horses can be kept warm in their bodies by the use of clothing, but no anount of clothing will keep out the moisture and cold which is so frequently experienced in districts where rapid climatic changes take place, and proves so disastrous in many instances, though it is to be regretted in the interest of oivners, that trainers and stud 
grooms too often fail to recognize the importance of providing against this natural difficulty; indeed, there is no doubt in the author's mind that among race horses described as non-stayers, or that make a noise (roarers, whistlers, etc.), the cause in the majority of cases is to be traced to stable surroundings; the temperature of the building should not exceed $55^{\circ} \mathrm{F}$., good food, clothing and exercise will do all else that is required to keep a horse warm and comfortable; in conclusion it need hardly be added that cleanliness is a sine-qua-non for the horse, as for the man, and that all excrementitious material, whether solid or fluid, should be swept up and removed with as much expedition as possible from the confines of the building; it is astonishing how rapidly putrefactive changes take place in a horse's excrement if allowed to accumulate, and specially does this apply to the urine, and when the process is established the gases are quickly diffused over the building and the otherwise pure air is loaded with foul exhalations which breathed in through the lungs speedily gain access to the blood and bring on low fevers of an insidious type; indeed, they are more insidious and deeply reaching in their effects upon the animal constitution than is generally recognized and render the system less able to combat those forms of disease which by their distinctive manifestations have more importance attributed to them; many a horse may be the subject of these low types of fever without showing any very precise symptoms or even appearing seriously ill, and while ready to respond to the call of the whip or the spur is quite unable to realize the fond hopes of his owner and trainer by winning a race or a match; but in the majority of instances the condition which is responsible for such failures may be avoided by observing the precautions in stable management herein indicated, and this applies with no less force to horses of all breeds and classes so far as general utility is concerned.

The subjects which include forage, grooming, exercise and stable management generally, might fairly be included under the head of "Hygiene," but as it is desirable not to lengthen out this division of the work inordinately, and every horseman is supposed to understand these matters and to appreciate their value and importance more than the great majority appears to do that affecting the buildings, no attempt will be made to treat of same except to give a warning note about the water; this has such a 
powerful bearing upon health that it cannot be omitted. First. See that your service tanks are regularly and not unfrequently cleaned out. Second. Be sure that no contaminating source from drains or otherwise can come in contact with your water supply. Third. If your horses are constantly supplied with water in the stall, be sure that the supply is changed at least twice daily, so as to avoid the possible contamination from gases originating from putrefactive sources. Fourth. Let your water supply be natural soft water if possible; but should it come from a hard spring, by all means have it boiled in order to counteract the influence exercised upon the digestive organs by the minerals naturally held in solution, which are capable of acting upon the system much as a drug does when administered as a poison. Should this suggestion of the boiling appear to the practical mind of some horse owner, a vague, theoretical, and impracticable sort of idea, which he has not the patience to carry out, then let him see to it that this hard, cold spring water is collected in a tank exposed to the sun's rays for a few hours before it is used; this is the next best thing, but do not fail to understand that much more care is necessary with regard to water supply than is generally acknowledged if you desire to do the best you can for your horses to keep them in health. There is one more point worthy of consideration before leaving this subject of water, and whereas it is one upon which practical horsemen differ it deserves a special word: "When is the best time to allow a hard-worked horse to drink?"

In coming to a definite opinion upon this vexed question it behooves the practical man to bear in mind the anatomy of the horse; First. Remember that the stomach of the horse, compared with other parts of the body, is decidedly small; Second. That he is supplied with a large bag-shaped compartment in the intestinal tract, which forms a sort of cul de sac and is called the Cæecum which serves the purpose of what may be described a water stomach; when a horse drinks, the fluid does not remain any length of time in the digestive stomach but quickly passes on to the Cæcum and from thence is distributed over the body. Now this being the case it points distinctly to the desirability of allowing the horse to partake of such an amount of fluid as the natural call of thirst demands before taking food, because the water which has passed on to the Cæcum will serve the purpose of 
slaking thirst without diluting or interfering with the normal digestive secretions of the stomach which begin to pour out so soon as masticated food enters the organ and hence the process of digestion, can go on without interruption, and the assimulation of the alimentary material in its physiologically natural condition will take place; if water is given after feeding, while the process of digestion is going on in the stomach, the natural digestive fluids are diluted, they cannot act in this state upon the alimentary material and digestion is arrested sntil the fluid has passed on to its proper locality, the Cæcum; still further arguments, might easily be adduced in favor of allowing a hard worked horse to drink before he is allowed to eat, and in the cases of horses such as hunters which have probably been called upon for the exercise of great exertion, and have been hours without any food, it would be a safe course to allow at least a quarter of an hour to elapse after letting them drink before givingfood of any sort, and even then not more than a handful or two of long hay while they are being cleaned and dressed, after which the circulation will have assumed its normal pressure and the stomach will be prepared to receive the food and perform its natural functions.

The object of this chapter has been to merely touch upon the main points affecting the sanitary conditions which have a baneful influence on horses of all classes, and not to attempt to deal with the subject in extenso; it is intended to serve as a sort of warning to owners against some of the dangers they have to provide against; to deal with hygiene comprehensively would entail a much longer chapter than the limits of this will provide, therefore the reader must please understand that no attempt has been made to deal with this important subject in an exhaustive manner. 


\section{DIAGNOSIS.}

HOW TO FIND OUT THE BEST COURSE OF TREATMENT.

One of the chief difficulties, which besets even the experienced professional practitioner, is to determine what is really the matter with his patient, especially when first called into a case; without doubt there are distinct types of disease which it is comparatively easy to distinguish at first sight, but the cases which baffle the honest practitioner to discern right off the reel are occurring very frequently, especially if called upon to state what really is the matter in orthodox medical phraseology; and if the experienced practitioner finds it difficult to discover how the case stands, certainly the layman is placed in a much more difficult position when compelled by force of circumstances to rely upon his own powers of discrimination unaided by professional experience. To assist such a one is the object of this chapter; it is comparatively easy to write a description of the various diseases affecting the horse, but it is not so easy to explain to the untrained novice how he should proceed. Certainly an intelligent layman, who is endowed with powers of observation and discrimination, can the more readily learn what to do in cases of urgent necessity when guided by the principles of homœopathy, than can the allopathist with his vague and uncertain generalities; still for any one to turn to practical account a work on medicine, written in the plainest and most unconventional language, demands the exercise of keen observation. Many and varied are the indications which horses of varying temperament and differing character exemplify when they first begin to feel ill. These indications will be referred to further on; but first let it be understood that having observed that something appears wrong with your animal, what should you do to n11ake sure you have not formed a wrong impression; in other words, 
how are you to proceed to determine FIRST, whether there is anything the matter, and SECOND, what is it? In the early stages of disease, before any decided symptoms present themselves, there is nothing so surely indicative of prospective trouble as the exaltation of the internal heat of the body above that recognized as the normal standard; to enable any one to satisfy himself upon this point a cheap little instrument, known as the thermometer, is available; it is so constructed that one portion of the quicksilver serves as an indicator which remains in position after use until shaken down; any instrument maker selling same will show a purchaser how to proceed if he does not already understand its application and use; most of these instruments are constructed on the Fahrenheit record, and, according to this, the normal or healthy standard is 98.5 degrees, and anything above roo degrees must be considered suspicious in the horse; a further test in a few hours should be made to discover whether the thermometer continues to rise, if it does so, then further developments must be looked for; this departure or variation in the temperature of the body from the normal standard of 98.5 degrees may be taken as a most significant indication of the development of disease, and no horse owners, especially those who have to rely upon their own unaided judgment in the management of their stables, should be without a clinical thermometer; in England a good one costs about twelve or fifteen shillings; not infrequently, in cases of simple fever brought on by extra exertion on a very hot day, the temperature will run up to I05 or 106 degrees rapidly, and, after proper treatment, recede almost as quickly; but, as a rule, a high temperature, say of IO3 to IO4 degrees that is maintained, means a serious illness: if such proves to be the case, the regular use of the thermometer must be relied on at stated intervals, and, better still, at positively exact hours, say 8 o'clock in the morning and 8 o'clock in the evening. As a rule, under favorable conditions, the thermometer will register two or three decimals of a degree higher at night than in the morning. And so long as the instrument shows an uniform register for several days, it is fair to conclude that the crisis is not reached. Should the temperature rise still higher it generally leads one to conclude that matters are rather worse than better; again, if the thermometer shows a rapid fall in temperature and registers below the 98.5 degrees, say 95 or 96 degrees, it 
is almost a certain indication that nature has entirely given way and death is at hand; but the most favorable indications, judged thermometrically, are when the temperature, after attaining the maximum, gradually drops a few decimals of a degree every day until the normal 98.5 degrees is again reached and nature's balance is restored.

PULSE. - Next to the temperature of the body as registered by the thermometer the state of the pulse ranks in importance; but considerable practice and experience is called for, otherwise too much may be made of certain indications on the one hand and too little on the other; it is hardly necessary to state that the pulsations of an artery indicate the contractions or beats of the heart, which, according to circumstances, may vary in rapidity within a given time; also in rapidity and degree between the beats; in hardness, softness, wiriness, or fullness, according to the amount of blood pressure; in the interval occurring between the several beats, whether regular or irregular, and, if the latter, in the form the irregularity assumes. The ordinary number of beats or pulsations in the healthy horse varies from 36 to 40 , though occasionally a slow, heavy-dispositioned animal, who is not easily disturbed, may be found with a pulse of 32 ; on the contrary an irritable, nervous horse will have a normally healthy pulse of 45 . This variation in character and mental impression in the horse demands thoughtful consideration and due allowance to be made when about to take the pulse; if the horse is naturally unconcerned and immovable no great caution is called for when approaching him for the purpose of testing the pulse; but if, on the contrary, he is naturally excitable and nervous it is well to spend a few minutes in gently talking to him with a view to gaining his confidence and allowing time for the heart, which has probably been considerably accelerated in its action, to slow down to the condition in which it was before you entered the stall or box; by the exercise of sucl care only can you discover all you want to learn from the pulsation of the heart; and inasmuch as it is impossible for a layman to estimate correctly the difference in the various pulsations and the relative meaning of any variation from the normal standard so as to differentiate between a structurally diseased heart and one that is merely affected sympathetically, it would be wise of every horse owner, trainer and stableman to practice periodically the taking of 
the pulse in a healthy horse, as he will be able at all events to distinguish between a healthy pulse and one that indicates a disordered state of the system, and this, after all, is about as much as a lay horseman can expect to attain to; there are three special things to be observed in taking the pulse, namely, the number of beats per minute, which in health will on the average be 36 to 40 ; the regularity in the time between one beat and the next; and the eren state of the blood pressure in the artery rendering it uniformly compressible; the following variations from the normal may be observable, viz: hard and full; soft and full; intermittent; irregular as to compressibility; weak, thin, small, wiry, thready; oppressed, by which is understood a very full artery with a very indistinct pulsation; and the hard, throbbing pulse, which is suggestive of acute inflammation in some organ; finally there is the exceptionally slow pulse, which, when present in an animal that has in health a pulse of normal speed and regularity, suggests brain disease.

The artery, which is most usually selected for pulse taking, is that known as the submaxillary; it will be found winding round the angle of the jaw in company with the vein and the duct of the parotid gland, from which two vessels it must be distinguished; the artery is almost always, if not invariably, found situate in front of the duct and vein, and will be found to be the most firm and elastic of the three; another artery which may conveniently be used for the purpose is the radial; it is situate higher up, inside the forelegs, and will be felt just in front of the elbow-joint by introducing the fingers between the leg and the breast; this artery is also accompanied by a vein. The two central fingers, or the second and third, are the best to take the pulse with, and these should be laid transversely along the artery with just sufficient pressure thereon to enable the operator to observe the number of beats per minute, which should be told off with a stop-watch having a large second-hand. It is absolutely necessary to carefully distinguish between an artery and a vein, as in the latter no pulse is observable for anatomical reasons that do not call for explanation here, suffice it to say that it is the artery that must be relied upon.

Another very satisfactory method of checking off the number of heart beats per minute is to have the near foreleg pulled right 
forward and place your right ear against the side of the breast, when you will distinctly hear the beat of the double heart; that is to say, you hear the closing of the valves of the upper part of the heart first, immediately followed by the closing of the valves of the lower half of the heart; these two sounds have to be counted as one in calculating the pulsations of the artery; but the plan affords a very nice check in case of irregularity of the pulsations and if the substance of the heart or its valves are at fault, it is the more readily observed by this method of auscultation or listening to the heart's sounds. In utilizing the pulse for purposes of diagnosis it must be borne in mind that while frequency of beat is always present in cases of acute fever and in inflammation of the internal organs, and may be relied upon as a certain indication of disease, provided the frequency is maintained for any length of time-say some hours-still it must be remembered that temporary alteration in the action of the heart may be brought on by violent exertion, by excitement, or even by indigestion after partaking too freely of food on an empty stomach, as in the case of a hunter after a long day or a cart horse that has had many consecutive hours of work, all of which must be taken into calculation in estimating the importance and bearing of any deviation from the recognized healthy standard of the pulse.

RESPIRATION. - One of the first things that attracts the attention of a practical horseman to the fact that there is something wrong with an animal, is that the horse is blowing, but it is very easy to attach either too much or too little importance to the irregular performance of this function; it has this advantage, however, that whereas other indications of present or coming illness might easily be overlooked until well established, the acceleration of the performance of the act of breathing generally commences as soon as the horse begins to feel unwell, and in this way it serves as a warning to the stableman that some attention is called for; under such circumstances the first thing to do is to take the temperature and then the pulse; the best place to observe the number, and in a certain degree, the character of the respirations is the flank; the normally healthy horse breathes as a rule thirteen times in sixty seconds. While in health there is a fairly uniform relationship between the act of breathing and the pulsation of the heart. because of the interchange of chemical products which 
takes place between the air and the blood as the former passes in and out of the lungs, it is a singular fact that in disease this uniform relationship is not maintained; for instance, in the earlier stages of a disease the pulse may have risen to 85 or 90 beats per minute; the temperature stand at 105 degrees and the breathing be fifty respirations a minute; in the course of twenty-four or thirty-six hours the respiration may have dropped to 25 per minute, while the state of the pulse and temperature are only slightly changed; or, on the other hand, the temperature might have dropped to say 103 degrees and the pulse to 60 without any decrease in the number of respirations; from this fact it will be seen that uniformity of action on the part of the the heart and the lungs must not be always anticipated, nor need the absence of the uniformity cause too much anxiety; it is a proof, however, that nothing must be left to casual observation, nor must you allow yourself to be misled by the mere fact that on the one hand the horse is the better becalise he breathes less frequently, or that he is no better because his respirations continue unaltered in frequency. It must also be remembered that the character of the act of breathing differs; on the one hand you have what is called abdominal breathing, this is effected by the contraction of the muscles of the abdomen and is most noticeable in the flank; again there is the chest breathing and whichever of these two classes of breathing predominates and are most clearly observable it indicates that the other is the seat of disease because the muscles of the diseased portion of the organism cannot act properly and so the burden of the respiratory act is thrown on the other part, namely, either the cavity of the chest where the lungs are located, or the cavity of the abdomen, the part where the intestines are situated. There is one special form of breathing in the horse which deserves notice in passing because it serves as a distinct evidence of that condition known as "broken-wind;" the inspiration or act of drawing in the air, and the expiration or the act of sending out the air are not regular, but spasmodic in expiration; this will be observed by noticing a line along the course of the flank as though the muscles were tightly drawn together every time the air is expired and this line is seen to move like a wave along its course with two distinct efforts of expiration; at the same time the horse is troubled with a peculiar cough; this, 
however, is only mentioned in passing; the fuller particulars will be gone into under the proper heading.

When the abdominal breathing is very pronounced and you have therefore an indication that the thoracic cavity is the seat of the disease, namely, that either congestion of the lungs, or bronchitis or pleurisy, or worse still, all three combined are present, then your attention must be given to find out by what is called auscultation, (or listening to the sounds) of the chest, by applying the ear to both sides of the horse; the chest, roughly speaking, being included in that portion of the body which is enclosed within the ribs, and whereas the lungs occupy a considerable space, they offer a rather large surface for examination, for which reason the ear should be carefully applied to various parts of the chest in order to be sure which portion of the lungs, and whether only one is affected, or both are. As recommended in the case of taking the temperature and the pulse, an amateur would do well to practice carefully on healthy animals so as to learn what the normal sounds of the chest are, and this will enable him the more readily to discern anything out of the common when disease is present. It is very important that the operation should be practiced in a perfectly quiet place so that the attention of neither operator nor patient is distracted. As there would be no practical utility in going deeply and closely into a definition of all the recognized deviations from the healthy standard of breathing in the horse, and it will be sufficient for the purpose of this work to endeavor to explain two or three of the most noticeable departures from the normal, it is essential to a clear understanding that the sounds observable in health. should be explained; shortly, they represent an even, soft murmur like the gentle rustling of thick foliage on a quiet summer's night listened to at a distance; the sound pitch is much the same during both inspiration and expiration, though it must be distinctly understood that between the two acts a pause takes place; the cliaracter of the sound has also been likened to that produced by gently rubbing two pieces of silk together. In contra-distinction to the soft respiratory murmur heard in a healthy animal, modifications of the same will be observable in disease; the sounds may be harsh and rough, suggestive of inflammation of the lungs; deep in tone, indicating the early stages of bronchitis when the larger tubes are 
first affected. Should this condition remain unchecked and the disease extend to the finer ramifications of the very small bronchial tubes the sound will become high pitched like a whistle pipe. Further the sounds may convey the impression that the air is passing orer something dry or that rough substances are being rubbed together, while on the contrary the sounds may represent air bubbles passing through a liquid.

The dry, grating sound is generally observed in the earlier stages of respiratory disease, and hence precedes the moist sounds; the latter suggest the presence of mucus, blood or pus in the cavities of the bronchial tubes. A still further modification in the respiratory murmur is a crackling sound like the breaking of small sticks; this again may be followed by a gurgling or dripping sound like the dropping of fluid into fluid; these conditions are generally present in cases of pleurisy, and this diagnosis may frequently be confirmed by observing that the acts of inspiration and expiration are not regular as in health, but catchy, short and very irregular.

There is still one more abnormality in the chest sounds, which, though very infrequent still involves such serious consequences if not recognized and properly treated, that passing notice must be granted it; reference is made to that sound which is represented better than anything else by the term cavernous, namely, like the sounds emitted from a hollow cavern in the rocks; and this description is very appropriate as these particular sounds never occur unless a cavity, due to an abscess, is present in one of the lungs, the abscess being a sequel usually, though not invariably, to inflammation of the lungs in the horse; one very unmistakeable characteristic of this condition is, however, almost always present, namely, "stinking breath," which seems to impregnate the whole atmosphere of the stable. There are other sounds associated with respiration that have not immediate relation to the the lungs but may be due to other parts of the respiratory tract or to the supply of nervous force thereto, such as grunting, roaring, whistling, coughing, broken wind, shortness of breath and so on, but it is not necessary to deal with these here, as they will, with sufficient treatment, have to be considered under separate headings, moreover, every practical horseman can recognize them without the necessity of any suggestions here. So far the consideration of 
aids to diagnosis, or how to find out what ails the animal, have been confined to temperature, pulse and respiration; now we must proceed to note other evidences of illness as they present themselves in the patient; in other words, we want to get at the symptoms; not merely one or two of those most easily observed, but the totality, the whole of them; this is most important, and calls for the exercise of patience, time and keen observation.

Assuming first that the temperature is high, say 104 or 105 degrees, and the pulse and respirations rapid, it is fair to conclude that we have to contend with some disease in an acute form; next, we must, if possible, determine whether the whole system is involved, and if so, what class of disease we have to contend against, or whether some particular organ or organs, say the kidneys, or the liver, are implicated and the brunt of the disease settled therein; to assist one to form a conclusion as to which, if either, of the organs is invaded, we have in the case of the kidneys the condition of the urine to be noted, examined, and perhaps tested by an analytical chemist if such an one is available, or if the liver is the chief seat of disease, the yellow color of the mucous membranes of the eyes, nose and mouth serve to point to this organ1; moreover, in confirmation of this suggestion as to the liver, it is very frequently found that the fæces (or dung) are pale in color and very fluid in consistence, excoriating the surface of the skin wherever the fæces happen to touch; the urine, also, will be of a deep orange color; in addition to these objective symptoms there is a very important subjective symptom to be noted; on the right or off side of the horse just behind the ribs is the seat of a prominent portion of the liver, if you press this with the ends of your fingers you will be able to learn whether there is any pain or tenderness of the organ, as the horse will tell you by flinching, or in an acute case by grunting; care, however, must be taken to discriminate between animals that are naturally tonchy and do not care to be handled at all, otherwise you may be misled; should it be clear on pressure that pain is experienced, it is fair to assume that congestion of the liver is present. In further examining a patient it is well to look at the lining membrane of the nose and eyes and note the condition; whether it is dry or abnormally moist; whether the color is the healthy pink or whether on the other hand it is blue and leaden or of a bright vermillion, either 
of which is suggestive of mischief; proceed next to the glands between the jaws and also the parotid gland, which lies just behind either jaw from the bottom of the ears downwards, if the glands are clearly perceptible to the touch, being either hard and knotty, or soft, swollen and tender, it is clear that these symptoms will have to be taken into account. That portion of the poll, just between and slightly posterior to the ears, should be examined, for when the injury known as "poll evil" has advanced to the stage of suppuration (formation of matter), it affects the nervous system of the horse to such a degree that he appears very dull, heavy and generally ill, and no doubt feels so, and very much more than mere surgical interference is called for here; the same remarks apply with equal force to a case of fistulous withers, which are brought on generally by badly fitting saddles, and occasionally collars; it is very important in such cases as these or in those affecting any other part of the body where injury has been sustained and serious inflammation set up, followed by suppuraion (formation of matter), to regularly take the animal's temperature, as the formation of matter generally affects the whole system, makes the animal feel ill and unless properly treated with a remelly which is capable of arresting the formation of matter (pus), serious consequences may and do frequently follow if such means are not adopted; and the body temperature is a guide to tell one whether the tendency to form pus is arrested or not; if not, the temperature will either continue to rise, or if previously high, will be maintained; on the other hand if it gradually falls, one is justified in the conclusion that the tendency to form pus is arrested, and that the existing abscess will speedily ripen and discharge itself and thereafter the cavity heal up; it may be well to remark in passing here, lest the idea should be conveyed that the internal administration of the suitable drug should be solely relied upon, that antiseptic local treatment may also be advantageously adopted; indeed it is absolutely necessary where, as in fistulous withers, the opposing walls of the sinus (or cavity), come constantly in contact, because the living organisms which certainly encourage the further development of pus require to be destroyed, hence the internal and the local treatment should go hand in hand. One is not less important and necessary than the other, if a rapid and complete cure is to be effected; it should, 
however, be distinctly understood that homœopathic practitioners are alone able to apply this double-barrelled system for the simple reason that in such cases allopathists rely solely upon local and surgical treatment and indeed know nothing of the remedies homœopathists use for arresting the formation of pus in the body.

To proceed with your inquiry, it should be the aim to discover if the horse has any pain, and, if so, where. When the pain is located in some part of the abdomen (or belly), the horse more frequently than not lies down, rolls, all of a sudden jumps up and turns his head to one or other side, and, perhaps, if very acute, will snap at or try to bite the place where the pain is most severe; these are the methods the horse has of telling where the pain is situated, and, of course, it points to some portion of the intestinal tract (or gut), or to some organ, as kidneys, liver, spleen, etc., located in the abdomen and among the intestines, or it may be to the presence of a calculus (or stone) in the intestines; having this guide you will then be in a position to find out from other symptoms what has to be contended with and how to proceed.

There is one practice very common amongst veterinary surgeons, as well as stablemen, in cases that so frequently occur among draught horses which the author, from practical experience, strongly condemns, namely, the custom of keeping a horse continually on the move when suffering from any pain that naturally induces him to roll. "Keep him on his legs," the man says: "don't let him go down!" The author condemns the practice as absolute nonsense on the one hand and gross cruelty on the other, for by preventing a horse from rolling, you frustrate the only thing he can do to afford himself some measure of relief; by one's own experience when suffering from the "belly-ache," it is quite certain that relief does follow a good roll, and if in the man, why not in the horse?

The advocate of the "keeping on the legs" principle will tell you that to allow a horse to roll involves the risk of a twisted gut; but where is the proof? If a horse that afterwards died proved to have a twisted gut, it is most probable that the twisted gut was the cause of the pain and not the result of a roll while the pain was on; the "twist" more than likely having been made when the horse was called upon for some extra exertion in pulling a 
heavy load. No! Whenever your horse has pain that induces him to roll, take off his halter and all his clothing, put him into a big, loose box, or open yard, where there is plenty of straw and let him roll to his heart's content, you in the interim watching that he does not get cast on his back, and doing what you can by the administration of suitable remedies, or rather a suitable remedy, to remove the cause of the pain. There is one very suggestive habit a horse has, particularly when he is in a loose box, if he is the subject of a calculus (or stone,) in the intestines, namely, that of pressing his hindquarters firmly against the wall, and all the while straining as though he were going to have a motion. Horses will frequently rest their heads sidervays on the manger, or against the wall; in such cases look out for diseased molar teeth or brain disease; the former can readily be discovered by examination, and the latter may be partially confirmed if the pupils of the eyes are either very much dilated or contracted.

Another very suggestive subjective symptom occurs when the horse poses himself repeatedly, as in the act of urination and probably strains as though he wanted to pass water which in all probability he does; in such cases the condition of the urine will furnish the confirmatory indication required.

It is hardly necessary to state that the condition of the fæces (or dung) is an all important physical symptom which serves as a guide in many instances to disorders of the digestive system, and under this head it will be necessary to look for information herein, before deciding what to do. There is one point that almost invariably exercises the mind of a horseman; indeed the subject is one that causes great anxiety to almost all men, whether it effects themselves or their charges; we refer to constipation of the bowels; this matter will be dealt with in its proper place and merely in passing do we wish to draw your attention to the fact, because there really is no necessity in ninety-nine cases out of a hundred to be so wonderfully concerned if the excretion of the faeces is temporarily suppressed; how to get over this difficulty will be explained under its proper heading, and it will be found that this object can be attained without the usually violent measures of purgation.

Roughly speaking the foregoing are some of the most prominent indications by which a horseman may discover what 
disease he has to refer to, and therefore the line of treatment to be adopted in cases of illness; much remains for him to find out, and there is a great call for the exercise of common sense; still it is hoped that this chapter, taken in conjunction with the list of predominant symptoms and the chapters specially dealing with each disease in the body of the work, will go very far to enable one, who is a real observer, to alleviate the pains and sufferings which so frequently fall to the lot of the horse, especially the hard-working animal, that contributes so largely to the material prosperity of his owner, from whom he deserves the utmost care and consideration that an intelligent human being can lavish upon one who is entirely dependent for the most ordinary comforts of an existence upon his forethought and provision. 


\section{THE STRENGTH of DRUGS and the DOSE.}

The subjects which we propose to treat of in this division of our work demand the careful and thoughtful consideration of any and all who would turn to best account the information we hope to offer to our readers and students; the term "strength of drugs", is here adopted not because it strictly represents the author's views or is by any means a correct description of the various pharmaceutical processes to which all drugs, other than those in the absolutely crude form, should be submitted by the honest homœopathic pharmaceutical druggist; we repeat it is not because the term is a correct one that we use it, but because to the untrained mind of the layman it more nearly conveys the idea which he has been accustomed to accept as the explanation of the various potencies or attenuations which all who have accepted Homœopathy as their law in medicine are acquainted with; at the same time we shall try and explain why we do not consider it a correct term to use, and further why it is calculated rather to mislead. It has been already stated that potencies and dosage have nothing to do with the law "Similia Similibus Curantur," nor do they in the slightest degree bear upon the true meaning of the principle laid down by Hahnemann. This fact cannot be too strongly emphasized by the author nor remembered too often by the reader; potencies and dosage are merely matters of experience; it has been found that all drugs, generally, and some more than others, are far more effective in their action-the same being more prompt, decisive and permanent-after being submitted to the various processes which will now be explained. In the first place let us point out that the homœopathic druggist has to be mathematically precise if he is to do his work correctly and according to the rule of the homøeopathic pharmacy; to this end two forms of calculation have been adopted in the reduction of drugs, the centesimal and the decimal; these words explain their own meaning: and here it may be pointed out in passing, that although the term 
"potencies" has so far been adopted, it is far too closely allied in meaning to the word "strength" to which we have already taken exception, to be further used; our object has been to gradually bring the student round to understand the application of the term " ATTENUATION," upon which we shall hereafter rely in describing the fractional minuteness and the infinitesimal quantity of the various drug preparations-and it is certainly not used here in the sense applied to it in the British Homœopathic Pharmacopœia as indicating that the specific attenuation contains more or less of the crude material, but rather that it indicates the extent to which the drug has been attenuated, pulverized, dynamized and diffused, by which means its power has been developed: the prevailing idea that the stronger the drug is in the possession of its natural qualifications for producing specific effects on the healthy organism, the better and more reliable it is for administration to the sick, has long been exploded, even among allopathists, if we are to accept their prescriptions as illustrative of their simple faith: but homœopathists, especially those who possess faith enough to follow strictly all the tenets of their master, Hahnemann, have discovered that drugs in their crude, and therefore physiologically strongest condition, do not best serve the purposes of the healing art; indeed, those who are most skeptical on this point will admit the illustration which common Sulphur furnishes in support of this statement, for it is a well-known fact that this agent will pass through the system practically unaltered in its crude state, but after it has been submitted to the various processes of attenuation up to the thirtieth centesimal, and much higher still, the effects it will produce upon the system is simply marvellous; if with Sulphur why not any other drug you can name? Some one may say that its inertness in the crude form accounts for this, but that argument does not seem to meet the case, as any one who will think for a moment will readily decide. Before offering our reasons for the greater utility of the attenuations which we claim to exist, we must hark back to a description of the processes the drugs should undergo that the student may the better appreciate the importance of obtaining the exact attenuation prescribed. For the sake of brevity and conciseness let it be understood that the drugs used in plarmacentical preparations exist in two forms, the fluid represented by tinctures and the solid represented by 
porvders or triturations; the vehicle used for reduction of fluids generally consists of alcohol, that for solids consists of sugar of milk: in preparing the liquid attenuations the process starts at a fixed standard, which in preparing from the vegetable substance the druggist understands how to fix uniformly and describes as the mother tinctures: from this mother tincture the centesimal and decimal scales are prepared; namely, for the first centesimal from two to six drops of tincture are mixed with ninety-four to ninety-eight drops of alcohol according to drug power of tinctures; for the second centesimal one part of the first centesimal (which is recognized by the plain figure of one) to ninety-nine of alcohol and so on from one attenuation to another until you attain the thirtieth or two hundredth; the same proportion is adhered to in the decimal scale, namely, from two to six drops of tincture are mixed with four to eight drops of alcohol according to drug power of tincture and so on through each series up to the thirtieth decimal, each attenuation being recognized by the marks $I x, 2 x, 3 x$, and so on as high as the preparation has been carried; a similar course of proceeding is adopted with the solids by weight, say ninety-nine grains of sugar of milk to one grain of the crude material for the centesimal scale, and nine grains of the sugar of milk to one grain of the drug proper for the decimal scale, and so on with each attenuation as high as the dispenser desires to carry it. But this actual measurement by no means exhausts the necessities of the process; the liquid attenuations have to be submitted to violent shaking or succussion; and the powders have to be submitted to an exhaustive course of trituration or pulverization with pestle and mortar, according to distinct rules fixed by Hahnemann, and even if these processes are carried far beyond the limits assigned by the great master no harm will come of them; it is better to err on the side of excess than the other way about; and to show why this is the case we will proceed to explain the advantage derivable from these various processes. During each progressive process of trituration the various particles of the medicinal agent become more finely divided, and the author is of opinion that not only is it to this very minute subdivision of particles that the agent derives its activity, but that it derelops an inherent power not previously possessed; but without attempting to reason this out we will confine ourselves to the physical aspect 
and on this ground furnish a reason for a belief in the greater activity of a highly attenuated drug: we take it that no one will question the assertion that six, twelve or fifteen processes of trituration must of necessity reduce the particles of a drug more and more as each process is effected, namely, that those particles of the drug in the fifteenth decimal attenuation would require a much higher power of the microscope to discern than do those in the third decimal, for instance; now let us consider in what way medicinal agents so broken up are better qualified to do their work than those administered in their original state. To this end we must remember that the various parts and organs of the body are built up of tissues peculiar thereto; for instance muscle, fat, cartilage, bone, nerve, etc.; each of these tissues consists of special elements varying in structure and density but in all alike, notwithstanding their various modifications as recognized by the naked eye, can be traced back as the starting point of their ultimate structure what is described in physiology as the cell, to discover which one has to call in the aid of a microscope.

Of these simple materials the body is built up, and before a drug can exercise its own peculiar power it must be rendered capable of penetrating the walls of these cells, the first elements of the tissues of the body; and whereas the cells themselves are so small, it follows as a natural consequence that drugs to permeate or pass to them must be reduced to a condition to render such a process physically possible: to further illustrate our meaning, look what takes place in the vegetable world as ordained by the great power that made and rules the Universe; how do plants appropriate nutriment which comes to them through the media of rain, sunshine and air? It is generally acknowledged that this takes place through the leaves only, if you examine a leaf under a high magnifying power, you will observe that the surface is studded with thousands of minute openings; microscopic pores, and through these the rain has to pass if the chemical products it contains are to be utilized as nutriment; can a drop of rain pass through these? Certainly not! But nature has her methods and plans of attenuation; each drop of rain the size of a pea can be broken up into millions upon millions of molecules, and this is effected in the form of dew or condensed vapor; so fine, indeed, that the moisture in this form can freely pass through the micro- 
scopical orifices on the surface of the leaf and thus reach the primary elements of plant life; what says the "Word" on this subject: "My' doctrine shall be as the rain, My speech shall distil as the dew as the small rain upon the tender herb." If such minute provision has to be made in nature's laboratory for the appropriation of ordinary nutriment in the regetable world, should it be cause for surprise that at least a similar amount of care and trouble is called for in the animal world when the healing of the sick is concerned!

We hope that this simple illustration will serve to point a lesson as to the necessity of the carefulattenuation of drugs and that the importance of this pharmaceutical process, peculiar to the homœopathist, will be fully appreciated. Some persons have an idea that animals require stronger medicine, and very much more of it at a dose, than do human beings, physiologically. We cannot now, nor ever could, see a reason for this, and experience certainly does not confirm the suggestion. Some allowance certainly is made, as a matter of practice, for size and bulk of body, but whether it is absolutely necessary, is open to considerable doubt.

The adoption of the word "strength" in its application to the various processes of attenuation is apt to mislead because it conveys the idea only of the relative quantity of the crude drug present in the preparation; for instance, a remedy such as Arsenicum marked 3 . means that the preparation contains the one millionth part of the drug arsenic; in other words, it has been submitted to three processes of trituration on the centesimal scale; take Arsenicum 6x, this, like the former, contains the one millionth part of the drug arsenic in its composition, but it has been submitted to six processes of trituration under the decimal scale in consequence of which the arsenic in this form must be worked up to a much finer state than the sample that has only been triturated three times, and according to the author's belief, which is based on practical experience, this sample under the decimal scale possesses powers of action which that under the centesimal cannot have, inasmuch as the latter has only been triturated three times. So far for the attenuation of drugs; we will now pass on to the dosage.

As a rule to the larger animals such as the horse, it is usual to 
administer from ten to fifteen drops per dose whatever the attenuation, being guided more by the condition of the maladywhether the same is acute or chronic-than by the precise attenuation of the drug. In very acute cases such as those of simple fever brought on by exposure to the sun on a very hot day in which the temperature runs up rapidly as high as Io6 degrees or even 107 degrees-though the latter is considered extremely suggestive of danger-the drug may satisfactorily be given in the crude form, when ten drops should suffice; but these are rare cases, and we may possibly account for their useful administration in this form from the fact that the excessively high temperature renders the tissues more susceptible and hence better capable of appropriating the remedial qualities of the drug, but as soon as a turn takes place, the drug should be given in gradually higher and higher attenuations, and this same principle applies with equal force when the malady to be treated is not of so acute and exalted a character, and the ordinary attenuations of $3 \mathrm{x}$ or $6 \mathrm{x}$ as prescribed in the body of the work are administered in the earlier stages of the case; it will be found extremely useful to commence with these and as convalescence is becoming established to administer the same drug in a higher attenuation, by which is meant, commencing with $3 \mathrm{x}$ then $6 \mathrm{x}$ and finish off with $\mathrm{I} 2 \mathrm{x}$.

In all cases therefore, where the dose is not referred to under the various prescriptions given it should be understood that ten minims (or drops) of a tincture and ten grains of a powder (or trituration) are the doses to be given. In cases of acute illness the repetition of such doses must depend upon the seriousness of the case and the nature ot the malady. If the animal is in very acute pain, the doses may be repeated as often as every quarter of an hour for a time until some relief is obtained, after which the intervals between the doses may be extended to an hour, three hours and so on, but in ordinary cases of illness three or four doses daily at intervals of four hours are sufficient.

In administering these medicines the tinctures are best mixed with a small quantity-say a wineglassful - of quite clean water; rain water that has been filtered is the best if it is not practicable to obtain distilled water; if the latter is available, by all means use it; a strong soda water bottle is far the most useful instrunent for drenching the horse with, because the glass does not absorb the 
essential quality of the drug used, and can readily be cleansed with very hot water; moreover these bottles are made of glass that is so hard and tough they will even bear the force which a horse can exercise with his jaw without breaking: horns are very frequently used for the purpose but cannot be recommended because their porous nature decidedly favors the absorption of whatever agent is used, and whereas the homœopathically prepared drugs are very sensitive their influence may easily be neutralized by coming in contact with what has been previously administered from a vessel made of horn.

Great care must be exercised in the use of triturations, not to administer remedies of lower attenuation than are prescribed herein; in all such drugs as arsenic, mercury, copper, etc., nothing of a lower attenuation than the third decimal should be used, otherwise a poisonous dose may easily be given: it must be remembered that the third decimal attenuation is equivalent to one part of the crude drug in a thousand parts of the attenuated powder, while in the second decimal scale one part of the crude drug is contained in a hundred parts of the triturated powder; were one to give continuous ten-grain doses second decimal of such dangerously powerful drugs as arsenic and mercury serious and quite unlooked for consequences might be the result. There is still another side of this question bearing upon the influence the process of trituration has upon certain agents like sulphur, which in the crude form are practically inert, there is no doubt that this process wakens up a sort of new energy and acquires for them a physiological activity which in their natural condition was quite dormant so far as their influence upon the animal organism is concerned; gold, silver and flint are further illustrations of this kind of agent, in whose case it is not the lower attenuations that have to be guarded against so much as those of a higher order; hence it is important that those, who practice according to the information laid down herein, should allow themselves to be guided by us as to the attenuation to be relied upon in specific disorders: it is moreover peculiarly interesting to note what the effects of these pharmaceutical processes upon different drugs are, because they serve to entirely upset the theory that drugs are most efficacious in action when used in the crude form as is the custom of the allopathic practitioner; undoubtedly, from a busi- 
ness point of view, the higher attenuations of all drugs prepared strictly according to the rules laid down by Hahnemann for the guidance of the pharmaceutical druggist, are worth more pecuniarily than those of a lower scale, and the druggist should be paid more for them; their proper preparation inrolves an immense amount of labor and hard work, which it is quite unreasonable to expect a druggist to expend if he is not paid for it: we are strongly of opinion that pharmaceutical druggists are not without blame themselves for not demanding suitable remuneration for work of this sort, but on the other hand they have grave difficulties to contend with in making their customers rightly appreciate the matter, until it has come to this that only druggists of high standing who value their reputation more than their banker's account, can be confidently relied upon to strictly adhere to the pharmaceutical rules aforesaid; to this most unfortunate fact may be attributed the failure and disappointment so often heard of at the meetings of medical societies when practitioners are favoring their professional brethren with all and sundry of their experiences, whereupon no little discredit devolves on the devoted heads of those who through good and evil report are staunch to the true faith; in a very large number of instances failure is due in practice to indifferent pharmacy; and for this indifferent pharmacy a stingy, mean short-sighted public is mainly responsible, while at the same time close-fisted medical practitioners do much to render the druggists' experience a very sorry and disappointing one, by becoming their own dispensers; hence the importance of seeing to it that drugs are purchased of those whose word may be relied upon, and of never failing to elicit from the druggist that the remedies sold are strictly in accordance with the prescription. The author feels that he is justified in going somewhat closely into this matter of attenuation, because of the important bearing it has on clinical (bedside) results, and in again reiterating its importance, it is felt that it will not detract from the urgency of this branch of the subject when it is borne in mind that Dr. Carroll Dunham, one of the most scientific and successful ply'sicians the United States of America ever knew, was one of its most strenuous advocates: the author in his practice among the lower animals, owes much of his success to information gleaned from this learned man's writings, and it is with feelings of personal 
gratification that the present offers the opportunity to present an humble but earnest tribute of acknowledgment and indebtedness to his revered memory. 


\section{ARRANGEMENT OF DISEASES.}

To facilitate a ready reference to the malady of which a horse is temporarily, the subject, is now our object and, the difficulty of realizing this in a simple way, so that he who runs may read, is not easily overcome; the list of "suggestive symptoms," it will, it is hoped, materially aid the horseman to discover under what classification of diseases the malady is to be found; a large proportion of these "suggestive symptoms" will be found to refer to various maladies and at first sight this may strike the student as somewhat perplexing; but this condition of affairs is simply unavoidable, because the same symptoms do regularly appear in different maladies. This is one of the obstacles which the allopath, who in his superior way has never condescended to make a study of the principles of Homœopathy, can never surmount; the obstacle however, is by no means so insurmountable as he (the alopath) would feign believe, the whole crux of the matter is summed up in the word TOTALITy. Having made a list of all the symptoms observable it will be found that while three or four of these are each present in some half dozen or more maladies, there is still one more sympton which is only found in one of these said half dozen maladies and this will be the disease you will have to study. For instance, you will find staring coat, quickened breathing, rapid pulse, heightened temperature, constipated bowels urine very high colored and diminished in quantity in no end of maladies and were these or but one of these symptoms taken alone the prescriber would find it difficult to suggest a remedy, but take them as they stand and you have a picture of common simple fever, at the same time they one and all may be observed in a very large number of maladies that present not only these but one or more symptoms which you must discern before you can prescribe, hence it becomes absolutely necessary to carefully trace the various symptoms presented by the patient from one diseased condition to another until you find the group under one malady 
and to this reference must be made for the treatment, and from the description of the disease thereunder some idea can be formed as to organs or parts that are affected. To the uninitiated the process may at first seem a trifle wearisome but practice will soon clear the course and render comparatively easy that which at first seemed like chaos.

There are some forms of disease which appear to affect in greater or less degree the whole system of the horse, those which properly come under this classification will be described under the heading of GENERAL, while others localize themselves in special organs and in the course of description these will be referred to under the various Tracts, Organs or parts specially affected. 


\section{GENERAL DISEASES.}

\section{SIMPLE FEVER.}

This malady, as the name indicates, is a febrile condition affecting the whole body generally; and is distinct from that kind of fever which accompanies or presages an inflammation of some special organ, such as the Lungs, Kidneys or Intestines; here the fever is the diseased condition itself-unassociated with any special part or parts of the animal system; the fever is the prominent feature that has to be combatted; this once allayed and there is no necessity to anticipate any bad after consequences.

Symptous-Heightened Temperature varying from 104 degrees to Io6 degrees. Quick strong full pulse; more frequent respirations; legs cold; shivering fits; staring, harsh coat; loss of appetite; increase of thirst; bowels irregular in action, tendency to slight constipation; less urine passed than usual, and what there is appears high colored.

Treatment.-Aconite $\theta$ five drops every hour for three doses, when temperature will probably drop two degrees in a few hours; after which Aconite 3x ten drops at intervals of four hours will serve to complete the cure and in five or six days the horse will be convalescent; theclinical thermometer must be frequently used, as the internal heat must serve as a guide to indicate the patient's progress; after the early and sudden decline the temperature usually subsides gradually,

If the legs are very cold they should be dry hand rubbed to arouse the circulation, and thereafter a flannel bandage, not too tight, put on; the rubbing and the bandaging being periodically renewed. As soon as the body temperature begins to stubside the horse will evince a desire for food, which should be of a light and easily digestible character, administered sparingly at first; the thirst will all along be observable, and to slake this to his heart's content the horse should be furnished with a constant supply of 
cold water. Should the temperature have risen very high, viz. Io6 degrees or 107 degrees, and the subsidence after the first fall has proved very gradual, convalescence when attained will befollowed by marked weakness and exhaustion; the horse will require building up, to effect which it will be better to administer two doses of Sulphur 30. for two successive evenings, to be thereafter followed with ten drop doses of China $\theta$ night and morning, for a week; by this time the powers of assimilation will be restored, and the full benefit from the food will be derivable and experienced.

\section{BILIOUS FEVER.}

This is much like the last malady affecting more or less the whole system, while at the same time the force of the fever appears to be centered upon the liver; the duct which should convey the bile to the intestines is blocked and cannot effect an exit; the bile, as secreted, is then thrown back upon the organ; it passes through the walls of the bile tubes and thence through those of the hepatic arteries and is conveyed over the whole body by means of the circulation of the blood; this is how it happens that the mucous membrane lining the mouth, nose and eyes, and not infrequently the skin of white animals, takes on such a yellow appearance.

Symptoms.-Precisely as in Simple Fever, with the addition of the yellow appearance of the visible mucous membranes.

Treatment.-Aconite $3 \mathrm{x}$ in the early stages; Arsenicum 6x gr. $x$ to a dose; when lining membrane of eyes is particularly yellow; when the stool looks light colored and the food is not digested; when the horse drinks a little at a time but very frequently; and when he appears alternately depressed and irritable.

Bryonia 3x. Pain on pressure over seat of liver; seems to experience pain in limbs when moved; lips and tongue yellow, dry and cracked; bowels constipated, fæces dry and hard, as though burnt or scorched.

Mercurius Cor; $3 \mathrm{x}$ gr v. to a dose; when the yellowness of membranes extends to the skin and is very pronounced; motions colorless, grey or whitish, with considerable straining both before and after relief; breath smells very foul; urine scanty and of brownish red color having a foetid smell.

Eupatorium perfoliatum, $I x$. - The chief characteristic for the selection of this drug in Bilious Fever is the violent bone pains; if 
you handle the horse about the shanks and pinch them between your fingers he will give evidence of pain by flinching; or, again, press the ends of your fingers into the bones of the face and he will soon show you how much it hurts; in such cases, taken in conjunction with the symptoms previously enumerated, this may be accepted as a leading indication for Eupatorium Dr. Dunham discovered the difference between this drug and Bryonia in cases of bilious fever, and came to the conclusion that in Bryonia the perspiration is free, while in Eupatorium it is suppressed. Eupatorium is suitable when the patient is restless and uneasy. Bryonia when quiet and apparently depressed, or rather unable to move.

Nux vomica, $3 x$. - When the region of the liver externally is hard and swollen; horse refuses all food; when symptoms are aggravated, early in the morning; constipation with frequent unsuccessful urging and straining to effect a stool.

Leptandra Virginica, $I X$.- The principal indication for the selection of this drug is the condition of the stool; when this is frequent, urgent, black, tarry in consistence and color, pappy and smells badly, resort should be had thereto.

When convalescence is attained Sulphur 30 and China $\theta$ may be used with advantage as suggested under simple fever, and the instructions under that heading as to diet, et cetra, should be followed.

\section{STRANGLES.}

This malady is more particularly associated with young horses, and in our experience it has proved communicable from one young horse to another; at the same time the disease is not restricted to adolescence, as horses of all ages are liable thereto; but while adult horses do not appear so likely to be infected by association with one of their own period of life that is the subject of strangles, young horses, until they attain the age of four years, are more readily infected from an aged horse than by one of their own years; at least this is our experience; and it is well known that as is the case in most infantile diseases, one attack does not protect a horse from a second or third, although in the majority of horses one attack in a lifetime suffices, while a few seem to escape entirely. Strangles is wuch more likely to prove infectious in a 
large stud where the surrounding sanitary conditions are bad or only imperfectly provided against, and where the numbers of young horses are kept in close proximity; in studs where large numbers of valuable young horses are kept as soon as strangles is dereloped the sufferer should be isolated and his box immediately disinfected.

The term strangles derives its origin from the fact that it consists of a more or less extensive swelling of the glands in the region of the throat, or at the back of the tongue, which unduly presses upon the windpipe, the effect of which is to choke or strangle the patient.

Strangles is recognized as belonging to the class of eruptive fevers, more or less affecting the general constitution, but centering itself upon the glandular system, particularly those large glands which are situated between the under jaws, among which large and painful abscesses are developed, accompanied with very decided febrile symptoms; the temperature often rising to 105 degrees, or eren higher, before the crisis is attained. This crisis is generally reached when the abscess is fully matured and ready either to burst of itself or be discharged by operative surgery; after this period is reached the febrile symptoms abate and the temperature gradually descends; but if by careless treatment, such as exposing the abscess to a cold draught, or allowing too much time to elapse between the application of the necessary poultices the maturation (or ripening) of the abscess is delayed, or fresh and unfarorable constitutional symptoms are dereloped, other abscesses may break out orer the body and it will be found that the temperature is beginning to rise again, when the febrile condition will assume an altogether different type, not improbably of a septic character involving great trouble and no little risk to the animal's life.

Syuptours. - Inability to swallow food; running at the nose; cough, rough but feeble, as though it gave much pain; frothy saliva dripping from mouth; head poked straight out in an aimless manner; temperature 105 degrees or more; pulse rapid; respiration not so urgent as in many febrile conditions; sometimes not affected in frequency, but a great roaring noise is made both in inspiration and expiration. The space between the jaws, where the glands are situated, is much swollen and very hard and 
occasionally extends to those glands at the back of the jaw bones, when the swelling is diffused and the whole head is affected.

TREATMENT. - Isolate into a large, airy box, free from draughts of cold wind; keep body warmly clothed and legs bandaged with flannels; food nourishing but sloppy; crushed oats well steamed, mixed with boiled linseed; a plentiful supply of barley water made with pearl barley in the ordinary way.

Local applications should consist of well prepared poultices of linseed meal, or boiling water poured over spent hops, either of which should be enclosed in a gauze bag to fit the parts, covered with a piece of oilskin over which and to support the poultice a portion of horse rug or several thicknesses of close house flannel should be used. The poultices should not be allowed to get cold, and should be changed three times in trventy-four hours. The change should be effected rapidly, but before applying a fresh poultice the parts should be gently bathed with hot water containing a few drops of Condy's Fluid, so that the parts may be kept sweet and clean.

By the aid of internal medicines three or four days will generally serve to mature the abscess, which will be recognized as ripe by its softness, when it may be left to discharge itself or be opened; unless a veterinary surgeon is at hand to advise, the former is the safer course from all points of view; if allowed to spontaneously discharge, as soon as it has burst, the whole abscess should be gently squeezed and thereafter washed clean with a soft sponge and hot water medicated with Condy's Fluid; after which poulticing should be continued until the whole of the matter is discharged; and to complete the cure the parts should be dressed with powdered Iodoform and still kept covered up with medicated dry cotton wool until the orifice is healed.

INTERNAL TREATMENT. - In the first instance, while the fever is developing and the temperature rising Aconite $3 x$ for one day; to be followed by Hepar, sulphur $6 x$ ten grains dry on the tongue four times a day at intervals of four lours. This is all that will be required for simple or benign strangles, but should the more dangerous symptoms be developed already referred to, and fresh swellings containing matter (pus), spring up over the body, which are suggestive of blood poisoning a change in the remedy must be made; and not improbably the animal will give 
evidence of such decided constitutional debility as to call for the administration of some stimulant, such as good, sound old ale mixed with beef tea, or raw eggs beaten up and mixed with wine or whiskey, while the most suitable remedy will probably be found in Lachesis $I 2$, ten drops every four hours. Some careful nursing will in all severe cases of strangles, especially those in which the more serious symptoms supervene, be found essential, to facilitate which the administration of China $\theta$ twice a day will afford material assistance.

\section{INFLUENZA.}

The designation adopted to describe the various forms of illness which are supposed to be included thereunder, is a very ambiguous and unreliable one; in olden times Influenza was presumed to express a feverish cold in the head attended with an irritating fluid discharge from the nostrils which by some was considered infectious, by others not so; as at present used, however, the term has to cover a much wider area, inasmuch as it affects at one time the respiratory organs, at another the digestive organs, while yet again it may centre its force upon the nervous system.

In one form the United States and Canada, in 1872 and 1873 , experienced a visitation of a very virulent type of this disease while Great Britain and various localities on the Continent of Europe have, on several occasions, had outbreaks of a serious character and under varying conditions.

Probably the chief feature of each type is the extreme prostration experienced by the patient, and in most there is a distinct soreness of the muscles and a pronounced disinclination to move; dullness, and a sort of "care nothing for anything" attitude is very marked, especially when the malady is thoroughly established; the surface temperature of the body as revealed to the touch is extremely variable; the lining membrane and the tissues thereunder of the eyes are very swollen and suffused with red streaks, tears trickling freely from the corners over the face; the membrane lining the nose is intensely injected; the internal temperature rises to I04 or 105 degrees; the pulse is rapid but small in volume and weak in force; the respirations are regular but much more frequent than they ought to be; the mouth is usually excessively hot, and the saliva hangs therefrom in long, ropy 
strings; when the force of the malady is fixed on the respiratory organs auscultation of the chest right in front under the wind pipe will reveal a rough, grating sound, which suggests a complication in the bronchial tubes; when these symptoms are developing the horse will have a harsh, rough cough, which apparently causes no little pain and inconvenience. As a rule the fæces are dry and difficult of expulsion, but when the motions begin to take place, the drug pellets will frequently be covered with pieces of mucous membrane, commonly described by stablemen as "skin;" the urine is mostly scanty and high colored. One very marked characteristic of the disease is the extensive swelling of the legs down their whole course; this is due to what is termed an infiltration of the connective tissues, and as a result of this swelling the horse experiences general stiffness and soreness; the swelling in horses (males) not unfrequently extends to the penis, along the abdomen, to the under portion of the chest; if the swellings are not reduced, we have seen cases where a mixture of blood and serum appeared to ooze through the pores of the skin, which, of course, clearly indicated that the effusion of fluid under the skin and among the muscles and tendons was so extensive it could not be retained, notwithstanding the swelling and elasticity of the parts, and must, therefore, find an outlet somehow; when the fever seems to exercise its force on the windpipe, bronchial tubes and lungs, the difficulty of breathing is much more marked; the nostrils are dilated and the heaving at the flanks is very noticeable; moreover the horse invariably evinces a desire to put his head over the box door presumably to get fresh air; the nasal membrane instead of being bright red, assumes a purple or leaden hue, and the secretion is generally thicker and more glutinous; the internal temperature will rise as high as I06.5 or 107 degrees, and the animal evinces more marked prostration than ever; if the earlier developments of bronchitis are not arrested the disease will progress until inflammation of the proper substance of the lung tissue is established, which may be discovered from the greater difficulty experienced in breathing; by the various sounds observable on auscultation (listening) of the chest over the sides where the ribs extend, which, of course, only a properly qualified and experienced veterinary surgeon can discern; however, if inflammation of the lungs does supervene, it 
is generally attended by the discharge through the nostrils of blood which will serve at all events as an indication for the selection of a suitable remedy.

In addition to these chest and lung complications we have, not unfrequently, to combat such as attack the digestive organs, and these, while sometimes occurring independently, do frequently follow those already indicated, and that, of course, at a time when the system is very low and unable to combat any additional strain upon its recuperative powers; it is probable that of all the abdominal organs the liver is the one that first feels the effect of this Influenza Fever, as is evident by the extremely yellow color of the visible mucous membranes; the first thing that draws the attention of the horseman to the fact that the disease has settled itself upon the digestive organs is the indication of pain in the bowels, the horse will lie down, roll, get up again, look around at his flanks; and whereas, during the earlier stages of the disease, he refused to do anything but stand, he is continually now lying down, at the same time restless and ill at ease; manual examination of the body over the region of the liver will point to distinct tenderness; the fæces are sparing in quantity, dry and coated with mucus; the urine is more than ever scanty, very dense in substance, and highly colored; if there is any alteration in the pulse, it is more wiry, and as before pointed out, the respirations will be thoracic, (or from the chest,) because the pain is chiefly experienced in the abdomen and breathing is therefore effected so as to relieve the painful parts; the tongue also serves as a very useful indieator, inasmuch as it will be found to be swollen, will pit on pressure, and is pulpy to the touch, while the mouth is constantly full of sticky saliva; the temperature is generally not so high, as in the respiratory form, so that as a sequel to respiratory complications a fall from $106^{\circ}$ to $104^{\circ}$ cannot under these conditions be deemed favorable: this is one of the few exceptions when a decrease in internal temperature cannot be relied upon, as indicative of convalescence; but as the fall does not steadily continue but will be maintained at I04 degrees for some days there will be no difficulty in recognizing that the first drop was not an indication of convalescence, but rather a change of attack on the part of the malady. It is pretty well agreed by those competent to form an opinion that Influenza or Grippe as the malady has been some- 
times designated, is more likely to spread over a stud of horses, when the stable accommodation is too cramped and limited, and the surroundings are of an unsanitary character; such circumstances also seem to favor an outbreak; we have no doubt as to the infectiousness of the malady, not only from horse to horse, but also from horse to man.

These conclusions point to the desirability of isolation so soon as an outbreak is recognized, to avoid as much as possible an extension thereof; this, however, may not always be successful in stopping its spread, if the theory that atmospheric conditions favor the development of the malady, be reliable; nevertheless no harm can come of the precaution, and it is always best, from an economical point of view, to adopt preventive measures, especially such as sanitation and common sense suggest.

Complications affecting the intestines and other abdominal organs, if not successfully combatted, very often develop typhoid symptoms, especially when stables are overcrowded, and these are the cases that usually prove fatal; but even these with homœopathic remedies available should show a marked diminution in mortality over the ordinary allopathic treatment as there are several drugs specially suitable for these conditions that are not recognized by orthodox medicine.

TrEatment.-A large, well ventilated, loose box well supplied with fresh air and light serves as the best hospital for a horse sick of Influenza; the bedding should be of sawdust for preference, and if of straw it should be cut short to enable the horse to move about without obstruction, he by reason of stiffness and soreness being unable to lift his legs off the ground in the ordinary way; the supply of fresh water should be constant and the trough swilled out many times during the day to wash away any accumulations of saliva; the food must be of the lightest, most easily digestible and nourishing description, making allowance for stimulants when other food is not taken in sufficient quantity; the food being given, a small quantity at a time and oft repeated, care being taken to frequently cleanse the manger as there is no doubt in our mind that the ropy saliva which is a peculiar secretion of this disorder is calculated to retard recovery when re-mixed with fresh food and allowed to accumulate in the manger from time to time; as the surface temperature is so variable in this disease it 
must be maintained at au equable standard by warm clothing to the body and legs, and this clothing should be removed at least three times a day and the horse be rubbed down with gentle friction before replacing same; to avoid the risk of chill one man on either side should be engaged in dressing him that the process may be got through with as little loss of time as possible and the clothing put on again before the animal has had the chance of getting cold. The administration of medicinal agents must be arranged according to the special symptoms.

Aconite, 3x.-This remedy always comes first in these diseases that are ushered in by decidedly febrile indications, and in many cases of influenza great benefit is derived from its early administration as it serves to abort the fever, and in this way cuts short the further developments; but, as a rule, a horse is frequently allowed to go beyond the stage when Aconite is useful before the nature of the malady is discovered.

Arsenicum iodide, 3x. - This remedy is peculiarly efficacious in those cases of influenza when the predominant symptoms are running at the nose and eyes; great prostration and weakness; temperature I04 degrees; pulse feeble and frequent; respirations urgent; thirst gratified only by small, but very oft-repeated draughts of water; appetite precarious and uncertain; very pronounced swelling of legs. Dr. E. M. Hale, of Chicago, a wellknown homœopathic physician and literateur was one of the first to test this remedy on his own horses, during one of these epidemics in the United States, the results of which were eminently satisfactory, and to this gentlemen we are indebted for drawing our attention to the specification of the drug under circumstances when these symptoms chiefly prevailed in a stud of horses we were attending.

Gelsemium, IX.-There are several very characteristic symptoms which occur in influenza for which this drug, in the earlier stages, is peculiarly appropriate; we have proved it on several of our patients and on one occasion with marked success on ourselves when we believe we had been infected from inhaling the breath of a patient that presented these particular symptoms; they are, very marked swelling of the eyelids, to the extent of absolutely closing the visual opening; there are indications of marked pain in the head by the dull, heavy expression of the animal's face as 
though there were great oppression of the brain; the horse seems unable to control his movements, the legs being powerless or even paralyzed; there is also erident giddiness. Under such circumstances this remedy may be given in the earlier stages in the place of Aconite, and it will be found that under its influence a temperature of 104 or 105 degrees, will, in the course of twelve hours drop down to IO2 or IOI degrees. In our own experience it acted in this manner, and seemed to fairly abort the threatened malady by lowering the temperature most effectively. With regard to this remedy we believe the honor of introducing it into practice properly belongs to Dr. E. M. Hale, of Chicago.

In cases wherein the disease extends its infuence to the bronchial tubes and proper substance of the lung; Bryonia and Phosphorus, or such other remedies as will be found prescribed under chapters on bronchitis and pneumonia should be administered and to these we must refer the student. Much the same may be stated with regard to those complications which affect the intestines and abdominal organs; at the same time special note may be made of the following remedies, viz:

Nux vomica, $3 x$. - When the fever is maintained and the horse gives evidence of chilliness and shivering; hard cough, accompanied with breaking of wind per rectum when the horse coughs; want of appetite and constipation of bowels attended with straining to obtain relief.

Rhus toxicodendron, $3 x$. - The horse evinces great disinclination to move, but when he does, stretches his limbs as though to obtain relief from the aching pain; lies down and stretclies, then rises again; tip of the tongue will be red as compared with other parts of the organ, and the internal temperature will rise higher at night but falls slightly in the morning; movement seems to afford relief, which is the exact opposite of Bryonia.

Oxygen gas.-This, from the standpoint of a homcopahist, can hardly be described as a therapeutic agent, its administration must be included under the head of sanitation; in many cases of influenza, and indeed, other diseases as well, the animal, notwithstanding the most assiduous nursing and careful prescribing, seems to gradually become more depressed and unable to stand up against the ravages of the invading malady. A something in the surroundings seems to be wanting; the vitality of the system appears 
to be gradually ebbing away, and the prominent symptoms affecting, especially the respiratory organs, become more and more urgent, neither remedial measures nor stimulants produce any appreciable effect for the better. These conditions probably owe their existence-it may be said their overpowering existence-to the fact that the vitalizing influence of the ordinary atmosphere is by reason of its fixed constitution not equal to burn up and destroy the immense quantity of effete material with which the blood stream is loaded, consequently the blood becomes more and more effete in quality, and nature is thwarted in her efforts to restore an equilibrium. What is required? Our reply is oxygen! We are indebted to our friend Edwin Faulkner, Esq., M. R. C. V. S., of Manchester, England, for first drawing attention to this agent and its marvelous utility under such conditions; in his experience, and since in our own, it has proved a veritable life saver; and although it is rather expensive treatment, and the administration demands considerable care, where valuable horses are concerned these are matters of no moment.

In England oxygen gas is manufactured for sale in large quantities and supplied in strong cone-shaped iron cylinders, which contain a given measurement of the gas, the size most suitable for veterinary purposes being that which costs about sixteen shillings; each cylinder is supplied with a brass tap to which may be attached an india rubber tube; a leather nose-bag having been adjusted to the horse's head the aforesaid tube is introduced to the bottom of the bag, just under the horse's nostrils, and the tap is turned on sufficiently to allow a gentle stream of the gas to pass continuously for a period of twenty minutes into the bag and so pervade the atmosphere which the horse is inspiring; this, according to the greater or less urgency of the case, should be repeated three, four or five times every twenty-four hours. As a rule marked improvement speedily supervenes upon this procedure as evidenced in the first place by the calmer performance of the respiratory functions and the lowering of the internal temperature. In this manner the ordinary provision of nature, as determined by the fixed law of atmospheric composition, has been super-added to by the aid of chemistry and the conditions surrounding and affecting the body of the patient are reduced to submission; nature is 
now in a position to avail himself of strictly therapeutic assistance and effect a complete restoration to health.

Eucalyptus, $\theta$.- Still another valuable agent must be referred to, which under some conditions is capable of acting therapeutically, while at others it appears to act chemically, in virtue of its disinfecting properties; it is more with regard to the latter that we propose to advocate its use in stables where a number of sick horses are from force of circumstances necessarily kept together; the apparently volatile character of the organisms or germs, through the medium of which influenza is spread from place to place, or by which one animal is the medium of infecting another, makes it desirable, nay imperative, that no effect should be left untried that may possibly tend to arrest the progress and further development of the infective virus; this result may frequently be attained by the agent, Eucalyptus, now under consideration; as a disinfectant and deodorizer it may very usefully be used in a stable by means of a spray diffuser. The mother tincture will, when used in this way over the general area of the stable until the whole surrounding atmosphere of the building is impregnated, (which may be determined by the excess of the aromatic over other smells, ) serve at a small expense and little trouble to prevent healthy animals from falling victims to the malady and will facilitate the cure of those already the subjects of treatment.

Antimonium tartaricum, 6x.-When the cough is loose though attended with a good deal of oppression and apparent difficulty; thick lumps of soft gelatinous looking mucus will be discharged from the nose while the animal is undergoing a fit of coughing. The exertion of coughing evidently shakes the animal, this is suggestive of stomach complications for which the remedy is eminently suited.

Lachesis, 30.-When the swelling down the legs and along the abdomen persists and increases ultimately resulting in the oozing of drops of blood and bloody serum through the skin. If this remedy does not act promptly and within six hours give distinct evidence of arresting this hemorrhage it should be substituted by Crotalus, i2.

Under such serious conditions the remedy should be adininistered frequently, at least once in every two hours, and intermediate between the doses stimulants should be given, probably 
nothing is better than Scotch whiskey and milk in suitable quantities according to the strength of the patient, varying from one to fire fluid ounces of whiskey in an equal quantity of milk.

\section{ERYSIPELAS.}

This is an acute febrile disease affecting the whole thickness of the skin and the underlying parts; it, as a rule, diffuses itself orer a wide area; there is much general swelling and pain and the evidence of its presence is shown by the hot red shining condition of the inflamed skin upon and within which a number of very small blisters which contain a yellowish fluid mixed with blood may be observed. In the human subject it is described as a contagious disease, but by some eminent authorities on horse pathology it is not considered capable of propagation from one animal to another. Without wishing to arrogate too much to ourselves we are distinctly of opinion that it is innocculable from one horse to another, and therefore we should consider it might prove contagious especially if some of the exuded serum from one patient comes in contact with an abraded wound on another animal.

The disease as a rule commences to develop at the fetlock joint or hock and spreads in an upward direction covering the whole superficies of the leg; on this account it may be distinguished from lymphangitis (or weed) which usually commences at the upper portion of the limb and spreads as it descends. So far as swelling, heat and tenderness occur in weed they resemble erysipelas, but the skin in the latter is generally a brighter red, more shining and tense, while in weed we do not find that tendency to form little vesicles and sloughing sores that are generally present in erysipelas.

Symptous. - The first indications are similar to those observed in many other febrile diseases, viz: Exaited temperature, full and rapid pulse, quickened breathing, staring coat, mouth hot and clammy, loss of appetite, breath very unpleasant, much prostration and waste of the muscular tissues. The local symptoms are, at first, slight swelling from which a yellowish fluid exudes; the strelling gradually extends over the limb, which as a rule is one of the hind ones; as the swelling increases the affected parts will pit on pressure but the indentation will fill up again soon after the finger is removed; if this condition is not arrested by suitable treatment, 
the parts soon become so full of fluid under the skin, that the latter is firmer and no impression can be made on it; this is the period in the development of the disease when large numbers of small vesicles will form, ostensibly to relieve the parts from the pressure of the accumulated fluid; should this proceed to suppuration or the formation of matter (pus), the skin will become dead in patches and peel off and in very severe cases it has been known to penetrate to the muscles, tendons, ligaments and joints the consequences of which may be very serious, leading to stiff joints or even to death; but under homœopathic treatment, with oruinary care and attention, results such as these should be unknown.

Treaturint.-Aconite, IX is the most useful remedy to commence with when the fever is very high at the outset, the skin dry and hot, the pulse full rapid and bounding, and when giddiness excitability and nervousness are evinced and the horse cannot bear to have the parts touched; if taken in time this remedy will not infrequently abort further developments and complete the cure.

Apis Mellifica, 3x.-This is a peculiarly efficient remedy in the more superficial forms of the disease, when the swellings containing fluid are spread over a greater surface and do not form the small vesicles (or pimples), and when the parts are not particularly red and shining; there is one special symptom to guide in the selection of $A p i s$, when the horse coughs as though the throat were rough and dry, nor does he care to drink to relieve the dryness; the urine also is scanty and very high colored; the remedy has been found very efficacious in those forms of the disease which arise as the result of a wound or injury; a general diffused swelling of the eyelids, as though fluid was dispersed under the skin which may arise independently of or in conjunction with erysipelas in other parts points distinctly to this drug as the suitable remedy.

Belladonna, 3x. -The leading indication is the smooth, bright red, shining condition of the skin, the œdema (or swelling) is not so considerable as that for which Apis is suitable, but the parts are hotter and more tender to the touch; that peculiar symptom referred to on several occasions, throbbing pulse of the carotid arteries also serves to determine in favor of Belladonna, as does an 
intolerance of light; the horse will poke his head into any corner to get away from the window or open door,

Cantharis, 3x. - It is well known that local physiological manifestations from the use of this drug are pimples, vesicles and pustules; but erysipelas like many other pathological developments is often accompanied by symptoms in the organs or parts of the body which do not seem to be associated, at the same time when they appear together and form a totality of present symptoms the one remedy cures the lot; so it is in the case of Cantharis in erysipelas when the urinary organs are affected at the same time, there being a constant desire to pass water, but ability only to do so a few drops at once; itching, however, is not a predominant symptom; the affected parts rather feel hot and burning; the pimples are large and flat containing a good deal of their fluid serum, and the vesicles burst readily.

Rhus toxicodendron, 2x. - One of the chief remedies in vesicular erysipelas, especially if the near hind leg is attacked and thereafter it extends to the off leg; the surface of the skin is very red, burns to the touch, swells considerably, and the vesicles are small and numerous; itching is intolerable, as the horse will give evidence of by rubbing the legs together or against the sides of the box.

These are the principal agents that are likely to prove effectual in cherking the spread and further development of this disease; the internal administration of the drugs, which must be selected according to the totality of the symptoms, will be rendered more rapidly effective if also a local application consisting of one part of the mothar tincture of the selected remedy is mixed with two parts of glycerire and three of water and applied to the skin with a soft brush twice or three times a day. As the febrile symptoms are usually very pronounced, and the waste of muscular tissue is in consequence considerable, the most nourishing and easily digestible food must be given, and in conjunction therewith during convalescence nothing better than China $\theta$ ten drops night and morning can be combined to give tone to the system and promote assimilation of nourishing diet. 


\section{GLANDERS AND FARCY.}

These terms serve to describe manifestations of one and the same disease in different parts of the body; they are both due to one and the same specific virus (or poison); the term glanders is applied when the recognized symptoms peculiar to this malady are developed and observable in the lining membrane of the nose, the glands between the under jaws, the upper portion of the air passage, the windpipe and lungs; and farcy when the disease locates itself chiefly in the lymphatic vessels which accompany the course of the veins as they travel down the legs, the hind legs being more often the seat of attack than the fore; these lymphatic vessels are swollen and hard, and at intervals small enlargements like buds on a young branch in trees are observable; it is a very common thing for stablemen to speak of any enlargement of the hind legs, accompanied by a diffuse swelling and discharge of sticky fluid as belonging to a horse that is "farcied;" this, however, is a misappropriation of terms, if by this word it was intended to convey that the horse was the subject of "farcy" proper.

In describing this disease we shall be understood to convey the impression that we are dealing with one whose characteristics are most malignant; it is capable of transmission from one horse to another by immediate contact, by which we desire to convey the idea that the discharge from the ulcers peculiar to this disease if brought into contact with an abraded surface on the skin or mucous membranes of another healthy horse will reproduce a similar condition, the virus (or poison) having found its way into the system through the medium of the general circulation of the blood; moreover we would go further and state our belief that the morbific material is capable of transmission from one horse (diseased) to another (not diseased) through the media of food, water, litter via the digestive canal. Again we are strongly of opinion that the virus of this disease may be conveyed from one animal to another through the atmosphere; that is to say, it is considered to be volatile; not volatile in the sense that cliemists use the term, but that the poisonous substance is so finely divided into the most minute particles that it becomes capable of transmissior from one place to another-to say nothing of one horse to 
another-on the wings of the wind; and this is by no means a fanciful fiction, as minute portions of lung tissue are acknowledged by physiologists to be regularly expelled at each act of respiration, and it requires that no great demand should be made upon the ordinary intelligence of man to appreciate that at each expiration active disease organizations should be conveyed, which may still further be distributed by atmospheric currents, and become inhaled through the breath into the lungs of a healthy horse, from thence into the fluid stream and thus become developed like new seed upon fresh soil. To go closely into detail into the pathology, modes of propagation, incubation and special characteristics of this disease, would in a work of this kind, be a waste of time and energy; the main thing in the first instance that has to be impressed upon the minds of the probable readers of this book is the extremely infectious and contagious character of the disease; too much cannot be said upon this point, nor can any horseman be too much warned against the serious consequences of letting his charges once come near enough to a subject of the disease to risk their becoming contaminated; in Great Britain and various countries on the Continent of Europe the losses sustained through the dire effects produced by this awful disease cannot possibly be estimated, so rapidly infectious is it when once established, while at the same time its approach is occasionally most subtle by reason of the length of time it may lie latent or undeveloped in the system, so far as external manifestations are concerned. Without doubt the first thing an owner has to do who recognizes that he has a case of glanders or farcy in his stable is to isolate such an animal, and the isolation stable should be situated at a considerable distance from that ordinarily used for healthy horses; moreover it is not less important that the stableman whose duty it is to attend a glanderous patient should be kept strictly to his one job, and under no circumstances allowed to go near other healthy animals; the box or stable occupied by the infected animal up to the time of the discovery that it was the subject of glanders or farcy, should be immediately disinfected by first burning powdered sulphur on a charcoal fire, every door, window and aperture in the place being stopped up, the process to be actively carried on for at least two hours; thereafter the walls and paint should be carefully scraped and the refuse there- 
from burnt, the walls and partitions being thoroughly washed down with a solution of corrosive sublimate consisting of one part of the drug dissolved in five hundred parts of boiling water; this being completed and the place dry, the walls should be thoroughly lime-washed and the wood-work repainted, after which the stable will be fit for habitation once more; pails and all stable utensils previously used for the affected animal must be also subjected to a similar disinfecting process; the man who attends the diseased animal must either subject his clothes, more particularly the outer garments made of wool, to disinfection or better still have them burnt before he rentures to appear in the ordinary stable; if these precautions be taken, and nothing less stringent will do, then the propagation of the disease may be arrested; but if the affected animal was in a stable in company with other horses which so far present 110 outward manifestation of disease, such horses must in the interest of the owner, be subjected to the MALLEIN test hereafter explained, to determine whether they are any or all the subjects of the disease in a latent, outwardly undeveloped form; if they are, then they also must be isolated and treated as we shall direct further on. As experience has taught that in a very large number of cases considerable time elapses between the reception into the animal system of the virus (poison) of glanders and the manifestation or outward development of the characteristic symptoms it is a most important matter to understand how the presence of the disease may be determined; but thanks to recent research in Great Britain and on the Continent of Europe, a fairly-if not absolutely-reliable test has been discovered of a simple character that any intelligent horseman can put into practice after being supplied with the proper agent; in England reterinary practitioners are mainly-if not entirely-indebted to Professor McFadyean, of the Royal Veterinary College, London, for introducing Mallein, the agent referred to, to the notice of the profession, and further still for preparing and keeping up the supply for those members of the profession who are putting MALLEIN to the test: Professor McFadyean in conjunction with one or two other members of the teaching staff at the college have put. Mallein to the test in a large number of cases-something like one lnundred and fifty we believe-and as the result the professor gives expres- 
sion to the following opinion in the "Joumal of Comparative Pathology and Therapeutics" for March, I893, viz:

"The very numerous observations that have now been published at home and abroad regarding the action of Mallein appears to warrant the following conclusions:

I. "If in any horse that presents symptoms exciting a suspicion of glanders or that is known to have been exposed to the infection of glanders, an injection of Mallein raises the temperature from about the normal (under Io degrees) to Io4 degrees and produces a marked inflammatory reaction at the seat of injection that horse may be pronounced 'glandered.'

2. "If in such a horse an injection of Mallein determine a marked local reaction and an elevation of temperature equal to 2 degrees, that horse may be pronounced 'probably glandered.'

3. "In horses that have already a febrile temperature ( I02 degrees or over) the temperature reaction after Mallein is inconstant and unreliable as a guide to diagnosis.

"It only remains to be added that the local reaction deserves to be called 'marked' when the swelling extends for three or four inches from the point of injection."

It is now necessary to explain for the right understanding of the reader that Mallein is prepared by what is called cultivating the virus (poison) of a glandered horse, the virus being found in the discharges from the nose and eyes and this is cultivated from one growth to another in the Pathological Laboratory until it is sufficiently attenuated for use, and may be obtained sometimes in the fluid form and sometimes in the dry as is exemplified by what is described as Foth's 'Dry Mallein' nor does there appear to be any difference in the reaction of the two samples; presumably the dry sample keeps the best. The usual quantity used at one inoculation is $2 \mathrm{~T} / 2$ cubic centimetres of the fluid preparation which should be injected with a chemically clean subcutaneous syringe that has been rendered properly aseptic under the skin of the neck; probably no better method of rendering the syringe aseptic can be adopted than plunging the various disconnected parts into boiling water and there holding them for a few minutes, after which they can be put together and used; the middle part of the neck measuring both the length and depth of same, is the best place to select for the operation; this of course is the point where 
the local swelling referred to by Professor McFadyean takes place after the Mallein has been injected, which swelling has to be measured both as to its length and breadth to determine in conjunction with the rise in temperature, whether the horse is probably the subject of glanders. With respect to the observations to be made with the thermometer, it will be necessary to take the temperature six hours before the injection of the Mallein, at the time of the operation, and erery six hours thereafter, until thirtysix hours has expired from the time the Mallein was injected, on which occasions also the measurements of the local swellings must be taken; each of these particulars must be registered in detail; if the register of the temperature shows that the thermometer has risen from 100 to 103 degrees or higher, and the local swellings extend an average of five or six inches both ways, then it is pretty safe to condemn the horse as the subject of glanders, and he must at once be isolated; but if during the period of thirty-six hours following the injection the temperature rises only one degree or a fractional part thereof the evidence is not sufficient to warrant the conclusion that the horse is the subject of glanders; the test operation should be repeated a week after.

It is perhaps hardly necessary to state that if the services of a professional veterinarian are available, it is far better to entrust such an one with the performance of the test operation; on the contrary if one is not within reasonable reach, the Mallein should be obtained through some reliable wholesale druggist who may be trusted to obtain the proper agent from the right source.

The next question that has to be considered is how to form a conclusion from symptomatology that a horse is affected with glanders and to this end we will offer a list of the principal guiding

Srmptoms, and to do this satisfactorily it is almost necessary to divide them into two classes, namely, the acute and the chronic: we shall take the acute first: the temperature will be considerably exalted; the pulse quick and rather soft, the respirations rather more frequent than is usual in health; the coat has a generally unthrifty appearance and feels harsh to the touch, dry and stands up on end; the animal speedily loses condition, and becones wasted and thin; the urine is rather increased in quantity and has little or no color; the mucous membrane of the nostrils is of a 
dark leaden hue, on which will be observable, very shortly, small patches about the size of a pea, which to the eye seem to contain a yellow fluid, the margins of which are surrounded by gray zone this yet again encircled by a red areola; after a few days these pimples or patches develop into open ulcers with ragged edges which discharge from their centres a sticky matter (pus). The glands between the jaws are swollen and hard, and after a time become attached to the surrounding parts and immovable; these glands are as a rule very tender, and the horse does not like to have them pressed upon or squeezed; the lips and outer wings of the nose become swollen, and upon them ulcers sometimes form which discharge purulent matter; in consequence of the swelling and thickening of the upper internal parts of the nose and sometimes the larynx of the throat, the breathing is considerably interfered with and assumes a snuffling character which is generally accompanied by a cough, soft and painful; if not arrested in the earlier stages the lungs are rapidly implicated and symptoms of bronchitis and pneumonia supervene, after which the horse soon gives evidence of rapid decay, the appetite fails and the breathing is more distressing; the legs commence to swell, the cords and buds of farcy appear and the animal speedily succumbs.

The symptoms of chronic glanders, by reason of the subtle invasion of the virus are more slowly developed and not so easy of recognition; the disease may be thoroughly established in the horse's system for many months before the more obvious symptoms declare themselves; all the same, however, the horse so affected is a centre capable of disseminating the virulent poison; these occult cases, as a rule, are affected chiefly in the lungs, and it has frequently been a matter causing us no little surprise on making a post mortem examination that the horse had not given more distinct evidence during life of the pathological conditions that had evidently been progressing for months in the lungs, and at the same time no visible symptoms had presented themselves; we once knew a case of this sort which was productive of the most painful consequences to the owner and his friends: the gentleman owned a horse that was in regular hard work; he purchased a three year old filly and put her into the next standing to the old horse; the following day after her purchase he thought she would be better for an alterative ball, and administered it himself, in doing 
which he grazed the back of his hand against a sharp molar tooth; in a few days the young mare and the owner both developed all the signs of acute glanders; in six weeks the owner after a most painful illness died: the old horse meanwhile developed a suspicious cough, and as the young mare died shortly after her master, it was suggested that probably the older horse was the origin of the outbreak, and he was accordingly slaughtered; there was no evidence of the disease in any part of his body except the lungs, and these to the pathologist were a sight to wonder at, this case furnishes a description of one kind of chronic glanders occasionally met with: the more common cases are those in which the animal presents an unthrifty looking coat, whose appetite is capricious and uncertain; that one day appears fairly bright and well while on another it is depressed and indolent; the glands between the jaws are very hard, much enlarged and adherent to the jaw bones, not necessarily very tender, but generally rather so; there may or may not be a discharge from the nose and one or more ulcers may be developed rather high up in the nasal chamber, left side for preference, but the lining membrane of the nose almost always displays that very significant blue or rather slate color; with regard to the discharge from the nostrils and the character of such discharge it is necessary to be observant, otherwise a case of nasal catarrh or ozœna may be mistaken for glanders; the discharge varies in character as the disease progresses, being first rather thick and viscid, from which it changes to a decidedly purulent discharge not unfrequently mixed with a little blood, or it may still alter its character by assuming a very green color; it is quite true that under the worst conditions the character of the nasal discharge cannot be accepted as positive evidence of the presence of glanders virus, but it is certainly very suggestive and serves as a very good indication for the adoption of the MLILLEIN test; there is probably no more correct indication of the presence of chronic glanders than the up and down variations of the internal body temperature; if the horse appears dull and unwell and the temperature be taken regularly two or three times a day for three weeks consecutively, considerable variations will be registered; one day the thermometer will stand at Iof degrees, another Ior degrees, yet again to IO4 degrees, then fall to IO3 $_{3}$ degrees, and again to 100.5 degrees, and so on from one day to 
another, all the while the animal will have a capricious appetite and present alternating indications of depression and renewed vitality; the urine is generally very much increased in quantity and lacks its normal color.

FARCY is recognized by the swelling of the legs, especially the hind ones, diffuse and general, attended with marked heat and pain; the course of the lymphatic glands and ressels is soon marked out by these standing out beyond the more general swelling in well developed cords and buds; these buds become very prominent; they are painful, swell more and more, then burst and discharge the matter peculiar to this disease, leaving deep ulcers with ragged edges.

We believe that the foregoing list of symptoms will, at all events, serve to enable a horseman to determine if he has a suspicious case of glanders or farcy in his stable, and if this be the case the next procedure in his own interests is to subject the suspect to the Mallein test, or if that is really not available then the practice of auto-inoculation may be resorted to, which consists of the following operation: shave off the hair in the middle of the neck about three inches square in extent; carefully wash the surface of the parts with carbolic soap and dry with a clean cloth; take a sharp scalpel or knife previously held in absolutely boiling water for two minutes, make a very slight incision of one inch long but only sufficiently deep to exude about one or two drops of blood; with the point of the knife take a small quantity of the discharge from one of the ulcers present on the nose or leg, and gently rub. the same into the incision; if the horse is the subject of the malady, the symptoms already developed will become intensified, and the temperature will probably rise 2 or 3 degrees, and the seat of inoculation will swell considerably.

In England and on the Continent of Europe the prevailing impression among allopaths is that glanders is an absolutely incurable disease, and as in pleuro-pneumonia among cattle, the stamping out process is in rogue, and the law is so framed that it steps in to enforce these regulations; it is certainly an exhibition of great weakness and impotence on the part of the veterinary profession that such steps should not only be rendered necessary, but should be encouraged by the profession as a body; at the same time we cannot overlook the fact so long as a glandered. 
horse is allowed to mix with others, so long is it a source of risk to the healthy, by reason of the virulent and infectious nature of this disease; moreover while the disease is considered by the leading lights - to say nothing of the rank and file-of the profession to be incurable, and therefore no efforts are made to effect cures, it would seem as though no other course but the stamping out process is available in countries where these views prevail. Nevertheless while it may seem extremely presumptious for one individual to firmly adhere to views diametrically opposed to those held by an overwhelming majority of a learned profession, we venture to assert that in our opinion glanders and farcy are capable of being cured just like any other disease, and we can discover no valid reason why glanders should be an exception to the general rule; moreover we have good and sound reasons for believing that cases of glanders have been repeatedly cured; and by this we do not mean apparently cured, as may sometimes appear to be the case in consequence of the healing of the ulcers and sores on the nasal membrane, leaving a cicatrix behind as evidence of the same, while at the same time the virus of the disease remained in the system, and the horse was as much a medium for the spread of infection as ever he was; we mean an absolute cure, the virus of the disease to all intents and purposes dead and positively inactire, in which the capacity for infection no longer exists, the living organisms (bacteria) starved and incapable of carrying on their direful effects upon the horse's constitution; all this we confidently assert may be effected, the whole allopathic profession notwithstanding, by means of properly selected homcopathic remedies; and in passing we venture to allude to what we believe to be the terrible moral responsibility which rests upon the medical profession for ignoring homøopathic practice, as a sort of forlorn hope if for nothing else, in cases of this dire disease on the luman subject; certainly no harm could come of a trial with a homceopathically selected drug in a disease which is generally admitted to be absolutely incurable by orthodox practitioners; without doubt orthodox practice is impotently helpless in combatting glanders, but that is no reason why men should be allowed to die, when successful treatment is available and within the "ken" of any" practitioner who will condescend to seek after it; we have no hesitation in arerring that many men have been convicted of murder 
. on much more slender charges than could be brought against some medical men who have allowed cases of glanders in the human subject infected by glandered horses to die because knowing of no cure in orthodox practice they would not seek a cure from the despised (?) Hahnemannians.

We have already affirmed that by means of homœopathic treatment glanders may be cured; one of the agents used is glanderinum, which like Mallein, is the attenuated virus of the disease; such remedies are described as nosodes, they have in this and other diseases such as tuberculosis (tuberculin, the nosode,) proved remarkably effective in bringing about cures when all other drugs have failed, and the administration of these has been extremely disappointing; glanderinum, however, is invariably reduced to a much higher attenuation through the method of preparation adopted by homœopathic druggists than is Mallein, and we believe that to Dr. Swan, of New York, is due all the honor for first bringing into prominent notice this and similar preparations; hence the followers of Hahnemann who consider the administration of nosodes to be strictly within the homœopathic law can claim to have recognized the value of the principle involved in the use of such agents long before the discoverer of Mallein, long before Professor Kock with his much vaunted tuberculin; long before Pasteur with his anthrax protective inoculations; this is a very interesting fact and not less true than interesting, because it serves to show how much the homœopathist is in advance of the allopathist in everything that appertains to scientific research. Glanderinum is most probably quite as effective in curing glanders as Mallein is in detecting the presence of the disease; but the question at once arises, why does not Mallein cure sometimes? To this question we reply by giving in extenso an article from the "Journal of Comparative Pathology and Therapeutics," of June, I893, edited by Professor McFadyean of the London Veterinary College, from which it appears that under given conditions it does cure; the article is a reprint from "Berliner Thierärztliche Wochcnschrift," and is headed "The CuRative EFFECT OF MALLeIN IN GLANDERS." It then goes on to state that "In February last Professor Pilavios, of Athen's, sent to the French Academy of Medicine a report regarding the use of Mallein in the treatment of glanders. He has been pursuing his investigations since, and he 
now reports that both he and his colleagues have been struck with astonishment at the success of the Mallein treatment. Horses suspected of glanders have been completely cured by repeated injections of Mallein at intervals of eight days. In all eight horses have been thus treated, and all these animals came from regiments in which glanders had prevailed for years. Before injection the horses showed all the clinical symptoms of glanders, and had on that account been isolated. They reacted to the first two injections in the ordinary way, but at the third and each succeeding injection (with large doses) they behaved like healthy horses, and exhibited no reaction. Immediately after the third injection the symptoms of glanders began to abate, and after 40-45 days they had completely disappeared. After other 35 days the horses were again injected with Mallein, but not the slightest reaction followed. At the date of the report the horses were doing their work as well or even better than other sound horses. The Mallein treatment has been found successful only in the early stages of glanders; in the advanced stages of the disease the injection of Mallein may hasten death. In some of the latter cases the horses died with the symptoms of peracute nasal glanders three or four days after the first injection." From the latter clauses of this article we come to the conclusion that the agent prepared in the form Mallein is probably in a majority of cases produces an aggravation of the symptoms, and consequently horses "in the advanced stages of the disease" have not stamina and vitality of constitution enough to enable them to withstand the potent action of the more porverful Mallein; but here steps in the advantage of the homœopathically prepared agent; glanderinum (Swan) is attenuated to the centum mille $=100,000$ th potency, and may be relied upon to do its work effectively without any risk of aggravation of symptoms.

According to experience we are disposed to think that glanderinum is more likely to prove useful in old standing chronic cases rather than in the more acute and recently developed ones in which latter other remedies possibly answer best.

TrEATMENT-Kali bichromicum, 3X.-Ten grains three or four times a day, dry on the tongue, when lining membrane of nose is blue or slate color; ulcers developed thereon with ragged edges; discharge thick, glutinous, yellow, hanging in strings; submaxil- 
lary glands very enlarged, hard and adherent to bones of jaw; tongue thickly coated; dysenteric diarrhœa. In addition to the internal administration of the remedy it may very usefully be applied locally to the ulcers on the nasal membrane, the outer skin of the nose and face and the buds of farcy; a suitable lotion for this purpose may be prepared by dissolving one drachm of the crude drug in ten fluid ounces of distilied water; should there be any ulcers in the upper parts of the nose out of reach, either a syringe or a spray diffuser can be used to effect the desired object.

Mercurius corrosious, $3 \mathrm{x}$ grains, five to a dose, repeated three times a day. Should the temperature not descend and the ulcers show signs of healing under the influence of Kali bichr., resort should be had to Mercury.

Aurum muriaticum, 15.- In cases where the ulcers are deep enough to penetrate the bone of the nose and have a tendency to spread among this hard tissue, this drug may be given in alternate doses with one of the foregoing ones, ten to fifteen drops at a time, but should be discontinued so soon as the bone heals.

Glanderinum (Swan) C. M.-Fifteen to twenty drops to a dose; this remedy should be tried in acute cases if others fail, or in the first instance in chronic, old standing cases; but the dose does not require to be administered oftener than once in.two days.

In addition to the internal treatment the ulcers may with advantage be dressed with Eucalyptus $\theta$, either through the instrumentality of a syringe (glass) or a spray diffuser. The box or stable should be subjected to a free diffusion of the Eucalyptus several times each day with a view to disinfection and preventing the spread of the disease.

During the time the horse is under treatment it should have gentle walking exercise, provided it does not come near either horse or man other than the usual attendant, the food should be of the most nutritious and digestible character, and if possible green food or some succulent roots should be included in the allowance; the box requires to be frequently and regularly cleaned out, but the bedding ought to be burned immediately.

\section{AN'THRAX.}

Although this disease is but rarely encountered among horses in Great Britain, there is good reason for believing that its geo- 
graphical distribution is not limited to any particular localities; while in some it is more frequently met with than in others, a fact probably due to the special conditions under which it owes its spread and development; and inasmuch as its presence has been clearly recognized among the western states of the North American Continent we have deemed it advisable to include it, if only as a precautionary act, in the list of maladies dealt with in the present work; and we consider ourselves fully justified in this course; for if there is one disease more than another that calls for early recognition on the part of the lay horseman it is anthrax, and that on account of the rapidity with which the virus invades the system of whatsoever species of animal unfortunately receives it and the very short time the patient survives the invasion if not successfully treated; in the majority of instances, even where the services of a professional veterinarian are available they can rarely be secured in time to save the first case, for as a rule when one case presents itself others soon follow in its wake; and even then the probabilities of success under allopathic treatment are very remote, and only a prompt recognition of the disease backed up by the most judicious nursing and the regular administration of the most appropriate remedies, of which there are but two or three, will effect a cure under homœopathic treatment. This disease owes its origin, development and spread to a vegetable organism recognized by scientists as the bacillus anthracis, and it is now generally admitted that this organism can invade the system either by means of inoculation, through the digestive organs, through food, or by inhalation during the act of breathing; this organism appears capable of retaining its vitality under the most peculiar conditions and for an unlimited period; the body of an animal that died of anthrax and was buried, may if disturbed at some future period, prove a source of contanination and infection; or if water that drains into a pond where horses are accustonled to drink, should in its course of filtration through the soil, cone in contact with that dead body it is very likely to prove a sonrce of contanination. Pasteur who has given great attention to the subject of anthrax, asserts that earthworms are capable of bringing from such a dead body, though deeply buried, the anthrax spores to the surface from whence they conld be imparted to the animals grazing on the land adjoining, and moreover it is in the opinion 
of some scientists quite within the range of possibility for the infective virus as represented by spores to be distributed from one part of a country to another through the media of birds, dogs and even flies if affected carcasses were exposed to the attacks of these creatures.

It is quite recognized that in the malady known as wool sorters' disease, which unquestionably possesses anthracoid characteristics we have an illustration how certainly the disease may be propagated through wool and hair that has long been taken from the animals which were as certainly the subjects of anthrax; this serves to confirm our previous assertion relative to the almost unbounded vitality of the organism and the readiness with which its infective properties are transmitted. The place in the body which this organism occupies and thrives in is the blood, and when an animal dies and there is a suspicion that it is due to anthrax, it is best to confirm the existing doubt by an experiment on one of the smaller animals; take, say a rabbit, make a slight incision in the skin of the ear and rub in gently one or two drops of the blood of the dead horse; most probably a very few hours will suffice to show whether it is anthrax, as the symptoms of the disease followed by death will speedily transpire: we are not to be understood as generally advocating the principles of vivisection, indeed we may say that we strongly object to their general practice, as there is no proof that the millions of animals which have been cruelly tortured and sacrificed to the whims of fanciful scientists have ever produced the slightest benefit to science, inasmuch as the results obtained from such experiments have never saved a single life; this is strong language to give expression to and a very bold statement to make, but we believe it capable of distinct proof; nevertheless there are occasions when experiments on living animals are justifiable where there can be no question about the advantage to be derived and where speculative results are not looked for; the present is one of the few of those cases and the end here justifies the means. Now we are of opinion that without orerloading this article with closer details, sufficient has been advanced to show that aptitude of recognition and smartness at combatting difficulties are absolutely necessary qualifications if this disease is to be overcome; and believing that details as to life, history, pathology, etc., would only serve to cumber 
this article without rendering it any more understandable, we proceed to define the

Symp'roms, characteristic of the disease in horses; the most notable indication, assuming that 110 prior suggestion has been presented is the violent shaking of the body followed by sweating, which may be constant or occasionally alternate with cold; the breathing is exceptionally violent; the horse loses control over his movements: if at this period the temperature be taken it will be found as high as 105 degrees or even I07 degrees; after the beforementioned symptoms have been in evidence some hours the horse will possibly become delirious to be followed by a period of coma or unconsciousness: the pulse will naturally be increased in frequency, the beats being rather of a tumultuous character; there is one notable symptom that has been referred to by several observers, namely, a swelling of the glands of the neck and chest, for sometime the temperature is inclined to rise higher, but when it does the pulse becomes weaker in tone and the respiration more hurried; as the disease advances and obtains a stronger hold upon the system the nasal membrane become spotted over with blood markings and the surface assumes a pale, sickly appearance: from these blood patches blood of a dark color oozes out, and the mouth is filled with frothy, sticky saliva; this is the period that delirium supervenes and the horse shorvs how much he suffers in the brain by forcing the head with some pressure against the wall or side of box; the muscular tremors will become more pronounced, shivering and sweating will be renewed; the fæcal discharges will be mixed with blood and the urine very much reduced in quality will be of a claret color; at this period of the disease the temperature will begin to decline until the animal heat is reduced below the normal standard; this is suggestive of speedy collapse, and the end is generally attained amidst convulsive struggles. This is the picture of a case that cannot be cured; now for the

TREATMENT. - This is one of the few diseases in which among animals the administration of a nosode is followed by success; and that remedy is Anthracinum C. M., the virus of the disease in an attenuated form, but it does not follow that it nunst of necessity be the first remedy administered, indeed, n11less within easy reach of a druggist who kept same in stock, it is most probable that it could not be obtained in time for a first case; but 
should any of the characteristic swellings generally observable in the ox, but rarely in the horse be present, and these be accompanied by a red and swollen condition of the natural openings from which a rusty colored mucus is issuing, Anthracinum should be administered, and more especially if the patient has reached that stage of the malady when the brain is affected and delirium superrenes.

Lachesis, I2.- This is a most efficient remedy, and as it is one that under proper conditions can be safely kept at hand for immediate use when called for, and is also likely to prove useful in many other diseases; it is fortunate that its action is so reliable in a malady whose ordinary development after reception is so rapid: the usual quantity (ro drops) at intervals varying from one to three hours according to the urgency of the symptoms.

The accessory measures are in the first place to separate the healthy from those that are diseased; if death occurs the carcasses should be buried at a depth of six or eren ten feet, and a very liberal supply of quicklime should be introduced under, over and around the carcass. During the period of treatment every precaution should be taken to linder spread of infection by means of the excreta or whatever in the shape of food, water and utensils have been in contact with the patient; the stable and its surroundings strictly disinfected on principles hereinbefore laid down for glanders; and last though not least, the source of infection ought to be traced to prevent a further dissemination of the virus; particularly does this refer to the water supply, which should be properly tested by an expert and traced to its source and through its course howerer derious; should this fail the food supply should be examined, and this is a rery likely source, seeing how readily the virus is transmitted, as witness the previous illustration of wool sorters' disease.

In cases where the patient gires eridence of receiving benefit from the remedial measures adopted, but at the same time exhaustion, weakness and inertia predominate and seem to hinder the restorative process, much benefit would accrue from the inhalation of oxygen gas as described in the chapter on influenza, as it is generally considered that this gas plays an important part in attenuating the poisonous qualities of the bacillus or anthrax organism. The food must of necessity be of a light, easily 
digestible description; such as small quantities of oatmea., boiled linseed, pearl barley boiled, carrots, artificial grasses cut up into short lengths; eggs beaten up and mixed with a little port wine; beef tea; a selection to be made according to the ability of the horse to partake and the effect produced.

If swellings appear on the body, suppurate, burst and discharge the open wounds should be carefully washed with a non-irritating antiseptic, such as a solution of Sulphurous (not Sulphuric) acid or Eucalyptus.

\section{RHEUMATISM.}

A specific malady, affecting particular tissues, of an inflammatory type, attended with some swelling and much pain, a peculiar characteristic being the readiness with which it leaves one part and shifts to another; it is markedly affected by climatic influences both as regards its origin and continuance; the tissues chiefly affected in the horse are those described as " volite fibrous" of which tendons, ligaments, and their sheaths consist; the first indication of its presence in the system is made manifest by an observation that the horse is lame; next to the tendons, the joints of the legs feel the force of the attack and here it is the "fibroserous" membranes that are the seat of the disease process; these particular membranes may be recognized by any one who will examine the ends of two bones forming a joint; the end of one bone is rounded to fit into the cavity of the bone it comes into opposition with, but both are covered with a glazed-looking membrane, which with some trouble will peel off; this membrane receives a fluid called synovia, secreted in a special apparatus close at hand which serves to lubricate the joint and make the two ends of the bones glide smoothly one upon another; not infrequently a cliange seems to take place on this tissue under the influence of the rheumatic attack, the quantity of the fluid is materially diminisled and the gliding function of the joint interfered with in consequence, hence stiffness of the parts supervenes and causes great inconvenience, even though the pain is not acute.

The next tissue upon which the rheumatic poison centres its force is the muscles; but as it is found much more frequently in these muscles that are clothed with a thin, but very strong covering consisting mainly of the aforesaid white-fibrous tissue, while 
those muscles into the composition of which white-fibrous tissue does not enter are rarely the seat of rheumatism, we feel justified in coming to the conciusion that these connective tissues as they are called are the chief seat of attraction for this disease. It is rare for the horse to be the subject of rheumatism in that acute form which is experienced by the human subject nor does its derelopment frequently extend to that vital organ, the heart, as is the case in man; at the same time if a horse has been the subject of chronic rheumatism for a length of time and the treatment it has experienced has not proved satisfactory, cases have come under notice in which the valves of the heart seemed to be affected during life, a diagnosis that has several times been confirmed by us, post mortem; in examining a horse for soundness, we invariably make a rule to auscultate the chest to discorer abnormal heart sounds, if present; and on one oscasion warned the buyer that the valves of the heart were diseased-probably rheumaticin origin - but so much was the buyer's heart set upon this particular animal that he determined to risk purchase against our adrice to the contrary; and paid the penalty accordingly, for it Tas not long before the horse fell dead in the street when draming the carriage; we also know the case of a racehorse that was known to be extremely speedy who seemed rarely able to win a race collapsing and dying away as it were at the critical part of the race; he was designated a "non-stayer;" I diagnosed him as the subject of heart disease; one morning he was found dead in his box, and the autopsy showed thickening of the valves of the heart; these cases, however, are in our experience not rery numerous; this somewhat extraordinary derelopment of the disease does not however offer any serious obstacle to successful treatment; certainly the drugs required under such conditions differ from those that are so successfully used when the extremities are the seat of affection. If it can be affrmed that the homœopathic principle shines in some diseases more than others, certainly rheumatism should be included in the list; but in our opinion the reason why success is more notable in what may be termed the exceptional diseases is due to the fact that Allopathy fails utterly therein and therefore the comparison is all in faror of the system that effects a large proportion of cures.

In cases where the disease locates itself in a rery acute form 
the temperature is as a rule exalted; the pulse full, rapid and the artery unyielding to pressure; at the same time it is very aften the case that the disease confines the force of its action upon the locality affected and by the general system is not much disturbed; nor are the febrile symptoms very pronounced.

The advent of the disease is sudden. An animal when left at night may to all appearances have been perfectly sound, while in the morning the groom found it incapable of movement. Examination of the limb or limbs will show a swollen joint or the back tendons very full, and on manipulation they will be found hot and extremely tender; this may be the condition of things for some hours, when all at once affected limbs will be relieved, but the other two may be similarly affected and so by ringing the changes on the limbs the disease declares itself and recognition is not diffcult. Should the disease assume the chronic form the swelling and tenderness on manipulation may not be prominent symptoms, while a decided stiffness of the joints or muscles is clearly discernible by the peculiar dragging method of progression. Then rheumatism locates itself in the muscles of the shoulder the horse will be found standing with the limb flexed and resting on the point of the toe; when called upon to move the horse is unable to lift the foot off the ground and drags it along in a helpless manner. The same mode of progression is observable in a hind limb when the seat of the disease is the hip joint or the muscles of the loins; again, when the lameness is situate in the shoulder, the animal stands as though transfixed, it requires considerable force to induce him to more; this is often called "shoulder-tied;" when it affects the hind limbs it is described as "loin bound;" it is difficult to state which portions of the limbs are most frequently affected as the disease will very often display its force upon the knee and fetlock joints, but rarely in the hocks; so far as our experience goes we have observed it more in the shoulders than any other parts, the peculiar dragging gait and tenderness on manipulation enabling us to locate it. The condition of the urine not infrequently serves to confirm the opinion that we are face to face with a case of rheunatism, for if tested, chemically, it will be found abnormally acid, but apart from that, if collected and allowed to stand till cool, a thick deposit will be observable. Rheumatism $\mathrm{s}$ said to be due to climatic influences; whether this is a fact we 
do not pretend to assert; but one thing is quite clear, that whatever produces the disease, it is in a very marked degree affected by atmospheric surroundings. Some cases being aggravated by damp, while others are affected by dry cold, and these indications serve as very reliable guides in the selection of a remedy. By some the malady is considered to be due to hereditary taint, but with this view we do not concur, sare that in our opinion all diseases are more or less hereditary; by which we mean that if either sire or dam have during their life been the subject of any disease in an acute form, there is a probability of a tendency to that particular disease, whatever it may be, in the offspring; among the principal causes which operate in the development of rheumatism may be included poverty, indifferent diet, unhealthy surroundings, exposure, fatigue and moisture.

TREATIIENT.-There are three remedies which are preeminently suitable to cure rheumatism namely Aconite, Bryonia and Rhus toxicodendron, and in the majority of cases they corer the whole ground so far as horses are concerned, there are, horrever, some few exceptions which will be duly noted as we proceed.

Aconite 3x.-Fever pronounced, temperature ro3 degrees or over. Restlessness, unable to stand still, although it gives pain to move; affected parts red and swollen; very tender to the touch; respirations hurried; unable to pass water, with evident pain when it is attempted; swelling shifts from one leg to another in cold, dry weather; skin dry and hot, great thirst.

Bryonia 3x.- Stiffness of joints; inability to move; breathing evidently painful, respirations short and catchy; joints swollen but not red; skin is dry generally but perspiration bursts out occasionally, when the stable atmosphere may have an acid smell; thirst is considerable; stools dry and dark in color; cold, dry winds aggravate, moving about increases the pain as evidenced by the animal refusing to move when called upon; pain in the chest.

Rhus toxicodendron 3x.-Damp atmosphere and wet weather aggravate symptoms; horse moves about and evidently obtains relief from so doing; affected parts swollen and red; warm applications seem to relieve; great tenderness on manipulation as when the limb is strained; continued restlessness whether lying or standing. 
Belladonna $3 \mathrm{x}$ will occasionally prove to be more appropriate than Aconite in the early stages of acute rheumatism when the following symptoms predominate: stvelling of the joints or other parts red, tense and shining; horse starts every now and again; the eyes staring and bright, and the pupils dilated especially when the starting takes place; this pectliar symptom is probably due to a sharp shock of pain darting through the limb; and the leading indication for Belladomna visible pulsation of large superficial arteries, notably the carotids where exposed.

Caulophyllum $\mathrm{Ix}$-Very useful in cases where the disease attacks the fetlock joints, and shifts frequently from one leg to another or from the extremities to the loins; especially so with mares that have been pregnant and aborted.

Ruta graveolens $6 \mathrm{x}$ in cases where the knees of the fore legs or the hocks, or either are the principal parts affected more especially when constipation is also present which requires great straining to effect a stool; further when the parts of the body upon which the horse has been resting are tender and sore to manipulation.

Among the measures adopted from the nurses' standpoint, the most important are the use of warm clothing; the maintenance of an even, dry temperature in the stable, say 60 degrees F.; abundant facilities for rest and comfort; bedding straw should be cut into short lengths or sawdust a foot deep provided; food to consist of light, digestible things, such as milk, oatmeal and bran in equal proportions; carrots, and if available, artificial grasses, such as clover, lucerne, sainfoin; for drinking purposes gruel made from pearl barley is the best that can be utilized. In the majority of cases the symptoms are aggravated by damp, moist climate, and therefore Rhus tox, is the probable remedy, when this is so, great relief may be afforded and the cure liastened by locally applying the remedy to the affected legs; a lotion of Rhus tox. $\mathrm{A}$, one part of same to five of water suffices; take a good piece of tow, thoroughly pull it to pieces, dip it in aforesaid lotion and allow it to soak sufficiently long to become thoroughiy impregnated, after which wring it out and apply to the joint or tendons, with a layer of oilskin to enclose and thereafter bound round with a flannel bandage to keep it in apposition with the parts; this may with advantage be removed three times a day; where other remedies are indicated a similar procedure may be adopted or in the place 
of tow, medicated cotton wool used dry may be resorted to, in order that the parts may be protected and kept warm; after the swelling and tenderness are abated the dressing should be discontinued, but in order that a relapse may be avoided, it is better to continue the use of a lighter flannel bandage for some days until the limbs become gradually accustomed to dispense with a covering, and so the risk of extreme exposure may be arerted.

\section{BLOOD POISONING.}

\section{PYEMIA SEPTICAMIA.}

It is not intended to deal with this condition as one that arises of itself, but to point out that it is usually the concomitant of some other more clearly defined disease process or is the resultant of an injury; judging, however, by experience, whatever definition may be attempted to describe the process, it appears to produce a febrile condition of decided intensity and one that is peculiar to itself, and as medicinal treatment has been found capable of counteracting its pernicious influence on the animal system, we have deemed it wise to set apart a short chapter to its consideration. The change which takes place in the blood leads one to infer that a something simulating decomposition takes place in that fluid; the infective material, whatever it may be, and whether due to vegetable organisms or not, seems to gain entrance more generally than in other ways, into the system through ruptured tissues as the result of injury or surgical operations; this, having obtained access into the blood current, is rapidly conveyed over the body and the consequence is vascular irritation and general disturbance of the system; this not only results in a considerable elevation of temperature, but frequently in the establishment of an inflammatory state, which ultimately gives rise to the production and development of matter (pus) which endeavors to find exit in the production of abscesses over various parts of the body. If the blood be examined it will be found much darker in color than ordinary, when allowed to stand it does not form a clot, and it contains similar vegetable organisms (bacteria) to those found in the matter (pus) when submitted to microscopical examination; the infective material can enter the system other than through wounds, but in 
the horse we have never known of such a case, and other writers vouch for the rarity of the condition among equines; wounds, such as punctured feet, either as a consequence of carlessness on the part of a blacksmith or through picking up a nail in the street, may easily be attended by blood poisoning; wounds inflicted during an imporcant surgical operation, if there are any putrefactire products in the immediate neighborhood, may easily account for the ultimate development of blood poisoning; while there is no doubt it may appear during the course of or as a sequel to some well-defined disease. Blood poisoning is generally ushered in with marked suddenness; the elevation of the internal temperature is very rapid; the horse exhibits marked indications of systemic exhaustion; when the abscesses form internally the lungs are often the organs attacked, consequently all the symptoms of pneumonia in an aggravated form are present; this latter condition is peculiar to a disease known among racing men in Great Britain as "Newmarket Fever," which will be referred to more in detail farther on, the author assuming that racing men in the United States will be interested in this peculiar, and among sportsmen, well-known disease, the consequences of which are recognized as responsible for so many thoroughbreds disappointing their owners during their running career. When the infection takes place through a wound the condition may be recognized by some local changes in the surrounding parts, which become dark, and as though an unusual quantity of blood were collected thereabouts; the wound looks angry, and ultimately the skin appears dead and pieces will drop off and the wound instead of healing in the ordinary way continues to discharge a thin, reddish-black fluid.

TREATMENT. - Allopathy evidently knows of nothing but antiseptic measures apparently with the object of destroying the bacteria in the blood; but as the orthodox profession is compelled to admit, no doubt with great reluctance, the majority of cases prove fatal; homœopathists can fortunately show an altogether different record. America has a very notable case in point, that of the late lamented Dr. Carroll Dunham, to whom passing reference has already been made; he was the subject of blood poisoning, as the result of a wound inflicted during the performance of an autopsy, and we believe we are well within the trutl when we state that he was so ill in consequence as to be nigh unto death, 
and only as a last resort did he consent to test a ho:nœopathic remedy; this, however, he did try with the happiest results, as his life was saved; he was converted to homœopathy and ultimately became one of its most ardent and consistent advocates.

The remedy which was instrumental in saving Dr. Dunham's valuable life is the one we have found useful on more than one occasion among the lower animals; we refer to Lachesis i2. Another remedy of the same class is Crotalus, but our experience is that it is not necessary to look beyond the first; for all such malignant conditions which arise from a poisoning of the blood and all the attendant complications and consequences there is no remedy more strictly homœopathic than Lachesis i2. So far as local applications are concerned we still believe in this remedy and applying it by means of the spray diffuser in the same strength as administered internally, namely, ten or fifteen drops in a wineglass of water; or, if an antiseptic agent is preferred, and from some points of view this may be desirable, if only to act as deodorizer, then a weak solution of Condy's Fluid or Sulphurous acid can with advantage be availed of. Every facility should be afforded for the admission of fresh air, and for a few days the horse should be supported with eggs beaten up in milk, in the proportion of three fresh eggs to a quart of milk, to be repeated every three hours; this may be varied by some beef tea and an occasional wineglass of Scotch whiskey in a teacup of milk, but so long as the horse will take the non-alcoholic food, and does not get too low, it is better to dispense with the whiskey, as the blood is already in a too irritable condition.

When abscesses form externally and do not burst and discharge readily, they may when located in situations where the skin is thick and tough and takes a long while to break down, be advantageously opened, discharged and cleansed.

The atmosphere of the box should be regularly impregnated with Eucalyptus $\theta$, by means of the spray diffuser, as before suggested, and the patient kept comfortably warm by means of clothing; so soon as the febrile conditions are allayed and convalescence has set in a dose or two of Sulphur I2x should precede a course of China $\theta$, ten drops twice a day for a fortnight, or longer if necessary; the ordinary food being gradually resorted to so soon as the horse seems able to digest it. 


\section{RABIES.}

This terrible disease can only be developed in the horse as the result of inoculation and can generally be traced to the bite of a dog; spontaneous generation is not now recognized as possible; of course the disease may be imparted to a horse through the bite of one that is already rabid, and it is with a view of preventing such a calamity that we deal with the disease at all in these pages, for while considering it not altogether impracticable to effect a cure, provided proper measures are taken in good time, still the risk incurred by reason of the dangerous propensities it gives rise to, and the damage which in attemping treatment might be inflicted by so porverful an animal, we are strongly of opinion that the safest and wisest course is to slaughter the sufferer as soon as the unquestionable proof is forthcoming that a case of rabies has to be dealt with.

It is more than likely that a horse may be inoculated with the virus of rabies by the bite of a dog without the owner or his attendants being cognizant of the occurrence; it is, therefore, desirable to give the list of symptoms by which madness may be recognized, so that, at least, those in charge may be able to gain the necessary information, the possession of which is all-important to put them on their guard against the more serious and dangerous developments.

There is no time that can be fixed as the period of incubation after the animal has been bitten, nor is there anything in the manner of the horse to suggest that he has been inoculated with the rabies virus until the more definite symptoms, peculiar to the disease, commence to display themselves. Probably annong the earlier symptoms observable are great excitability, inability to control its movements, the muscles of the loins and hind legs generally become hard and unyielding to the touch, as also may those of the back and neck, and caution must be exercised that the rigid condition of the large muscle is not mistaken for tetanus (lockjaw) nor tetanus for it; there are symptoms of differentiation, easily recognized by the professional veterinarian, but the layman needs to be on his guard to discern the one disease from the other; to do which satisfactorily he must study both diseases carefully for lininself and get the difference in the symptoms impressed on his mind 
lest the consequences of such an error cost him dearly; to continue the symptomatology, the earlier symptoms referred to are speedily followed by the exhibition of an ungovernable temper; the slightest noise in or near to the stable excites the animal to such an extent that he will dash himself about to the imminent risk of knocking the partitions and doors down; as the disease advances the salivary glands become greatly influenced and large quantities of saliva will flow from the mouth, while the animal makes a vicious grab at anything and everything that comes within its reach. One of the most marked differences between tetanus and rabies, so far as the spasmodic condition of the muscles is concerned, that in rabies the muscles of the jaws are rarely affected while in tetanus this is the most frequent and special seat of action, and this, as is well known, to an extent that the jaws are incapable of extension and hence the designation "lockjaw."

As the disease gains a more decided hold on the horse the fury becomes more pronounced until it reaches such a height of intensity that it can do no more; then intervals of cessation are observable and the disease assumes the form of periodical fits, which gradually become less and less violent, until a relapse into the opposite extreme, that of stupor and even paralysis takes its place; this is an indication that death is not far off and its thorough establishment is soon followed by the closing scenes as exemplified by a most painful exhibition of suffering.

TREATMENT may with reason be attempted if the fact that the horse has been bitten by a rabid dog or animal is recognized at the time, also in the earlier stages where symptoms and surrounding circumstances warrant the suspicion that rabies has to be contended with; but once the disease is thoroughly established and the more violent indications of its existence are displayed, to attempt treatment would be undiluted folly, were it for no other reason than the risk to human life which must attend it. Among the remedies that have been proved capable of destroying the virus of rabies, none stand out more definitely than

Belladonna, and this should be administered in a fairly high attenuation say the $6 \mathrm{x}$. We believe that Dr. Hering, one of the most popular and successful homœopathic physicians that ever practiced in the United States of America, advocates the administration of Hydrophobin which is of course none other than the 
active virus in an attenuated form-and here again is an instance of Homœopathy taking precedence of the scientists, as vide "Pasteur" and his cure of rabies inoculated patients; the symptoms for the selection of Hydrophobin are that the wound made by the rabid dog assumes a bluish-red color and the edges thereof are hard and swollen. Other remedies which may be occasionally useful are Stramonium and Hyoscyamus but as these belong to the same natural order as Belladonna the differences are rather refined and call for a closer study than can be given here when the general recommendation is slaughter; we would issue one warning, never under any circumstances adopt the suicidal practice of cauterization; it is absolutely the surest way of insuring the development of the virus because by its adoption the blood vessels are all sealed up and the escape of the virus is impossible; if within the range of possibility submit the animal to a Turkish bath or some such process so as to secure the most profuse perspiration, in this way you may succeed in sweating out the virus; if you use a cauterizing agent you ensure its being firmly locked into the system.

\section{WEED.}

\section{LYMPHANGITIS.}

Among stablemen this form of disease, whose presence is recognized by lameness and swelling of one or both hind legs-rarely the forelegs-is described as "Monday Morning Disease" presumably because it usually makes itself manifest after the customary rest on the Sabbath or succeeding an enforced rest on account of the inclemency of the weather. Its cause is generally attributed to a disordered state of the digestive functions and it was a matter of question with the writer whether its proper place in this work should not have been among Diseases of the Digestive Tract; but on second consideration, it was determined that though closely allied with the function of digestion, it could not be affirmed that the digestive organs proper, namely those organs that are enclosed within the abdomen, are responsible for its development, nor is its pathological condition located in these organs; moreorer it is a disease which exercises a disturbing infuence upon the whole system, as is evidenced by the exhalted temperature, increased fre- 
quency of pulse and respirations with other symptoms common to many febrile disorders which profoundly influence the general constitution. In the absence of an acquaintance with the general physiological processes associated with digestion and the assimilation of food as it undergoes digestion for the purpose of restoring wasted tissues, it is a somewhat difficult undertaking to attempt an efficient explanation of the relation which exists between these processes and the somewhat remarkable development in the legs of a horse, and therefore we shall have to ask our readers to take a great deal on trust. We may perhaps venture to assume that most men who have enjoyed the advantages of a moderate education are acquainted with the fact that the blood is carried from the heart to the outermost limits of the body by means of tubes or vessels known as arteries; these arteries gradually become smaller and smaller and increase in number, as they approach the limits of the body and are then described as capillaries; these again turn round the corner after arriving at the skin and begin to enlarge gradually until they become veins which again further enlarge until the blood passes into one vessel that empties itself into the heart; in this manner the blood performs a circuit, so to say, of the whole body, and ultimately comes back again to its starting point the heart, which has to act as an engine for pumping the blood through the system of tubes called arteries, capillaries and veins; in conjunction and side by side in many parts of the body, with the blood vesselsis another system of tubes called lymphatics whose function is closely connected with the distribution of material that serves to build up and renew the body and also to convey same to the blood with which it is connected by means of the vessels already referred to; in structure the larger lymph vessels are like veins; the material these vessels contain is collected by absorption from the tissues through which they pass, and is in the first instance the watery constituents of the blood, but these vessels pass through various calling stations, if we may so describe them, called glands where it is considered reorganization of the material goes on and as the circulation of the material progresses in its course along these channels changes are affected in its composition, certain matters being left behind and others taken up for conveyance to the blood stream, some of which are probably intended to be conveyed out of the system while others undergo changes which 
adapt them for nutritive purposes; many of these small $1 \mathrm{ymph}$ vessels start from small points in the intestines and while the process of digestion is going on take up portions of the imperfectly digested material, called chyle, conveying it also along these tubes and this in its course presumably becomes mixed with the watery constituents of the blood picked up by these vessels in other parts of the body.

Now as these vessels (lymphatics) are found all over the body, generally in company with blood vessels, at all events in the legs of the horse, it will be understood how it is that digestion is considered to play so prominent a part in the production of $1 \mathrm{ym}$ phangitis (or weed). The ordinary constitutional symptoms are very similar to those which present themselves in most febrile diseases, but the distinguishing symptom is localized generally in the liind limbs, and consists of considerable swelling, which commences in the groins, accompanied by extreme tenderness, which gradually extends downwards to the hock and fetlock joints; the swelling is produced by an exudation of fluid from the $1 \mathrm{ym}$ phatic vessels and the veins; and the anticipated result of administering a remedy for this condition is the taking up again of the fluid on the part of the veins, that has passed through their walls already and those of the lymphatics; it is perhaps necessary to explain here that the walls of these lymphatic vessels and veins are so constructed that under excessive pressure, brought on under certain inflammatory conditions, the fluids contained are able to pass out on a modified principle of the sieve, and where the fluid has passed out, it can of course pass in, provided the necessary attraction is present to draw it in again; this attraction is just the power that is wanting so long as the inflammation exists; let that be allayed, and the conditions are altered, the vessels are then capable of retaking up the fluid and passing it on to its proper destination and the swelling subsides; but when the necessary remedy which is required to allay the inflammation is not administered, and the vessels are not reduced to the condition which enables them to reabsorb the exuded fluid, something lias to be done with this fluid, and nature has ordained that if not removed it must be turned into something solid, and so a tissue is formed which, if examined under the microscope, is found to consist of the most minute fibres worked up into very beautiful mesh- 
like forms; but like many other beautiful things to look at, it is not only useless but harmful; hence the object of treatment in this disease is to allay the inflammation, prevent the exudation of the fluid as much as possible, and to ensure that such as has already exuded shall be taken up afresh and not allowed to remain to become formed material, as one peculiarity of this disease is, that once established it is rery difficult to get rid of; it will continually recur on the slightest aggravation and each time the consequences and results are apparent by the continual thickening of the leg and the general enlargement of the limb; this becomes most unsightly, interferes with the horse's action and produces a chronic state of lameness.

The constitutional symptoms, as the same are indicated by rise in temperature, hurried pulse and respirations generally present themselves at the same time as the swelling of the hind limb; the appetite is usually very poor, but the desire for liquids is pronounced; the horse will not infrequently point with his muzzle to the affected parts as though he would direct attention to the seat of pain.

Treatument.-Aconite, $3 x$.-As soon as the febrile condition declares itself the remedy should be resorted to every two or three hours, but cannot be expected to do more than reduce the temperature and so prevent the aggravation of the inflammatory condition; the digestive organs must be influenced by more direct remedial measures.

Belladonna, $3 x$, may occasionally prove more useful in the earlier stages than Aconite when the skin over the swollen parts of the legs is very tense, bright red and shining.

Hamamelis $\theta$. - In cases where the swelling is so intense that the fluid exudes through the skin and is accompanied by some blood; bearing in mind the close relation, anatomically, of veins and lymph vessels, it is probable that this drug might prove eminently successful in a large number of cases.

Kali bichromicum, $3 x$, strongly recommended by the late $\mathrm{Mr}$. James Moore, M. R. Col, of London, both internally and locally as a lotion; we have used this remedy in a large number of cases, only, however, to be disappointed; nevertheless we feel that after the experience of so practical a man as the late Mr. Moore, a 
remedy recommended by him should not be left out of a work of this sort.

Iodium, $2 x$. - We have found considerable advantage accrue from the use of this remedy, and were indebted for the suggestion that prompted us to give it a trial to Dr. Richard Hughes' Pharmacodynamics; in the article upon this drug, Dr. Hughes quotes from an observation of Dr. Herbert Nankivell, "that Iodine enables fatty food to be digested which otherwise could not be given;" Dr. Hughes also directs attention to the specificity of this agent in its capability to influence the coats of blood vessels at certain points, as was proved by Dr. Thin at a post mortem; upon these grounds we were induced to experimentize, and the result was eminently satisfactory.

Undoubtedly lymphangitis is a rather refractory disease and is very liable to recur, moreover its treatment lias caused us very considerable anxiety and no little annoyance by reason of the persistence with which it resisted our various attempts at cure.

Local applications are desirable and very helpful if only to alleviate immediate pain; our plan to invoke the aid of moist heat to allay the inflammatory swelling has been followed with marked success in some cases, while in others it was not so self-evident; we, however, account for some failures on the ground of inefficient application, and to the fact that some horses are so persistently fidgety that they will continually renew their efforts to shake off the application; our plan has been the common one of binding the leg from bottom to top with a soft hay bandage, and thereafter frequently applying water, as hot as can be borne by the naked hand; after this has been continued for some hours, the hay bandage should be taken off, the leg rubbed dry and a broad flannel bandage lightly applied as high up the leg as possible, and if the swelling is not reduced the hot fomentations must be repeated as before.

With respect to diet, the horse should have light digestible food including the artificial grasses and linseed boiled to jelly. Alcoholic stimulants should be avoided. If the swelling of the leg does not yield to treatment, then when administering Iodine internally an ointment of the same may be applied locally with gentle friction once a day. Exercise must be postponed until the swelling and tenderness are reduced. 


\section{PURPURA HAMORRHAGICA.}

This may well be taken to succeed the chapter on weed as there are some points of similarity, while as yet the distinctive features are marked. Among horses this disease frequently succeeds immediately upon convalescence from some exhaustive and lowering diseased conditions such as are observed in influenza; at the same time we have known many cases which, so far as we could tell, developed quite independently of any previousillness; whether the blood alone or the bloodvessels of themselves are responsible for the condition known as "purpura," we are not prepared to positively affirm; one opinion, however, is that a disorded state of the blood and a want of tone in the vessels accounts for the symptoms peculiar to this disease; one of the earliest indications is the swelling of the head, particularly about the nostrils and lips, but extending more or less all over; large swellings with distinctly sharp margins arise on the abdomen and chest, and about the upper portions of the legs, fore and hind; these swellings are neither particularly hot nor tender, but upon their surface a large number of small spots (or vesicles) appear, which contain a reddish-colored fluid; these little vesicles soon burst and the fluid oozes out, the swellings are considered to be due to an escape of the blood from the bloodvessels into the tissues through which they take their course; either muscle or so-called connective tissue, chiefly among the latter; and, inasmuch as the blood has got out of its proper channel in the parts where these swellings are found, its natural tendency is to escape somewhere, hence the regular oozing of the red fluid over the surface of the large swellings. In addition, blood spots will be observed on the mucous membrane lining the nose; these which at first merely look like star-shaped spots of a very bright red color, also discharge the red fluid, and the spots have a distinct tendency to run together and form large ones; after the oozing has been going on for a few hours the color of the fluid gradually assumes a much darker hue and dries and cakes over; this, however, is due to the drying influence of the atmosphere and not to the properties of the blood which seems so changed and altered in its constitution as to have lost its normal tendency to form a clot, the fact being that as it becomes blacker in color it is less likely to congeal and rather keeps up a constant 
trickling from the nostrils and the swellings about the body. As an evidence that purpura is a constitutional disorder it may be mentioned that the temperature, pulse and respiration certainly undergo a change from the normal, though not to such a marked extent as is observed in many diseases of a more pronounced febrile type. The thermometer will, perhaps register 102 or 103 degrees; the pulse beats number 60 to 65 and the respirations 25 to 30. The appetite is almost invariably considerably impaired and the powers of digestion very weak, while constipation is frequently observed.

It is a notable and rather remarkable fact that this disease is apt to recur after apparent convalescence, a condition of things more frequently observed in purpura than any other disease we know of; this may perhaps be accounted for by the fact that the blood having undergone such evident change in constitution takes longer to recover its normal condition than practitioners liave been disposed to allow, also that there has been a want of a suitable remedy and that hence while nature had been struggling to gain the ascendency she has been blanked in the effort by reason of unsanitary surroundings and the lack of that assistance which can only be secured through the aid of some remedies only recognized by avowed and conscientious homœopathists. If the disease is not arrested and does not progress to its final termination, the skin over the large swellings on the body becomes cold and hard and ultimately drops off in dead-looking shreds, sometimes exposing a raw, unhealthy-looking patch; the sheath of the penis is usually swollen to an enormous size, the urine is high colored and smells very offensively, and the breathing is difficult, of a muffling character and is sometimes so oppressed that the horse seems as though he would choke; the difficulty in breathing is produced by the swollen condition of the membrane lining the nose and air passages, the fact being that the internal organs are affected in a manner quite similar to the external portions of the body; should this condition of affairs continue to get worse and the horse give evidence of suffocation, the only method of relief for the time being is to perform the operation of tracheotomy which consists in making an opening into the windpipe and inserting a tube made for the purpose; this of necessity den1nands the aid of a qualified surgeon. 
TREATMENT. - Hamamelis $I x$ is indicated when the hemorrhage is of a passive character, that is to say, where the blood drips away slowly and continuously, and especially if the veins are noticed to be distended, as though very full, and the nasal membrane has a blue (not black) appearance, and further when the bleeding is observed at the anus during or after stool.

Lachesis $I 2$ is more often than any other the remedy that has to be resorted to in purpura, probably because the disease has generally advanced to the stage at which it is best fitted to cure, by reason of delay or loss of time in recognizing what was the matter in the first instance. Constant oozing of black hlood that will not coagulate is one of the chief indications for Lachesis; copious flow of dark-colored urine; constipation.

Phosphorus 3x. - Where there is reason to believe that the internal organs, particularly the liver, are affected; this may be judged by the general yellow color of the skin and mucous membranes, namely those of the eyes, that are not affected with the blood spots, and the oozing of blood.

Iodium $I X .-$ By a singular coincidence, the use of Iodine has quite recently been introduced into allopathic practice, for cases of purpura, and for the time is looked upon as one of the most recent novelties; to whom we are indebted for the introduction of this remedy among the British Veterinarians we are not aware, unless it be to Mr. I. A. W. Dollar, of New Bond St., London. We have ourselves proved the value of this agent in such cases, and although it does not strike one at the outset as being a remedy for the disease, our attention was drawn to it some years ago, when reading Dr. Hughes' article on Todine in his Pharmacodynamics, wherein it is stated: "It can hardly be imagined that so univer" sal an irritant of the living matter should circulate in the blood " without affecting its corpuscles. But whether this be the " rationale or not, it is certain that Iodide of Potassizm every now and " then causes petechia and purpura and that under the long con" tinued influence of Iodine the blood and the secretions become " thin and watery." The first case that we submitted to Iodine treatment had been for some days previous taking Sulphuric acid and that without any apparent advantage; in thinking over the case we happened to recall to memory the remarks of Dr. Hughes just quoted and immediately commenced to administer Iodine $I x$ 
with the most satisfactory results. We have reason to believe that in allopathic practice, administered in substantial doses of a preparation consisting of one part Iodine, two parts of Iodide of Potassium and roo parts of water, injected into the trachea (windpipe) very satisfactory results have followed; but this fact does not deprive the agent of its homœopathicity in purpose; it is merely a further illustration of a statement we once heard to the effect that when allopathists manage to effect a cure it is always on homœopathic principles, an opinion with which we fully concur.

So soon as the animal can be induced to partake of nourishing food the better for its prospects of complete convalescence; meanwhile, the usual careful nursing and building up with easily digestible food must be assiduously resorted to.

\section{DISEASES OF PARTS AND ORGANS INCLUDED IN THE RESPIRATORY TRACT.}

Little introduction is called for in approaching the consideration of this class of diseases, which in the horse produce some of the most serious conditions affecting the animal's utility, that have to be combatted by medical treatment; already we have referred to the methods and importance of physical examination to enable one to determine, as far as that is possible, what particular parts are the seat of disease and to what extent that disease has advanced; such as tapping the chest over the region enclosed by the ribs, technically described as "percussion," to determine the condition of the lungs; listening to the sounds observable as the processes of breathing, "inspiration" and "expiration," go on or auscultation, to determine up to a certain point the condition of the lungs, together with that of the fine membrane which lines the outside of the lungs and the inside of the walls of the chest, called the pleura; hence the well-known term pleurisy.

Already these physical signs have been touched upon so far as the same are likely to prove useful to the layman; the detection of the finer and more delicate symptoms by these methods calls for the experience of one trained and practised in the art, and therefore we deem it inadvisablc to take up further space in deal. ing with this special branch of our subject. 


\section{COMMON COLD.}

While in common cold a horse gives unmistakable evidence of feeling the effects in his general constitution and all over the body, it is nevertheless more distinctly associated with the respiratory tract as the lining membrane of the nostrils is most involved. In professional language the terms coryza or catarrh are applied to a common cold and by these it is intended to indicate that the lining membrane of the nasal chambers is in a highly inflammatory condition, the result of which is that from this membrane a watery fluid is discharged, the same condition being present in the eyes, accompanied by sore throat and consequent cough.

In the outset the nasal membrane is dry and very red, but subsequently the fluid discharge appears which at first is acrid and irritating to the parts over which it flows, as the disease advances the discharge become thick and turbid and is bland so far as its effect upon surrounding parts is concerned; in addition to the local symptoms already indicated we find the systemic symptoms include elevation of temperature to 103 or 104 degrees, the horse is very heavy and dull, has a staring coat, and distinct shivering may be observed; the pulse may run up to 84 or even over and the respirations too frequent.

The great thing to be observed is good nursing in conjunction with the treatment to be indicated with a view to prevent extension to the lungs or throat.

Aconite $3 \mathrm{x}$.- As a rule when taken in time nothing more is wanted than the regular administration of this drug every four hours; but too frequently the time has gone by for Aconite before any treatment is attempted.

Ammonium carb. IX. - When the nose is stuffed up and the horse has to breath through his mouth, which it is most dificult for him to effect in consequence of the veil to the palate already mentioned as existing; it is especially useful when an irritating coigh caused by mucus in the bronchial tubes is present; this may be best tested by listening at the front of the chest and if in the windpipe a rattling noise is heard, it is fair to assume that an undue quantity of mucus is present.

Ammonium muriaticum Ix. - In other words sal volatile; this remedy exerts great influence over catarrh when, as Dr. Hughes 
states, it " is accompanied with chilliness, lassitude, sluggishness and prostration; loss of appetite; and profuse sweating and urination."

Arsenicum album 3x or Arsenicum iodide 3x.-Both these remedies are useful when the discharge from the nose and eyes is thin, watery and burning, accompanied by rawness of the throat and a cough arising therefrom; one of the best indications for the use of either of these remedies, more especially the former, is a constant desire to drink, but only a little at a time; this symptom may be taken as a leading indication for these two remedies.

Belladonna 3x.-When the lining membrane of the eyes is very much swollen and injected with streaks of red; when light appears to cause discomfort; when the throat is so sore that there is a difficulty in swallowing.

$N u x$ vomica $3 \mathrm{x}$ - Very frequently an excellent remedy for cold in the head, especially when the nostrils are stopped up and the bowels are constipated.

As accessories to the above it is frequently useful to cause the horse to inhale hot steam, medicated with Aconite or plain vinegar; fill a nose bag with hay chaff, put it on to the horse's head; introduce a few drops of Aconite $\theta$ or a quarter pint of vinegar; then pour two quarts of boiling water on the chaff and allow the animal to inhale the steam for five or ten minutes; this may be repeated three times a day.

Food should consist of warm mashes, linseed gruel and barley water ad libitum.

\section{NASAI GLEET.}

This term is applied to a chronic catarrh of the nose, which as a rule, in consequence of neglect or bad management has taken on a purulent form; in the horse nasal gleet assumes a more serious aspect by reason of the large cavities or sinuses, as they are called, which occupy and help to form the face of this animal; into these cavities there are small openings about the size of a quill pen, which connect the nostrils therewith; the membrane which lines the nostrils is continued through these small openings and again expands over the inner surface of the cavities, so that a diseased condition of the nostrils easily extends to the inside of these cavities; and if the catarrh of the nostrils is not cured, but beconies 
chronic, it may and does extend to the inside of these sinuses, and the matter which is formed therein, finding no ready point of escape becomes accumulated, and assumes a fetid character as is often observable in old standing cases of nasal gleet; in addition to the membrane of these cavities the bones of the face and the teeth frequently become affected, when the smell is simply unbearable.

There is one disease with which nasal gleet may be confounded, namely, glanders; and this mistake it is most important to avoid; now, however, that the simple test for glanders is available, no such error in the future need creep in.

Syuptons.-As a rule only one nostril is affected at a time and from this, mucus will be discharged; the character of the mucus depends chiefly upon the length of time that the horse has been the subject of the disease; and whereas nasal gleet is usually the sequel of what in the first instance may be described as a common cold accompanied with a profuse running at the nose we shall commence with a description of the discharge at that period when it has assumed the consistence of starch; if not arrested, it proceeds from bad to worse, until the mucus becomes inspissated or clotty, is mixed with blood and ultimately assumes the characteristics of pus (or matter); if this stage is attained the membrane lining the bony cavities is penetrated, and the bones themselves are attacked; this of course is the most serious condition and may certainly be averted if proper treatment and care be adopted; the discharge, under any of these conditions, is not constant but comes on periodically, some hours occasionally intervening; but an outpouring of mucus may be set up at almost any time by submitting the animal to a little gentle exercise, after which it will give a good blow, and for the time the nasal passage will be comparatively clear, after the horse, with its head in a dependent position has relieved itself of a profuse quantity of glairy mucus, which comes away in clots or plugs.

To test the presence or otherwise of mucus in the sinuses of the face, tap the bony prominences of the face on the affected side, from the eye downwards, and if the sound is dull and wanting in resonance it may be taken for granted that the cavities are affected and that they are occupied by an accumulation of mucus.

The glands situate between the jawbones may or may not be 
enlarged, swollen or hard and indurated, generally, however, one or other is the case.

The temperature of the body is no certain indication, but as a rule the horse looks unthrifty in the coat, soon tires at work and gives general evidence of impaired health. If the disease is allowed to develop and the sinuses (or cavities) of the face become blocked up with mucus or pus (matter) the shape of the face on the affected side is altered, inasmuch as the bones bulge out. The majority of veterinary practitioners considers that there is nothing for it but the operation of trephining when the cavities of the face are affected, as it is maintained that an accumulation of mucus or pus must of necessity be removed and the carities cleansed before any hope of cure can be held out; by trephining is to be understood, a surgical operation involving the removal of a portion of bone over one of the cavities of the face sufficiently large to allow for the removal of the mucous or purulent contents; this is by no means a serious operation, but it calls for the experienced surgeon to perform it; although homœopathic treatment suffices to effect cures of the worst cases without resorting to trephining, the operation in very extreme cases, where the collection in the cavities is purulent and the bones are also affected, will facilitate and hasten the cure, as the diseased parts can be flushed with a lotion of the remedy that is specific to the morbid condition after the contents are evacuated, thus obviating the possibility of reinfection which the parts would be liable to, if the process of absorption under the dynamic influence of the drug had to be carried on in the absence of all operation; but the great secret after all is by prompt internal administration of the specific drug to prevent the diseased process arriving at such an adranced stage as we have indicated, and this can be done.

TREATMENT. - The first remedy is Hydrastis $\theta$, and its administration must be effected topically as well as internally; if the horse will put up with it, a lotion of Hydrastis $\theta$, I to 5 of water, must be injected with some force up the affected nostril; an ordinary four-ounce metal syringe, with a wooden nozzle about eight inches long adjusted thereto, is the best instrunent for the purpose; the head of the nozzle should be nicely rounded off to prevent injuring the mucous membrane of the nose; after carefully testing the soundness of the joints of the syringe, fill same 
and carefully introduce the wooden nozzle as far up the nostril as it will go, then forcibly eject the contents; if some portion of the contents passes down the other nostril or escapes into the throat and is swallowed, it may safely be conjectured that the walls of the nostril and the posterior parts of the nose are thoroughly bathed with the lotion; this should be repeated trice daily. Prorided the horse objects to this form of topical application and resents further efforts to realize it, inhalation must be resorted to; a nose-bag half full of finely cut hay chaff must be attached to the horse's head, upon this chaff pour sufficient boiling water to saturate the quantity contained in the bag, immediately thereafter sprinkle about one ounce of the Hydrastis $\theta$, and quickly throw over the animal's head a thick horse rug, with a riew to retain the steam about the nostril and so enforce the inhalation of the medicated steam; in bad cases this should be repeated three times a day until the discharge is less, which is generally observable in two days; though the application may be daily less frequent, it will have to be continued once a day, probably for three weeks or a month; at the same time ten drops of Hydrastis $\theta$, in a wineglass of water, should be given internally three times a day and continued for a fortnight before reducing the number of doses per diem.

Kali bichromicum, $3 \mathrm{x}$, being a remedy specially effective in diseases of a chronic character is certainly indicated in some forms of nasal gleet; and the main symptoms are as follows: When upon the nasal membrane there are any ulcers (at the same time always beware of glanders and test with mallein); when the horse is off his feed and the tongue is corered with a yellow fur which on removal leaves a red surface; when the discharge from the nostril comes amay in long tough strings.

Aurum muriaticum, $3 \mathrm{x}$, when the bones of the face are diseased which is unmistakably recognized by the horribly fetid smell emanating from the nostril; there will also be a probable swelling and tenderness of these bones, and the production of salira in great excess will be observable.

The before-mentioned treatment requires to be supplemented by careful nursing and good liberal diet on easily digestible nourishing food; the animal should certainly be laid aside from work and allowed to occupy a healthy, airy, loose box. 


\section{LARYNGITIS.}

This term is intended to convey the idea that the mucous membrane and soft structures of that complex organ situate at the top of the trachea (or windpipe) are inflamed; through the mechanism of the larynx the pitch or tone of the voice is mainly regulated, and though among the lorver orders of animal creation this function is not turned to much account, it is an organ which in the horse demands careful and thoughtful consideration because of the important part it plays in the performance of the various acts involved in respiration and the serious consequence affecting the pecuniary value and general utility of an animal whose larynx is structurally defective.

We shall consider first that condition known as inflammation of the larynx (laryngitis) because it usually precedes in greater or less degree inflammation of other parts of the respiratory tract, and that alteration in structure of the organ which is the cause of a horse making the noise known as "Roaring;" and then before proceeding to the consideration of affections of other parts of the respiratory tract, roaring will be dealt with from a homœopathic standpoint.

Laryngitis is generally accompanied by a more or less extensive inflammation of the surrounding parts and is marked by a hard, dry, rasping cough which suggests that the calibre of the organ is reduced in size or tliat its shape is materially altered, and herein is the danger which attends its development, lest the opening through the larynx should become blocked up, interfering with the function of respiration and so producing suffocation.

The cough usually appears to cause inconvenience and some pain, and comes on in paroxysms; the throat generally is swollen, extending sometimes to the glands between the jaws and those situate at the back of the jawbone from the ear downwards, known as the parotid glands; the horse almost invariably stands with its head straight out, the nose elevated, and if the upper part of the box door happens to be open the animal will be found with its chin resting on the lower lalf of that which is closed; great difficulty is experienced in swallowing cither solid or liquid. nutriment; the temperature is exalted; the pulse full and liard and the respiration decidedly urgent. A favorable termination 
may be anticipated when the hard, ary cough is changed to one less resonant and softer in character, and when the hitherto dry nasal membrane becomes moist and a thin fluid discharge runs down the nostrils. The rapidity with which this disease progresses renders it absolutely imperative that the most prompt steps should be taken for its alleriation, and no stone left unturned to modify the sererity of the symptoms.

Treatuent. - Much depends in selecting the first remedy as to the condition of the patient at the time; in cases where the inflammatory stage is observed early, is the result of exposure to cold and accompanied by very decided febrile symptoms, such as a difficulty of breathing (though the noise made during respiration is not markedly harsh and rasping), hot mouth high temperature, hard, frequent pulse, scanty, high-colored urine Aconite $3 \mathrm{x}$ should be administered in half-hour doses; but in those where the breathing is not only difficult but somewhat slow, urgent and attended with a decidedly dry, rasping sound, and the cough resembles the passage of a saw through a hard piece of mood Spongia $3 \mathrm{x}$ trituration, a dose erery hour, is almost certain to afford relief; as a horse at such a stage of the disease generally experiences great difficulty in swallowing fluids, the trituration is preferable to the tincture, as it can be quietly placed on the tongue where it will gradually dissolve under the influence of the saliva and be swallowed slowly and gradually as the horse feels able without any risk of choking; as soon as any relief in the urgency of the breathing and cough is observable, the intervals between the doses may safely be extended. In cases where the throat is very much swollen and the glands are extremely painful; the cough rather inclining to be soft; swallowing so difficult that fluids return through the nostrils; a great deal of saliva is formed and drops out of the mouth Belladonna $3 x$ should be given in alternation with Mercurius solubilis 5; namely, commence with the usual dose of Belladonna and in one hour gire a dose of the Mercurius sol. and so on for four hours after which the intervals may be gradually extended to two and three hours between the respective doses; under no circumstances must these medicines be given mixed together in one dose.

Sanguinaria Canadensis $\theta$ has been highly recommended in cases which threaten suffocation in consequence of a swollen and 
pulpy-looking condition of the mucous membrane of the throat; to discover this it is necessary to open the horse's mouth sufficiently wide to expose to riew the parts around the root of the tongue and about the tonsils; if instead of looking red, as is usually the case, the membrane is pale and flaccid, and here and there small superficial ulcers are observable with possibly shreds of flaky-looking particles adhering to the edges, it will be safe to conclude that the condition for which Sanguinaria is useful has to be contended with, and this remedy should be administered.

ACCESSORY MEASURES. - In such a disease as laryngitis, where the administration of large doses is almost an impossibility and is certainly attended with considerable danger to the patient, it is no small advantage to have remedies prepared in a manner that renders their administration comparatively easy; at the same time it is most important that during the acute stage, which may last thirty-six hours, the nursing and dieting should be carried out with an intelligent appreciation of the circumstances affecting the patient; to attempt to force the animal to swallow liquid nutriment by drenching, as is no uncommon practice among stablemen, would simply prove fatal; if the animal absolutely declines to take food of any sort voluntarily by the mouth, then resort must be had to enemas of strong beef tea and milk; on the other hand, no pains or trouble should be spared to entice the horse to partake of such diet as gruel made of nourishing invalid foods; carrots cut up into thin pieces and offered by hand, a bit at a time; if available small handfuls of artificial grasses such as clover, lucerne or sanifoin; anything, however, that requires much mastication is out of the question. An outward application in the form of a water compress, consisting of four folds of soft linen dipped in cold water, wrung out and applied to the throat, covered with a piece of thin oil skin supported in position by a nice piece of thick, but soft flannel will be found more than useful in allaying the inflammation and restoring tone to the weak and now extremely susceptible larynx.

\section{ROARING.}

This is a very important subject to the horseman and the horse breeder, the term roaring is only too often used indiscriminately; in point of fact, although an essentially common and vulgar term, it 
should be made only to apply to horses that have an affection of the larynx which involves structural change of the organ in which one portion of this complex instrument-for such it may reasonably be styled, by reason of its porvers of local production-is through loss of nervous energy rendered physiologically useless; and worse than that the part so affected is not only useless but absolutely physically injurious by reason of the obstruction to respiration which the structural change in the larynx brings about; there are other causes which render it very difficult, if not absolutely impossible, for a horse to breath either freely or without making a noise in the process, and that without the larynx being affected, hence the necessity for discrimination; we very much prefer as a general term the phrase "makes a noise" to express all the varied abnormal conditions which affect the respiratory tract, rather than to speak of every horse that makes a noise as a "Roarer," whistler, grunter, etc., leaving it to the circumstances and conditions to determine the seat and origin of the defect, points most difficult of solution during life but which can as a rule be accurately determined post mortem; this, however, is a very unsatisfactory state of affairs, as the horse orwner necessarily desires to discriminate correctly during life in the hope of effecting relief and thus render the animal more usetul. The opinion held by a large majority of the veterinary profession, and among them some of the most experienced men of the day is that by far the larger proportion of horses that make a noise are roarers proper, that is to say structural change has taken place in the the larynx in consequence of a wasted condition of certain muscles of the organ, the said wasting being due to want of healthy innervation, and resulting in one division of the larynx falling inwards and so causing an obstruction to the passage of the air into the lungs as the animal draws its breath inwards, or, in other words, effected an inspiration; in this opinion we are not able to concur, as we fully believe, after a somewhat varied experience, that though large numbers of horses are roarers proper, a still larger number make a noise from other causes.

It may be as well in passing to enumerate some of the causes to which the varied noises are due, which are continually observed by those whose duty it is to examine horses for soundness or who have frequent opportunities of observing animals they have never 
seen before; one cause of somewhat rare occurrence is a polypus or polyphoid tumor situate in the upper part of the nasal passage; thickening of the mucous membrane which covers the walls of the nose, resulting from chronic catarrh or cold, a condition which materially lessens the calibre or size of the nasal passage, and which after exertion is apt to become rather more swollen and so still further diminish the size of the air passage and produce a wheezing sound extremely perplexing to a young practitioner anxious to do lis duty by his client; he readily observes the noise, but does not consider it sufficiently pronounced to indicate roaring, and in this he is correct, but the doubt still remains as to the cause; a speculum might probably reveal something to assist one in arriving at a conclusion, but the facilities for applying this test are rarely available; moreover as it would involve casting the horse, it is very improbable the seller would permit such a course to be adopted; hence all that can be said is the horse makes a noise! Horses with short, thick necks, having the parotid glands very fully developed will not infrequently make a noise as bad as the worst roarer during a test gallop, while all the time there is no defect in the larynx; we consider this to be due to the turgid and swollen condition of the parotid glands, as the result of the quickened circulation, the glands pressing upon the opening of the larynx through the position of the horse's head, his nose being drawn into his chest while hard held, and the size of the respiratory passage materially constricted; such an animal without a bearing rein, would do ordinary work in harness at a fair trot and give no evidence of making a noise; this sort of exercise would not excite the circulation sufficiently to cause any disturbance. We next come to the larynx itself for diseased conditions other than the chief and inost acute one already referred to involving an alteration in the shape of the organ by reason of structural defects; these are mainly due to inflammation, such as occurs in laryngitis, already dealt with in the previous chapter; this form of inflammation affects the other tissues which go to form the vocal organ, such as cartilage the component parts or sumz 0 . them being united as the result of inflummation and thus altering entirely the shape of the larynx or the connective tissue which serves to keep the various cartilaginous parts in position which 
during the inflammatory action has become thickened and has not had time to become resolved into its normal healthy condition.

Further, the wind pipe or trachea may from various causes, produce an unnatural sound in breathing in consequence of an alteration of shape due either to injury or inflammation of the lining membrane; probably one of the most frequent causes of difficult respiration and making a noise is that which arises from disease of the air tubes in the lungs and the substance of the lung tissue which surrounds these tubes; among thoroughbred horses the disease known as "Nerwmarket fever," to the consideration of which a special chapter will be devoted, is responsible for respiratory defects in far greater measure than is generally acknowledged, in consequence of its after effects; these result in a complate alteration in the general structure of the lungs which renders it impossible for the animal to draw in that amount of air that is requisite to enable it to sustain prolonged exertion; simple inflam. mation of the lungs also leaves behind similar injurious consequences and unless a suitable remedy is administered capable of restoring the lungs to a healthy state by getting rid of the diseased produsts which are the result of the inflammation the animal is rendered permanently defective in its breathing; there is reason, however, to believe that such a result may be attained in the majority of cases under homœopathic treatment, and this is the chief point of interest for our consideration.

The whole of the list of cases, including even the most serious, is due in a great measure to the inflammatory process which exercises a marrellous influence upon the various tissues of which the respiratory tract is made up, and effects such changes that the shape of the passage in its whole length is more or less altered; and in this way the production of unnatural sounds in the act of breathing is brought about; this being the case, it is deserving of serious consideration whether any drug exists that is capable of exercising a potent influence upon this uniform condition of affairs; if so, there is reasonable hope that relief may ba afforded in most cases and cure in many others; but it may be argued, and with no little show of reason, that this does not account for tile structural change in the larynx due to a wasting of the muscles which in its turn is accounted for by a lack of nerre stimulus, the effect of which accounts for true roaring; but here a difference of 
opinion as to the cause of the wasting and degeneration of the muscles may fairly be held, because cases of wasted laryngeal muscles have been observed in post-mortem examinations wherein no defect or disease of the nerve which supplies the physiological stimulus to these particular muscles could be discovered; in addition to this negative argument, we cannot overlook the fact, that the degenerative change, described as fatty degeneration, affecting the defective muscles of the larnyx may be brought about by causes altogether independent of nerve force, and this fact renders the possibility of cure or relief all the more promising, as in homoeopathic practice there is at least one remedy that is capable of contracting the diseased condition known as "fatty degeneration" therefore when this is the cause of roaring, there is reasonably good hope for anticipating the restoration of the laryngeal muscles to a healthy state under its influence, the renewal of the proper physiological functions and the removal of the cause which produced the noise and interfered with sound, healthy respiration, more especially if treatment is commenced as soon as the defective respiration is observable in young horses. It may be desirable to note in passing that several operations have been attempted to overcome by surgical measures the defects already referred to, that are due to structural alteration of the larynx, such as the removal of the portion of cartilage which through degeneration of the muscles cannot maintain its normal position and falls inwards; and again a very ingenious operation has been tested by which the recurrent nerve, that by some is considered responsible by reason of atrophy for the muscular degeneration, was severed and joined to another nerve trunk in the hope of supplying the necessary nerve stimulus from a new source and thus restoring the muscles to a healthy state; but neither of these operations has answered expectations, and it may be asserted that from a really practical standpoint they are both absolute failures.

Now as to the method of treatment to which we advise a horse to be subjected; inasmuch as it is most difficult, if not absolutely impossible to positively determine what is the cause of a horse making a noise in the early stage of the disease, which at the same time it is possitively essential in order to effect a cure that treatment should be commenced at that period we consider that the two remedies which have on various occasions afforded 
marked relief, should be administered alternately, namely Arsenicum album $6 \mathrm{x}$ in doses of fifteen grains every morning, and Phosphorus, $3 \mathrm{x}$, in doses of twenty minims every night, this should be continued for a week; then a dose of Sulphur I 2, consisting of fifteen grains, after which two or three days should be allowed to elapse without any medicine being given, and thereafter the same procedure should be repeated over a period of six weeks or two months. This system of treatment is applicable in most cases where the defective respiration is not due to any injury to the windpipe, such as fracture of one of the cartilaginous rings of which the trachea is composed, under which circumstances only operative surgery is effective; nor do those cases, where the bones of the face are altered in shape, through malformation, come within the range of medicinal treatment; but polypi and polypoid tumors are easily amenable to the action of drugs, and as these, when present, are discernible by careful examination there is no difficulty in determining the cause; Teucrium applied locally in the mother tincture and given internally in the third decimal attenuation in alternation with $\mathrm{Cal}$ carea carb. I2, will generally disperse these offending tumors and that without resorting to the barbarous system of tearing the tumor away by means of a wire noose, in doing which the mucous membrane is frequently severely lacerated. During the course of treatment, as before indicated for laryngeal affections, it is desirable that the animal should not be subjected to any violent exercise, nothing more than plain walking, but of that it should have several hours daily. The diet should be wholesome and sound, and the hay be cut into short chaff; çarrots are a decidedly favorable form of nutriment, as they are easily digestible and serve to stimulate the natural secretions and at the same time counteract any heating tendency there may be in the cereal portion of the diet. We cannot guarantee success in all cases, but our experience justifies us in offering the assurance that a sanguine hope may be entertained of rendering an otherwise hopeless case capable of useful work: we have known several cases of some standing in race horses that could not gallop at anything like top speed over five furlongs come out after a course of treatment with Arsenicum, $3 \mathrm{x}$ or $6 \mathrm{x}$, and win a sprint race over that distance in right gallant style; but these old standing-cases always require a 
month's course of the remedy before making such an effort; the beauty of Arsenicum is that it not only does not interfere with the training operations but in reality acts as a tonic and the horse trains on better while taking it; the same remarks of course apply with equal force to hunters or any other class of horse.

\section{THE LUNGS.}

The consideration of the various forms of disease which affect the lungs, must for the sake of distinction be divided into three classes, but before defining them it is desirable, if not necessary, for a proper appreciation of the subject, to explain as simpiy as possible the construction of these vitally important organs. Complex as the whole organism is, and necessary for the maintenance of healthy life as each individual set of organs may be, probably the lungs hold the post of honor in relative importance when the all important topic of how life in its pristine vigor is to be maintained comes under consideration. In the first place let us inquire of what do lungs consist; taken into the hands and examined under pressure they feel not unlike a piece of sponge; there is a certain amount of elasticity about them which under pressure effects a sort of rebound, after being compressed into a small compass expansion takes place naturally and they assume their original shape; this physical fact is accounted for by their construction; the lungs, speaking roughly, consist of a net-work of hollow tubes (called bronchial tubes) of varying sizes supported by connective tissue, called the parenchyma or true lung substance, while in company with the bronchial tubes blood ressels (both arteries and veins) follow much the same course among the connective tissue or lung substance; the whole mass is then encased in a fine mesh-like membrane which has a glazed external surface called the pleura, which helps in some measure to keep the lungs in the form and shape they naturally assume; it must be understood that the bronchial tubes described as one of the principal divisions of the lungs, are in reality continuations of the trachea or windpipe, which in the first place divides into two branches, one for each lung; these main branches then enter the lung and thereafter divide and subdivide into smaller and still smaller branches until they are so fine that it needs powerful magnifying aid to discern their shape and course, ultinately 
terminating in minute pouches or air cells; like the bronchial tubes the blood vessels which accompany them also become smaller and smaller until they are described as capillaries, and the membranes which form the walls of tubes and capillaries are so fine that the blood is readily exposed to the action of the air in the bronchial cells and the interchange of the chemical constituents requisite for the maintenance of liie here takes place. The larger bronchial tubes are formed externally of a tough membrane, next to which is a layer of muscle and the internal parts or lumen of the tubes are lined with mucous membrane; it is desirable to remember this in order to properly appreciate the meaning of bronchitis, one of the forms of disease hereafter to be referred to. Thus in considering the morbid conditions to which the lungs are liable it is necessary to bear in mind that there are three distinct parts which may either be separately and individually the seats of inflammation, or as is more generally the case in the horse, all three may be affected at one and the same time; namely, the bronchial tubes; the true lung substance and the pleura; when these are the seat of inflammation they are described respectively as bronchitis, pneumonia and pleurisy.

\section{BRONCHITIS.}

Inflammation of the bronchial tubes, like all kinds of inflammation is preceded by congestion or excess of blood to the parts, and if only this congested condition is recognized in time, the difficulty and responsibility of treatment are materially modified, but unfortunately it is not often that during this stage the absolute state of affairs is discerned in the horse. Bearing in mind, what has already been stated, that the bronchial tubes are continuations of the windpipe, and that this portion of the lungs is of necessity the first to feel the effects of cold air it is not surprising that as a rule bronchitis develops itself before either pneumonia or pleurisy, though it must be clearly understood this is not an absolutely fixed rule.

Exposure to cold and a consequent general lowering of the body temperature, more frequently than anything else accounts for bronchitis, but why the lungs should be the particular organs upon which the force of the inflammatory process is ultimately centered is not quite clear unless predisposing weakness either 
from hereditary or other causes will account for it; as in the human subject, the horse is more liable to an attack of bronchitis in youth and old age, but at the same time there is no doubt that hygienic surroundings are frequently responsible for attacks of lung disease among mature animals that would come under neither category; when stabled in close, hot, ill-rentilated habitations, where under the mistaken apprehension that heat is a necessity, horses are continually breathing a vitiated atmosphere, and thereafter in course of ordinary work, or special exercise for training purposes are either allowed to stand about in a cold northeast wind or inhale a cold, moist wind during violent exercise, it is not to be wondered if the bronchial tubes already surcharged with blood receive such a shock that the normal balance of the circulation is not restored and consequently that the air tubes are rendercd exceptionably susceptible; this in itself will account for many cases of bronchitis that under no other condition would be developed, hence the importance of providing healthy surroundings for all classes of horses in places occupied during periods of rest or when not actively employed. Common cold is in a large proportion of instances the precursor of this fatal disease and it is impossible to exercise too much caution in order to prevent further developments when once the mucous membrane of the respiratory tract shorvs signs of becoming affected, for unless proper care is taken, there is no telling how far it may spread nor how serious may be the ultimate consequences; it is a rery common practice for the human subject to trifle with a simple cold and to make the remark "oh it's only a little cold, it will soon go off," but 'ere long, in numerous instances, bronchitis and pneumonia follow and death supervenes, much to the surprise of those who are left to mourn the loss of a life that with due precaution need not have been sacrificed; the same applies to animals, especially such as are coddled up in a hot stable one hour and the next exposed to the biting blast of a keen nor'easter with less clothing and bodily protection on than when in the stuffy stable.

It has already been observed that the bronchial tubes are continuous, gradually dividing and subdiriding, something like the branches of a tree, until the smallest tubes are so sma!l of calibre that they cannot be discerned by the naked eye. Now, at first sight it may seem somewhat singular, but it is nevertheless the 
fact, that the smaller the tubes affected with inflammation, the more dangerous is the form assumed by the disease and the greater the risk of its proving fatal. This is, in some measure, due to the fact that the larger tubes are invariably first attacked by inflammation and the disease gradually spreads from smaller to smaller tubes until the whole tubal portion of the lungs is invaded, and in this way the disease gains a continuously growing hold upon this portion of the organs until no part remains free from its destructive influence. Moreover, the smaller the tubes the more easily are they blocked up with the exudation of mucus, which is due to the inflammatory process, and thus rendered useless for the purpose of the passage of air through them, breathing being extremely difficult, resulting in that feeling of suffocation which only those who have themselves suffered from bronchitis can appreciate. This serves to show how important it is to arrest the disease in its earlier stages, that is before it has extended beyond the larger bronchial tubes. In order to be able to decide how far the inflammation has penetrated resort must be had to auscultation or listening with the ear against the chest. When the larger tubes only are affected, the respiratory sounds will be deep and sonorous, and may be observed chiefly in the front of the chest, just underneath the windpipe; but when the disease has penetrated to the deeper and consequently smaller ramifications of the tubal portion of the lungs, the sound is shrill and high pitched; to discern these properly, the ear must be pressed firmly against the ribs and the test applied anywhere over the region of the ribs on both sides. In the early stage of the disease, that is to say, when the respective parts are first invaded, the sound is dry, but as it progresses this is displaced by a moist sound brought about by the secretion of fluent mucus which follows the dryness observable when the febrile conditions first result in an entire arrest in the secretion of the normal quantity of mucus from the internal membrane.

Symptoms. - The first thing to draw the attention to the horse will be probably a short, dry cough; or possibly loss of appetite; the coat will be rough and staring, and the clinical thermometer will show that the temperature is higher than it ought to be; the pulse is rapid, probably 65 or 70 beats per minute; the breathing will comparatively be more frequent than the pulse; the horse will 
give distinct evidence of thirst, and its general demeanor be decidedly listless; the mucous membrane lining the nose is redder than usual and in the early stage dry; the same condition exists in the bronchial tubes, which accounts for the harsh sound observed on auscultating the chest; as the disease advances this dry condition of the lining membrane will be changed and replaced by an increased secretion of mucus, producing a moist sound; this is a favorable condition, as it is indicative of the fact that the inflammation is subsiding; when the disease is at its height the animal rarely lies down in consequence of the difficulty experienced in breathing. At this period it is important to select those remedies which tend to assist in the expulsion of the accumulated mucus, otherwise some of the smaller bronchial tubes may become blocked up permanently, and the result will be what is known as thick wind, a condition which materially reduces the value of an animal and renders him unable to perform work which demands strong and continuous exertion.

Treatuent.-Aconite $3 \mathrm{x}$. This is invariably the first remedy to be given to abate the febrile conditions; especially when the skin and mouth are dry and hot, and thirst is very pronounced; membrane lining nose dry and red; cough harsh, dry and short; urine scanty and high colored.

Bryonia 3x.-After two or three preliminary doses of Aconite and the inflamed condition of the membrane of the windpipe has extended down to the point in the chest where it divides into two branches and enters the lungs Bryonia is the remedy; the Aconite may be discontinued; under Bryonia the dryness of the membrane which produced the short, dry cough, and particularly, if this is aggravated by motion, will be replaced by a moist exudation; but when the disease has extended beyond this point Bryonia nuust not be relied upon as it has no effect upon the smaller bronchial tubes.

Mercurius solubilis 5.-This remedy has a great reputation for inflammatory bronchial affections, and is credited with the power of penetrating to the finest tubes; it certainly is peculiarly effective under such conditions, when other symptoms, such as swollen glands, sore throat, slavering from the month, moist, soft cough are also observable.

Antinonium tartaricum $6 \mathrm{x}$. - This is an extremely serviceable 
remedy at that period of the disease when the moist sounds are due to an accumulation of soft, white mucus that comes away in lumps; but especially, if the animal seems distressed in breathing by reason of want of power to expel the mucus; loud gurgling sounds will be heard in the windpipe and lungs generally; the cough loose, accompanied with a rattling noise.

Phosphorus 3x. -There is no doubt that this is one of the most valuable lung remedies we have, and that when its own peculiar disease producing effects are present, there is none to excel it; post mortem investigation in subjects poisoned by Phosphorus renders this fact very clear; but we believe that we shall be confirmed in our opinion by recognized authorities, when we state that it is more in that complicated form of lung disease known as broncho-pneumonia, wherein the substance proper of the lungs, as well as the bronchial tubes are implicated, that it is indicated, of this we shall treat further on; at the same time, if the animal is suffering from a suppressed bronchial cough, sometimes loud, at others feeble, but always attended with erident pain; the discharge from the nostrils scanty, but at the same time of a rusty color, and distinct evidence of physical exhaustion betrays itself, resort may reasonably be had to this potent remedy.

Arsenicum album 3x. - In cases where the effects of the disease in the very fine air tubes does not seem to have passed away, that is to say, in which the exudation of mucus therein has become consolidated, and the tubes consequently blocked up and rendered useless for respiratory purposes, this remedy if persisted with for some time, will frequently afford relief and from the results which accrue from its administration, it is fair to assume that it effects a resolution of the consolidated tissue and brings about its re-absorption; however, be the actual result what it may, the fact remains that persistent administration of Arsenicum enables the horse to breathe more freely and renders it a more useful animal.

Sulphur 3, as in other diseases, is in this also an excellent intercurrent remedy, and by its occasional administration appears to render valuable service, and seems to stir up an otherwise sluggish system to renewed vitality. 


\section{CONGESTION OF THE LUNGS-PLEURO-PNEUMONIA BRONCHO-PNEUMONIA.}

Inflammation of the proper lung tissue is invariably preceded by congestion when it appears as an independent diseased condition; and it will, therefore, be well to consider what can be done for the congestion, as this frequently appears in the horse independently and may be arrested without pneumonia stpervening at all; congestion is an accumulation of blood that ought to pass on in the ordinary course of circulation but does not; congestion of the lungs is due to an engorgement of the bloodvessels which penetrate the substance of the lung tissue to its deepest parts; it generally occurs as the result of overexertion, especially in young animals that have not been properly trained or fitted for the work they are called upon to do; to exposure to wet and cold when in an exhausted condition; the respirations are performed in a very laborious style; the horse evidently longs for fresh air, and if in a box will make for the first opening that can be found; the eyes are bloodshot, and the pupils stare and stand out; the legs and body are deathly cold; pulse extremely weak and small but very rapid, often up to I 20 ; breathing frequent, as many as Ioo respirations a minute, or even more; the animal stands with his head dependent, almost to the ground, and has an anxious countenance; the dryness of the skin in some parts and the cold sweat that bedews others are each the more noticeable by comparison; the mucous membranes of the nose and eyes are blue or even purple in color, and if the ears be placed over the region of the ribs a crackling noise is observable, due probably to the rapid exudation of fluid into the air tubes by reason of the tension from blood pressure. There is one remedy that we invariably use for this condition and have never known to fail, Ammonium causticum $3 x$, twenty drops to a dose, repeated every fifteen minutes; if this is given in time and followed up the greatest confidence may be reposed in it; but if the attack has been allowed to make headway resort must be had to Aconite and Phosphorics.

Accessory measures will much facilitate matters and aid the remedy in its work; first, the animal nust be got into a box in which fresh air without draughts abounds; if there is much cold sweat about the body wheat straw that is not broken should be laid 
lengthwise along the back, and orer this two or three warm horse cloths placed; the straw is intended to aid the rentilation of the body and in getting up the heat; the legs should be hand-rubbed and then bandaged with thick flannel, and the ears also be firmly rubbed the way the hair lies; if the skin generally is dry and there is no sweat, an effort must be made to induce a healthy perspiration by clothing the animal with sereral thick cloths and keeping the hood on when not rubbing the ears; if the horse will drink let him have as much tepid water as he will take, or previously boiled oatmeal may be mixed with the water as an appetizer; as the perspiration is established care must be taken that the animal does not experience another chill; four men, two on each side, should set to work with straw wisps to dress it down for five minutes, after which the clothing should be replaced and continued attention given until the coat is dry and the respirations are calm and natural.

\section{PNEUMONIA.}

Under this heading we shall include all the forms which by pathologists are dealt with individually according to the particular tissues affected, as it is not necessary to trouble the reader with a consideration of these minutiæ because such differences as exist will be treated of under the various remedies according to the special symptoms dereloped by each respectively, we will, howerer, just explain that by pneumonia we refer to inflammation of the true lung substance, which consists of the connective tissue that serves to support and maintain in position the vast net work of air tubes that ramify its substances and form so large an integral proportion of the breathing organs; pneumonia is, therefore, a simple term which applies to one description of tissue; but so intimately associated are all the component parts of the lungs, and so nearly allied the one with the other, that as has already been stated in a former chapter, it generally happens that, by a combination of circumstances rarely combatted, an inflammation in one tissue extends to that adjoining, hence simple pneumonia assumes a compound aspect when the bronchial tubes are also affected and is desribed by pathologists as broncho-pneumonia, while yet again a second compound inflammatory condition is established when the Cisease extends to the pleura, the fine membrane which en- 
cases all the other parts, when we have to deal with pleuro-pneumonia. To attempt, in such a work as ours, to explain all the varieties of morbid action arising out of a study of these three forms of pneumonic inflammation would not result in any useful purpose, as it would necessitate a dissertation that after all would not assist the layman to treat and cure his animals, but would probably serve only to perplex and confound; moreover, the beauty of the homcopathic system lies in its simplicity, and in the fact that the various phases of this disease are each discernible by the outward manifestations in the form of symptoms and these, when compared with the drug symptomatology hereafter indicated, will prove far more efficacious and effectual for good to the practical horseman than the most profound study of all the intricate pathological developments which may be observed during the period this disease, in its varying forms, is making inroad upon the animal system. It is a recognized fact that under ordinary treatment the disease occupies an approximately fixed period of time from incubation to defervescence, and we believe that three weeks is the shortest time this process is recognized as occupying; the questions then that arise are, can the disease be entirely aborted if successfuly treated during the initiation period; or failing that, can the subsequent periods of its development be materially lessened and the cure effected in a shorter time? From our own experience we believe that both these contingencies are capable of realization under suitable homœopathic treatment; at the same time we distinctly recognize that there are under our own, as under any other treatment, distinctly recognizable phases through which the patient has to pass when once the disease has got that hold upon the system that the period has gone by when it might have been aborted during the incubative stage; to the allopathist the bare suggestion of the possibility that such a disease can be aborted when once it has invaded the system will doubtless sound as puerile in the extreme; at the same time we are satisfied, that though very exceptional from the difficulty arising out of uncertain timely recognition it is quite within the range of possibility or even probability. It is not necessary to refer again to the fact, that inflammation of these organs is generally preceded by a chill that declares itself in the form of a common cold any further than as a mere reminder; we shall there- 
fore, pass on to the consideration of those symptoms which are peculiar to the disease when once it is established; the incubative period is ushered in by occasional shivering, but the first attention would probably be directed to the coat, which stands up and has a very open appearance; on handling the horse the skin of the body generally, but especially that of the legs and ears, is very cold; having discovered this, a very short observation will note the rigors or shivering; the animal's individual appearance is suggestive of extreme languor; the mucous membranes lining eyes and nose are of a deep dark red, and they are tumified or swollen; the internal temperature will rise to I03 or I05 degrees; the pulse and respirations are much more frequent, the latter being sometimes repeated as often as the former; the appetite fails entirely, and it is only by the exercise of considerable ingenuity that a horse can be induced to partake of nutriment in any form; indeed so marked is the anorexia in some cases, that the animal has to be drenched with food in small quantities of a highly nutritious liquid character to maintain the bodily powers in any degree; in the majority of cases the animal maintains a standing posture, and never lies down until breathing is performed more easily by reason of the clearing up of the air tubes after defervesence of the disease; he stands with head stretched out, nostrils dilated, fore legs wide apart, and heaving flanks; the character of the pulse varies as the disease advances; in the early stage it is full and hard and numbers 80 or 90 beats per minute; thereafter it becomes softer, the artery feels full, but the actual beat of the heart is not readily discernible; in unfavorable cases the pulse thereafter becomes small and wiry and is increased in frequency to I2O; the respirations are urgent and appear to give pain in their performance, especially is this the case when the pleural membrane is involved; under these conditions the horse appears afraid to turn or even move, and by way of confirmation that pleuro-pneumonia is present, pressure of the finger between any of the ribs will cause the animal to wince with pain; the difficulty experienced in breathing is due, as in capillary bronchitis, to the fact that the air tubes, in their very small ramifications, are blocked up and there is no room for the air to pass in and out as the animal breathes, and in addition to this, those air tubes of the next larger calibre to the finest of all, where they are not abso- 
lutely blocked up, are pressed upon by exudation into the surrounding connective tissue which is the result of the inflammation, and consequently their size is reduced, and the air which is requisite for the proper interchange of its chemical constituents with the blood cannot pass in and the lack of the necessary oxygen produces a sense of suffocation.

Auscultation of the chest does not do much more than reveal how large a portion of each lung is invaded by the inflammation, as in those cases where the proper lung tissue is affected the sound is that of general dulness; however when resolution of the exudation takes place, the healthy respiratory murmur gradually returns, which serves as an indication of the speedy restoration to health of the patient. The urine is generally much reduced in quantity, and is of a high color; the fæces are dry, constipation and torpor of the bowels being generally present; should this condition turn to diarrhce it may be accepted as a very unfavorable indication and suggestive of typhoid complications-such as are observable in Newmarket fever, hereafter to be referred to in detail; in the advanced unmitigated form of the disease, abscesses develop in the deep-seated structure of the lungs, and are productive not only of immediate danger, but if overcome they frequently leave results behind, which interfere with the usefulness of the animal in a marked degree, the abscesses may form in the tubes or in the lung substance proper, but in either case they are very liable to spread from one tissue to the other, breaking down the walls of partition and leaving great cavities; this purulent form of disease is easily recognizable by the smell of the breath which is fotid and objectionable in the extreme.

TrEatment.-Aconite $3 \mathrm{x}$ should invariably take the first place, and that alone for a few doses; this is possibly the one remedy that is capable of aborting the disease if only it is given in time; true, one who is opposed to this line of treatment might say that at such a stage it is impossible to affirm positively that lung inflammation was likely to become established, and therefore there is $n 0$ reason in claiming that such a disease can be aborted; were it necessary or even useful to combat such an argument it might be attempted, but we do not think it would be and therefore rest contented with the bold assertion that we think there is justification in the claim made for the abortive powers of Aconite; as 
usual the early indications for this drug are hard, full, bounding pulse; exalted temperature; quick respiration; red, swollen eyes; short, hacking cough; diminished urine, constipated borvels; on the other hand when, as is occasionally the case, the pulse is very small, feeble, and hardly detectable, the respirations are almost as frequent as the pulse, and labored; the legs and ears are especially cold, accompanied with frequent fits of shivering a few frequent doses of Ammonium causticum 3x should precede the Aconite.

Phosphorus $3 \mathrm{x}$ is unquestionably one of the chief remedies in pneumonia, and especially in that form known as broncho-pneunonia; in animals poisoned by phosphorus distinct hepatization was observable and therefore on homœopathic principles it should prove serviceable where such physical signs are observable. It is a capital remedy to follow Aconite, or to be given in alternation with it, when the internal temperature keeps up, and under such circumstances doses of first one and then the other should be administered every two hours; one of the principal symptoms occurring in this disease which specially indicate that Phosphorus is the most stitable remedy is the discharge of red or rusty-colored mucus from the nostrils; when this is present it will be better to rely entirely and alone on Phosphoncs, and discontinue Aconite if that has previously been given in alternation.

Chelidonium majus $\theta$. - We were indebted to Dr. Hughes' "Pharmacodynamics" for drawing our attention to the value of this remedy under the following special conditions, and can from the experience gained in one or two cases, confirm this gentleman's conclusions. It is by no means an unusual coincidence that in pneumonia in the horse there are liver complications, as evidenced by the yellow color of the mucous membranes of eyes and mouth; pressure over the seat of the liver, close up against the last rib on the off side, will reveal considerable tenderness, the horse will wince and draw away from you; and in the cases referred to the right lung was principally involved, while urgent and frequent coughing was specially noticeable; the influence of the remedy in these particular cases was very marked; the cough was relieved in a great measure within two days, the yellow color of the membranes gradually changed to a normal pink, and the diseased lung underwent the desired changes until no unnatural condition was observable; as we have had certainly two cases of this sort, and 
both went on in much the same way, we consider that they serve to confirm Dr. Hughes' views concerning the special indications for this drug in a remarkable and very satisfactory manner.

Bryonia 3x.-When deposition of formed material has taken place in the true lung tissue, and that form of the disease known as pleuro-pneumonia is developed, which, as before stated, can readily be recognized by the pain the animal evinces as the result of pressure between the ribs, this is a splendid remedy; further evidence of this state of things may also be gleaned from the nature of the animal's cough, which is short, painful and catchy, an effort is evidently being made to suppress the cough, if possible; if this is of the dry character, as though there were no mucus to cough up, and the membranes were harsh, it serves as an additional indication for Bryonia, under the influence of which the tickling that serves to excite the continuous cough is relicved; the liver also comes under the same category, provided the yellow color of eyes and mouth is neither too deep nor pronounced; when the discharge through the nose is profuse and rusty colored in conjunction with the symptoms previously mentioned as peculiar to Bryonia, it will be well to alternate this remedy with Phosphorus; but alternation of remedies is, in our judgment, only permissible in such diseases as this, where two or three pathological processes are going on at the same time; to be strictly in accord with Hahnemann it should be noted that alternation of remedies is only very occasionally allowable.

Antimonium tartaricum 6x.-Although this agent has been relied upon among medical practitioners for the human subject in the old system, it is not often prescribed by veterinarians and as is ably pointed out by Dr. Hughes, it is not in the earlier stages of pneumonia that it is likely to prove efficacious; this fact we are able to confirm from experience among horses and cows; but there is a period in the course of the disease in which it exercises a very marked effect for good; we have already endeavored to make it clear that as this inflammation progresses, the smallest air tubes and cells beome blocked up with a fluid effusion that ultimately becomes formed into a more solid form and also that a fluid exudation takes place into the mesh-like fibres that go to make up the true lung tissue, surrounding the air tubes, which in turn assume a solid tissue, or, as it is described in pathology "formed 
material; " now, in reference to both these conditions it is quite clear that before the lung can be restored to a healthy state and rendered capable of performing the function of respiration aright, this formed material, which is certainly a foreign body must be remored; this is performed by what is commonly called "resolution" by which we must understand that the formed material or solid tissue situate in and around the air tubes has to be resolved into a fluid again, taken up by the various blood ressels and lympathics and in this way be convered out of the system; very frequently while this process of resolution is going on, the formed material does not become fluid enough, nor have the air tubes sufficient power and vitality to expel it in its more solid form in the shape of expectoration, therefore some remedy is called for that will facilitate the process and render it possible to get rid of this accumulation; - Antim. tart. will as a rule effect the desired end and afford the patient the relief so urgently needed; in order to determine the proper time for the administration listen carefully with the ear against the ribs in various positions for a bubbling or rattling sound, as though air was passing forcibly through water, while at the same time the horse erinces difficulty in breathing and seems well nigh choked by the partial rising of a large quantity of soft mucus which he cannot quite succeed in expelling.

Arsenicum album $3 \mathrm{x}$ is called for not infrequently in cases that after progressing so far discontinue improvement and fall back again; especially in cases that assume a typhoid form; diarrhœa, increased fever, weak, small, wiry pulse, effusion of fluid into the chest, (which may be discovered by pulling one foreleg foreward and listening at the bottom of the chest, when a dripping as of water into a well may be heard, ) increased difficulty of breathing: restlessness, unwillingness, more than ever, to lie down; no appetite, but increased thirst; cold, clammy condition of mouth and wings of the nostrils; extreme prostration, are the indications for this remedy.

It is further useful in conjunction with Phosphorus (not administered together) in those cases where resolution of the formed material has not taken place thoroughly, and, so called thick wind is the consequence; a week of Arsenicum followed by a week of Phosphorus will often materially improve such a case, especially 
if one intermediate dose of Sulphur I2, consisting of fifteen grains be administered.

China $\theta$. - In cases that have progressed satisfactorily to convalescence and no bad results are left behind, complete restoration to health will be considerably facilitated by administering a ten-drop dose of China $\theta$ night and morning for a week or fortnight or even longer, provided the animal continues to go on well and improve; otherwise it should be discontinued and one dose of Sulphur I2, as mentioned above be given to complete the cure.

\section{PLEURISY.}

We have already endeavored to explain that the outer covering of the lungs, the membrane which serves to enclose them is called the pleura; a membrane in all respects very similar in character and appearance to this, also covers the internal portion of the cavity of the chest, namely, that which is inclosed within the ribs, and as both have a smooth, shining, glazed surface, they are able to rub together in health without either noise or sensation, but when once inflamed a very different state of affairs arises; it must be understood that during life there is no space between the lungs and the wall of the chest, therefore it is necessary that the membranes (pleura) covering both lung and chest walls should be perfectly smooth, that the lungs may, as they move, glide easily over the inner surface of the chest walls; let inflammation, however, attack this delicate membrane and it no longer glides easily upon itself; a roughness is the result, which, as the lungs move in the act of respiration, produce great pain and auscultation reveals the frictional sound, due to two rough surfaces playing one upon the other; such a sound as is observable when course sand or very fine gravel is rubbed between the closely approximated palins of the hands.

The inflammatory action may center itself directly and independently upon the pleural membrane, in which case it generally owes its origin to cold and other meteorological influences; or, it may be due to injury; in most cases, however, it is associated with inflammation of contiguous portions of the respiratory organs or diseases of the heart. In health, this very finely constructed membrane secretes a fluid sufficient in quantity only to lubricate it, and so render one part capable of gliding easily upon the 
other, but when inflammation sets in, from whatever cause, the secretion is arrested and the membrane is rendered dry and rough. After a short time this dryness is succeeded by an excess of fluid secretion, (dissimilar in character from the normal, healthy secretion,) which is so constituted that in a short period, if not taken up by the vessels again, it forms into organized material of a fibrous character that becomes interwoven, and so the lungs may become actually adherent to the walls of the chest and unable to move with the freedom requisite for comfortable breathing. It is in connection with pleurisy that we get what is commonly known as dropsy of the chest, because of the great quantity of fluid that is poured out it becomes necessary for the allopath to tap the chest, if only to give some relief to the pressure which this excess of fluid produces; unfortunately, however, the mere fact of drawing off a portion of the water on the chest does not do away with the cause which produces it, and hence the carity of the chest soon refils and the difficulty of breathing is as great as ever; here again Homœopathy steps in to effect by therapeutical measures what surgeons fail to realize; the remedies necessary for combatting this painful, and while it lasts, distressing condition are few but marvellously effective, so much so that if the tendency to form fluid is discovered early, it may be arrested before any serious consequences arise, that which is already formed becoming reabsorbed and passed out of the system through the urinary organs. But first we must recapitulate the main symptoms; chilliness and slight shivering usually precede the development of the more characteristic indications, attended by an exalted temperature, rapid, hard pulse and quickened breathing; the difficulty of breathing is accentuated by the evident pain caused in the performance of the function; when the horse draws his breath in, he frequently coughs, when he expires or lets it out, the act is frequently effected at twice as it were; that is to say, a pause in expiration takes place; the animal experiences considerable pain in turning round; the breathing is chiefly performed by the abdominal muscles, namely those behind the ribs, with a view, no doubt, to save as much pain as possible to the chest, and in the abdominal locality the external muscles are corrugated, especially if one lung is more affected than its fellow; pressure of the finger-point between the intervening spaces of the ribs will cause the patient to wince and 
move away and in the act of turning round the animal very frequently grunts with pain. The individual peculiarity of the cough in pleurisy is marked by the evident effort of the animal to suppress it by trying to break off in the middle of the act.

TREATMENT.-In the first stage, when the febrile symptoms initiate the invasion of pleurisy, a few doses of Aconite $3 \mathrm{x}$ may be administered with great advantage; but when the disease is not discovered until the recognized indications of pleurisy are distinctly observable Bryonia $3 x$ alone may be confidently relied on, a aose every three or four hours; this is due to the fact that Bryonia exercises a specific action upon such membranes as those of which the pleura is a notable example; these membranes differ entirely from the so-called mucous membranes that line the internal parts of the digestive and other organs; in the first place, they occupy a different position anatomically, being located externally, as a covering to the organs they protect; and, secondly, their functions differ materially from mucous membrane; they are called serous membranes and are capable of producing a fluid or exudation, hence the excessive quantity of fluid formed in a case of pleurisy when this membrane is inflamed.

Apis mellifica Ix.-In long-standing cases, where the reabsorption of the fluid in the chest is not fully completed, this remedy will often prove effective in bringing about the desired result; it doubtless exercises a specific action upon the serous membranes and at the same time stimulates the kidneys to the performance of the onerous duties which fall upon these organs when an excess of fluid has to be got rid of from some distant part.

Arsenicum album 3x. -This remedy also may often prove more effective in getting rid of old-standing dropsies of the chest, and among other symptoms by which it may be recognized as displacing Apis mel., is the fact that the patient wants to drink a little and often, whereas when Apis mel. is indicated thirst is repressed and noticeable by its absence; furthermore, when the heart is associated with the dropsical condition of the chest, this remedy will often prove to be specially called for, as it exercises a profound influence upon the vital organ referred to; palpitation, in conjunction with great difficulty in breathing, by reason of the oppression experienced from the dropsical condition, should suggest this remedy. 
Hepar sulphur 6x.- In some cases where an animal is not favorably located from a hygienic standpoint, and the general surroundings are not of a healthy character, the fluid which is effused into the cavity of the chest is not reabsorbed and ultimately assumes the form of pus (or matter); while, at the same time, some of the fluid becomes organized and membranes are formed which bring about adhesions of the lungs to the walls of the chest; under these circumstances this remedy will frequently afford relief, by altering the character of the exuded fluid and effecting resolution of the false membranes.

ACCESSORY MEASURES are in all these lung complications to be observed much as in all enervating diseases; the animal should be placed in large, airy boxes; be kept free from draughts; be supplied with abundance of clean bedding; be well clothed and have just as much of the most easily digestible food as he will take at one time, such as mashes, boiled oats, green food, carrots, and so on; if the bowels are very constipated resort may be had to tepid enema injections to relieve the discomfort arising from undue pressure upon the walls of the rectum; only under circumstances of extreme exigency should alcoholic stimulants be resorted to; and then Scotch whiskey in milk is the best that can be given.

\section{ASTHMA-BROKEN WIND.}

By some eminent veterinary pathologists asthma and broken wind are considered to belong to distinct classifications, and notably the late Professor Robertson seems to have held this opinion; for our own part we consider them to belong to one and the same morbid condition, placing asthma first, as representing the the acute form, and broken wind, second, as representing the chronic form, and we are the more inclined to maintain this position from the fact that the remedies which serve to cure the one are equally capable of relieving the other. The mode of respiration and the character of the cough are very similar in each, the only difference recognizable being that in so-called asthma the attacks come on periodically with intervening periods of relief, while in broken wind the symptoms continue without intermission.

Symptoms. - In the earlier stages of the disease, namely, that which is described as asthma by such as believe that the disease is distinct from broken wind, the difficulty of breathing is spas- 
modic, the inspiration or drawing in of the breath being performed easily and quickly, while the expiration or expulsion of air from the chest is performed with some difficulty, and frequently a distinct pause takes place in the act, dividing it, as it were, into two separate acts; if the ear be placed over the chest a wheezing noise is readily detectable, and the cough is short, quick and difficult of performance; the symptoms while they last produce an expression of anxiety; they are urgent, and soon bring on evident exhaustion; but the greater the severity the shorter time they continue. In the more chronic form of the disease, according to one view, when it would be recognized as broken wind by those who differentiate between the two conditions, there is not much alteration in the act of inspiration, but expiration is rendered much more difficult and labored; the muscles of the abdomen become contracted, forming a ridge which is observable from the lower part of the hip bone to the bottom of the ribs, and the double effort at expiration will be easily noted by the rolling motion of these muscles being arrested, and recommencing in the one act of expiration. The cough of broken wind is soft, and more resenbles a grunt which is wanting in force; the animal seems unable to expel as he would like to do, and the cough is easily excited by exercise, eating and drinking, by a poke in the ribs or any similar disturbance. The sounds observable by auscultation are not reliable, as they differ in various cases. The digestive system would appear to exercise considerable influence in the production of this condition, hence we can only conclude that the nervous system plays no insignificant part in connecting the two systems; moreover, care in dieting invariably assists in alleviating the more acute symptoms; to attempt to explain the relation between cause and effect would take up too much space, and probably involve an argument in physiology that would hardly be appreciated in this work.

TreatMent. - If the disease is fortunately detected in its earlier stage Digitaline $3 \mathrm{x}$ administered three times a day will usually arrest the development of the more chronic form and effect a cure.

Arsenicum album $3 x$ takes the next place in the rota of remedial agents.

Nux vomica $\mathrm{IX}$ is specially indicated when the disease can be 
distinctly traced to the digestive organs, as indicated by a readily observable symptom, namely, the passing of flatus (or wind) from the anus when the animal coughs.

Ipecacuanha $3 \mathrm{x}$ is a useful remedy in the early stages of asthma when the paroxysms are associated with digestive troubles, and these may also be traced to a slightly inflamed condition of the respiratory tract, such as running at the nose and eyes.

Lobelia IX is undoubtedly an excellent remedy for some cases, namely, those in which the paroxysms of coughing and difficulty of breathing are specially aggravated by exertion or movement; distention of the abdomen, and passing much water and that frequently, are corroborative indications for this drug.

Sulphur 12.- Independently of the marvellous power which this drug seems to possess of arousing the systen to a higher susceptibilty to the action of drugs, it would appear from Dr. Hughes' Pharmacodynamics that it also enjoys a reputation in human practice for a specific power to control chronic asthma; however this may be, we are able to add our testimony in support of this view, as several cases of some long standing that had, according to the position we maintain, arrived at the stage of broken wind (emphysema) yielded to the action of Sulphur I2, at the same time it is only fair to add that the patient had for several weeks previously been receiving Arsenicum album 6x, but with only slight indications of improvement; the question therefore arises, was the action of the Sulphur specific and individual, or did it serve to arouse the system to the action of the Arsenicum alb.; it is, of course, impossible to assert dogmatically which was its action, although after consulting Dr. Hughes' work we incline to the opinion that the Sulphur acted independently; anyhow the result of the treatment was satisfactory, and where Arsenicum fails, we commend the use of Sulphur.

ACCESSORY MEASURES undoubtedly exercise a potent influence upon whatever remedial measures may be adopted to overcome this troublesome form of disease, which, for some unaccountable reason, appears to find a readier seat of action among the heavy class of horses than those that are better bred.

The consideration of the diet to be allowed to a broken-winded animal is all important; bulky food must be avoided; straw and hay, with chaff of the same, had better be withheld, or only given 
in very small quantities; to make up for this oats that have been carefully crushed, with a suitable proportion of cracked beans or split peas must be given in increased quantity by fifty per cent. to that which the horse would receive were it in receipt of the common mixture of hay or chaff; and succulent diet such as vetches, clover and lucerne in the summer, and carrots in the winter should be allowed in moderate quantity as aids to nutrition on the one hand and digestion on the other; if the horse has fast work to perform care must be observed to so order the time of the meals that the work has not to be performed upon a full stomach. During the daytime the horse's head should be tied up short to prevent the possibility of getting at bedding straw, and at night when head must of necessity be let down, a muzzle should invariably be used; in order to avoid the practice of taking large quantities of fluid at one time it is a good plan to have a constant supply always available, as under these circumstances only small quantities of water will be taken in the stomach at one time.

\section{NEWMARKET FEVER.}

Gentlemen who take an interest in sport, and racing in particular, have doubtless often read in English sporting papers of a disease called "Newmarket Fever," and as it is frequently described as very fatal, and by some writers as infectious and therefore likely to spread through a stud, it may be of some service to devote a chapter to the consideration of its principal characteristics, more especially as some of the leading sportsmen in the United States are sending over their thoroughbreds to compete on our English race-courses.

With a view to confirmation as to the pathology of the disease we placed ourselves in communication with one of the most eminent resident veterinary practitioners in Newmarket, Mr. E. H. Leach, F. R. C. V. S.; who promptly and very kindly furnished some interesting details of cases that had passed through his hands, and a post-mortem specimen consisting of a piece of a lung taken from a two-year-old filly, which had been a subject of the disease, and with great pleasure we own our thankful indebtedness to Mr. Leach for the trouble he took in this matter. The disease, according to this eminent practitioner, is called "New- 
market Fever" in Newmarket and the sporting papers and no where else; it is in fact a local term that has gained world-wide notoriety-it is generally known elsewhere, says Mr. Leach, as infectious pleuro-pneumonia, typhoid pneumonia and influenza; from the post-mortem specimen which Mr. Leach kindly forwarded for our inspection, we formed the opinion that the filly from which this was taken had been the subject of septic pleuropneumonia, by which we mean that the case was one of very acute pleuro-pneumonia in the first instance followed by and intensified by blood poisoning; the symptoms as furnished by Mr. Leach were, when he was called in, "blowing, off feed, temperature 105.2 degrees, pulse 78 , respirations 44 per minute; visible mucous membranes a nasty pinky-yellow; legs and ears cold; bowels rather costive. Next morning filly about the same except that her temperature was I03.2 degrees, and she had eaten about a double handful of mash and drank half a pail of water. In the evening about the same. Next morning temperature I05.4 degrees, breathing worse, discharge from nostrils mixed with blood. As the filly was a very bad specimen of a race-horse, being small and weedy, I, with the consent of the owner, killed her."'

Judging from the advanced stage to which the disease had attained, as evidenced by the condition of the piece of lung we received, there is very little doubt that Mr. Leach was called in some days after the animal was taken i11, and in consequence the opportunities of effecting a cure were considerably reduced, and Mr. Leach was severely handicapped in his treatment thereby.

Mr. Leach does not consider the disease so very fatal as the sporting papers would in the past have led us to believe, and he considers that on an average of several years a loss of five or six per cent. would fairly represent deaths from "Newmarket Fever;" moreover, he is, from past experience, of opinion that most cases recorer rapidly and the animals do not appear any worse afterwards, unless they be such bad cases as the one before referred to, when they frequently go roarers, or as we should describe it, they make a noise, to distinguish a lung affection from that of the larynx. Although we cannot claim to have had any experience of cases of the local form of the disease, we have had our fair share in other places of cases that are doubtless, pathologically, the same disease, hence our reason for venturing to give a sug- 
gestion that the disease is really septic pleuro-pneumonia. By Mr. Leach's invitation we gave him our idea of the line of treatment such a case would call for, and it was as follows: In the first place Aconite 3x a dose every two or three hours would have been the first remedy when called in, to be followed, after three doses, by Bryonia 3x; if, as was the case with Mr. Leach, the mucous discharge from the nostrils ultimately became colored with blood, our remedy would certainly have been Phosphorus $\frac{1}{500}$, and had the symptoms of septic poisoning supervened Lachesis 5 would have been resorted to. The reason which, in our judgment, accounts for cases of this sort becoming ill at all, is not that it is of an infectious character, but that it orves its development to an over-heated atmosphere of the stable which is supercharged with effete material emanating from the breath of the horses; and when these cases develop typhoid or septic characteristics it is due to a lack of good sanitation and hygiene: the stables are overcrowded according to the cubic area, and the ventilation at the best is always imperfect and very generally, actually faulty. With all due deference to Mr. Leach's opinion we are unable to agree with him that animals the subject of this disease rapidly get well; doubtless from Mr. Leach's experience, it is so at Newmarket, but not in London and Liverpool, which are the places where our cases were located. Further, our opinion is that in patients whose lungs the disease has invaded pretty thoroughly, the chance of rendering them useful, at all events for fast work, is remote under Allopathy; but with such homœopathic remedies as Bryonia, Phosphorus and Arsenicum album the prospects are bright and promising, and it behoves owners of flat racers, steeple chasers and trotters, if they would save their animals from developing into "Musicians" after being the subjects of inflanmation of the lungs or bronchitis to see to it that they are pulled through the illness with this sort of treatment. 


\section{DISEASES OF CIRCULATORY SYSTEM.}

Before entering upon a consideration of the diseases which affect the different parts that go to make up the circulatory system, by means of and through which the blood traverses the body, an attempt must be made to explain of what these parts consist and how the function of the circulation of the blood is maintained and carried onl. In order to keep up that regular and constant flow of blood through all the intricate channels of the animal frame that is necessary for the maintenance of life and health, it will be apparent that some force or driving power is an essential requisite; without such force it would be no more possible that the body of fluid, which is represented in the animal body by blood, could be kept constantly and regularly flowing than that a number of railway carriages can be kept moving without the power generated in the engine by means of steam; the weight of the fluid demands a propelling power to keep the same in motion. The engine which keeps the blood flowing is the heart; this organ is sitnate in the cavity where the lungs are located, and its position is intermediate between the two lungs, rather nearer the front than the back of the chest; the heart is covered externally by a very fine membrane called the pericardium, which has a smooth surface outwardly, so that it may glide easily against the outer surface of the lungs, already described as the pleura. The heart is divided into four compartments or chambers, two above, called auricles, and two below, called ventricles; an auricle over a ventricle on the right side, which communicate with one another by orifices that can be closed by means of valves, and the same on the left side of the heart. In connection with the heart there are sets of tubes which convey the blood away; the first is that which passes the blood from the right ventricle through the capillaries of the lungs that the blood may come in contact with the fresh-air passage in and out as the animal breathes, in order that it may be purified; it then returns through the pulmonary reins back into the left 
auricle of the heart, and from this into the left ventricle, directly under it, in connection with which is the largest blood tube of the body, called the aorta; from this large tube branches, called arteries, divide and subdivide to the various parts and organs of the body; these arteries or branches of the aorta in the course of their distribution over the system become so small and fine that the name capillaries has been given to them; in the course of its passage through these capillaries the blood undergoes considerable change, as may be noted from the alteration in color; from a vivid bright red it becomes dark or blue red, and having thus done its work it becomes necessary to return it to the heart to be repurified, and so it passes from the capilliaries into the veins, which in turn become gradually larger and larger, until the whole stream is collected into two large tubes which empty themselves again into the right auricle of the heart, and here the round of circulation begins once more. The heart itself consists of muscular walls of varying thickness, and by means of the contractile powers of these muscular walls, which are stimulated to action by the nerrous system, the blood is propelled into the arteries, thence through the capillaries and back again through the veins; each time the heart contracts a certain quantity of blood is driven forcibly into the aorta, and that which is expelled at one contraction forces further on that quantity which preceded it, and so on as each contraction fu1fils its work, until continuous pressure on the whole stream is kept up from behind, and so the circulation is maintained; it is considered that the walls of the arteries by means of their elastic recoil contribute some force to aid the heart in the performance of its function; the arteries are open tubes with no internal obstacles to the flow of blood, and their walls consist of muscular and elastic fibres which expand as the heart contracts and forces blood into them; while during the pause which takes place when the heart is momentarily at rest, in consequence of there being no pressure, recoil of the elastic fibres takes place and in this way the blood is kept in motion. The veins assist the circulation through the medium of cup-shaped valves, which are attached to their inner walls; the object of these being to prevent the blood from receding or moving backwards; during the period of contraction, when the blood is being forced on in its proper direction, these cup-shaped valves lie flat against the wall of the veins, and 
leave a free onward course for the blood; but during the interval of rest, between the heart contractions, when the blood would otherwise recede backward, they fill out and so offer a complete barrier to a backward motion.

It will thus be clear that any interference with the healthy conditions of the walls of the heart, or with the valves that divide one compartment of the organ from another, or yet again, with the arteries or veins, must of necessity seriously impede the regular and continuous flow of blood through the system. At the same time it is hardly necessary to add that any obstruction to the maintenance of a regular and continuous circulation of the vital fluid cannot be other than seriously detrimental to health, bearing which in mind, we shall proceed to consider the various phases of disorder to which the heart and its subsidiary conduits or tubes are liable. We are strongly of opinion that in the horse the heart is the seat of disease far oftener than is generally admitted; several prominent cases have come under our notice in which valuable racehorses, whose running in public was altogether inexplicable, were the subjects of heart disease, with reference to which, had they been professionally examined with a view to determine the state of this organ, it is highly probable there would have been no difficulty in determining what was really wrong; as it was, all sorts of reasons were assigned for the failure of these animals to win races which were considered on some of their form to be absolutely at their mercy; some attributed their "shutting up " in the middle of a race to temper, others to the belief that they were "non-stayers" - the fact really being that the valves of the heart were diseased and were therefore unable to properly fulfill their functions; the heart itself, in consequence, was overloaded with blood, and a sense of suffocation experienced which absolutely deprived the animals of the power to keep up top speed for the necessary distance; ultimately each of these horses died suddenly, one of them just after he had passed the winning post, to the imminent risk of the jockey, who fortunately, however, escaped with nothing more serious than a severe shaking; these facts, however, go to prove that the possibility of heart disease, even when health generally appears good, should not be overlooked. The methods of examination to determine whether the organ is affected or not cannot, in the case of a layman, be other than very restricted; at the same 
time, we hope to be able to suggest such methods of procedure as shall at least be sufficient to arouse suspicion, which it would be well afterwards to have confirmed by an experienced veterinarian; but here we must draw attention to the fact that among allopaths the treatment of heart disease is well-nigh exclusively confined to the administration of tonics, with a view to the building up of the constitution generally, and to the ultimate throwing off the heart disease as the result thereof; they do not recognize the possibility of specific drug action upon the various morbid conditions affecting the organ or any of its constituent anatomical parts; in this the homœopath has a distinct advantage, as will be seen when we deal with the subject of treatment.

Physical examination of an animal to detect heart disease is conducted by "palpation," that is, applying the hand over the region of the heart to feel, if possible, the character of the impulse; or, better still, by "auscultation," namely, listening to the heart's sounds with the naked ear or by the application of an instrument known as the stethoscope; in order to do this satisfactorily the ear or the stethoscope must be applied directly over the space in the chest, nearest to which the heart approaches, which is discovered by lifting up the near foreleg, pulling the same straightforward, and selecting the lowest part of the chest as far forward as the extended leg will allow, where the muscles over the ribs are the least thick; in this position the sounds of the heart will be distinctly observable, and there will be no difficulty in detecting any irregularities, always bearing in mind that for every contraction of the heart, which is equivalent to one beat of the pulse when the same is felt in an artery, there are two sounds which may be expressed by the words "lubb dub;" one-the first-soft and prolonged, the other-the second-short and sharp; the first sound is the result of the driving of the blood from the auricles into the ventricles, and is produced by the closing of the valves which serve to divide the two upper compartments, the auricles, from the two lower compartments, the ventricles; the second, short, sharp sound is due in like manner to the valves which close the outlets of the ventricles, namely, the artery which leads to the lungs, and the aorta, or large tube, which conveys the blood all over the body. At this point we should strongly recommend any one who desires to turn to good account what follows, to practice 
on a healthy horse, in order to become acquainted, as far as it is possible, with the normal heart sounds; in this way experience will be obtained that will enable one the more readily to detect abnormal sounds and morements.

Disturbance of the heart's action is due to two distiuct causes, namely, first to interference with the healthy performance of its functions which arises from a want of balance in the nerve supply and also from irregularities of the digestive organs; and second, to organic and structural alteration, such as thickening or thinning of the muscular walls of the heart; dilatation or lessening of the cavities in size; thickening of the valves due to inflammation of the serous membrane which lines the cavities and covers the valves.

\section{PALPITATION.}

It will be well to give some careful attention to the consideration of this disorder, because we believe that among the higherbred class of horses, especially those kept for racing purposes, owners and trainers frequently erroneously attribute the failure of their charges to defective respiration, whereas the weak spot is the heart; palpitation comes under the category of a functional disorder, and may therefore be the more easily controlled, if the right measures are resorted to. Blood horses are of essentially excitable and highly-nervous temperaments, which fact alone is sufficient to account for many cases of palpitation, and although very little importance has hitherto attached to cardiac diseases among the great number of the veterinary profession, we have no hesitation in affirming that palpitation occurs much more frequently among highly-bred horses than is generally acknowledged. This want of recognition may probably be accounted for by the fact that a horse may be the subject of it and yet keep up the appearance of an animal in the bloom of health, betraying no outward and visible signs of weakness beyond hurried breathing after a sharp gallop; under such circumstances trainers and owners, who do not possess even an elementary acquaintance with physiology, would naturally attribute this to the wind, and inasmuch as these gentlemen are, as a rule, very well contented to rely upon their own knowledge, the real truth never comes out; and, though we regret to have to state the opinion, we fear that not a few profes- 
sional veterinarians might also overlook the cause, unless particularly requested to make a most careful examination for a client who did not object to pay a suitable fee for the extra special attention such cases demand. Whatever may be the exciting cause of the palpitation, it is characterized by increased frequency in and force of the heart's contractions, at times so tumultuous that it is well-nigh impossible to distinguish the beat; the breathing is urgent, rapid and difficult of performance; the pulse beats are also irregular and sometimes intermittent, by which we mean that a certain number of beats follow on one another with equal rapidity and interval; then a pause takes place, as though the heart had ceased acting, when the beats are renewed again for several times, followed by another pause, and so on. The horse will break out into a cold sweat; stands with forelegs wide apart tottering and shaking as though he would fall; in the worst cases syncope (or a fainting fit) comes on, when those who do not know better, fail to recognize the real cause and attribute it to a form of brain di,ease known as "staggers."

TREATMENT. - Aconite 3x.-No remedy in the Pharmacopœia exercises so marked an influence on the circulation as Aconite, and in such cases as those where the heart is tired out by excess of work or effort to work, as in palpitation, this remedy is generally capable of producing a restoration to calm and rest; moreover, it is specially indicated if the existing cause is in any measure associated with rheumatism.

Moschus rx.-In extreme case of palpitation, where the nervous excitement is very considerable and the body becomes cold, this will be found an exceptionally useful remedy.

Acid hydrocyanicum $3 \mathrm{x}$ may be administered with great advantage in cases that do not assume symptoms of an extra acute character; where palpitation is attended with a weak and rather slow pulse, and a tendency to fainting marked by difficult breathing, with an obstinate refusal to take food, this will be found useful.

Cactus grandiflorus $\mathrm{Ix}$.- This remedy may be styled the analogue of Aconite, and by some authors it is credited with taking the paln over that remedy in diseases of the heart; indeed, there is hardly any morbid condition affecting the organ that it does not take an active part in ameliorating, from nervous palpitation to obstructural change arising from acute inflammation; there is one leading 
symptom that suggests its selection for the human subject, namely, a feeling " as if the heart were grasped and compressed with an iron hand;" as a horse cannot explain by word of mouth that such a symptom is experienced it is hardly possible to avail of it; at the same time, if there is reason to suspect heart disease and the animal suddenly assumes a rigid posture, and, as it were, holds itself in one position for a few seconds, or even minutes, it would be a fair assumption that some such feeling as that indicated was experienced, and by inference one would be certainly justified in administering Cactus grand. in the hope of furnishing relief.

Among the diseases which affect the vital organ are pericarditis, or inflammation of the fine serous membiane which invests or clothes the heart, and dropsy of this membrane, but as both are exceedingly rare, we shall pass on to hypertrophy, or dilatation of the heart, which is doubtless of more frequent occurrence in the horse.

\section{ENLARGEMENT OR DILATATION OF THE HEART.}

By this designation we mean that the walls of the heart are increased in thickness and the cavities of the organ are proportionally larger; at the same time while we intend dealing with this particular form of alteration in structure, we must explain in passing that it is possible for the walls of the heart to be thickened without any corresponding increase in the size of the cavities; and at the same time for the cavities of the heart to be considerably increased in calibre without any alteration of bulk in the muscular walls; hypertrophy with dilatation is more frequently observed in horses and therefore we select this form of structural change for treatment.

It is also necessary to observe in passing that all the compartments of the heart are not equally susceptible of this structural alteration, indeed it is only fair to state that the left ventricle is more often affected than either of the other three divisions of the organ; a fact that is due possibly to the strain put upon this compartment in driving on the main volume of blood over the general system; and so long as the thickening of the walls of the heart keep pace with the dilatation or enlargement of the cavities, the impairment of function will not be so observable; it is when the size of the cavities is out of proportion with the thickness of the 
muscular walls that the disease fully declares itself; presumably because the heart has a capacity for taking in more blood at one time than the walls have the power to drive on through the arterial system; consequently the impulse of the heart becomes weaker and the weight of the vital fluid is too much for it to overcome; hence the circulation becomes slow and torpid, and the blood regurgitates, a phenomenon that is readily discernable by that peculiar backward movement in the jugular veins that may frequently be seen along the groove in the horse's neck formed mainly by the windpipe; when this pulsation in the veins is observed, attention should at once be directed to the heart, because it is essentially an abnormal condition, the pulse never occurring among veins in health.

Among the causes to which dilatation of the heart are attributable, are frequent overexertion, such as occurs among horses subjected to severe training for long-distance races, and hunters or steeple-chasers; it must not be understood from this that we consider horses incapable of being prepared for this sort of work, but the consequences are attributable to the fact that the preparation goes on and is persisted in when the animals are not fit to undergo work demanding so serious a strain upon the vital organ; were this fact recognized at the proper time and suitable measures adopted to remedy the temporary weakness, the animal's constitution would recover its natural vigor, and the requisite course of training and preparation could be conducted without any subsequent ill-effects, nay more, the very work itself would tend to render the horse more hardy and capable of taking his own part in the field or between the flags in a satisfactory manner.

A further cause of dilatation arises from some obstruction to the free and natural circulation of the blood which may be due to defect in the valves of the heart or the large arteries, also to diseases of the lungs and kidneys which give rise to some impediment in the circulation by reason of an alteration in the tissues of these organs. When the dilatation of the heart increases while the walls become thinner, the power to drive on the blood is reduced and consequently the pulse is weak, slower than normal and the beat is prolonged; the beats become irregular and intermittent (the meaning of the latter word has already been explained); the breathing becomes difficult; the legs do not maintain their natural 
warmth, and at times are absolutely cold; the legs also swell and symptoms of dropsy present themselves along the abdomen and under the chest; the pulsation of the jugular veins is generally observable, and the animal is weak and aitogether wanting in spirit and energy.

Arsenicum album 3x should be given three times a day in doses of ten grains; and especially when the dropsical condition is exhibited; it serves to give tone to the muscular walls and relieves the urgent breathing.

Cactus grandiflorus ix. - When hypertrophy (or thickening of the walls of the heart) is present in more marked degree, the pulse differs in character from that when dilatation predominates; the impulse of the beat is increased and is much stronger; the sounds, especially the second one produced by the blood passing into the aorta, are intensified and instead of the short, sharp "dub" are more of a ringing, metallic character; under these circumstances Cactus grand. is the more suitable remedy.

Digitalis $3 \mathrm{x}$. -The circumstances under which this remedy has been found effective are when the pulse is weak, irrregular, intermittent and the quantity of urine passed is much less than is usual in ordinary health; the cedema or swelling sometimes observable on the under surface of the chest and abdomen may also be included as one of the indications for this drug.

\section{VARIOUS CARDIAC INFLAMMATIONS.}

\section{CARDITIS, ENDOCARDITIS, VALVULITIS.}

In endeavoring to deal with the effect of inflammation upon the various parts of the vital organ we must first remind our readers that the heart consists of muscular walls, which are lined both externally and internally with a special form of membrane, and that the internal membrane extends over the valves; to properly appreciate this fact we advise one and all who desire to master the details (which though difficult to explain we are compelled to refer to in language that is doubtless rather vague to those who have never studied anatomy), to obtain from the slaughterer's a horse's heart; first examine it carefully as a whole, then cut it open from top to bottom; in this way it will be rendered clear what is meant by the 
various divisions or compartments, valves, outlets and inlets, and the ocular demonstration will no doubt render it easier to distinguish between the different parts already frequently referred to and to be alluded to hereafter. By carditis is meant inflammation of the substance of the muscular walls; it is derived from the Latin word cardis, which means heart; endocarditis is a term which implies inflammation of the endocardium (or internal lining membrane) of the organ; it consists of a very fine, glazed, fibrous membrane, which with care may be peeled off the muscular walls. Valvulitis indicates that the inflammation has attacked the fine membrane which extends over and covers the valves. By some authorities on equine medicine, notably the late Professor Robertson, it is considered that the horse is rarely the subject of these inflammations as independent diseases; whether this is absolutely the case we are not prepared to say, but that they do occur, and that not infrequently, we are satisfied; and whether arising independently or in association with some other morbid condition, they are sufficiently pronounced to demand our careful attention; moreover, if the totality of the symptoms serves as a guide in the selection of a drug, both those of the heart and the associated disease, if there be any, will yield to the action of such drug; hence there is no necessity to be so careful in distinguishing betrveen independent and associated disease. Horses are frequently the subjects of rheumatism, and as there would appear to be some intimate relation between that disease and the internal membrane lining, the heart and valves, there need be 110 great wonder if horses are affected in the heart. We have already pointed out that thickening and dilatation of the walls of the heart is unquestionably due to overexertion or to long-continued exertion that makes excessive demands upon the organ which has to pump the blood over the whole body; bearing in mind, therefore, these two facts, namely, the susceptibility to rheumatism and the possible consequences upon the heart, and the liability to organic alteration in the structure of that organ in consequence of orerstrain in the performance of its functions, the view that we hold regarding the probable combination of all these conditions in one subject does not seem unreasonable. There is an appendage to the valres of the heart which has not been referred to, which ninght strike anyone making a careful inspection of a heart as a careless onis- 
sion on our part; we refer to the string-like chords which are attached at one end to the margins of the valves and to the other at the walls of the heart; they are called chordæ tendinæ; these chords are found in the ventricles of the heart; those parts of the walls to which they are attached are irregular in surface and rounded, the object of which is supposed to be the drawing tight of the said chords during the period of the heart's contraction, and by means of these chords the segments (or parts) of the valves are kept in apposition, so that the orifice is left open or closed according to the functional requirements; these chords are clothed with a membrane similar in quality to that of the valves, and may in like manner be affected by inflammation and thus rendered incapable of performing their duties in a satisfactory manner. The defective action of the valves results sometimes in a backward flow of the blood, which produces that venous pulse sometimes observed in the jugular veins, which pass down the well-known grooves in a horse's neck; at other times to an accumulation of blood in the ventricles, and yet again in the lungs.

The symptoms are not easy of recognition whereby any one or more of these morbid conditions can be definitely fixed upon, except by experts who have made the sounds and sensations characteristic of the same their special study; therefore, we shall not pretend to enumerate them here; but satisfy ourselves by dealing with the more general indications for the selection of drugs under the head of

Treatuinnt.-Aconite $3 \mathrm{x}$ in this, as in a large proportion of inflammatory diseases, comes first and foremost; and without attempting to argue from a physiological standpoint as to the why and wherefore of the action of Aconite upon the circulatory system, we satisfy ourselves with the broad and possibly very unscientific adrice that horsemen who know nothing from a professional standpoint of drug action, can certainly never do wrong by administering a few drops of Aconite, whatever may be the peculiar morbid condition where the heart is affected, watch the result, and if not satisfactory, resort can then be had to other remedies according to the symptoms indicated; but we shall not err on the side of caution if we suggest some of the more leading symptoms indicating the selection of Aconite, or its active principle Aconitine; the association of acute rheumation (the symptoms for which 
must be looked for in the chapter on that disease), always connects Aconite with diseases of the heart; when the impulse of the heart is increased and the pulse at the jaw is full, bounding and rapid the same conclusion is arrived at; exhaustion and distress accompanied by palpitation point to Aconite; it will be thus seen that the conditions vary, but the drug is a far-reaching one and at the same time an exceedingly reliable friend in circumstances of extreme urgency.

Actaa racemosa Ix. - In breeding establishments or in stables where mares are kept, this is a valuable remedy because of the intimate relation which seem to exist between it and the female system; it is well-known that a remarkable sympathy exists at times between the uterus (womb) and the heart; take a mare that is with foal or has recently had a foal, or one in work whose sexual desires have been excited, and she becomes the subject of an attack of rheumatism; it is no uncommon thing for these two organs, the uterus and the heart to be the two chief seats upon which the poison of rheumatism expends its force; its influence upon the heart may be recognized by the outward manifestations already so many times referred to; should the uterus be also implicated the mare will give evidence of pain by turning her head to the side, prostrating herself for a stretch with the hind legs, uneasiness, unwillingness to lie down, the urine will be highcolored and diminished in quantity, together with the ordinary febrile symptoms indicated under rheumatism, when this remedy may be relied upon to afford relief.

Arsenicum album 3x. - While Aconite appears to act upon the blood and through it, upon the circulation generally, Arsenic would seem to act directly upon the principal organ of the system, having the power to inflame not only the muscular tissue but also the endocardium (or internal lining membrane) and therefore also the valves; special symptoms indicating its selection may include extreme systemic prostration; a tendency to faint after exertion; feebleness of the heart's action; pulse almost imperceptible: palpitation, difficulty of breathing; dropsy as indicated by swelling along under part of chest and abdomen, with the legs.

Cactus grandiflonus Ix.-By some authorities the palm is given to this drug over Aconite in heart diseases; certainly from the experience of those well qualified to offer an opinion, it deserves to 
rank very high in cardiac disorders; and from some slight experience of its use, we can confirm the high estimate formed of the drug by those who have submitted it to more crucial tests than we have had the opportunity of doing; so far in our cases the febrile symptoms were very pronounced, shivering and sweating alternating with one another; the animals hang their heads down as though heavy and aching; considerable palpitation and short, oppressive breathing were very marked; there was some diarrhœea, and a good deal of thick-looking urine passed; Aconite had been previously given in each case, but was not followed with the usually-expected result, while to Cactus grnnd. all the symptoms yielded readily and the normal action of the heart was restored. In Dr. Hughes' Pharmacodynamics the drug is credited with the exercise of beneficial influence upon diseases ranging from nervous palpitation to inflammation of the organ, hypertrophy and valvular disease; and we have no doubt that Dr. Hughes only claims for Cactus grand. what it is quite capable of realizing under specific conditions; these facts, coming from such an authority, and in some small degree confirmed in our own experience, only serve to intensify the faith we entertain that given the discovery of the toiality of the symptoms there is absolutely no morbid condition affecting the animal system (human or otherwise) that would not yield to a homœopathically-selected drug; the fact that there are so many failures to effect cures, in what some consider incurable cases, owes its existence both in medical and veterinary practice to the non-recognition of the totality of symptoms, or to belief that the changes of structure that take place in some organs by reason of the invasion of inflammation, are not capable of restoration to either their normal condition or their original utility; our faith only demands the discovery and recognition of the totality of the symptoms to enable drugs to effect anything in the shape of restoration to health and usefulness.

Digitalis Ix.- Irregular and intermittent pulse as observed at the artery that winds round the under jaw; regurgitation in the jugular veins; dropsy, as evinced by swelling of the legs, may be accepted as the leading indications for this drug.

Spigelia $\mathrm{Ix}$. - A most helpful remedy in cardiac affections associated with rheumatism; moreover, it includes within the sphere 
of its action, the pericardium (or the membrane that clothes the heart externally) and the eyes; when the symptoms which draw attention to the heart are also accompanied by a weakness of the eyes, as evidenced by a desire to avoid light, and the whites of the eyes are shot with red lines, a suggestion is before one to resort to Spigelia; and should the patient be weak, thin and lifeless, another reason will be added for its selection; a capricious appetite, constipated bowels, rough coat, and general dullness are included in the symptomatology.

Spongia $6 \mathrm{x}$.- This is an essentially useful drug when the valves of the heart are affected; the associated symptoms are a rough, husky cough, painful palpitation, extreme difficulty in breathing, with intermittent periods of apparent suffocation, during which the horse will stand with forelegs wide apart, tottering at the knees, as though he would fall; after a while this passes off to be repeated again in a less intense form. 


\section{ATROPHY OR WASTING.}

\section{FATTY DEGENERATION OF HEAR'T.}

The wasting of the muscular walls of the heart, it goes without saying, ultimately results in a loss of substance, and a general thinning, which of course, renders them quite incapable of performing their functions; it does not follow that the whole of the organ shall become affected at the same time, and if one part is more frequently implicated than another it is the auricles or upper divisions of the heart. Weakness and feeble pulse are the most characteristic symptoms, but it cannot be affirmed that these in any way help the layman to discern the cause.

Fatty degeneration of the muscular tissues involves an entire change in the structure of the organ; the fibres which constitute healthy muscle are softened and rendered incapable of strong contractile power, by reason of the deposition of fat between the layers of muscle, and in some extreme cases the muscular fibres themselves appear to assume the appearance and qualities of fat.

For both these conditions Allopathy knows no remedy; and inasmuch as diagnostic symptoms are conspicuous by their absence there is not much chance for Homœopathy; but if other indications point to the remedy it is believed that Phosphorus $\frac{1}{5} \frac{1}{0} 0$ administered twice daily may ultimately arrest the destructive process, if it does not absolutely aid in restoring the tissues to their healthy normal condition. Much of course will depend upon the stage at which the disease process has arrived.

\section{ARTERIES.}

The disease conditions affecting arteries are of two kinds, the one known as Embolism, which is due to the formation of a clot that plugs up the artery and interferes with the proper circulation of the blood; the other as Aneurism by which is understood that the walls of the artery have become diseased and expand over a small surface so as to form a tumor; this may arise of itself from 
some unexplained cause or originate from an injury, the coats of the artery become thickened and sometimes calcified (or hardened by a deposit of mineral substance.).

It is not an uncommon disease in the horse, as post-mortem examinations aid one to testify, and when present it is generally observed in the aorta, or large artery, at the point where a branch is given off called the mesenteric artery.

The symptoms are not positively indicative, but when a horse becomes thin, emaciated and unequal to work; breathes hurriedly; pulse is irregular, and great stiffness when called upon to turn round is exhibited together with tenderness to pressure over the loins, and the hind legs swell constantly, there is good reason to suspect this condition.

As a rule it does not declare itself sufficiently for recognition until well established, hence the greater difficulty in effecting a cure; but it is not without hope of alleviating the condition if Lycopodium 3x be administered three times a day, and the horse be allowed meanwhile to rest in a roomy, loose box.

\section{PHLEBITIS ; INFLAMMATION OF VEINS}

is not a condition often met with in the horse; it rarely arises without some external cause, mechanical injury, such as bleeding; as however this operation is of comparatively rare occurrence nowa-days it is more than ever rare; should it however be met with there is one condition that requires some care to obviate, namely, ulceration, which of course involves the formation of pus (matter); this becomes serious when the pus is carried into the general circulation away from the seat of origin, which is most likely to be the case, as its distribution will probably give rise to the formation of abscesses in various parts of the body, and the ultimate sequel would be blood poisoning. An inflamed condition of the veins is recognized by dilatation of the vessels, and the locality where they most readily expose themselves to observation is the inside of the hind legs; swollen veins are distinguished from arteries, in a like condition, by their being nore superficially placed, and the knotted enlargement or pouches which are presented at varying distances along the course of the swollen vessel; the knots are due to the arrest of the blood at the points where the valves are situated. 
TREATMENT.-Hamamelis $\theta$. This is the one and only remedy we shall suggest for use under such conditions; if the affected locality admits of topical treatment, compresses of this drug made by mixing one part thereof with four of water should be applied in addition to administering five-drop doses internally three times a day.

\section{HICCOUGH-SPASM OF DIAPHRAGM.}

In the first place it is necessary to explain that the diaphragm, which consists partly of muscle and partly of fibrous tissue, serves to divide the thorax from the abdomen; it is attached at its upper part to a ligament belonging to the vertebræ or spinal column, and each side of the margins of the ribs; at all events this roughly explains its situation and its object; under certain conditions this fibro-muscular membrane becomes cramped; horses that have been required to do fast work, in a long journey on an empty stomach are generally, the subject of the spasm; it has been frequently mistaken for palpitation of the heart, but it may always be distinguished from this by the fact that in spasm of the diaphragm the horse always suffers from hiccough, a condition which calls for no explanation; it is a marked and constant symptom.

TREATMENT. -The late Mr. James Moore, one of the pioneers of Veterinary Homœopathy in London, used to advise the administration of Stannum 6x for hiccough, and when one bears in mind the powerful influence this drug exercises over the nervous system, the explanation of this gentleman's success with this agent is not far to seek.

Nux moschata $3 \mathrm{x}$ is what we have been accustomed to rely upon for spasm of the diaphragm, but the cases that have come under our care have all had a marked bloated condition of the abdomen, as is observed in flatulent colic, a symptom that specially indicates this remedy, by reason of which the action of the heart and the breathing is rendered very oppressive.

ACCE:SORY MEASURES. - To aroid a possible recurrence of this malady, it is most desirable to give the horse a few days' rest; keep up the condition with good, but easily digestible food, avoiding bulky material, and bring the animal to its work again by degrees. 


\section{DISEASES OF DIGESTIVE SYSTEM.}

The digestive tract, which starts at the mouth and ends at the anus, may fairly be described as one long continuous tube which varies in size in different parts; commencing at the mouth it passes to the pharynx, which is also shared with the respiratory tract, as the back of the nose also empties itself into that organ; from the pharynx the tube is continued as the œsophagus, which passes down the neck side by side with the trachæa (or windpipe); the œsophagus is commonly known as the gullet; this joins the stomach, which is nothing more than a large dilatation of the digestive tube; passing out of the stomach the tube becomes very small, and there commence the smallest intestines; the intestines vary in size until some short distance before arriving at the anus (or external opening behind); a short distance from the commencement of the small intestines, not far from the stomach, there is a tube connected with and coming from the liver, which empties the contents of that organ (the bile) into the intestines; the bile assists in the digestion of the food; this small tube (or duct) which comes from the liver has also another tube which conveys the secretion of a gland called the pancreas and joins the duct of the liver before it enters the intestine; this gland secretes a fluid called the pacreatic juice, which also assists in the process of digestion. The process of digestion commences in the mouth, where by means of mastication the food is rendered fit to be acted upon by the saliva, the gastric juice which is formed in the stomach, the pancreatic juice and the bile, and finally the various secretions from the glands situate in the walls of the intestines; in plain language, the process of digestion is one of dissolving all the way along the tube, or of rendering solid food soluble, so that it may be taken up and transferred to its destination by means of the blood and other channels through which it passes while being distributed over the body for assimilation. 
This, of course, is but an extremely rough and ready explanation of what goes on in the system, and is offered with apologies for meagreness of description, at the same time, were we to attempt to offer anything like so elaborate an exposition of the subject as its importance demands, we should proceed beyond the ken of those for whom this book is written, and moreover far exceed the prescribed limits; our object is merely to convey a rough idea of the digestive organs and of what they consist, so that readers may the more readily follow us as we proceed to deal with various dișorders to which animals are subject in this portion of the organism. The diseases of the digestive tract are certainly more under control and capable of prevention on the part of stablemen and owners than are those of any other portion of the animal body; the character and quality of the food; the methods and time of giving it, are points which deserve far more careful consideration than they generally receive; for instance, while the better-bred animals, such as race-horses, trotters, and high-class harness horses are well provided for as to quality, it does not follow that necessary caution is exhibited by the attendants as to the methods and time of feeding and watering, having in view the nature of the work the horse has been doing, or the time occupied in its performance; on the other hand, take the coarser-bred animals, such as are worked on farms, or for hauling purposes in large torns; here the character and quality of the food is frequently very indifferent; they are expected to consume and dispose of all or any of the coarsest material, especially agricultural horses; at one time they may have to go for six hours at a stretch without any food, while at others the man will have a nosebag on almost continually, according to the particular work that is being done and the facilities it offers for this sort of thing; what wonder, then, if under conditions of such irregularity colic supervenes; ignorantly mistaken kindness at one time and careless indifference at another. All descriptions of horses, except the more carefully tended race-horse and trotter, are liable to be kept out many hours at the stretch, and to make up for this are, when brought home, immediately supplied with a blow-out of water, and food enough is placed before them to account for two or three ordinary meals; not only does the animal return home tired and leg weary, but his whole system is in sympathy with the exhausted muscles, and the vital energy is tempo- 
rarily lowered; under such conditions a short period of repose is as essential for the digestive organs as for the legs and body before calling upon thein for active work such as the process of digestion involves; under such circumstances the horse should be allowed two or three mouthfuls only of water, with about a double handful of hay to play with while being cleaned and dressed, and at the expiration of one hour an ordinary supply of water to be followed shortly by the usual feed of corn; in this way nature is gradually restored to her normal state and digestion will proceed in the ordinary course without fear of the dire consequences that frequently supervene upon the well-intentioned but very-injudicious methods referred to above.

It must therefore be understood by owners that it is a false economy to allow their horses, whatever the class or breed, any thing but good, sound, wholesome food, and further that if the very frequent cases of disorders affecting the intestines are to be obviated, it must be by the exercise of common sense and ordinary intelligence, in the manner of supplying the food, making due allowance when animals have been called to fast long and continuously, not to overload the stomach unduly thereafter, nor to lower the internal temperature suddenly by allowing a hot, fagged and thirsty animal to drink his fill immediately on arriving home; nor in the cases of heavy draught horses to sanction their being allowed to drink absolutely cold water while at work, and on a long journey; at such times a very necessary refresher should consist of a moderate quantity of warm thin oatmeal gruel; in offering these suggestions we fully sympathize with the difficulties against which owners have to contend through the carelessness and indifference of stupid servants. The subject of dietary is an all important one and calls for more careful discrimination than it generally receives; if one were to judge by the ordinary actions of horse owners and stablemen, it would be quite reasonable to come to the conclusion that the majority of these men look upon the digestive apparatus of this animal as a sort of metallic machine into which must be crammed to the full, whatever comes to hand in the shape of food, good, bad and indifferent, nevermind which, so long as the greatest quantity can be stowed away in the smallest space of time; this at all events used to be the prevailing idea; but thanks to the veterinary profession methods more in harmony with an intelli- 
gent appreciation of the laws of physiology are now adopted; still there is ample scope for improvement and were we writing a work upon hygiene, the subject would furnish abundant opportunity for the exercise of our best abilities; our present duty, however, is to point out how indiscretion may be rectified, and the subjects of indiscretion relieved of the sufferings they are compelled to uncomplainingly bear.

\section{THE TEETH.}

There are varions conditions affecting the teeth to which we might refer, but we shall confine ourselves to one or two which can readily be observed after careful examination by the novice, and that are easily capable of relief. It is largely necessary to point out how important it is that the teeth should be maintained in a condition that fits them for thorough mastication; this is their physiological function; it is the process or mechanical operation by which the alimentary material is prepared for the chemical action of the juices of the stomach and intestines, to act upon and render soluble; and this especially applies to animals, such as the horse, which feed on grain and vegetable products, which require minute subdivision before they are rendered susceptible to the action of the digestive juices. For the proper and satisfactory performance of the act of mastication it is essential that the surfaces of the crowns of the large molar teeth should be level so that those of the upper and lower jaws should meet or approximate together as nearly as possible. For various reasons due either to the character of the food or the quality of the different substances of which the teeth are composed, it frequently happens in horses over seven years of age that some of the teeth wear more than others and that consequently there are spaces left between some of them in which those of the upper and lower jaw do not meet properly and hence the mastication is imperfect or plugs of food are imbedded between the teeth; to obviate this condition, the rasp must be brought into action, or if one or two teeth have proved themselves equal to an extraordinary resistance of wear and are standing out prominently above the majority, they must be sacrificed by catting off their crowns to the level of the rest. Between the ages of three and four years young horses require special attention, as this period of dentition is frequently a trying 
one, and where difficulty is experienced in cutting through the permanent set, and dislodging the teinporary ones at the periods when the change ought to take place, much benefit will derive from the administration of Calcarea phosphorica $3 \times$ ten grains night and morning, so long as the difficulty lasts; not only will this treatment help to bring about a normal developement of the masticatory organs, but the general health of the animal which will probably have suffered as a consequence, will rapidly improve -an appreciation of this difficulty and the method of obviating the same should be understood, especially by owners of race horses who are probably greater sufferers from this condition than any other class of horse, which fact may be accounted for by the artificial forcing to which these animals are subjected from their earliest infancy. "Caries" (or decay) of teeth is a disorder that may affect any class of horse and though it may not be of frequent occurence, when present it must be as painful and quite as inconvenient to the horse as the human subject; horses are generally so patient and forebearing that they may for days be the subject of this pain without an attendant noticing anything amiss; ultimately, however, the animal goes off his food, or makes an attempt to masticate it, and drops portions of it only partially comminuted into the manger, this is called "guidding;" in the worst cases the horse will rest his head on the manger, against the side of the stall or rack; this is the time for a careful examination of the mouth and each individual tooth; a decayed tooth will generally exhibit some discoloration, even if no portion is broken away; to test these a few gentle taps with some instrument will enable the examiner to detect if there is pain and soreness, if so it is reasonable to assume that the faulty tooth is discovered and the treatment should consist. of Mercurius corrosivus $6 \mathrm{x}$, ten gr. every four hours, while the food should be given in small quantities and be rendered soft by steaming; bran and crushed oats in abundance without chaff or hay of any sort; if the pain appears to continue after one day's trial of Mercurius cor. it may possibly suggest the presence of an abscess at the root of the tooth in which case Silicea I 2, shunld be given; and even supposing there is no abscess, which almost invariably yields to a course of Silicea this remedy frequently proves successful in cases of caries where Mercurius cor. fails.

The remaining condition affecting teeth to which we shall refer 
is that of the presence of a space between any of the molars in which partly macerated portions of food get imbedded, and ultimately decompose, producing not only as bad a smell as a decayed tooth, but as the result of decomposition damage to the outer layer of enamel of each of the teeth against which it remains plugged; the pressure of this foreign substance, which, as mastication proceeds, is being continually added to, produces considerable pain and inconvenience; to obviate this difficulty, a piece of good quality gutta percha should be obtained, and after rendering the same perfectly soft and pliable by heat, the space should be packed with it so as to fill up the cavity level with the crowns of the teeth or nearly so; if a veterinary surgeon is not available, it would be better to call in the aid of a professional dentist to perform the operation; and here we must point out in passing that the only safe method of examining a horse's teęth that can be adopted is by the aid of a so-called "balling iron," which can be obtained and its mode of application explained at any veterinary instrument maker's. The extraction of a permanent molar is, under the most favorable circumstances and at the hands of an experienced surgeon, a most serious and formidable operation, and one that should never be attempted save under exceptional and pressing requirements, and then only by a qualified practitioner; of course, by the majority of allopathic veterinarians, the idea of relieving pain produced by a carious tooth, or of dispersing an abscess situate at the end of a fang by means of internal medication would be ridiculed as preposterous; nevertheless our experience among horses and dogs warrants us in affirming very positively that such results are attainable, and considering the hard character of the tissues of which teeth are composed, in numerical proportions far exceeding what the most sanguine advocates of Homœpathy could reasonably anticipate; furthermore, our experience on our own person, and on the persons of countless stablee men that have received most acceptable relief when suffering the agonies of toothache, confirms all that has been claimed for the treatment of animals under like conditions.

LAMPAS.

This common and well-known condition affecting the mucous membrane lining the mouth generally, is often made an excuse 
among stablemen, and especially horse dealers, for adopting the barbarous and cruel practice of burning the roof of the mouth with a searing iron or gashing and pricking the same with a horse nail. When we come to consider the real cause of the swelling, namely, congestion or an excess of blood to the parts, produced by dental irritation while the animal is cutting its teeth, or by stomach disorder, it will readily be seen that such brutal methods, the practice of which should be relegated to the dark ages, can do no earthly good; to produce pain to effect a good object is not only allowable but commendable; to wantonly cause pain without any reasonable prospect of advantage to a patient, is to deserve the practice of similar methods on the principle of "an eye for an eye and a tooth for a tooth," etc.

In most cases the swollen condition of the membrane is due to the two causes already enumerated and is displayed orer the roof of the mouth and the gums in the space betreen the incisor and molar teeth; at the same time it may be caused by violence, such as a sharp bit that has been applied with undue force; these cases rarely show much swelling of the roof of the mouth, and cannot therefore be strictly defined as lampas, but the membrane of the lips and cheeks is much tumefied.

TREATMENT.-Belladonna $3 \mathrm{x}$ for true cases of lampas in which the swelling is due to dental troubles and therefore generally occurring in young horses; a dose every four hours.

Nux vomica $3 \mathrm{x}$ in cases of lampas arising out of sympathy with some gastric (stomach) or intestinal trouble, such as simple indigestion; repeat dose three times a day.

Arnica mont. $3 \mathrm{x}$ when the swelling of the buccal membrane owes its origin to mechanical injury.

ACCESSORY MEASURES. - In all cases the animal must be put on soft diet; bran mashes and steamed oats that have been previousiy crushed; no hay, no chaff, nor indeed anything that demands active mastication; good strong linseed tea, made by slowly simmering one pound weight of linseed in a couple of gallons of water until the lot is reduced to one gallon by measure, will materially assist in keeping up the strength until the congested and sore state is ameliorated. Under no conditions, however, should food remain before a horse after it has partaken of as much as the appetite requires; any remnants should be removed and the man- 
ger washed out, as moistened food rapidly turns sour, taints the manger, and the animal continues to refuse its food, in consequence of the objectionable taste and smell imparted to it by the decomposition of previous unfinished meals. The chief symptoms t'iat direct attention to this state of the buccal membrane are, frothing and slavering, refusal to take dry food, and extreme tenderness of the mouth on attempting to examine, as evinced by a determined opposition to being handled. At these times the balling iron must never be used, as the interdental spaces between incisors and molars are swollen and highly sensitive to touch; gentle handling and coaxing will generally suffice far better than rougher proceedings when it is necessary to examine the mouth that is in this condition.

\section{GLOSSITIS-INFLAMMATION OF TONGUE.}

Under this heading it will be necessary to inclucie several conditions affecting the organ; in the first place we have idiopathic glossitis, which is an inflamed state of the structures of the organ that arises as the result of bad health and for which no external cause is responsible; this is not a common complaint with the horse; there is, however, an inflamed state of the horse's tongue that is by no means uncommon, we regret to say, because it owes its origin to injury effected either by carelessness or actual brutalityon the part of an attendant; the organ may be abraded, torn or cut by being carelessly included in the halter when this is used instead of a proper bit, to lead a horse; again, the tongue may be accidentally bitten by the animal itself; or it may be wilfully and maliciously injured by caustic agents, such as Ammonia and Turpentine.

It is of course necessary to determine what is the cause of the inflammation before attempting to treat it; this is not so difficult as at first sight it may seem: in primary glossitis, or that from which develops of itself and is the evidence of bad health, the organ is swollen, painful, but when protruded out of the mouth the exposed parts are dry and brown; the animal is unable to swallow, and a good deal of sticky mucus adheres to the side of the cheek and about the teeth. When the tongue is inflamed by means of irritating caustic agents or by hot water, the organ is very much swollen and hangs out of the mouth; but the 
part that is exposed instead of looking brown and dry, has rather a whitish appearance and portions of the mucous membrane will peel off and hang in shreds; the membrane may be dry but more often it is covered with thinish mucus, and the animal continues slavering-an injured tongue of course declares itself. In the case of the natural primary form of glossitis, Mercurius cor. $3 \mathrm{x}$ is an excellent remedy administered in frequent doses, say once every three hours; the horse should be induced to gargle his mouth voluntarily, if possible, in a weak, warm lotion of Condy's Fluid, just sufficient being used to color the water a rich magenta shade; if the animal will not do this of his own free will, then the mouth should be freely syringed out with this lotion two or three times a day, to keep it clean of the adhesive mucus and to disinfect the organ. In cases that have been injured by some caustic agent a cooling lotion, consisting of one part of common vinegar with two of water, serves to counteract the chemical action of an alkali and is also very acceptable to the patient; after some relief is obtained, the healing of the injured parts will be much facilitated by painting the organ by means of a camel's hair brush with a lotion consisting of Calendula I part, Glycerine 2 parts and water 3 parts.

In the cases of glossitis which owe their origin to injuries much depends upon the nature and extent of same; should the organ be much torn it may be necessary to invoke the aid of a surgeon; if a veterinarian is not available it would be wise policy to seek to induce a medical man to do what he can by way of suturing and to advise the most desirable antiseptic dressing; the operation is too delicate a one for a layman to attempt; conservative surgery is an absolute necessity in dealing with the tongue; for ordinary cases of injury the dressing should consist of a lotion of Arnicx $\theta$ I part, Glycerine 2 parts and water 6 parts, with which the tongue must be frequently dressed.

The food must, of course, consist of soft mashes and scalded oats previously crushed; no hay or claff; liquids would be better if nutritious, such as linseed tea, milk, etc.

\section{PAROTITIS-INFLAMMATION OF PAROTID GLANDS.}

These glands are located behind the inferior maxillary jaw bone extending from the bottom of the ears downwards; in some horses, 
especially coarsely-bred animals, they are very distinctly observed, and in many respects the results of inflammation are very much like those of strangles, with this difference only, that the glands are situated in another locality; indeed, at times the parotid glands are sympathetically affected in cases of strangles; the parotid glands; on either side of the head, are rather large in size, and it often happens that the suppuration which follows their inflammation does not affect the whole gland, but only a part, and for this reason the process is frequently a slow one. At other times no suppuration takes place at all; the gland becomes very hard at the onset, and thereafter softens without the formation of an abscess and the discharge of matter. The symptoms are that the horse is unable to more its head freely from side to side; there is a good deal of swelling and pain over the seat of the glands; and not infrequently the pressure upon the larynx in consequence of the strelling of the glands on either side of this organ produces an unnatural sound in breathing. When the inflammation proceeds to suppuration the locality of discharge shows itself by pointing or swelling in various parts of the gland or glands; these, of course, require poulticing and fomenting with hot water in bringing them to a head; as a rule they burst spontaneously; if not, some surgical aid is called for. To induce the rapid maturition or perfection of the abscess there is nothing like Hepar sulphur $3 \mathrm{x}$, ten grains every four hours, and after the abscess is discharged, to promote healing, Silicea $6 \mathbf{x}$, three times a day, is the best practice. The parotid gland, to which we have been referring, has for its function the secretion of saliva to aid the process of digestion; for the convenient discharge of the saliva into the mouth, so that it can readily mix with the food as mastication goes on, a small duct (or tube) connected with the lower portion of the gland, about the size of a small quill pen, passes along the side of each cheek and there empties itself. Occasionally these ducts are blocked up by small, round or oval calculi (or stones) which consist mainly of lime, and for the well-being of the horse it is necessary that, when present, they should be remored; this operation necessitates the service of a skilled surgeon; the presence of these calculi will be discernible by the swelling they produce, and the hardness of the substance.

An ascident occasionally brings about the establishment of a 
pipe-like opening (fistula) from the parotid duct, through the little salivary canal having been pierced or wounded; when this is the case, the saliva continues to pour out externally so long as mastication proceeds, and is consequently wasted. These cases are frequently somewhat difficult to cure, but to effect a union of the adjacent parts, the edges of the wound may be lightly dressed with Nitrate of silver, and thereafter an adhesive plaster placed right over the part; the horse must be kept for some days on liquid nutriment to obviate the necessity of mastication, and so keep the gland in a state of quiescence; milk, beef tea and linseed gruel may be tried with probable success; the horse should be tied up short at the rack to prevent it from eating its bed and also from keeping the head in a dependent position; nor should the animal be allowed to lie down for several days until the plaster is removed.

\section{PHARYNGITIS-INFLAMMATION OF PHARYNX- SORE THROAT.}

This condition is usually first declared by a cough, but so far as the distinguishing characteristics go, they are by no means easy to define; some are hoarse, rough, and short, others soft, weak, and prolonged, according to the extent of the inflammation and how long it has existed; one of the most reliable indications is the amount of soreness displayed on handling the throat externally, and also the extent of redness exhibited about the throat at the back of the tongue, and in the region of the tonsils; inflammation of the pharynx does often occur in conjunction with influenza, or any fever in which the air passages are involved, but at the present we are considering it as the primary disease in which sore throat is the most pronounced symptom: of this leading indication we have minor or detailed symptoms such as difficulty of swallowing; the effort to swallow food brings on a cough; the same applies to liquids, which are sometimes returned through the nose; at others the difficulty of swallowing saliva is apparent by the fact of the horse every now and again drawing his nose in towards his chin, just as a man would under similar circumstances, while partaking of food or water produces no sensation of pain; it is really nothing more nor less than a sore throat, but the remedy for this is not always easy to hit off; the totality of the symp- 
toms are comparatively few. One of the finest agents for curing this congested condition of the pharynx is Sulphurous acid inhaled for some moments, until the effect of the acid is felt upon the mucous membrane lining the pharynx; certainly it produces an active fit of coughing at the time, but the alleviation thereafter of the soreness and fullness is simply remarkable; the only way that can be suggested for its administration to the horse would be to close up the apertures in a loose box, set fire to a charcoal caldron over which a small quantity of powdered Sulphur must be sprinkled; as the fumes are given off the horse will begin to cough more or less violently, and after the animal has been compelled to breathe this sulphurous atmosphere for three or four minutes, the stable door should be opened and the heated caldron be removed; it is only necessary that the horse should inhale sufficient of the fumes to act upon the whole of the mucous membrane of the throat; it is a cheap and effective remedy for this sort of thing, but of course care must be exercised not to stifle the animal with an excess of the Sulphurous acid gas.

Apart from this, other remedies are Aconite 3x, Belladonna 3x, Mercurius solubilis 5, and Lachesis 5.-Aconite in the early stages; Belladonna when the throat is very bright red, the eyes are glistening and pupils dilated; Mercurius sol. when there is a great deal of saliva dropping from the mouth, and Lachesis when the animal is dull after several days' treatment, and the temperature goes up, which symptoms indicate complications calling for special remedial measures.

Inflammation of the pharynx, if allowed to get a regular hold upon the structures of the throat not infrequently results in the formation of abscesses; these circumscribed collections of matter (pus) are found in the muscular walls of the pharynx and by reason of their size, just prior to discharge, cause considerable inconvenience in consequence of the obstruction offered to breathing; in some cases the external swelling, on one or both sides of the throat, is sufficient to draw attention to their presence, in which circumstances manipulation of the parts generally reveals marked tenderness; but should the external swelling not be observed, attention will be drawn to the horse by the difficulty experienced in breathing and swallowing, and by the continuous formation of saliva which drips from the mouth in tenacious 
strings; this discovery should lead the careful stableman to examine the throat internally, and should the swelling appear likely to cause grave results, it may be necessary to open and discharge the abscess; on the other hand, this necessity will not frequently arise, as the administration of the homøopathic remedies which exercise a special influence on suppuration, usually mature and ripen abscesses, wherever located, with considerable rapidity and these burst and discharge naturally without the necessity for operative intervention.

TREATMENT.-Belladonna $3 \mathrm{x}$ in the earlier stages while the mucous membrane of the throat looks bright red and dry; soreness and difficulty of swallowing are very apparent; the eyes also are frequently streaked with red lines over the white portion; the body temperature is exalted and the pulse more rapid than normal; under such conditions the remedy will frequently abort the inflammation and prevent the development of suppuration.

Hepar sulphur $3 \mathrm{x}$ when the swelling in the throat is thoroughly established and it is quite clear that the formation of pus has commenced, this agent will aid in the rapid maturation and ripening of the abscess.

ACCESSORY MEASURES. - Much assistance may be afforded by making the horse inhale hot steam; a nose bag containing bran or finely cut chaff should be attached to the head; thereupon pour sufficient boiling water to saturate the contents of the bag, then throw a rug over the horse's head to keep the steam from evaporating too rapidly.

\section{CESOPHAGUS-GULLET.}

The diseases affecting the gullet are rare in the horse, indeed, so rare that beyond referring to ordinary inflammation of the œsophageal tube, it is not necessary to mention them; but the tube may suffer from mechanical injury, either as the result of external violence or through swallowing food that is not sufficiently broken up or macerated, such as a piece of carrot or turnip; the consequence of such an occurrence may lead up to a dilatation of the gullet, which, of course, will be chiefly observable during the period that a horse is eating or drinking, as the the dilated portion of the canal becomes extra distended at this time; the probability of doing much good under such circum- 
stances is decidedly small; some advantage might possibly accrue from repeatedly blistering the surface of the skin over the dilatation, or from a light application of the actual cautery (firing iron) over the same. By some such a prescription will doubtless prove curious reading in a homœopathic work, but it is strictly in accordance with the principle. Inflammation is probably the cause of the dilatation, therefore produce inflammation to cure it; we shall have cause to refer to this subject under some forms of lameness in which nothing but the firing iron is of the slightest use, therefore will not dilate upon it here beyond affirming our belief in its utility under such conditions; the inflammation set up by the firing iron will cause the dilated muscular wall to contract and so do away with the distention. If the dilatation is not too large and of long standing, continued pressure for a considerable period will sometimes affect the desired object, but the inconvenience to the animal of such an application would be much more serious than the temporary pain inflicted by the cautery, and would not prove so effectual.

If a horse swallows something that will not pass into the stomach because it is too large to do so, and becomes fixed in the gullet, which is occasionally experienced with a greedy feeder, the swelling will be plainly visible; if not so by reason of the obstruction being in a portion of the œesophagus that is not exposed to ocular demonstration, the horse refuses food, slavers at the mouth; if he drinks, the liquid returns through the nose; spasmodic contraction of the muscles of the neck will be observable, and the animal keeps on making futile efforts at swallowing; the easiest method of getting over this difficulty is to pass the instrument called the probang down the gullet until the obstruction is met with, when great care is called for lest the mucous membrane be injured or the muscular walls are ruptured; the probang should be well oiled, and firm but gentle pressure used to move on the obstacle; if possible this should be entrusted to a veterinary surgeon, as the removal of a foreign agent from such a position demands great care and some experience.

\section{GASTRITIS-INFLAMMATION OF STOMACH.}

We now come to consider the various disorders affecting the first important natural dilatation of the digestive tube, the stomach; 
this organ is endowed with a special qualification that enables it to produce a secretion in the form of a fluid which acts upon the food, (after it has been prepared in the mouth by means of mastication with the teeth and softening with the saliva), as a solvent to render it fit to pass on into the intestines where the process of digestion is completed and the alimentary material is rendered fit for absorption and assimilation. As this organ has such important functions to perform, there need be little wonder, if unnatural liberties are taken with it, that it should be the seat of various disorders. Considering the size of the animal, and comparing the horse with the ox and other classes of animals, the size of the stomach in the equine division or order is remarkably small; but undoubtedly compensation is made in the extra development of the colon or large intestine, as compared with other classes of animals, a very interesting fact which doubtless is explained in some measure by the digestive processes peculiar to the equine race; nevertheless while physiology helps to clear up these remarkably interesting differences in the development of the digestive tract in various classes of animals, it also directs the attention of the pathologist and therapeutist to those organs which demand special consideration from the respective points of view of these scientists; the stomach of the horse has proved a stumbling block to the veterinarian in more ways than one, and depend upon it the organ demands a more careful and intelligent study than it has yet received at the hands of members of the profession, if the horse is to be kept in health, and to be saved very much of the suffering which countless numbers undergo from sheer ignorance of the subject, and a want of appreciation of its importance; there are probably no disorders that are productive of anything like so much pain and suffering among horses as are those of the stomach and intestines and undoubtedly more horses fall victins thereto than to all the other diseases to which they are susceptible or liable put together; it is tierefore a matter of the first importance, in the interest of horse ow:1ers, that this part of our subject should be fully dealt with and intelligently studied. Primary infannmation of the stomach is not often net with in the horse, but consequent upon unwise and indiscreet dicting, the stomach may become impacted with a solid mass of alimentary material or be distended by gas which ultimately results in irritation that 
produces inflammation of the organ itself or of the mucous membrane that lines its walls, and is so intimately connected with the physiological process of gastric juice secretion. Again, injury from foreign substances present in the food readily sets up inflammation in this always delicate organ, and poisonous agents such as Arsenic, sometimes indiscreetly used by a stableman in the hope of producing a glossy coat, or Mercury and Lead accidentally taken into the system, will each set up in its turn more or less inflammation in the organ. While not infrequently horses experience no little damage, when turned out to grass, through partaking of some poisonous herb or tree, such as the yew for instance. Having in view the fact that there are so many causes that may produce this dangerous condition, it is all the more unsatisfactory that the special symptoms of each are not more marked and recognizable, because, of course, when produced by poisons the antidote is the first thing to be administered; unfortunately, however, we are compelled to own that recognition is by no means easy and in many cases absolutely impossible until after death; there are, however, one or two suggestive differences which may in some slight degree help to furnish a clue to the best course of action to be adopted under such circumstances.

Vegetable poisons exercise a marked influence upon the brain and nervous system generally, producing at one time violent convulsions at another stupor and coma, this may probably be followed by paralysis affecting the organs of locomotion or interference with the co-ordination of movement in the limbs; the eyes at one period evince a wild look at another are heavy and sleepy, the breathing is hurried, urgent and intermittent.

Poisoning by minerals is recognizable from the fact that the whole of the force of the drugs seems to be centred upon the stomach and the intestines; this is evinced by pain about the abdomen, the horse directing his attention to that part of the body where he suffers most; a horse does not so often roll as in ordinary colic, but paws the ground and otherwise evinces discomfort and irritation by marching about the box if loose: the respiration and pulse are abnormally hurried, and the heart beat is hard; the animal has a generally anxious and wearisome sort of expression on the face, while sweat breaks out over different parts of the body. 
Nausea is apparent by a complete loss of appetite; and should the poison have been Arsenic thirst is notable for its contancy, while the animal partakes of a few sips at a time; with some other minerals the thirst demands a large quantity at a time but partaken of seldom for its slaking. After awhile the pulse becomes weaker and almost imperceptible; the fœces loose, attended in discharge with much straining; the legs and extremities generally become deathly cold and sweat is general over the whole body. When the poison belongs to minerals of the mercurial order, salivation is a peculiarly marked feature, while in copper the muscles are subject to spasms; the internal temperature sinks below the normal, and there is general loss of power. If the source of the poison and the nature of the agent that has been partaken of can be discovered, the selection of an antidote is a simple matter. For Mercurials and Copper, white of egg and milk; for Arsenic, Peroxide of iron; for Lead, Epsom salts; for the yew tree, Camphor; for Ammonia and other Alkaline agents dilute acid as vinegar or lemon juice, and for acids dilute Alkali such as Ammonia, a very small quantity to plenty of water. By way of nutriment at such times, all solids must absolutely be dispensed with for many days, and nutritious mucilaginous drinks, such as milk, linseed gruel, barley water, thin arrow root, etc., provided instead.

Inflammation of the stomach, as a primary disorder, rarely presents itself in the horse; but as has already been stated, among other causes an overloaded or impacted condition will set up inflammation of the organ; at the same time the animal will probably experience considerable pain and inconvenience long before inflammation of either the muscular walls or simply the mucous membrane lining them is established, and the point which the stableman has to determine so far as he can is whether the pain the horse evinces is due to an overloaded state of the stomach or to ordinary colic affecting the intestines; when in consequence of a ravenous appetite or partaking of coarse, indigestible, unsuitable food, the stomach is filled to bursting, the process of digestion is arrested and the alimentary material does not pass on, symptoms very similar to those already quoted will present themselves; such as, pawing with the fore-feet attempt at vomition accompanied by an escape of gas through the month or nose; pain evinced by the horse turning its 
head frequently to the side; trembling and shaking of the muscles of the neck and limbs; partial sweating, particularly about the neck; extra secretion of saliva which escapes from the mouth in abundance, pulse hard, wiry and frequent; the expression of the countenance very haggard; horse rarely attempts to lie down as in colic, indeed, seems afraid to do so; the matter of first importance under such circumstances is to restore to the stomach, which has lost all nervous and muscular energy, - hence the reason the food has become impacted-its healthy tone; through being called upon to do too much at once, the coats of the organ are wearied out, they refuse to respond to the nervous stimulus; the pyloric orifice which opens into the small intestines is closed, the food that ought to pass on for further digestion is retained and the viscus is now more than replete with alimentary material; what is to be done? ordinary practice would suggest an aloetic purge, but what is the use of that? Aloes act upon the intestines almost exclusively; we have to deal with the stomach which is already so full that nothing will pass out of it; therefore, what good will aloes do; absolutely none!

What is required is a remedy that will give tone and impart renewed vigour to the muscular wall of the stomach, so that the pyloric orifice will open and the contents of the organ be passed on after saturation with gastric juice, into the intestines, and there is no drug better calculated or more likely to effect this than $N u x$ vomica $\mathrm{IX}$, of which ten drops in half a wineglassful of water should be given, and the dose repeated every half hour until relief is obtained.

In those cases where the gastritis is the primary disease and presents itself in the acute form, the symptoms are much like those already enumerated, and the question at once arises how are the two forms to be recognized and distinguished; it is somewhat difficult but the careful horseman ought to know whether the animal has had an opportunity of over-filling the stomach with either digestible or indigestible material; apart from that, the symptoms also include, with these already suggested some soreness of the throat, a swollen and an infiltrated condition of the eyelids; the animal may also be observed licking the walls of the box, and grinding his teeth together; the point of the tongue is red but the 
flat part of the body of that organ is dirty, white and covered with mucus.

TREATMENT. - Kali bichromicum 3x. - This is a famous remedy for many troublesome cases; the peculiar condition suggesting its selection is best recognized when the coating of the tongue is yellow, and the surface thereunder, after cleaning off, very red; further, when diarrhœa is present some remarkable cures have been effected.

Belladonna $3 \mathrm{x}$ when complicated with a sore throat, swollen condition of the eyes and discharge therefrom.

Mercurius cor $3 \mathrm{x}$ when salivation is a proninent symptom, in conjunction with sore throat and gums; breath very fœtid.

Antimonium crudum $3 \mathrm{x}$ when the eructation of gas is a prominent symptom and the tongue is thickly coated with a white covering.

Arsenicum album $3 \mathrm{x}$ when the animal becomes impoverished and thin; the breath and excretions offensive; the legs swell and the fever rises; thirst, a little water and often, is a marked indication.

Nux vomica $3 \mathrm{x}$ is such an important stomach medicine that any affection of the organ is almost certain to furnish a number of symptoms for which at one time or another this remedy is indicated; those suggestive of its selection are chiefly: loss of appetite; depression of spirits; constipation, fæces being hard and coated with slime; frequent evidence of a desire to pass dung, with some difficulty in effecting the function; pulse small, rapid and thin; tongue red at sides and coated with yellow slime on the surface; internal temperature elevated to $\mathrm{IO}_{3}$ degrees or IO4 degrees; pain attested by considerable restlessness.

Phosphorus $\frac{1}{500}$ is a remedy that proves useful in chronic cases of gastritis, where the disease has been hanging about for a considerable period; the most suggestive symptoms are vomiting, flatulence, hunger that cannot be appeased, dysentery and constant straining, the fæces being coated with mucus, blood and slime, wasting and continuous fever.

\section{INDIGESTION-DYSPEPSIA.}

Indigestion, like many other diseases, assu1nes two forms, acute and chronic; the latter is generally a sequel of the former; acute 
indigestion is brought on in the first place by overloading the stomach beyond its capacity with nutritious food, or by over repletion with material of inferior quality; it has already been pointed out in a previous chapter, that errors are frequently committed by stablemen, when by way of compensating for many hours of abstinence large quantities of food are put before a horse, under the impression that extra work calls for an increase of food supply; but we take this opportunity to again point out that at such times the digestive functions, like all the vital powers are wearied, depressed and unequal to extra work; that at such times and under such circumstances great care and circumspection should be exercised to avoid the untoward consequences which so frequently follow well-intentioned but injudicious management of this kind; at such times a horse necessarily feels faint and hungry and unless a higher intelligence is brought to bear regulating the amount of food to be partaken of, will eat voraciously, overload the stomach to such an extent that the function of digestion will be arrested and distension follows as a natural consequence; the result is pain, evinced by constant pawing with the fore feet; the food instead of digesting ferments in the viscus and large quantities of gas are formed, when the horse protrudes his head and makes efforts at eructation, sometimes accompanied by vomition of fluid material through the nasal passages; as the pain becomes more severe, the animal will throw itself down with violence and roll about in too evident agony, occasionally resting on the breast bone, with both fore legs bent into position as though it intended to rise; great anxiety will be apparent in the countenance, with considerable though partial sweats over the neck and body. If the stomach is not relieved by a discharge of its contents, the animal becomes sympathetically affected in the brain, stupor and partial unconsciousness supervening, as is indicated by the hanging down of its head or pressing the same against the wall; a loss of control over the powers of movement is also evinced and the pulse is full and resistant; this condition represents what used to be described as STOMACH STAGGERS.

The acute cases of indigestion in which prompt action for relief is called for are much rarer than the chronic form of the disease, which comes on as the result of injudicious feeding, and mild forms of engorgment which the animal manages to get over with- 
out experiencing the more formidable symptoms just enumerated; or again by an unhealthy condition of the mucous membrane and glands of the stomach, in consequence of which the gastric and other secretions are wanting in quantity or quality; such cases as these develop gradually and in such a manner as to render it difficult to recognize the real cause of the disorder; the attention is first drawn to the unthriftiness of the horse's coat, the appetite is capricious; the animal loses condition and has a tucked-up appearance; a very little exertion causes profuse sweating; the dung is very irregular in consistence, at one time voided in hard, blackish lumps and at another soft, coated with mucus and very offensive to the smell; the food, especially oats, passes whole and undigested; the urine is scanty and high colored or deposits a white sediment; the horse evinces also a depraved appetite by eating dirty, soiled bedding, and licking lime washed walls or picking up gravel off the road; the latter practices are very suggestive of a CRIB BITER and WiND SUCKER, especially when accompanied by acid eructations and unusual thirst; the opinions held by eminent veterinarians as to the cause of these troublesome and very bad habits are various, but we believe that they are invariably due in the first instance to chronic indigestion; the horse experiences these acid eructations, due probably to an unhealthy condition of the gastric secretion; what in the human subject is described as HEART-BURN is experienced by the animal and to obtain relief from the unpleasant sensation, it learns the habit of drawing in cool air which it endeavors to swallow with a view to alleviation; further, instinct teaches the animal that by firmly laying hold of some rigid structure such as a manger, the position attained produces a vacuum in the gullet down which the cool air rushes; as a natural sequence to this proceeding the stomach is overfilled with atmospheric air, and the animal, to obtain relief, endeavors to belch it up again; in consequence of this unnatural proceeding, which only affords temporary relief to the unpleasant burning sensation in the osoplagus (or gullet) the powers of digestion are still further impaired, the food is never properly assinilated, and hence the loss of flesh and condition. Having attached a good deal of blame to unwholesome and innutritious food as causes of gastric derangement, we must also draw attention to the fact that too much stimulating food, such as beans or other mem- 
bers of the leguminous order are not infrequently responsible for indigestion, inasmuch as they make too much demand upon the secreting powers of the viscus and impair the nervous energy, whereby the expulsive movement of the muscular walls is lost and the contents are not passed on as they should be.

The practice of giving horses cooked food is one that cannot be commended, and should only be resorted to under very exceptional circumstances, such as may be indicated in certain forms of illness; the objection is mainly that the animal is encouraged to swallow the food without mastication, without which, of course, little or no saliva is secreted, and the alimentary material is thus passed into the stomach devoid of that essential element in the digestive process; moreover the food is swallowed too rapidly and thus the stomach becomes overloaded and distended; the food instead of being softened by the saliva is rendered moist with a liquid that rather tends to counteract the action of the gastric juice and certainly dilute it, so that the material is rendered unfit to pass on to the intestines for the completion of the digestive process; it will thus be apparent that this also is conducive of indigestion and is a practice to be avoided. In young animals between the ages of two and four years, it should be remembered that the teeth may also be responsible for some cases of indigestion, as the food is not properly masticated but is swallowed in a condition quite unfit for gastric digestion, in consequence of these irregularities; the mouth should therefore be examined, and should it prove that dentition is backward or is not proceeding with ordinary healthy regularity the treatment must be directed towards the repairment of this difficulty, not so much by the extraction of the offending organs as by the administration of a remedy that will foster their normal maturation.

\section{RUPTURE OF THE STOMACH.}

This is a condition of affairs that admits of no alleviation either surgically or therapeutically and we include it in our list of ailments only to enable horsemen to detect the condition and so enable them to form conclusions as to possible hopes of recovery when cases of this description comes under notice.

By some veterinarians vomition is considered as a certain indication that rupture of the stomach has taken place, but this can- 
not be accepted as a positively reliable symptcm, as vomiting has been known to take place when the diapinragm or intestines have post mortem exhibited a rupture, while the stomach was intact; moreover the stomach has been found ruptured after death while during life no syruptoms of vomiting were presented.

The late Professor Robertson, whose experience mas very considerable, states in his "Equine Medicine" that "with regard to the relation of the symptoms of vomition or attempt at vomition, to the actual occurrence of the ruptures there has been considerable speculation and little certainty. Many have regarded the existence of the lesion as incompatible with any action of the organ approaching to what may be looked upon as vomition; that with the walls of the stomach torn, there could be no effort made for the ejectment of what material was contained in it, and that consequently the symptom of vomition, where existing, was always a symptom antecedent to the occurrence of the lesion. Of the correctness of this we are far from being satisfied; it proceeds upon assumptions we can scarcely admit, such as the necessity of a stomach ere vomition can be accomplished, the impossibility with a rent in its walls of pressure being exercised upon its contained materials, or of relaxation of its cardiac opening. To our mind these latter conditions will altogether depend upon the nature and extent of the rupture, and the relation of the viscus to other influences, nervous and muscular. The lesion can certainly be conceived of as being of such a character that its interference with forcible contraction of the muscular tissue and lessening of the capacity would not be obsolute and complete. While from observation made on many cases shortly previous to death, and immediately afterwards, there appears satisfactory evidence that rupture and escape of ingesta into the peritoneal cavity may exist sometimes antecedent to the exhibition of attempts at vomition. In some of these there has been ample evidence of inflammatory action consequent on the escape of contained material into the abdominal carity, and changes which could not possibly have occurred under a period of several hours, while not long prior to death we had attempts at vomition with ejection of material from the nose. Again it is equally certain that actual vomition has occurred during the sinple repletion and distension of the stonnach without any rupture of its walls, seeing that following the vomition and discharge of 
ingesta from the nostrils we have had perfect recovery of the animal. Thus while we do not appear to be in a position to give a distinct and incontrovertible opinion as to the exact relationship which the symptom of vomition or attempted vomition bears to rupture of the stomach, there is yet ample reason why we should as a general rule, particularly when this symptom is collateral with others, still continue to regard it as one of the most important." From the foregoing very valuable and important piece of reasoning, it will be seen that the late professor, while not placing implicit reliance upon vomition as symptomatic of a ruptured stomach, evidently considered it an important and suggestive indication; and to render some further aid in clearing up the symptomatology of this condition, we may add that when in conjunction with vomition, or attempted vomition, the following indications are present, it will be safe to conclude that little hope remains of saving the life of a horse under such circumstances; and the symptoms corroborative of this condition are: respirations gradually becomes weaker and the animal every now and again heares a deep sigh; the pulse becomes weaker and less frequent in the beat; the countenance assumes an anxious appearance; exhibits signs of pain and great uneasiness; the visible mucous membrane becomes pallid, the mouth and tongue cold and clammy; as death approaches the uneasiness ceases, the horse stands in one position, with head depressed apparently nearly unconscious, ultimately. drops and dies.

If there is a disinclination on the part of an orrner to put an end to the scene with-in this sort of case-the merciful bullet, then nothing remains but to render the last end comparatively easy by the subcutaneous injection of Morphia, that is to say, when it is quite clear no hope of betterment by medical treatment seems at all likely.

General Treatuent.-Hydrastis can. $\theta$. For dyspepsia or indigestion, this is one of the finest remedies in the pharmacopoia, and provided common caution is exercised to avoid improper diet, primary cases of indigestion will almost invariably yield to this agent, and the horse rapidly put on condition.

Arsenicum album $3 \mathrm{x}$ when attempts at vomition are made in the early stages, which are possibly due to an ulcerated condition of the mucous membrane of the stomach, and that, notrrithstand- 
ing the previous remarks anent vomition and ruptures, it is probable that this remedy would save the rupture, which, when it does occur, is sure to be present in a weak spot of the walls of the stomach, such as that where an ulcer has been present; should the horse be affected with any skin disease, other than one of those due to external parasites, this will serve as an additional indication for this remedy.

Carbo vegetabilis $3 \mathrm{x}$. This is a most useful remedy to check fermentation and allay that form of indigestion which is accompanied with acidity and flatulence; in cases where a horse has eaten voraciously, and distended the stomach to that extent that it is well nigh bursting, as indicated in symptomatology, the pure vegetable charcoal may with advantage be given, a tablespoonful being carefully mixed in a pint of water and administered; this will act mechanically by arresting the formation of gas from the fermenting material and as a "detergent of the mucous membrane" (Hughes). We have had several very satisfactory instances of cure by the aid of this remedy of chronic indigestion and have found it specially useful in the attenuated form-third decimal-in cases of crib biting and wind sucking. Further, we are able to confirm Dr. Hughes' symptom, that Carbo veg. is indicated in cases of flatulent dyspepsia attended with looseness of the bowels, rather than constipation.

Carbolic acid Ix. In view of the complicated and uncertain condition of things when vomiting is present, it is lighly important to test any remedies on the horse that have any power to produce vomiting, in the hope that a cure may be affected before a rupture of the stomach takes place; and in Carbolic acid we have such an agent. Vomition accompanied by the formation of gas in the stomach, as evidenced by the horse belching up wind through the gullet and frequently taking long breaths or siglinin, indicate this remedy. Should the urine be scanty, thick and albuminous and the eye lids be swollen and red confirmatory indications of its appropriateness are supplied.

Alumina 3x. We include this remedy in the list, as we once had an interesting case of chronic dyspepsia in an old linnter in whom a most satisfactory cure was effected. We were led to its selection by reason of the peculiar dryness of the freces and the presence of a hard, dry cough; it is specially useful in cases where 
the gastric juice is deficient, and we believe this was the case with our patient; he had been previously dosed ad nauseam with Aloes, but all to no purpose; a week's treatment with Alumina, two doses a day, served to effect a most satisfactory cure.

Kali bichromicum $3 \mathrm{x}$. Cases of chronic indigestion, attended with troublesome diarrhœa and the tongue coated with a yellow, fur which, if removed, leaves behind a raw surface, will generally yield to this drug.

Nux vomica 3x. No treatise on dyspepsia would be complete that did not include this remedy among its prescriptions; indeed, so great has the faith of sincere homœopathists been in " $N u x v o m$. for indigestion" that we have known cases-not a few-where disappointment has followed its use and some discredit brought upon Hahnemann's system in consequence of the blind faith put in this drug for all sorts of cases of indigestion; Nux vomica, like every other remedial agent, has its own field of operation, and the following may be accepted roughly as the symptoms which indicate its selection: Pain, accompanied by some distension; fæces hard and difficult of expulsion, frequent attempts to effect a passage with much straining; retching occasionally, but not necessarily, occurs; the animal becomes dull, heary and comatose; flatulence and acid-smelling eructations are observable; the back part of the tongue, only, is coated with fur; the horse absolutely refuses all kinds of food, nor is much water required.

\section{THE INTESTINES.}

Before attempting to describe the various disorders affecting this part of the digestive tract, we may with advantage explain how anatomists artificially divide the canal for the sake of distinction. The small intestines which commence at the opening out of the stomach called the pyloric orifice consist of three divisions; the first known as the duodenum which, as the horse stands, proceeds in an upward direction, over the rounded surface of the liver, supported by a mesh-like membrane called the omentum; the duodenum here receives the duct or tube which conveys the bile from the liver and the juice from the pancreas, both of which have been referred to as essential products for the completion of digestion; this tube enters the duodenum, about five or six inches from the pyloric opening; the duodenum then passes over the 
pancreas and here forms a curve round that organ, passes under the spinal column and terminates; the next portions of the intestines are the jejunum and ileum, which hang loosely in the fatty membrane called the mesentery terminating on the right side of the animal not far from the region of the kidneys at the ileo-cæcal valve, the latter provision (the valve) being evidently intended to prevent food passing back from the large to the small intestines; here commences the large intestines, which in the horse are very considerable and occupy by far the largest portion of the abdominal cavity; the cæcum is like an egg-shaped bag, the base of which is situate at the right side, extending forwards, though rather to the left, on the floor of the abdomen; it is sufficiently large to hold several gallons of water, from four to six, according to the size of the horse, and it is generally considered that the large draughts of water which horses sometimes consume, pass direct into this organ; if this conclusion be correct-and there is good reason to believe that it is -it points to the desirability of watering an animal before giving it any food, otherwise some portions of the undigested or only partly digested alimentary material may get washed into the cæcum, an organ which, unlike the small intestines, does not possess any glands capable of secreting digestive juices. At the point where the small intestine opens into the cæcum the large intestine known as the double colon commences at a junction described as the "cacum caput coli" ; after a short distance a large portion of intestine takes a turn and passes forward as far as the diaphragm on the right side; here it bends over to the left one, and then, after passing in a backward direction, turns once more at what is described as the sigmoid flexure; it proceeds yet again in a forward direction, then diverges to the left and blends itself into the single colon, which hangs loosely in the posterior portion of the abdomen and terminates in the rectum and anus. It will, from this description, be gleaned how extensive a surface the intestinal canal represents; and what with the muscular coats and the internal lining of mucous membrane of same, each of which is liable to get out of order, there is little wonder that the digestive tract of the horse presents opportunities for the development of painful conditions oft times resulting fatally; for, as has already been averred, the intestinal tract 
is too often treated, by those who ought to know better, as though it were a metal tube with neither sensibility nor susceptibility.

\section{INTESTINAL OBSTRUCTION.}

The title explains itself; the intestinal tract consists of a tube of variable size; the alimentary material has to pass along the whole length-probably forty feet or more-of this tube, some of which is withdrawn for nutrition and rebuilding of the system while the remainder is passed on and evacuated as solid fæcal matter. During the process an accumulation may easily be collected, either through an unhealthy condition of the mucous membrane; to which it adheres, or some other cause, and at this point the tube becomes blocked up; an obstruction is established. Yet again, an obstruction may be due to a displacement of the intestines, especially in those parts where they hang free and loose in the margins of the mesentery; one of the most common and frequently observed conditions of the intestines is a twist, in which the intestine becomes entangled in itself; another similar condition is observed through the mesentery being torn (the mesentery is a fibro-fatty membrane which is attached to the spine and to which the intestines are slung) and a portion of the intestines passing through the rent; in some mysterious manner the intestines form a loop and get tied into a knot. Once more, one part of the intestines passes within that which is continuous with it; this is known as intussusception or invagination. We shall presently deal with the condition known as colic, but it may be as well to state in passing that many cases which are considered in the first instance to be merely colic ultimately turn out to be twist, incarceration or intussusception of some portion of the intestines, while still another form of obstruction frequently met with is the presence of a calculus (or stone), which gets wedged into an opening where a large portion of the tube suddenly merges into one much smaller, as is the case when the double colon is continued by the single colon, and this is a very favorite spot for large calculi to become fixed and immovable. It will perhaps facilitate the better understanding of the matter if a short explanation be given how it is the alimentary material keeps moving along this tube; it must be remembered the muscular coat of the intestines consists of two layers; the outer layer consisting of fibres placed longitud- 
inally, and the inner layer of fibres placed transversely; by this arrangement the muscular contractions, which are brought about by a stimulus furnished from the nervous system, alternate, thus producing first an enlargement and then a contraction of the tube in consequence of which the alimentary contents are gradually pushed on; it should be observed, however, that these said contractions and dilatations of the tube proceed and follow one another like the waves of the sea and are not continuous from one end of the intestines to the other, as one movement; in this manner the food passes slowly and steadily along the digestive canal, meanwhile mingling with its secretions and being absorbed, as digestion is completed, through the various openings and bloodvessels of the lining mucous membrane. In dealing with these various forms of intestinal obstructions it may be as well to take that which, in certain places, occurs very frequently, namely the presence of a calculus (or stone); in our experience these intestinal concretions, which vary in consistence from material formed by the accumulation round a centre of undigestible provender to that which is as hard and brittle as a flint and also in bulk from the size of a small pebble to an ordinary cannon ball are found more often in horses belonging to millers and corn factors than anywhere else, and we attribute this to the probable fact, that bran is a staple commodity of food with owners of this class or trade; we could quote quite a number of instances, were it necessary, in proof of this opinion, in which after discontinuance of bran as an ordinary article of diet the presence of intestinal calculi never thereafter was discovered, and certainly no losses by death from this cause were experienced; inasmuch as bran contains or consists of a very large proportion of mineral matter, it is quite within the bounds of reason that the animal partaking of undue proportions of this diet should be unable to assimilate a chemical constituent of this character when the same was present in superabundant quantities, and it is not improbable that a hindrance to its evacuation might arise by reason of the chemical action of the intestinal secretions thereupon; hence the tendency to accumulate and deposit around a nucleus, in the way of a small nail, pebble or other foreign substance, such as are frequently found in the large colon of the horse; and this formation once established usually continues until one large calculus is 
formed, and not infrequently quite a quantity of small ones, of varying sizes, in addition. It is probably hardly necessary to state that unless the calculus passes from the large double colon into the single colon before it becomes too large to occupy the lumen of the latter portion of the intestines there is no other method of relieving the animal of the difficulty other than by surgical operation, by effecting an opening through the walls of the abdomen; we believe that a few very bold surgical operators have attempted this as a deurier-resort, but we cannot from personal experience speak as to the probable success of what looks like a yery venturesome operation; at the same time we are strongly of opinion that the horse will bear surgical interference with the contents of the abdomen far better than the teaching of the past would induce one to anticipate; be that how it may, however, such an operation could only be undertaken by one trained in the art of surgery and the consideration of the subject does not consequently come within the bounds of this work. The question then arises, to what extent can therapeutics aid in solving the difficulty, and we regret to add that in the event of a calculus being present which is too large to pass through the single colon only temporary alleviation can be afforded; ultimately the calculus is certain to become fixed in the opening where the double colon merges into the single colon, the constriction in the size of the canal being at this point very marked and sudden; the peristaltic action of the intestines forces the calculus into this position and there it is retained, unless a violent or sudden reverse peristalisis can be established to cause the muscular walls of the large colon to relax their grip of the stone, and it thence falls back into the bottom of the large colon, but only in due course to go through the same process once again; at the same time every horse owner would undoubtedly prefer the off chance of a temporary cure to having his animal destroyed on the ipse dixit of the most experienced veterinarian of the day. The remedy we have found capable of effecting the desired object is Nux vomica Ix, the dose to be repeated every hour until relief is obtained; assistance may be afforded three or four times for the same animal, periodical attacks coming on every two or three months, hut in the end it generally happens that the stone becomes so firmly wedged into the lumen of the colon, at the point already referred to, that it is immovable and results in the death 
of the horse after about twelve hours of the most excruciating agony. In cases where the Nux vomica treatment does not avail in two or three hours to effect relief, at all events in some degree, and the animal seems to be getting worse and experiencing severe attacks of pain, evincing growing weakness and prostration, it is better to anticipate the worst, and afford the poor animal some ease by the administration of an anæsthetic, such as two ounces of Chloral hydrate dissolved in a quarter pint of water and given per mouth, or repeated subcutaneous injections of Morphia-this, for humanity's sake, is the course we adopt where the prospect of a temporary cure seems unpromising.

Next in importance to calculi (or stones) so far as frequency of occurrence may be accepted as a guide in estimating the importance of the various forms of intestinal obstruction met with in the horse, we should allot the position to "TWIST" (or entanglement of some portion of the intestine upon itself). It is not so difficult, as may at first sight appear, to diagnose a case of twist from the symptoms which will hereafter be presented under one classification, the single classification being adopted to avoid unnecessary repetition; there are one or two special symptoms that serve to differentiate between twist and the presence of a calculus, which we shall point out later on under the general classification of symptoms in intestinal obstruction. When the twist takes place in the single colon or in the posterior portion of the dutuble colon examination per rectum occasionally reveals the condition; having thrust the arm up as far as one can reach, it will distinguish the presence of a twist by the cord-like state of the intestine, and the obstruction will prevent the hand passing beyond the point where this is perceptible; the position of the twist can be determined by the direction taken by the aforesaid cord-like condition; which ever way the cord turns, either to the right or left, the portion of the bowel that involves the entanglement must come from the opposite direction, and it is possible by closing the fist, and thrusting it well into the obstruction to swing the entangled portion to and fro and ultimately by a vigorous effort to throw it back again into its natural position; we are well aware that by many veterinarians sucl a result is considered inpossible of realization, but from experience we are satisfied that it can be done, having had the most satisfactory proof of the possibility in more cases 
than one; to mention a single case will probably be sufficient for our present purpose; we had been in attendance upon a brewer's horse, one of the heary class of animals used by this trade; the animal had been in great pain for six hours without intermission, everything had been done that was possible to alleviate suffering but without avail; the pains were continuous and increasing, already we had made several examinations per rectum without observing anything, and as matters were becoming more and more serious and the pain growing acute, we determined to make one more manual examination; on this occasion we distinctly discovered the cord-like condition already described, and adopted the measures for replacement herein suggested; the swinging to and fro of the entangled portion of the intestine followed by its falling over into the natural position, as the result of the jerk given by the arm to effect this result, were distinctly felt, and IMMEDrATELY the animal gave a sigh of relief, assumed a calm and easy position, the circulation became regular, the coat, previously dripping with sweat, rapidly dried, and the horse shortly commenced to feed, ultimately making a good recovery.

The incarceration of the intestines and invagination of one part of the intestines within that which is continuous with it, are also conditions affecting the horse occasionally, and when present generally take place in the small intestines, and are without doubt capable of reduction through the instrumentality of internal medication, though the possibility of such a result in therapeutics would probably be scouted as ridiculous by all practitioners except the followers of Hahnemann.

SyMptons. - In the opinion of many veterinarians of considerable experience the various symptoms which by others are considered indicative of intestinal obstruction are not accepted as diagnostic of the condition, and while we have no intention of posing as an infallible authority we cannot do other than offer our opinion that in a majority of cases the following symptoms will be presented in one or other of the different forms of obstruction and that if they be relied upon few mistakes will be made in diagnosing the conditions when they arise. The first symptom to which the attention is drawn will be the exhibition of considerable pain; the horse will lie down roll two or three times, groaning the while, suddenly jump onto his legs again, and commence walking 
round the box; it is difficult to divert the attention of the animal from itself; after moving round once or twice a sudden halt will be made and the head will be turned to the side the most pain is experienced, while at others the nose will be rested on the exact locality of the obstruction. After a few turns the animal will lie down again, roll, and then maintain the recumbent position for a few minutes, suddenly jumping up again and repeating the foregoing movements; meanwhile, according to the urgency of the pain, sweat breaks out over various parts of the body, and at times so profuse is the secretion that the coat is thoroughly saturated and it can be observed dripping off the bottom of the abdomen. In our experience one symptom is diagnostic of calculus that we have never observed in a case of twist or other form of obstruction, namely, the horse places itself with its tail and quarters firmly pressed against the walls of the stable and at the same time urges as though to effect a passage of fæces.

In cases of twist, invagination and incarceration of the intestines, the pulse and respirations are more properly influenced than when a calculus is the cause of obstruction; the respirations are urgent and hurried at all times and the pulse gradually gets more rapid, hard and wiry unless relief be afforded until ultimately the animal is so worn out and exhausted that no pulse is perceptible. We have remarked in quite a number of cases of obstruction the animal becomes after awhile very impatient of the pain, especially in cases of twist.

TREATMENT. - There are three remedies that are under their own respective indications capable of effecting a cure in cases of incarceration, invagination and twist, and of occasionally affording at least temporary relief when a calculus is the cause of obstruction, and they are Nux vomica, Plumbum and Belladonna and in the foregoing order their value and importance may be ranged.

Nux vomica Ix. Constipation is a most important indication, especially when accompanied by frequent ineffectual efforts at evacuation; a distended condition of the abdomen with flatus (or wind); hiccough and rising of either gas or food; a prolapsed condition of the anus as the result of repeated straining; the pains, while they may be more or less continuous, are certainly spasmodic, namely, worse at one time than another.

Plumbum $3 \mathrm{x}$, is a most effectual remedy in cases of obstruction 
due to impaction of hard, dry fæces shaped like balls, and generally black in color; the anus instead of being protruded and relaxed as in Nux vomica is constricted; except in cases of twist the abdomen is retracted and the horse has a tucked-up appearance, but when the obstruction is due to impacted fæces the abdomen is swollen and distended; this remedy is also very effectual in cases of obstruction arising from hernia (rupture) when the intestines protrude through the walls of the abdomen in the form of a tumor, but such cases are very rare except in foals and stallions; in the former they take place generally at the navel and are known as UMBILICAL HERNIA; while in the stallion the tumor appears in the scrotum, the seat of the testicles, and is known as SCROTAL HERNIA; whenever a hernia is found in an aged horse, it usually takes the form of STRANGULATED HERNIA which involves a constriction of the intestine so that the contents cannot pass onward, and consequently the circulation of the blood is arrested in that part.

Belladonna $3 x$ serves to assist in cases of twist where inflammation is set up; a swollen and very bright red condition of the lining membrane of the eyes; a firm, hard, resistant swelling in the abdomen on the course of the large colon with an indication of sharp griping pains at one particular spot, recognizable by the horse pointing with his nose repeatedly to the same place may be accepted as the symptomatic of this drug.

ACCESSORY TREATMENT. - The first thing to do in cases of this description is to make careful manual exploration of the rectum; well oil the hand and arm and empty the bowel of its contents, then search for either a calculus in the single colon or the presence of the cord-like condition of the intestine suggestive of twisted bowels; should neither of these be observed, it will be desirable to invoke the aid of a enema pump-an instrument specially used for the purpose-and therewith inject three or four gallons of water raised to blood heat into the intestines; in the case of calculus this proceeding may assist its displacement or if a twist it may afford mechanical aid in reducing it; under any circumstances the warm application will be grateful to the sufferer and it will aid in locating whatever fæces lie behind the obstruction. Beyond this and the regular administration of the most suitable remedy every hour or so little can be suggested; should 
no relief be afforded, then to save unnecessary pain, resort had better be had to one or other of the anæsthetics before mentioned.

\section{COLIC.}

A common stable term indicating that violent spasmodic contractions of the intestinal muscular walls are taking place producing sharp griping pains which come on in paroxysms with intermediate periods of partial relief; it has been affirmed that in colic of a simple and uncomplicated character there is neither exaltation of bodily temperature nor acceleration of pulse beat; if this be so our experience is an unique one, for we invariably make it a rule to take the temperature and test the frequency of the heart beats as revealed by the pulse, and it is in our experience a very rare circumstance to find the pulse normal and certainly more often than not the temperature is higher than in robust health; we freely admit that there is a vast difference between the state of pulse and temperature in a horse suffering from spasm of the intestine and one that is the subject of enteritis (inflammation of the intestines); but our experience does not allow us to confirm the statement of other writers on this subject with respect to the particular disorder now under consideration. It certainly appears at first sight a somewhat singular coincidence that horses are so generally and very frequently the subjects of this disorder, unless we account for it by susceptibility in consequence of the immense volume of the intestinal area; this certainly does not strike us as at all a satisfactory conclusion to draw, but probably in attempting to define the various causes productive of or tending to colic we may discover something like rational evidence to account for its frequency. Among agricultural horses food is in n11ost cases accountable for producing attacks of spasmodic and flatulent colic; some owners seem, by their actions, to hold the opinion that any rough material, never mind how coarse, is good enough for a horse that works on land; the horse returns home after long abstinence and being as most are a ravenous feeder, the digestive organs are gorged with material that is not only bulky but also too fibrous to yield to the action of the digestive juices; the consequence is that large masses of this undigested material accunnulate where they act as an irritant; the muscular walls of the intestine at this point become paralyzed after repeated ineffectual efforts 
to move on the accumulated mass of fæces; the spasms then commence as the result of the repeated efforts of the intestines above the obstruction to forcibly remove this mass of ingesta. Yet, again, farm horses are not infrequently the subjects of flatulent (or windy) colic either from this dry indigestible material fermenting and thus producing increasing quantities of gases which develop distressing and dangerous symptoms, or the same result also occurs from the injudicious use of succulent green food, by allowing it to be given in a too young and consequently immature state or under conditions, for which the atmosphere is responsible which are known to render this description of diet unsuitable for use. Yet, again, although many farm horses can and do live exclusively, during certain months of the year on succulent green food, their digestive organs require to become accustomed gradually to this kind of diet otherwise if allowed to indulge in a sudden repletion, flatulent colic is the usual sequel of this indiscretion. Where really good nutritious food is a staple commodity and horses are kept in high condition, intestinal disturbance resulting in colic is of frequent occurrence through the injudicious practice of administering more food than the digestive organs can dispose of, as is frequently done after an extra hard day's work when the urgency of agricultural requirements demand long hours at high pressure; the animals are supplied with more rich food than the system can appropriate and a greater quantity than will pass through the digestive canal, the consequence being that accumulations take place and obstructions are established with the results that have already been defined.

Horses both of the heavy and the light classes that have to work from one place to another, undertaking long, tiresome journeys, as is often the case with those kept in large towns in connection with big trading concerns, owe their attacks of colic more frequently to the influence of cold and damp; to a too free allowance of cold water; to at one hour proceeding at a rapid pace and then standing still for a considerable time and on their return home late at night to an over repletion of food on an empty stomach.

Other causes of colic are those of the various forms of mechanical obstructions, such as impaction of indigestible material, and the presence of large numbers of worms. 
Symptoms are in many respects very similar to those already described under the head of intestinal obstruction, with the exception that they are not so continuous, nor do they produce such severe effects, nor is the attack developed so suddenly; in numerous instances horses are capable of bearing a good deal of pain before presenting any distinct evidence of suffering, and there is little reason to doubt that frequently an animal may feel unwell for some considerable period before any outward manifestations are declared; it is when the pain becomes severe that a horse commences to paw with his fore feet, strike at the abdomen with the hind feet and otherwise give evidence of great restlessness and uneasiness; this will be succeeded by attempts to lie down, the prone position being ultimately effected, when he will either roll from side to side or throw himself right over two or three times and then suddenly jump onto his feet and remain quietly standing for some minutes, evidently the while comparatively free from pain; but on the spasm being renewed the pawing is recommenced, and after crouching in the act of lying down he will suddenly prostrate himself as before and go over the same process from time to time until relief is afforded. It is the practice of most horse keepers and stablemen, and also of very many veterinarians, to endeavor to hinder a horse from rolling, under the impression that it is attended with the risk of producing a twisted bowel; with this view we do not concur, and invariably allow our patients whatever comfort and ease is derivable from rolling, under the conviction that the act must afford some relief, and this impression receires some countenance, as illustrated by the human subject, who invariable tosses abouk and rolls from side to side when suffering acute agony from abdominal pain. Professor Robertson's "Equine Medicine" lays down the following points of differentiation for diagnosing which portions of the intestines are more particularly affected, as follows: "It seems probable that the symptoms of extreme restlessness, frequent pawing, much pain, with anxious turning of the head to the flanks, are indicative of involvement to a greater extent of the small intestine; while stretching of the body as if desirous of urinating, throwing the head upwards with curling of the upper lip and a disposition to move backwards and press with the posterior parts against some resisting object, as the wall or stall post are more particularly indicative of disturb- 
ance associated with impaction or distension of the large bowel."

In cases of flatulent colic, in which the distension of the large double colon is the most marked feature, it will be observed that horses are very undecided about lying down, and if they do ultimately resort to this position they remain in it but a short time, appearing to experience considerable discomfort over and abore the pain, and consequently after going down they quickly rise to their feet.

In flatulent colic also the respirations are especially affected, due probably to the fact that the contents of the immensely-distended abdomen press unduly upon the diaphragm and the lungs, rendering the breathing peculiarly difficult; it will be noticed that the respirations are short and quick, breathing being effected almost entirely by the aid of the thoracic muscles. The abdomen becomes tense and drum-like, and in the absence of relief there is some risk that either the intestinal walls or the diaphragm may be ruptured. Intestinal obstruction, simple spasmodic colic and fatulent colic may arise quite independently; at the same time there may be a combination of all three in one case at the same time; fortunately we have remedies capable of combatting each and all of these conditions, and in making our choice of treatment we must be guided by the totality of the symptoms, taking as our most important and reliable indication the condition which gires evidence of the most prominence; it is, however desirable that it should be distinctly understood that these three forms of colic need not necessarily occur quite independently of one another, but as Professor Robertson says, "Colic or abdominal pain may be the common bond of union which links together these different forms of disturbed function, spasm of the bowel, accumulation of excrementitious matter and varying degrees of tympany, it is probable that its most frequent manifestation is in connection with disturbance which is a variable combination of all these individual conditions."

Treatuent. - Aconite $\theta$ has proved a consistently successful remedy in cases of colic arising from cold and exposure; for colic brought on by allowing a horse to drink freely when overheated, and in cases where inability to pass water is specially marked; the horse repeatedly postures himself to urinate and strains, with the result that no urine passes, or only a few drops at most; these 
cases are usually observed in horses that work long hours at a stretch, among the heavy class, or among carriage horses that have to wait at the doors of theatres and concert halls in the chill hours of the night; the usual dose should be repeated every half hour until the horse passes water or gives outward evidence of relief.

Nux vomica Ix may probably be taken as the next most useful remedy, and especially in cases due to excessive engorgement from food accompanied by marked constipation and repeated efforts to evacuate; in compound spasmodic flatulent colic it affords speedy relief.

Colocynthis $3 \mathrm{x}$ when the pains are exceptionally severe and intermittent, accompanied by diarrhœa and straining to evacuate. The animal doubles himself up and rolls excessively; the flatulent condition, if present, shows itself by distension far back in the abdomen; it is essentially a neurotic remedy.

Veratrum album $3 \mathrm{x}$ is useful in extreme cases, leading on to collapse; circulation of the blood is weak and fluttering; purging is constant, retching may be present; the body is generally cold and bathed in a cold sweat; the muscles of the arms and thighs are all of a tremble; spasmodic pains frequent.

Chamomilla $\theta$ is essentially a useful remedy when foals are the subjects of colic, and especially when the spasms are so sharp and severe that the patient seems unable to bear the pain; no less an authority than Hahnemann states that "it is less benefical to those who remain patient and composed during their sufferings, - an observation he considered of the utmost importance;" (Hughes); the pains are worse for the application of warmth, such as hot flannels, etc., and they cause the patient to be spiteful, coming on as a rule during the night, accompanied by insatiable thirst.

Cocculus Indicus Ix very appropriate to mares with foal, especially in flatulent (windy) colic, accompanied by irritability, nervousness and general coldness of the body.

Dioscorea villosa $\theta$.- Severe pain in the lower parts of the abdomen, causing the horse to make efforts to kick itself in this part, and thereafter it will lie down and stretch all four legs; the general pain is continuous, while violent paroxysms come on at intervals; the lining membrane of the nose, eyes and mouth is sometimes of a deep orange yellow. 
Iris versicolor $6 \mathrm{x}$. - There are some cases of colic in which the liver and the pancreas-more especially the latter--are involved, which after $N u x$ vomica and Colocynth have failed will yield to Iris versicolor; attempts to vomit, purging and extraordinary secretion of saliva, soreness of the anus from the acrid state of the fæces and great tenderness on pressure just behind the ribs on the left side serve as reliable indications.

Plumbum 3x.-Colic due to persistent constipation when the fæces are dark in color, round and small in size, dry and lumpy in condition; flatulence is present with a constant desire to expel the wind; legs and ears are cold; appearance generally depressed and cadaverous; animal will rest on the abdomen as though pressure afforded relief, and there is suppression of urine.

ACCESSORY MEASURES.-Flannels wrung out of really hot water and applied to the abdomen; copious enemas of water raised to the temperature of the body; hand-rubbing of the abdomen; for the time being, entire abstention from food, and for some hours following relief; thereafter great caution not to give anything but easily digestible food, and that only in small quantities, for two days; no horse that has suffered from a severe attack of colic should be put to work for several days.

\section{RUPTURE OF INTESTINAL WALLS}

has been referred to as one of the possible contingencies and a sequel of flatulent colic when relief is not afforded by any means available; to obviate this unfortunate condition, in cases where medicinal agents for some reason or other fail of their desired object and the symptoms are extremely urgent as a dernier resort the abdomen may be punctured; but this requires a combined instrument known as the trocar and canula, and should be entrusted to a veterinary surgeon for performance; by the means of this operation, which may be performed with perfect safety in able hands, the accumulated gasses are released, the distension due thereto reduced and the attendant pain relieved, but it may be necessary to allow the canula to remain in position some hours until the tendency to form gas is overcome. In the case of rupture, however, the case has gone beyond medical or even surgical aid, and it is only to enable the reader to recognize the condition that it is referred to here and the symptoms presented for considera- 
tion, and to this end we cannot do better than quote Professor Robertson's lucid description; he says: "The symptoms which indicate the fatal termination of disturbed function are neither uniform nor diagnostic. In some the occurrence of the lesion seems to be followed by rapid collapse; in others it would appear that life may be prolonged for many hours. With one we may have mitigation of the distressing features previously existing; with anoiher, on the contrary, all these may suffer aggravation. When occurring in association with impaction or unnatural relation of ingesta in the colon, together with considerable distension from gases in the bowels, in which cases we often have restlessness and much straining, the occurrence of the lesion is naturally followed by relief in the symptom of restlessness, and a subsidence of the straining, comparative calm and quietness being the condition succeeding rupture until death. In all with the completion of the rupture I have observed that exhaustion is a feature rapidly developed; and that although relief from pain seems to have been obtained at once and unexpectedly, there is a haggard, anxious expression of countenance, a frequent and small pulse, steadily becoming more rapid and at last imperceptible, patchy perspiration, short, catching respiration, gradually a disinclination and inability to move, the animal balancing itself as it were on the limbs until the very last. Whenever cases of colic, marked by impaction of the bowels, with or without much distension, accompanied with straining, suddenly exhibit cessation of the pain and straining, together with the appearance of much exhaustion and other symptoms indicated, we have some grounds for fearing rupture of some part of the intestinal wall."

In face of the several suggested doubts as to the possibility of recognizing the absolutely diagnostic symptoms of intestinal rupture, we can but earnestly commend the practice of persistent treatment right up to the end, even in the most suspicious cases; the remedies to be used being those suggested under colic according to the totality of the symptoms. 


\section{INFLAMMATION OF INTESTINES.}

\section{ENTERITIS.}

The difference between an inflammatory condition of the intestine and that which takes place in simple colic, although from the character of the pain there is nothing striking to enable one to differentiate between them, is recognized in the fact, that while in colic the pain is due to "disturbance of functional activity" (Robertson), and in many instances is originated through some defects in the nervous system, in enteritis important changes in the structure of the intestinal walls are taking place, affecting either the lining mucous membrane or the more deeply-seated muscular tissues of the walls; in connection with or rather as the result of the inflammatory action there is a varying amount of effusion of a jelly-like material which mixes with the fæces when of an ordinary consistence, but when constipation is marked the evacuations are coated with what is vulgarly described as slime. The large bowel-double colon-is more often the seat of inflammatory attack in the horse than are the smaller portions of the intestinal canal; but unless the origin of the disorder arises from irritation, such as may take place when a horse has received too large a quantity of Aloes and superpurgation supervenes, the intestinal canal being more or less affected from one end to the other, the morbid lesions are generally observed in patches.

Symptons. - Enteritis is invariably preceded by shivering; the attack comes on suddenly; the temperature is exalted to ro 3 degrees or more; the pulse is rapid and wiry in character; the mouth generally dry and hot; the pain, though frequently less serere than some bad cases of colic, is constant, and manipulation of the abdomen with pressure is resisted; nausea and occasionally retching are observed; the extremities are invariably very cold; the animal will roll, drawing the legs up sharply and thereafter stretching them out to the full extent, while at times a distinct effort will be made to balance itself on the back; as the disease advances, where not successfully checked, the pulse increases in rapidity while the volume is distinctly lessened and the the action of the heart becomes much weaker. As a rule consti- 
pation is present from the first, but we have known cases in which diarrhœa was a marked symptom all through.

In all cases of enteritis that have proceeded to extremities, it is necessary to guard against the delusion that a horse is likely to recover in consequence of an apparent improvement from the alleviation of pain, and even though the horse may begin to pick at his food; the relief from the agonizing pain is in such cases probably due to mortification; to determine what measure of hope there is in such extreme cases one must be guided by the general appearance of the animal; if it still exhibits a haggard and worn countenance and is dull and listless in its manner, with a weaker pulse and more rapid respirations only the worst can be anticipated; on the contrary, if the horse maintains a brighter disposition, looks more cheerful, has a stronger pulse and breathes less frequently the disappearance of pain is a good angury.

TreatMent.-Aconite ix during the earlier febrile symptoms for a few doses to, if possible, reduce the temperature, this generally comes in most usefully before the diagnostic symptoms of enteritis have declared themselves; the horse appears dull, listless, and heavy; the mouth is hot and dry, and the chemical thermometer indicates a high rate of body heat; as soon as distinct evidence of continuous abdominal pain is evinced then the next remedy should be resorted to.

Mercurius corrosivus 6x. - When the large intestines are the seat of inflammation there is no remedy to equal this, and it is worthy of special notice that the attenuation here given is the proper one, under no circumstances should it be lower (stronger); as a rule the tongue will be found generally coated, and pronounced nausea is present; pressure on the abdomen, particularly on the right side, fairly forward in position will show marked tenderness; diarrhœa, if not present in the first instance, soon follows; the fæces are mixed with slime and mucus, while occasionally streaks of blood will be observable, or a deep tinge of yellow or green, indicating the presence of bile; the patient experiences a great deal of straining after an evacuation, and the anus and parts thereabouts whereon the liquid fæeces drip beconte excoriated and sore. A cadaverous and dejected appearance is present, sometimes accompanied by a profuse slavering from the mouth. 
The remedy should be repeated every four hours in doses not exceeding ten grains.

Podophyllum 3x. -This remedy is more especially suitable when the inflammation is located in the small intestines; the fæces will be mixed, rather than coated, with blood and glairy mucus, while in others marked indication of the presence of bile stain will be declared; the posterior portion of the abdomen will not evince so much tenderness, nor is distension from accumulated gases so frequent as when the large intestines are implicated chiefly; in cases that are complicated with diarrhœa at the outset, in connection with which there is a great deal of straining accompanied by protrusion at the anus of portions of the rectal mucous membrane this remedy will be found " en raport."

Lycopodium 6x. - In cases of enteritis in foals brought on by partaking of indigestible food, which is accompanied by considerable distension through fermentation of the ingestia and very audible rumbling in the abdomen with frequent sharp pains, a generally jaundiced appearance of the visible mucous membranes and pronounced constipation, this remedy in the usual doses every hour will soon afford relief.

ACCHSSORY MEASURES. - The animal must be kept perfectly quiet, in a box where the temperature can be maintained at an even standard, not below 60 degrees $\mathrm{F}$.; during the paroxysms of pain flannels wrung out of hot water must be constantly applied to the abdomen, and after the worst symptoms have passed arvay, the abdomen must be carefully clothed with a wet compress for several days. The very lightest food possible must be allowed, and that only in small quantities at a time; farinaceous diet is the best, with plenty of wholesome milk to drink, varied occasionally with an allowance of barley water and then linseed tea.

\section{DYSENTERY.}

This form of disease is, so far as our experience goes, rarely met with in the horse; during the time we have been in practice we can only recall two or three clearly-distinct cases; dysentery may be described as a combination of enteritis and diarrhœa; fever is always present, the fæcal discharges are fluid, mixed with blood and slime, and, unlike enteritis, constipation is never present; dysentery, however, owes its origin to very different causes to 
that of enteritis; bad sanitation and unhealthy surroundings; malarial poisoning, either through the air or water; persistent chronic diarrhœa, and exposure to extremes of temperature are mainly accountable for attacks of this disorder when they arise; hence very ordinary precautions will serve to protect horses from its invasion.

Symptoms.-Diarrhœa is the earliest noticeable feature of the disorder; in the next place fits of shivering will be observed, which should lead to the taking of the temperature; this will be found somewhat elevated and the pulse abnormally fast; prostration is generally well marked, accompanied by impaired appetite and general wasting of the muscular tissues; the fæcal discharges are usually liquid in character mixed with jelly-like mucus and blood, while shreds of mucous membrane will be frequently observed in the mass; as the disease makes further inroad, the appetite decreases, the thirst increases, the fæcal discharges become very fœtid, while wasting and exhaustion are hourly more pronounced; continued straining, both during an evacuation and thereafter is specially noticeable; the mucous membrane lining the mouth and tongue is frequently soft and pasty in consistence.

TREATMENT.-Aconite ix.--In the early stages this remedy, given in hourly doses, will at times arrest the febrile condition and thus prevent the further development of the disease; but should no apparent advantage follow its administration within three hours, it may fairly be concluded that the morbid process has obtained too firm a hold upon the constitution, and that drugs more appropriate to the precise condition are called for.

Nitric acid 6x. - In cases of dysentery where the mouth, tongue and throat are specially implicated and a dry laryngeal cough experienced, this remedy will be found very appropriate.

Aloes 3.-Forcible expulsion of watery evacuations, attended with much straining, and soreness of the anus, followed by evident exhaustion and faintness.

Colchicum 6.-This remedy fills up a gap that is occasionally difficult to supply, when dysentery is associated with the formation of gases and the large intestines are inflated, an exceptional condition that gives rise to considerable difficulty in treatment; this, however, furnishes a proof of the advantage of a homœopathically selected drug which orthodox practice fails to supply; the occur- 
rence is truly an exceptional one, but this only renders it the more valuable when it does arise; the accompanying distinctive symptoms are pronounced nausea, great prostration and rumbling in the large intestines.

Ipecacuanha $3 \mathrm{x}$ was in earlier times frequently administered in this disease and afterwards fell into disuse. Hahnemann, however, revived it in his day, and discovered the specific symptoms which suggested its selection, they are particularly persistent straining, with frothy, fotid and bloody evacuations, occasionally tinged with greenish bile and mixed with mucus; if nausea and retching are present they furnish additional reasons for its selection.

Mercurius corrosivus $6 \mathrm{x}$. - When the evacuations are specially of a bloody character, mixed with mucus and attended with severe pain and straining, both during and after the passage of fæces, with marked suppression of urine and great difficulty in passing the same, while the patient is comparatively composed and quiet, this is one of the most effective agents at disposal for this troublesome conditon; indeed it is, more often than not, in true cases of dysentery, the most reliable remedy in the whole pharmacopœia.

Arsenicum album 3x.-Great thirst, demanding frequent and small quantities at a time, cold breath, cold extremities, cold sweat, great weakness, persistent restlessness, weak heart, stinking evacuations, highly-colored urine, passed with difficulty, indicate this remedy.

ACCESSORY MEASURES. - A wet compress continually applied to the abdomen is generally of great benefit; while the most severe pains are on, flannels wrung out of very hot water should be applied, care being taken to have each successive one ready before the previous one is removed; warm injections with the enema tube may usefully be administered after an evacuation. Barley water, cold water and milk with eggs beaten up and mixed therein may be freely allowed; but all stimulating food must be avoided.

\section{PROLAPSUS ANI.}

\section{PROTRUSION OF LINING MEMBRANE OF BOWELS.}

This condition is occasionally observed in horses as the result occasionally of diarrhœa, but more frequently of constipation; 
while now and again it arises in consequence of protracted straining, produced by the presence of a large calculus in the colon.

TREATMENT.-The first thing to be done is to return the protruded mucous membrane; if it has become swollen and dry by reason of long exposure, fomentation with hot water is desirable in the first instance, after which the hand should be well lubricated with carbolized oil, and the exposed parts returned into their normal position; it very frequently happens that immediately this is done the horse strains, out comes the membrane as before, and all the work has to be done over again; in such cases a pad must be applied to the anus, which will bring external pressure on the parts and be kept there by passing side lines tightly drawn and fastened round the chest, the lines being first attached to a broad band that passes over the pad and keeps the same in position.

Ignatia Ix, a dose every hour, especially in foals, is a useful remedy where there are much straining and frequent ineffectual efforts to pass fæces; as soon as any relief is obtained, the frequency of the dose must be reduced to three times a day and continued for a week to overcome any well-established weakness of the parts.

Mercurius corrosivus $6 \mathrm{x}$. - In cases where the prolapse is attended with much irritation, accompanied by a discharge of mucus, and particularly if diarrhœa is present.

ACCESSORY MEASURES. - After the protruded bowel is returned the application of cold water is frequently attended with satisfactory results, not only externally, but internally, by means of a syringe or enema tube. The animal should be kept perfectly quiet. The diet should be light, nourishing, and calculated to favor a healthy and easy action of the bowels. If worms, calculus, constipation or diarrhœa are the cause of the condition the treatment under these headings must be consulted.

\section{PERITONITIS.}

The intestines are covered and supported by a very fine membrane, described as the peritoneum; this membrane, which is of the serous order, lines the abdomen and also covers the intestines and other organs of the abdomen; when attacked by inflannution, it is called peritonitis; inflammation of this delicate membrane may arise from cold; from irritation arising from an inflamed con- 
dition of the abdominal organs, such as the intestines, the liver and the uterus; from blood contamination in certain specific fevers, such for instance as are associated with the puerperal state in females; from operative surgery, such as the infliction of a wound in penetrating the abdomen for the relief of flatulent colic, or even in castration.

Symptous are generally ushered in by shivering and an elevation of temperature; pain is exhibited in the abdomen of a more or less constant character, and the parts are generally so sensitive that the animal can ill bear any pressure, the pulse is quick and thready; the patient is restless, and wiil not maintain any one position long at a time, repeatedly turns the nose to the seat of pain, and wears an anxious expression of countenance. In peritonitis, the result of mechanical injury or surgical wounds, the animal gives evidence of very marked internal pain by pawing restlessly with the fore feet and paddling with the hind ones; the respirations are short and quick, and are performed by means of the ribs and thoracic muscles; the pulse is very hard, thin and wiry; the internal temperature rises above the normal, and very considerably so if the mechanical injury is a serious one; the horse will not bear the abdomen to be hand rubbed, as in simple colic, as no doubt the pressure externally produces considerable pain within.

Treatuent.-Aconite ix when peritonitis is due to cold, and the febrile symptoms are very pronounced; the doses to be repeated hourly for some time.

Bryonia 3x follows the previous medicine in similar cases and where the pain appears sharp and is aggravated by motion; constipation and general uneasiness are further indications for its use.

A mica $3 \mathrm{x}$ when peritonitis owes its origin to mechanical injury and surgical operations, under which conditions it should be relied upon from the outset.

Mercurius corrosivus $6 \mathrm{x}$. - In cases other than those due to mechanical injury, especially when tympany and diarrhca are present, and the lining membranes of mouth and eyes are very yellow. Dr. Hughes affirms: "I have used it more frequently than Bryonia, and with most gratifying results."

ACCESSORY MIEASURES. - Hot fomentations by means of flan- 
nels wrung out of boiling water and continuously applied to the abdomen afford relief; the horse should have a supply of cold water near at hand in order to partake thereof as frequently as may be desired; when the worst of the pain is over a wet compress should be constantly applied to the abdomen for some days, and the food should be of a light, unstimulating character, administered in small quantities at a time, and not too frequently; perfect quiet is also very essential.

\section{ASCITES.}

\section{DROPSY.}

This form of dropsy is peculiar to the abdomen, and arises from the development of a fluid in the peritoneum; it sometimes follows an attack of peritonitis, and consists of a collection of fluid in the cavity of the abdomen round which the peritoneum forms an encircling fold; ascites is very frequently due to a diseased condition of other organs, namely, the heart, liver and kidneys, connected with which an obstruction of the venous system is associated, bringing about an escape of the fluid constituents of the blood, through the walls of the veins; in this way and at such times swelling of the limbs is often observed, which is due to the same cause; also the animal is dull and devoid of all natural spirit; bears a generally unthrifty appearance; has capricious appetite; rarely lies down, and when it does, remains in that position but a short time; in addition to the swelling of the limbs, the abdomen becomes enlarged and pendulous and the skin along the middle line of the belly is swollen, pits on pressure, and thereafter fills up again. The visible mucous membranes are pale and anæmic, the pulse is weak, and often intermittent; the urine is scanty, high-colored and thick; when the abdomen is very much enlarged and the collection of fluid is extensive around the intestines, the pressure upon the diaphragm is so great that the breathing becomes labored and difficult, and is performed almost entirely by the thoracic walls, which is recognized by the heaving and expansion of the ribs.

Treatuent.-Apocynum Cannabinum $H$.- This remedy is credited witl possessing a remarkable power over dropsy, and Dr. 
Hale, of Chicago, has drawn special attention to its virtues; Dr. Hale seems to consider that its influence for good is derived from the specific action of the drug upon the kidneys, restoring the urinary secretion to its normal constitution and in this way freeing the system from the surplusage of fluid constituents; probably it acts more generally, for in many cases the drug has effected relief after other remedies had proved ineffectual.

Arsenicum album $3 \mathrm{x}$ in cases where the legs are much swollen and disease of the heart is present; general debility, emaciation and poverty; difficult breathing; dry, scaly skin; continuous thirst; feeble and irregular pulse; coldness of the ears and other extremities are general indications for the selection of this drug.

Apis mel. 5 is a valuable agent when the animal has difficulty in passing water and only makes a small quantity at a time; also when the temperature is elevated and febrile symptoms are present.

Digitalis Ix when dropsy is due to the irregular action of the heart, as indicated by an intermittent pulse, accompanied by great difficulty in breathing and when the animal persistently maintains the standing posture.

ACCESSORY MEASURES.-Contrary to ordinary practice we advise that a dropsical horse should be allowed as much cold water as it desires to take; there should be a constant supply available, as we believe that water under such cases tends to increase the amount of fluid excreted and that far beyond the bulk that is imbibed; it also tends to improve the appetite and restore vigor to the constitution; in this way the pulse becomes stronger and the dropsical effusions are reduced. Food of the most easily digestible character must be allowed, such as artificial grasses, carrots, turnips, and the like, with plenty of linseed gruel and barley water. The place the animal is stabled in should be dry and warm; and if alcoholic stimulants should appear desirable Holland gin mixed with milk is the best agent under the circumstances.

\section{CONSTIPATION.}

This condition of the digestive tract is by no means an uncommon one in the horse, and it is frequently attended with consequences that do not lend to the general well-being of the animal; on 
the other hand, it is desirable not to be over anxious, if what is deemed to be the natural action of the bowels does not invariably take place; for in many cases of illness, especially those attended by much fever. the heat of the body seems to dry up the natural secretions, and among them the products of the intestinal glands, whereby the fæces, as they pass along the canal, are lacking in moisture and assume an undue condition of dryness; under such circumstances let but the right medicine be selected, appropriate, that is, to the main disease and the totality of the symptoms, and the constipation will yield to the action of the drug, quite independently of any specific action upon the bowels; but in this article we are dealing with constipation as an independent and special condition, and as such we have to consider its developments and treatment.

While we do not admit for one moment that constipation is a condition to be desired, we are perfectly satisfied that a great deal more importance is attached to it than the circumstances warrant; there is a tendency among horsemen and stablemen to jump to the opposite extreme and to treat the condition as though it involved the risk of life; no sooner does a horse show some torpidity of the bowels than an aloetic ball is prescribed and administered; nay! further than that, if a horse has to be got ready for any special work, such as hunting, racing, steeple-chasing or what not, an aloetic purge is considered desirable as a sort of preliminary to further preparation; to question such a course of procedure is of course rank hetorodoxy, nevertheless we have no hesitation in affirming that a more undesirable and unnecessary course of action was never pursued; one would think, judging by common practice in every sort of stable, that a horse's digestive canal was a reservoir of accumulated filth that called for a regular sluicing out, and that the intestines were nothing more than a metal tube which required flushing to render them pure; the positive effect of aperients upon the intestinal canal is completely ignored, and the fact that their action upon the system is " to disorganize the parts on which their force is chiefly expended " (Ruddock) is entirely orerlooked. Let us for a moment just look into the pathogenetic effects of Aloes; the action of the drug is mainly brought to bear upon the large intestines, the liver and the pancreas; it evidently excites the secretions of the mucous membranes, because the fieces 
are of a decidedly fluid character, but in a more intensified form it influences the muscular walls of the intestines to more energetic peristaltic action, the evidence of which is quite clear from the violent manner in which the fæces are ejected from the anus; its action upon the liver is very marked, inasmuch as the secretion of bile is considerably increased; over and above these the whole of the abdomen and its contents is very congested, there being a decided determination of blood to the whole of the viscera; when administered in quanties beyond the natural ability of the patient to bear, super-purgation is readily established which may be followed by inflammation of the intestines, and under such circumstances the chances of recovery are remote. The effect of an ordinary dose of Aloes upon a horse is at all times trying, and under the most favorable circumstances many days must elapse before the effects pass off; the animal has to be again built up by careful attention and feeding before its previous robust condition is attained. An idea is entertained by the majority of men who have to do with horses that purgatives are necessary every now and again to expel impurities from the body, and when after the administration of a purge the fæces smell very badly, they triumphantly point to the fact in proof of their theory; the real fact is that Aloes and many other purgative drugs have such an effect upon the intestinal canal that the unpleasant smell is really due to the drugs and would not have been obse-red but for the action of the drugs themselves; this fact may always be observed however good the previous health of the animal.

One of the bad effects of the action of purgatives, more especially as regards those that unduly stimulate the numerous secretory glands situate in the mucous membrane of the intestines is that a large quantity of blood is drawn to these parts, the glands pour out their natural secretion in excessive quantities, thereby impairing their future usefulness; a general debility of these glands is the consequence, they are unable thereafter to secrete a normal quantity of their proper fluids, the ingesta is therefore but partially dissolved and digested, the fæces are abnormally dry, chronic constipation is established, the necessary nutriment is not arailable from the food passing through the canal, and the horse becomes weak and unthrifty; such may be accepted as the natural consequences of frequent purgation. 
According to Hahnemann's principle of treatment, as based upon his method of drug selection, purging for constipation is the very antithesis, and after a fair experience we can cordially endorse all that true and faithful homœopathists aver as to the needlessness of purgation; nay, more, we have no hesitation in condemning the practice as positively harmful to the well-being of the animal system; it is quite possible that in some cases, where constipation is a prominent symptom, that the liver of the patient is disordered, and that the normal quantity of bile is not secreted; or, on the other hand, the organ may be abnormally active and secrete more bile than is necessary for the due performance of the function of digestion; whereas Aloes is a more than useful remedy by reason of its direct action upon the liver, it is quite possible that much benefit may have appeared to follow the administration of an ordinary allopathic dose of Aloes to a horse; under such circumstances the same amount of good would have followed the administration of a small dose of Aloes, such as we should ourselves give, without the undesirable effects brought about by a large purgative dose of the drug; but in the face of the good results obtained the allopath is quite content and never gives a moment's consideration to the consequences of heavy dosage, nor to the possibility of obtaining the desired result on any lines other than those which produce a regular clearance out; the really proper treatment for constipation is a remedy that is capable, in the healthy subject, of producing constipation, together with all the other observable symptoms; in point of fact, rather than give Aloes to a horse for constipation we administer it for the opposite, as found among some of the varied forms of diarrhœa, and specially when the rectum is swollen and hæmorrhoids or piles are present. Constipation is by no means a single-handed condition, other symptoms almost invariably accompany it, and this fact alone renders it all the more easy to grapple with and overcome without going to useless and injurious extremes, if the practitioner only las the powers of observation well developed and some practical acquaintance with the pathogenetic powers of drugs, so as to apply them according to the rules of Homœopathy; readers of this woik will find all the necessary information under the various remedies hereinafter referred to, and from the distinctive details given thereunder will be able to note not only how to overcome the difficul- 
ties, but in what they consist and upon what they depend; and it will be further discovered that to treat constipation effectively and so as to avoid an early recurrence, the object to be attained is not alone to bring about an action of the bowels, but rather to correct the disorder to which the constipation is primarily due.

Acid nitric 12.-This drug furnishes an interesting coincidence of how the same remedy administered in different attenuations is at one time appropriate to diarrhœa, while under somewhat different conditions it is not less useful in constipation; this peculiarity of circumstances provides a pitfall for allopaths and they aver that it is one of the things "no feller can understand;" it is quite certain anyhow that to properly appreciate such apparently contradictory results one needs to be an intelligent student of Hahnemann; but to return to the subject, namely, when is Nitric acid useful in constipation? To Dr. Dyce Brown, of London, we are indebted for the information, to whom Dr. Hughes also gives the credit of the observation; constipation accompanied by a dry laryngeal cough almost invariably yields to this remedy; but to attain the result a high attenuation, like $\mathrm{I} 2$. is according to our experience necessary; the lower attenuations, such as third decimal, would probably fail, if they did not actually intensify the symptoms; if general constitutional depression be very marked, this furnishes confirmatory evidence of the usefulness of Nitric acid under such conditions of constipation. Bearing in mind that this drug is essentially one for diarrhœa it may be interesting to note that beyond the fact that the fæcal pellets are rather large and somewhat hard, there is nothing characteristic in the condition of the dung, as there is in Alumina, to lead one to select it for constipation, but in addition to the cough and the general depression a foetid state of the urine is observable in Nitric acid cases; the reason for dealing thus fully with a drug that is probably but rarely indicated in constipation, is accounted for by the fact that some cases are exceptional, but when found extremely difficult to cure; indeed, impossible with any other remedy; it furnishes a splendid illustration of the necessity that frequently arises in practice for delicate differentiation without which no practitioner can succeed in a very large proportion of cases.

Alumina $3 \mathrm{x}$. - In this remedy we have a further illustration of the absolute importance of the nice discrimination that is requisite 
to enable one to prescribe successfully in many cases which sorely perplex the ordinary allopathic practitioner; at first sight, one who has not made a study of the action of drugs from a homœopathist's standpoint, would very naturally conclude that Alumina, known by many as the Oxide of Aluminium, was a peculiar agent to use as a remedy at all, and the conjecture would follow that if administered, the physiological result such a procedure would entail, would be, that constipation must necessarily ensue; or at all events a drying up of the ingesta and fæces involving great difficulty in the performance of the function of evacuation; we may state in passing that this deduction is an absolutely correct one, when the agent is administered in sufficient quantity to the healthy subject; hence its utility in one form of constipation as based upon Hahnemann's law of selection. In contradistinction to many remedies that are useful in other forms of constipation, Alumina may be selected on evidence that is obtainable from the characteristic condition of the fæces, namely, dryness, amounting to a crumbling condition, and paleness of color; but in addition to this we almost invariably find that the mucous membrane of the pharynx is in sympathy with that of the colon and rectum and a dry cough is experienced in consequence; dryness of the mucous membranes with some irritation is a characteristic feature indicating this remedy. (Hughes). The same author mentions that a frequent desire to urinate during the night, especially in old patients, suggests the utility of Alumina in conjunction with the before-1nentioned symptoms; this observation we can corroborate; in one case of a horse that had long been the subject of a dry cough and constipation, the fæces dry, pale and crumbling, all the symptoms yielded to a few doses of Alumina, and the owner was so struck by the marvelous rapidity with which the cure was effected-for the animal had been under ordinary treatment for many months-that it seemed too good to be true, and he entertained doubts as to its permanency; he was, however, ultimately satisfied that the horse was thoroughly restored to health, as he thereafter rapidly put on flesh and stood the work of the hunting field in his usual form.

Bryona alba $3 \mathrm{x}$ for constipation that is due to indigestion and eating unwholesome, undigestible food; there is no inclination for evacuation of freces; when passed the stool is black and dry and 
has the appearance of having been burnt; disorder of the liver is generally associated with this form of constipation; the dung balls are, as a rule, very large and difficult to pass.

Collinsonia Canadensis Ix.-A very valuable remedy for pregnant mares having a tendency to inertia of the bowels; this condition may readily bring about very undesirable consequences in mares that are eight or nine months on with foal, as the straining which is thereby provoked, may result in abortion; under such circumstances spasmodic and flatulent colic frequently supervenes, which in animals so situated will be relieved with this remedy.

Hydrastis Canadensis $\theta$ for constipation which is the immediate consequence of frequent administration of Aloes or other purgative agents; the colon and rectum having got into a debilitated state require something to restore them to their normal tone and vigor; in prolapse of the anus, due to weakness and general want of tone, and for hæmorrhoids (or piles) this remedy is worth a fair trial, and generally gives good results.

Lycopodium 6x. - In case of obstinate and chronic constipation associated with disordered liver this is a most excellent remedy; pain over the region of the liver, on the right side just behind the ribs, coldness of the legs and ears, and the passing of a large quantity of urine during the night, with a sallow appearance of the visible mucous membranes are leading indications for its selection.

Nux vomica $3 \mathrm{x}$.-Constipation is not infrequently due to a lack of harmonious peristalsis; consequently the evacuations are spasmodic and irregular and often accompanied by straining, namely, efforts to pass dung are ineffectual; these may be purely idiopathic cases of constipation, unassociated with any exciting cause, such as often arises from disordered liver, et cetera; the condition is essentially the disease, and for such cases $N u x$ vomica is the best remedy.

Opium 3x.-Here we have an illustration of a remedy applied by homœopathists for the exactly opposite condition to that which it is most generally used by allopathists; given in large quantities it certainly produces constipation, probably by paralyzing the muscular coats of the intestinal tract; Hahnemann once wrote: "Opium is a specific for certain kinds of the most obstinate constipation;" and so we have frequently proved it. 
The muscular walls of the small colon and rectum seem to have lost their peristaltic action; the fæces when passed come away in black, hard, glazed balls; drowsiness in a marked degree generally presents itself in such cases; the pupils of the eyes are contracted, and there may be some fever as indicated by the clinical thermometer; retention of urine takes place and colic pains speedily supervene; the constipation may even amount to obstruction, still Opium is the remedy in small but frequent doses.

Plumbum metallicum 3x.-Dr. Hughes says: "For obstinate habitual constipation when the stools are dry and lumpy and the intestiries half paralytic and half crampy, I have the utmost confidence in it:" this description is intended to refer to the human subject, but no language of ours could more correctly define its indications among the lower animals; as a rule the impacted fæces produce spasmodic colic, and a very reliable symptom as a guide to its selection is the retracted, tucked-up condition of the abdomen; in addition to the foregoing, if the horse is observed during an attack of colic, such as is here described, to knuckle over at the hind fetlock joints, indicating loss of power in the extensor tendons, the symptom serves to corroborate the selection of Plumbum.

AcCessory MeAsures. - Much assistance may be afforded in protracted cases of constipation when the intestines are loaded with fæcal matter by first carefully emptying the rectum with the hand and thereafter injecting tepid water with an enema pump; in this way the obstruction, if to such it amounts, will be broken down, and the fæces generally rendered soft; moreover the action of the water upon the intestinal walls will be to set up a quiet and uniform peristaltic movement by means of which frequent evacuations will be produced, and that without any irritating effect on the mucous membrane lining the intestines such as is produced by strong purgative agents.

\section{DIARRHCEA.}

The very opposite condition to constipation, only more to be dreaded by reason of its debilitating effect upon the constitutional vitality; the evacuations are frequent, excessive and more or less fluid; straining is occasionally but infrequently present; diarrhœa may arise from eating improper food, or taking impure water; the 
causes may be functional only or due to structural changes in the coats of the intestines; congestion of blood to the parts, and occasionally inflammation arising from cold; through partaking of large quantities of very cold water when overheated, especially in the summer time; or in consequence of a check to perspiration through standing about at draughty street corners or other exposed places. In the horse there is little doubt that more often than not injudicious dieting is responsible for the production of diarrhœa; changing the food during spring time from that which is of a hard, dry character to that which is green, moist and bulky; new hay and oats in like manner are frequently accountable for a relaxed condition of fæces, as also are oats that have become heated and turned acid; it is also worthy of note, as being a somewhat remarkable and interesting observation, that both deficiency and great excess of bile produce a liquid condition of the fæces; the difference in the two extremes being that deficiency of bile causes the fæces to scald and irritate the mucous membrane at the anal orifice while an excess of bile does not bring about this very unpleasant condition of the muco-cutaneous outlet, but imparts to the fæces a very deep color and pungent odor and renders them of extremely fluid consistence. According to Professor Robertson, raw potatoes are very calculated to produce diarrhœa, the "fæces being of a pale color, watery and of a peculiar and penetrating odor;' our personal acquaintance with the effect of potatoes has been confined to their use in a cooked form, and we certainly did not observe any ill consequences upon the digestive organs. Worms are at times responsible for the troublesome and persistent forms of diarrhœa, and to quote Professor Robertson, "the particular parasite which appears more liable than others to act as an inducing factor in the production of this state is the strongylus tetracanthus, a very small nematoid of a flesh color, a true bloodsucker and found inhabiting the coats of the intestines, chiefly the colon and cæcum. In addition to other symptoms indicative of its existence in this situation - as wasting, an unhealthy state of the skin, irregular appetite, with the occasional appearance of a helminth or two in the fæces-is intestinal irritability, with fitful diarrhœa, not excessively watery."

The only rational method to cure diarrhœa depending upon intruders of this kind is to get rid of the cause, but in the case of 
this ciass of worm it is no easy task, as they depend upon the life blood of the host for their sustenance and, not as many other worms do live upon the food taken by the host; the proper and only successful treatment under such circumstances is to administer a remedy that will render the mucous membrane of the intestinal canal incompatible with the nourishment and existence of these parasites; this is to be done, not by destroying the parasites by means of strong poisonous drugs, but by the administration of a remedy that will restore the mucous membrane to a thoroughly healthy state. A very troublesome and dangerous form of diarrhœa occasionally arises as the result of an over dose of purgative medicine, producing a condition known as superpurgation; or it may occur from undue exposure to cold or from being put to work while an ordinary dose of purgative medicine is operating; under such circumstances it is not wise to trust entirely to the recuperative powers of nature, some counteracting remedy must be administered to check the excessive purgation.

The common practice is to endeavor to arrest diarrhœa by administering drugs that act as astringents, but these measures are unsatisfactory, unreliable and not infrequently extremely prejudicial; they merely temporize and do not go to the root of the matter, inasmuch, that while one symptom is temporarily relieved others are aggravated and as a consequence a recurrence takes place.

TREATMENT.-Aloes $6 \mathrm{x}$. - Loose motions accompanied by great straining, soreness and raw appearance of the anus; animal appears weak and exhausted after a motion; quantities of gelatinouslooking material comes away with the stool.

Antimonium crudum 3x.-Diarrhœea which alternates with constipation; dung balls are coated with mucus; rumbling in the abdomen due to fermentation of ingesta; inability to retain water, urine thick and cloudy; animal is troubled with flatulence, is extremely drowsy and loses flesh rapidly; occasionally an eruption of the skin, the formation of pimples which suppurate and burst is present; the tongue is coated with a thick fur down the middle.

Acid phosphoricum 3x.-Exhausting diarrhoea of long standing, apparently painless and the animal is unable to retain its fæces, constantly passing some involuntarily.

Arsenicum album 3x.-Diarrhoea with extreme weakness and emaciation; constant desire to drink: extrenities cold; skin rough 
and coat harsh; eyes sunken; occasional griping pains attend the passing of a motion; fæces fluid and watery.

Bryonia alba 3x.-Although more generally used in cases of constipation this remedy finds its place occasionally in diarrhœa, especially during the heat of summer when looseness of the bowels follows exposure from great heat to sudden cold, or as the result of drinking cold water when heated by exertion.

Camphor-Rubini's tincture. - Or that of any competent homoeopathic chemist who manufactures it at the same strength. Ten drops on a dessertspoonful of moist sugar laid far back upon the tongue is an invaluable remedy for diarrhœa where shivering and coldness are observed in the early stages, accompanied by considerable abdominal pain. Dose to be repeated every hour until relief is obtained.

China $\theta$ for thin, watery diarrhœea with which are mingled. large quantities of undigested food, and taking place during the height of summer heat; not at any other period.

Ipecacuanha $3 \mathrm{x}$ is specially adapted for diarrhœa in young foals and colts; this often proves a troublesome condition to the breeder and great difficulty is experienced in arresting looseness of bowels in young animals; the fæces are of a pappy consistence, of a deep yellow color, and considerable griping pain attends the evacuation. The dysenteric diarrhœa in foals which sometimes occurs, when the fres are coated with mucus and tinged with blood generally yields to this remedy; indeed, among young animals it is an invaluable agent for this condition.

Mercurius corrosivus $6 \mathrm{x}$ is essentially the remedy for dysentery, when the slimy condition of the fres is the marked symptom of the case, of course accompanied with some blood; in other respects the fæces are pale, clay-colored and smell very offensively. In simple diarrhœa when no blood is passed, nor are there present the usual indications of the inflammatory process, Mercurius cor. is still a useful agent; but here again the presence of slime and the offensive odor are the leading indications for its use.

Pulsatilla Ix.-This again is a useful remedy for sucking foals when the digestion is upset by change of food; the fæces are variable; sometimes fluid, at others pasty; they are evacuater without pain, and appear to pass away spontaneously, the little animal having no control and being apparently unconscious that 
the motion is passing; it is said that one noticeable symptom for this drug is that the diarrhœe generally occurs during the night; this latter we have not noticed, but it is a sympton worth observation, as it might serve to lead to the selection of this drug at a critical time when other treatment had failed.

Podophyllum 3x.-Among young animals diarrhoea and the straining which frequently exists in conjunction therewith result in a prolapse of the rectum; this complication often proves very troublesome, and it is more than gratifying to be able to suggest a remedy that will overcome this vexatious condition of affairs; Podophyllum is that remedy; the agent appears to have a special affinity for the small intestines, and when they are the principal seat of the diarrhoic diathesis, Podophyllum will speedily afford relief; indeed, when the inflammatory process has attacked the duodenum jejunum and ileum it is the best remedy to allay the condition and effect a cure; the rectum again is another locality that feels the influence of this drug, especially among young animals; this remedy is indicated also when the diarrhœa takes place eariy in the morning; the amount of fæces passed is usually very large and the smell offensive, said to be not unlike that of carrion; a symptom we are able to confirm from experience.

Rheum $3 \mathrm{x}$. - We once had a very notable case in which this drug effected a distinctly marked cure; and the symptom that led to its selection was " purgation on movement;" the horse for which we prescribed this remedy had been suffering from the disease for a long period; so long as the animal remained quiet in the stable the action of the bowels was normal, but directly he was taken to work and began to trot, the purging came on-it was a butcher's horse; three doses of Rhenm served to effect a permanent cure and that without any recurrence. 


\section{DISEASES OF THE LIVER.}

Among the somewhat complex functions of the liver the most prominent and important is undoubtedly that of the formation of bile to assist in the digestion of food. Physiologists have already made some most important discoveries respecting the action of bile, but if we may judge by what has already been brought before our notice concerning the functions of this organ, we can only come to the conclusion that there is much more to be learned than has yet come to light; one very interesting coincidence has been observed by us; the absence of bile is productive of a very irritating form of diarrhœa; the presence of an excess of bile results in a form of diarrhœa that differs from the previous kind by an absence of irritation, by an excess of coloring material and by its peculiar odor; we do not for one moment arrogate to ourselves the ability to explain these differences, we merely state that such is our experience, and we are of the opinion that much has yet to be learned from the physiologist's standpoint as to the functions of this organ. Horses do not fall victims so readily to diseased liver as do dogs, nevertineless the frequent complications with other forms of disease in which the liver is involved serve to prove how sensitive this organ is and how easily it gets out of order; in the course of this work frequent reference is made to liver complications as evidenced by a yellow condition of the visible mucous membranes, the high color of the urine, and the state of the fæces, we have frequently remarked that were horses and dogs as free livers as men, and included alcohol in their dietary, they would in all probability be the subjects of very decided liver complaints, quite as troublesome, if not more so, as in the human subject; moreover, the relations of the liver with other organs, and its capabilities of influencing them in the performance of their functions, are deserving of consideration and attention; among these latter may be, mentioned one very curious instance in which a deranged liver has been held responsible for lameness of the off 
fore limb; it is therefore desirable and important in the interests of the owner and the welfare of the horse to be always alive to any possible liver complications that may arise in connection with almost every form of disease, the suggestive indications of which have already been mentioned.

\section{CONGESTION OF LIVER}

Is intimately connected with disturbance of the heart due either to an obstruction of the flow of blood as it returns through the large veins, or to an increase of blood over and above the normal in the blood vessels which convey the vital fluid to and from the organ itself; it has already been stated that the principal function of the liver is the formation of bile; the organ "is made up of small roundish or oval portions called lobules each of which is about $\frac{1}{20}$ of an inch in diameter, and composed of the minute branches of the portal vein, hepatic artery, hepatic duct and hepatic vein; while the interstices of these vessels are filled by the liver cells. These cells which make up a great portion of the substance of the organ are rounded or polygonal from about $\frac{1}{800}$ to $\frac{1}{1000}$ of an inch in diameter containing well-marked nuclei and granules and having sometimes a yellowish tinge, especially about their nuclei; frequently also they contain also various-sized particles of fat. Each lobule is very sparingly invested by areolar tissue" (Kirke's Physiology). The small vessles described as ducts convey the bile after it is formed in the cells to the main duct, which empties itself into the intestines, and as these lie in juxtaposition to the numerous blood vessels already named it will be apparent how it is that an excessive accumulation of blood, which does not pass away from the organ as it should do, accounts for much that would otherwise be difficult to understand in relation to the yellow color imparted to the visible mucous membranes, from which we learn by ocular demonstration that the functions of the liver are disorganized and out of order, for it would appear that when the flow of blood out of the organ is retarded, pressure is brought to bear on the bile ducts, hindering the free passage of the bile in its right course and causing it to pass through the walls of the ducts into and through those of the bloo! vessels, by which means the blood stream is overcharged with bile and its color altered, and in this way the yellow tinge is imparted to the pale 
mucous membranes as the blood continues its course over the general system.

Symptous.-Yellow condition of the mucous membrane of eyes and mouth; pain of the right side in region of liver, just behind the last rib, which the horse shows by frequently turning his head in this direction and by tenderness on manipulation; marked languor and dulness; impaired appetite; frequent pulse and quick respirations; but unless complicated with other disease the temperature remains about normal; legs and ears are frequently cold; at the same time it will be well to examine the patient for diseases of heart, lungs and intestines, as complications are frequently present.

Hepatitis or inflammation of the liver rarely occurs among horses; and "the condition when affecting the horse I have not been able during life to differentiate from the congestive actions already noticed. The existence of hepatic disturbance may be certain; to determine whether the gland is congested or superficially inflamed is, in the greater number of cases, not possible. The history of the case may in some instances assist us." (Robertson). The experience of this writer is in complete harmony with our own, but we have quoted his own words in proof of the fact we are not alone in being unable to definitely distinguish in all cases between simple congestive and inflammatory action; we shall therefore proceed to deal with the treatment of the disease as it generally presents itself among horses.

Treatment.-Bryonia 3x.-Tenderness on pressure; region of liver may be slightly swollen and enlarged; giddiness; pale yellowness of skin and mucous membranes; constipation, no inclination to pass fæces.

Mercurius solubilis 3x.-Shivering; cold sweat; fæces pale in color, constipated and offensive to the smell; appetite suspended; eyes and mouth yellow, but the skin is sallow looking; horse experiences so much pain in the region of liver that he rarely lies down, and when he does, it is to rest on the near side; the fæces may be relaxed, in which case they give evidence of the presence of an excess of bile so far as the color is concerned.

Aconite $3 \mathrm{x}$ in cases of sudden and acute bilious fever, when the temperature is exalted and the pulse and respirations much more 
frequent than they should be; bilious attacks that are the result of cold and chill.

Chelidonium majus $\theta$ has a marked action on the liver; chronic inflammation, jaundice and the presence of gall stones call for its remedial powers, and derive marked benefit therefrom; the fæces may be either soft and of a deep yellow color, or constipated and very pale; the skin and visible mucous membranes are generally of a deep orange color, such as is observed in a true case of jaundice; the urine thick, of a deep yellow color, and leaving a sediment after evaporation; the tongue thickly coated with yellow fur.

Leptandra Virginica $\theta$. -The usual symptoms of bilious fever or jaundice, but with one especial distinguishing characteristic of the fæces, "frequent, profuse, black, fretid and papescent." (Hughes).

Lycopodium 3x.-Obstinate constipation; action of kidneys unusually active, a great deal of urine passed during the night; rumbling of wind in the intestines; visible mucous membranes pale and sallow; extreme tenderness on manipulating the seat of the liver; oppressed breathing; deposit of brick-dust-looking sediment with the urine.

Hepar sulphur $6 \mathrm{x}$ in cases of congested liver after the patients have been ineffectually dosed with too large quantities of calomel.

ACCESSORY MEASURES.-Food of a non-stimulating character should be allowed in moderate quantity only; corn of all descriptions must be temporarily suspended; if the time of year permits it, artificial grasses, such as clover and lucerne, form the best and most suitable articles of diet; the horse should be placed in a roomy loose box, wherein he can move about if so disposed, and so soon as convalescence is established exercise on a gradually increasing scale should be given, the horse being led by hand for this purpose; but actual work must not be attempted until the animal has resumed his natural vigor and life, and even then should be brought to it by degrees. 


\section{DISEASES OF THE - URINARY AND GENERATIVE ORGANS.}

In attempting to treat of these subjects in a plain and easy-tobe-understood manner, we confess to entertaining some fear as to success, for we recognize no little difficulty in the effort before us; it is indeed by no means a simple matter to explain why such difficulty exists: the fact, however, is an acknowledged one, that even in the realm of physiology, masters of the science are unable to reconcile, one with the other, the multifarious details affecting the functions of the organs now under consideration, and precisely as to the results of the performance of said functions. It is, however: desirable for the better appreciation of the diseases affecting the urinary organs, that it should be understood that broadly speaking their functions are the separation from the blood of those substances that the body has no further use for, the collection of such in a state of solution and their conveyance out of the body; the kidneys are the organs through the medium of which the effete material in the blood is separated and collected for transmission through tubes which connect the kidneys with the bladder, the receptacle provided for retention of the urine as it is drop by drop filtered through the kidneys; from the bladder it passes through a still larger tube called the urethra, which in the male passes down the full length of the generative organ, while in the female it empties itself into the genital canal about two or three inches from the opening of the same. To return to the kidneys, their mechanism is arranged structurally to realize a continuous process of steady filtration; very minute blood vessels lie side by side with equally minute tubes for the collection of urine, the arrangements for which are most beautifully ordered for the realization of this object; the power of selection-if such a term may be applied-which the kidneys possess to draw off from the blood, only those constituents which are worn out and 
done with is certainly remarkable; according to the amount of pressure in the blood stream, which is, in a great measure at least, regulated by the force of the heart's contractions, so chiefly is the secretion of the urine augmented or decreased; at the same time the secretion may be modified if there is an obstruction in the reins, which is one way of explaining in what way the liver, when the portal circulation is out of order, has an influence on the urinary secretion; by way of illustrating the power which blood pressure has in the production of urine, it is only necessary to refer to the well known fact that in hot weather much less urine is passed than in cold, assuming that the amounts of fluid taken into the body are nearly equal; this is due to the relaxed condition of the capillaries of the skin through which the watery constituents of the blood exude in the form of perspiration, consequently the amount of fluid that has to be filtered through the kidneys is much reduced.

It should also be understood that while one of the main functions of the kidneys is that of filtration from the blood, there are recognized constituents in the urine which have not been observed in the same form in the blood, hence the conclusion has been arrived at that the kidneys have the power of secretion, and that certain constituents are added to the urine in its passage through the tubes of the kidneys; putting these facts together, it will be seen that the functions of the kidneys are of a twofold character; namely, first, the function of filtrating the watery and soluble substances from the blood; and, second, the removal of certain constituents which go to make up the whole of the urine by means of a secretory power possessed by the uriniferous tubes; these facts are worth noting and have a special interest when dealing with a case of suppression of urine in the horse. If a kidney be cut into two equal sections and the surface of the cut portion examined under a powerful magnifying glass, it will be seen that it consists mainly of convoluted tubes of various sizes, while the central portion of the organ forms a cavity wherein the secretion is collected; from thence the urine passes down a single tube of proportionately larger calibre and is emptied into the bladder, which is an organ consisting of various kinds of muscles lined internally with mucous membrane; as the bladder becomes filled the desire to evacuate same arises through the influence of certain nerve 
branches from the spinal cord, and the desire is responded to by the action of special nerres upon certain muscular fibres which go to make up the walls of the bladder, and therefore thesa muscuiafibres contract and in this way make the organ itself smaller, and so the urine is forced out into the urethra and from thence discharged as hereinbefore explained; other influences are brougint to bear in assisting the bladder to empty itself, but this will suffice for the object in view, namely, to supply a cursory glance of the function of urination. In order that the importance of obtaining an intelligent appreciation of this subject may be impressed upon the reader, it may be well to state, as shortly as possible, the principal constituents of urine; and as we proceed it is hoped that it will be discorered this has an important bearing upon the health of horses, as observations of the appearance of urine, so far as regards color and consistence are made. In the first place, the specific gravity of the horse's urine arerages Io 45 ; the range raries from IoI 6 to I060, the rariations depend in a great measure upon the mode of feeding as well as upon diseased conditions; the diet also has a bearing upon the condition of urine whether the same gives an acid or an alkaline reaction upon testing, a process that furnishes valuable aid in selecting a drug under certain conditions. The constituent composition of urine in health is approximately made up of water, urea and uric acid, which are decomposition products of food and of the tissues of the body; hippuric acid derived chiefly from food; coloring and aromatic matters, and salts, among which the phosphates abound. Much greater care in observing the state of the urine is called for than is generally exhibited during periods of illness, and there are several points calling for special consideration; for instance, urine may have either an excess or deficiency of the watery constituents; an excess of water may under certain conditions be farorable, as it serves to wash away from the tubes of the kidners any accumulation of solid matter that has collected during disease; on the other hand it may be an evidence of disease itself, as in one form of diabetes. Then, with regard to apparent deficiency of water, it may be due to the fact of the horse haring been submitted to hard rork in hot weather causing considerable perspiration; or the increase of urea and other solid constituents may be larger without a relative increase in the water; in both instances the alteration may take 
place without involving any morbid conditions; but should the changes occur in conjunction with the development of some febrile disease it would be clear that the one was associated with the other and this would undoubtedly be an aid to diagnosis and treatment. Further, it may be found by examination that there are substances present in the urine that are not found in health, such as albumen, bile, sugar, any or all of which will be present in a state of solution and require chemical tests to discover their presence; blood, pus and mucus, the presence of which can be determined by microscopical and chemical examination. It would not serve any useful purpose to mention in detail the several methods of testing for the presence of such abnormal and foreign substances, the safest and cheapest procedure is to submit the urine to a .qualified analytical chemist, and obtain a full report, as much may depend upon a proper appreciation of the actual facts as to the nature of the disease, its locality and conditions; and this is the more important, inasmuch as distant organs like the liver and the lungs, to say nothing of the organs of digestion and circulation, exercise a distinct and unmistakable influence upon the urinary secretion, and it is absolutely necessary to differentiate between morbid conditions due to other and distant organs and morbid lesions of the urinary organs themselves. We commenced the chapter by asserting that the subject of the urinary organs was a complex and diffcult one, and we believe this brief introduction to the main subjects will in the opinion of our readers fully justify the assertion.

\section{CONGESTION OF KIDNEYS.}

\section{RENAL CONGESTION.}

By renal congestion is to be understood an excess of blood in the structure of the kidneys; this congestion is a condition which invariably precedes inflammation of these, or, indeed, any organ of the body; and if the congestion can be allayed, inflammation will never follow. The word inflammation with the ordinary stableman, or even with the horse-knacker, is a phrase that is vulgarly applied to almost every case of illness where there is an evidence of excess of blood to a part withont regard to the real disease conditions or the organs affected; and we have repeatedly 
heard post-mortem congestion of the lung, on the side the dead horse had lain for some hours, seriously described as inflammation; it is therefore desirable that a more intelligent appreciation of the meaning of these words should be accepted by those who peruse these pages. Congestion of the kidneys is not frequently met with in the horse, a somewhat remarkable fact when we bear in mind that it is capable of development as the result of introducing into the system such irritant agents as Turpentine and Cantharides, both of which are frequently used as outward applications in connection with blistering and stimulating operations; we have known more than one case where distinct evidence of renal congestion was shown following a blister applied to the loins for a sprained back caused by a horse over-jumping in the hunting field; and one case in which a horse had an application of Turpentine over his ribs for congestion of the lungs; the best antidote in such cases is Camphor; the fact remains, however, as a standing monument in proof of the truth of the principles of Homœopathy, inasmuch as both these drugs prove remedial in all simple cases of congestion of the kidneys when brought on from cold or following upon some specific fever. It is desirable in all cases to observe the symptoms which indicate a congested condition of the kidneys, in order to prevent its developing into true inflammation, and probably one of the earliest of these is suppression of urine; the horse will repeatedly posture himself, as for the act of micturition, and strain out a few drops only of thick, turbid urine, sometimes accompanied with a little blood, but the latter will not always be observable to the naked eye, while yet again, the red coloring material may be distinctly observable and no blood corpuscles visible under the microscope, these being present in a broken-up state. The constitutional symptoms are not sufficiently marked to enable one to rely upon them as a sure indication that the horse is wrong, therefore we shall pass on to the

Treatment.-Provided that Turpentine is not the cause of congestion, there is no remedy more likely to prove effectual than Terebinthina 3x. Other remedies, such as Belladonna, Mercurius corrosivus, Cantharis and Arsenic have produced congested kidneys and would no doubt prove serviceable under given conditions, but these it is not worth while reverting to, in face of the almost invariable success of Terebinth. There is, however, one condition that may 
give rise to renal congestion, namely, external viulence and consequent injuries to the renal organs, when, as a rule, Arnica $2 \mathrm{x}$ will be found most suitable, and the internal administration of this drug may very usefully be combined with an outward application of a lotion of the same I-6 applied as a compress. In all cases where the patient exhibits symptoms of great pain by uneasiness and unwillingness to rest, warm compresses should be applied by wringing out flannel dipped in boiling water, apply same when at all bearable, cover with oil skin, and over that again a thick horse cloth.

\section{INFLAMMA'TION·OF KIDNEYS.}

\section{NEPHRITIS.}

Like some other organs of complex structure, the kidneys may be the seat of inflammation as a whole-certainly a rare occurrence in the horse-or as is more common, one portion of their structure is in a state of inflammation, while the other may be entirely free from the influence of inflammatory products; while it is common practice among laymen to speak of inflammation of the kidneys in a general sort of way as though one form and one only existed, it is desirable for the sake of successful treatment to endeavor to make it clear that a distinction exists, what that distinction is and how it may be discovered. Already an attempt, though a very crude one, has been made to explain something of the anatomical structure of a kidney, and we got so far as to show that this organ consisted mainly of tubes of varying size and configuration, arranged in bundles, and that as well as the tubes their structure consisted also of various shades and sizes of blood vessels; now it will no doubt appear quite feasible-indeed absolutely necessary - that some sort of support should be supplied to keep these tubes and blood vessels in place, and so there is a fibrous network cunningly introduced between the interstices of the tubes described as "connective tissuc," the whole being enclosed and kept in shape by a beautifully fine membrane called the capsule. Not to burden the reader with an unnecessarily long explanation we shall divide the possible inflammatory conditions of the kidney into two groups; first-inflammation of the tubes or 
tubal nephritis; and second-inflammation of the "connective tissue" or interstitial nephritis; a third condition howerer sometimes arises which may develop either among the tubes or in the substance of the "connective tissue" and may therefore become a sequel to either of the two main groups of inflammation, namely, suppurative nephritis, or the formation of abscesses due very frequently to blood poisoning. The next question that arises for consideration is how are these two main groups of inflammation to be recognized the one from the other.

When the tubes are the seat of inflammation, the deleterious and effete matter which is trying to make its way out of the system through the kidneys blocks up the urine tubes because the quantity of material to be conveyed is in excess of the capacity of the tubes, this being the origin of the primary congestion and subsequent inflammation; there being under these conditions no suppression of urine, the fluid constituents are unable to pass out as in health and a regular block takes place; the consequence is that with the pressure of the blood stream behind, the fluid portions must find an exit somewhere, and dropsical effusions under the skin are the result and albumen almost invariably makes its appearance in the urine; in the horse, the most common localities for the effusions to first appear are the breast and the penis, sometimes extending along the floor of the abdomen; as in the case of renal congestion the first thing to attract the stableman's attention is the uneasiness, the repeated posturing with hind and fore legs as about to micturate, standing up again and so on until perhaps a small quantity of thickish-looking urine is passed; a turning round of the head first to one side and then the other, and if not tied up occasionally lying down and on rising making a further effort to pass water.

The horse will experience some general disturbance affecting temperature (103 degrees), pulse (75), respiration uncertain. The appetite for food will be decidedly impaired and the desire for fluids almost nil; the horse will evince a good deal of pain when called upon to move, and the hind legs will be dragged along in a stiff, almost helpless manner; gentle pressure orer the loins on either side of the spinal column will cause the animal to exhibit distinct evidence of tenderness and pain. An opportunity must be arailed of, when the horse is able to pass a little water to have 
some collected in a perfectly clean vessel; this should at once be carefully transferred to a clean bottle, tightly corked down and forwarded to the nearest analytical chemist without loss of time, and should the report confirm the natural suspicion that tube casts, albumen and possibly blood are present, good reason will exist for administering Cantharis $3 x$ every three hours; should this fail to give relief in the course of twelve hours, and the suppression of the urine thereafter becomes complete then Terebinthina Ix must be tested.

In those cases wherein the effusion under the skin is very pronounced and the exhalations from the skin have a decided uriniferous smell, Terebinthina should be given in the first instance, and when the urinary troubles are relieved therefrom, but the effusions remain as large as before, Apis mel. Ix three times a day should be given. This urinary difficulty occasionally arises as a sequel to strangles or influenza in the horse; when this is so, and the dropsical condition about the chest and other parts is slow to be removed, Arsenicum 3x grains ten three times a day will often effect the desired object and otherwise tend to restore the animal to a good state of health and vigor.

To return to the other group, namely, Interstitial nephritis, or inflammation of the connective tissue of the organ, we have to deal with a far more serious condition of affairs, but fortunately for horse owners one only rarely observed in that animal; it has been stated that it may start as a sequel to tubal nephritis or in an independent character of its own; moreover, the extent of the parts affected varies, which no doubt makes a deal of difference in the results of treatment. By a remarkable coincidence, so far as cause and effect have a bearing upon the treatment suggested for this description of renal inflammation, we find that the late Prof. Robertson in his masterly work on "Equine Medicine," when dealing with the "causation" of this morbid condition states, "slow ingestion of lead and some of its salts are said to induce the condition," while Dr. Hughes in his Manual of Therapeutics in the chapter devoted to this subject affirms, "I have always pointed out that our most hopeful outlook is in the direction of Plumbum." In comparing these two statements, emanating as they do from such eminent authorities, we are compelled to cone to the conclusion that a distinct pathogenetic and therapeutic 
relation exists between lead and interstitial nephritis. We have never seen a case in the horse, but have good reason for believing that we once enjoyed the exceptional opportunity of doing so in the cow; so far as the animal was concerned she presented a most perfect picture of lead poisoning one could ever expect or wish to see, still no opportunity had existed for her to partake of the poison. Without the slightest hesitation therefore we prescribed Plumbum 3x, grains xv every four hours, and one of the most unexpected and marvellous cures was effected we ever expect to witness; the cow's urine gave unmistakable evidence of the condition of the kidneys; this was accompanied with spasmodic colic, knuckling over of the hind fetlock joints; paralysis of the intestines; frightful emaciation; constipation; retracted abdomen; suppression of milk secretion; slow, lethargic pulse; breathing oppressed; temperature below normal; eyes amaurotic; the urine had to be drawn off with the catheter, and the passage of the fæces was assisted with repeated injections of warm water, and when passed consisted of small, black, bullet-shaped masses. Now, although this was not a complicated case of interstitial nephritis we feel justified in quoting it as a practical illustration of the suitability of Plumbum for this disease condition.

We now pass on to the consideration of suppurative nephritis, namely that condition in which ordinary inflammation has developed into the formation of abscesses; the only special symptom over and above those already indicated is the presence in the urine of matter or pus; here again the analytical chemist must be consulted with a view to definite information upon which reliance may be placed. Beyond the ordinary possibility of inflammation developing suppuration, abscesses may arise in the tubes from the presence of stones in the kidneys, but when this latter is the cause suspicion may be aroused by the evidence of great pain that the horse will show; at the same time it is important to confirm such a suspicion by a watchful oversight and examination of the urine for evidence of the presence of stones, which, of course, can be only very small. For the suppuration per se, and in the absence of foreign substances, Hepar sulphuris $3 \mathrm{x}$ may be administered twice daily; but should there be unmistakable evidence of the presence of stone, Dr. Hughes recommends Uva ursi.

Whenever pain is very marked it will invariably be desirable to 
endeavor to allay this by topical applications, such as flannel wrung out in hot water, laid on the loins, and covered with oil cloth and externally a horse rug to keep up a state of warm moisture to the parts; this may be renewed whenever the pain seems specially marked; the feeding should be of the light, nutritious, easily digestible order, and the drink consist of linseed gruel and barley water.

If the horse is brought down low in condition it will be desirable to give him China $\theta$; ten drops, night and morning for a week; discontinue same for a week, giving one intermediate dose of Sulphur 3 , and recommence the China $\theta$ for another week and so on till condition is decidedly improved.

\section{DIABETES.}

This malady is, without doubt, more frequently met with among human than veterinary patients, and one peculiar feature in connection with it is, that whereas there are two distinct manifestations of the disease, the one that more generally appears in the human subject, is of rare occurrence in the horse; while that which is observed among equines is less frequently noted in man. It cannot be affirmed that diabetes is strictly a disease of the urinary organs, but we have indicated it thereunder because its chief manifestation, so far as human observation goes, is through this channel.

Diabetes is ascribed by some to dietetic causes, but our own opinion is that some reasons, other than these, are called for to account for its development. Already we have referred to the fact that the malady assumes two distinct forms and two names are accordingly employed to designate the one from the other, namely diabetes mellitus in which traces of the presence of sugar are observable and diabetes insipidus which is by no means of uncommon occurrence among equines; to the consideration of this form of the malady we shall mainly confine out attention, simply pointing out in passing that if the specific gravity of the urine at any time points to a probability that sugar is present the doubt can soon be set at rest by submitting samples of the water for several successive days to an analytical chemist, and in the event of the test affirming the suspicion three times out of four, it will be fair to assume that a case of diabetes mellitus has to be contended 
with when no better remedy than Phosphoric acid ix three times a day can be administered; meanwhile all food that contains an excess of saccharine constituents should be aroided.

Diabetes insipidus is characterized by an unusual proportion of watery urine; it is affirmed by some that the usual solid elements of the urine are not deficient, but that the watery constituents are so much in excess of the normal that it appears as though the solids were entirely wanting; the late Professor Robertson attributes the cause of "insipid urine" to disturbed innervation, while among existing influences, he considers damaged provender responsible for its development. The most notable case that has come under our immediate notice and care was that of a horse worked by a market gardener in conveying his produce from house to house during the morning half of the day; by no means heavy work; for a period of three months the animal had been gradually evincing less and less capacity for the performance of his comparatively light work; he lost flesh and had a precarious appetite, at one time eating voraciously, at another refusing the most dainty diet, it had been observed that he drank very copiously and always appeared to be ready for the pail; the owner's observation had not, however, been attracted to anything peculiar in the performance of urination; the only feature of the case to which our special attention was drawn was that presence of an extraordinary large number of nematoid worms, (Ascaris megalocephala) and for the eradication of these, we were consulted; usual remedies were administered with the result that though a very large number came away whole with the fæces, while others came away in bits, portions of which had been evidently digested by the secretions of the large intestines, the horse was no better; indeed, the emaciation was more pronounced; we therefore urged our client to send the animal into the infirmary which he reluctantly consented to; the horse had only been under our immediate care a few hours before we discovered what was at all events partly the matter with him; the box in which he was placed was absolutely flooded out; we afterwards discovered that his temperature fluctuated to an extraordinary degree from day to day, between 99 degrees and 104 degrees; this led us to suspect something more than diabetes; we at once commenced administering Phosphoric acid $\theta$, but as the result was not satisfactory, resorted to Scilla Ix; this latter certainly 
effected a marked diminution in the amount of urine passed; but as the post mortem proved the horse was the subject of general consumption (tuberculosis), both lungs presenting the most remarkable specimens of diffuse miliary tubercle we ever saw, and all the internal organs were more or less affected; this, therefore, and not the diabetes, was the cause of death; but it is deserving of special attention that notwithstanding these complications, the remedy administered for the diabetes was able to exercise the desired effect in some degree; and it would we think, justify us in the conclusion that in uncomplicated diabetes insipidus, Scilla is a promising medicine. The symptoms of this malady are greenish blue color of the visible mucous membranes; fæces constipated; temperature rather under than over the normal 98.5 degrees; the skin dry, the coat harsh and staring; pulse soft and weak generally about 50; urination excessively profuse without any coloring material in it; thirst specially marked, and appetite precarious and changeable. In the treatment of this malady there is one point worthy of notice; if, as is the case sometimes, there is distinct evidence that the digestive organs are at fault Muriate of Uranium $3 \mathrm{x}$ trituration is a serviceable remedy and preferable to others already prescribed.

\section{CYSTITIS.}

\section{INFLAMMATION OF THE URINARY BLADDER.}

This in the horse is of rare occurrence as a natural disease; when it does arise there is as a rule some extraneous cause to account for it, such as the irritation which the presence of a calculus (stone) would produce; and it is worth while to make a special note of this fact, lest the symptonus which in all cases differ but little, should lead anyone to attempt a cure by the internal administration of drugs when a stone was the cause of the difficulty; under such conditions nothing but failure and disappointment would accrue, and it would provide the enemy (allopaths) with a fine opportunity to point the finger of scorn at Homœopathy generally; when a stone is present in the bladder, a fact which is easily confirmed by manipulation of the organ per rectum, the only satisfactory method of treatment is remoral by 
surgical operation at the hands of an expert veterinarian; this fact furnishes no reasonable ground for the enemy to revile, because the removal of a foreign body does not come within the range of therapeutics at all but is a mechanical operation to effect which the aid of surgery must be invoked; where, however, a true case of cystitis arises which does not result from the irritation of such foreign substances, then medicine will avail as successfully as in all other forms of disease to which therapeutics proper are applicable. The symptoms are in many respects marvelously like those of nephritis, but there are two or three special symptoms which point distinctly to the bladder as the affected organ; and they are as follows: A continual paddling movement with the hind legs; an irritable swishing of the tail; and a more or less constant dribbling away of bloody urine; under these conditions we have found Belladonna $3 \mathrm{x}$ and Cantharis $6 \mathrm{x}$ administered in alternation, a dose every three hours, afford marked and speedy relief; in cases of stone after removal by operative surgery Arnica $3 \mathrm{x}$ three times daily should be administered, as this serves to remore the general soreness of the parts and facilitates the healing process.

Like nephritis this malady may be caused by the application of a topical irritant such as Cantharides, under these circumstances a few doses of Camphor spirits on moist sugar should be administered.

It will be noted under the chapter headed CoLIC that one of the conditions then frequently affecting horses is an inability to pass water; we consider that this is due to a paralyzed condition of the muscular walls of the bladder, either from colds or in consequence of the horse having held his water too long, under such circumstances a dose of Aconite $\theta$ every fifteen minutes, as a rule, affords prompt relief.

There is further a condition affecting mares wherein an inflammatory state of the organ is set up, namely, INvEKSION of the BLADDER; the first and most important procedure is to reduce the crgan to its proper site, an operation calling for the experience of a trained veterinarian; but after the operation is completed, much benefit will follow the internal administration of Arnica 3x for several days; it will help to restore tone to the organ itself, 
together with its supporting ligaments, and so facilitate its maintaining the proper position in the body.

As.we have referred to the possible presence of stone in the bladder so be it understood we may not infrequently meet with cases where GRAVEL accumulates in that organ and evidence of its presence is made known when a horse makes water on a flat slab of stone or some other smooth substance upon which the gravel can rest and discover itself after the water has dried up; under such circumstances it will be wise and most probably hinder the development of future complications to administer a dose of Lycopodium 6x, grains fifteen, night and morning for a week, meanwhile watching the effect; if the gravelly deposit still continues, which is certainly improbable, a course of Phosphoric acid $6 \mathrm{x}$, drops ten night and morning should be tried. Inasmuch as gravel sometimes forms in the kidneys in particles of such size that they cannot pass away without causing intense pain in their passage through the tubes, presenting symptoms of acute colic in the horse, it is desirable to mention that if the indications point to this condition Berberis Ix is the remedy; presuming that it was already known that a horse had passed sandy urine, and an attack of colicky pain supervened, characterized by short, sharp, oftrecurring attacks of pain, while on manipulating the loins over the region of the kidneys, one side evinced considerable tenderness, it would not be unreasonable to surmise that it was a case of renal colic, and the use of Berberis would be justified, although the malady cannot be considered as one of frequent occurrence in the horse, nor is it one that often presents itself in any animal; hence the desirability of not forming too hasty an opinion in such cases of pain.

\section{AZOTURIA.}

We have experienced some difficulty in determining to our own satisfaction under what head to introduce the consideration of this malady; inasmuch, however, as its chief manifestation is observable from the characteristic condition of the urine, and that post mortem the kidneys betray indications of certain morbid processes, it has been determined to aliocate a position under the head of urinary diseases. It is anong well-fed, highly-conditioned horses that this disease usually presents itself, whose work is irregular, 
smart active work alternating with a period of rest; the attack comes on with great suddenness and severity, and an animal which one hour was to all appearance in the very bloom of health is in the next a pitiably helpless object. The first indication of the malady is usually inability to proceed by reason of muscular spasms affecting the loins and thighs, a loss of control over the movements of the hind legs; breaking out into a profuse sweat, and trembling all orer; the posterior extremities soon become unable to support the weight of the body and the animal rolls orer on its side, often struggling violently when down with a very obvious desire to regain the standing position; ultimately the horse wearies of these futile efforts and gives himself up to the necessity of the case and thereafter shorrs a firm determination to lie down quietly.

Very shortly spasmodic twitchings of the large muscles of the loins and thighs superrene, ultimately these same muscles become rounded, hard and rigid, and seem to have lost all power of contraction.

It is, as a rule, necessary to draw off the urine with the catheter and then the character of the secretion is observed to be of a deep coffee color, somewhat more dense in consistency than normal urine. The pulse is increased in frequency generally to about 65 or 70 beats per minute, while the temperature will register I02 degrees or thereabouts; the respirations will be regulated very much by the state of calm or irritability the animal has exhibited when the attack first declared itself. In case the horse renerrs the struggle to get on to its legs, it is best to apply the slings and get it properly fixed up therein, otherwise it may speedily exhaust itself.

Mares are considered by some to be more frequently the subjects of this malady than male horses, but this is undoubtedly a mistake, for all our cases have been in geldings, and Professor Robertson's experience seems to coincide with our own in this respect in the main.

There is one very troublesome complication or sequel to the disease within our experience that does not appear, so far as records go, to have fallen to the lot of other practitioners, namely, LAMINITIS, or inflammation of the sensitive laminæ of the feet, those of the forelegs in particular, and in one case notwithstanding the most careful treatment this condition proceeded to ex- 
tremes, the pedal bones protruding through the soles; whether the long period of standing in the slings was the main cause of this we cannot say, but under the circumstances we should, after this experience, be disposed to advise allowing a patient to retain the recumbent position if it would do so quietly, satisfying ourselves with moving it over from side to side once in twelve hours, and using an abundance of soft straw to support the body, drawing off the urine with the catheter every four hours, administering an abundance of demulcent drink such as linseed gruel and barley water to wash out the urinary tubes and the bladder.

The medicine we. should first rely upon would be Causticum Ix, repeating the usual dose every three hours during the daytime, and if this only succeeds in restoring the urine to its natural color and consistence, the muscular rigidity will soon relax and a good cure may be anticipated; but as a rule these are by no means promising cases. The fæces generally show a tendency to constipation, but should there be any disposition to diarrhoa combined with a high specific gravity of the urine $\operatorname{Senna} \theta$ will be found an efficacions remedy; we have tested both these agents at one time or another and each in turn has seemed to render satisfactory results. Friction with Arnica liniment over the rigid muscles will sometimes afford ease to the patient; at all times the body should be kept warm with clothing to induce gentle exhalation through the skin, and the food must be light so as to avoid the risk attendant at such times upon overloading the digestive organs.

\section{OCCASIONAL, DISEASES OF URINARY ORGANS.}

There are several forms of disease which assume more of the surgical aspect than the therapeutical, at all events in ordinary practice, and their introduction here is more to prove that they are not overlooked than in the hope that much advantage will accrue upon their consideration; still as cases of extreme urgency may arise it is deemed better in the interest of the reader to lightly touch upon them with a view to amelioration of suffering should they arise under such circumstances. Those norbid conditions which it is proposed to refer to will be found only in the male and the first is inflammation of the URETHRA; this is the channel 
which conveys the urine through the penis from the bladder and also the semen from the testicles in the act of copulation.

Inflammation of the urethra may be of the simple, benign form, or, as in the human subject, it may also assume the contagious character of a GONORRHœA, the latter, however, is very rare in the stallion; still there has been sufficient evidence forthcoming to warrant the assertion that it may exist; the symptoms are those common to this form of disease; matter forms and exudes at the end of the penis; and if the sheath of the penis is full and well developed an accumulation of the discharge will be found in that part of the organ, irritating the surrounding parts and producing considerable swelling thereof; the animal experiences distinct pain and difficulty in passing water and evinces a frequent desire to perform the act.

The treatment is simple and effective; whether the discharge is benign or contagious it is similar; the parts should be carefully washed with warm water medicated with a small quantity of Condy's fluid; and Mercurius corrosivus 2x, grains three to a dose, dissolved in a wineglassful of water, administered internally three times a day.

Phimosis is a condition, affecting geldings generally, in which the penis cannot be drawn out in consequence of the undue contraction of the sheath; it is said to be caused by external violence, and it may also arise after castration, or when the sheath has become excessively swollen during an illness and for lack of sufficient exercise; in attempting treatment much depends upon the cause; probably the best thing to do in a case of emergency would be to apply frequent fomentations of hot water together with hand friction and the rubbing into the parts of Arnica lotion I-6; but if at all available the services of a qualified veterinary surgeon should be called into requisition.

PARAPHIMOSIs is the antithesis of the former, in this case the penis is protruded beyond the sheath and cannot be withdrawn; the organ or that part of it which is so unnaturally exposéd becomes immensely swollen; inflammation is speedily set up and the pain is evidently extreme; in consequence of the swollen condition of the penis, the sheath becomes tightly constricted, the circulation is interfered with, and the exposed portion becomes cold. If the condition is due to a paralysis of the organ, the pros- 
pect of restoring its pristine vigor is by no means promising, but the first thing to be done is to relax the constricted state of the sheath, and this in the majority of instances calls for operative surgery; if this is not available an effort must be made to reduce the engorgment with hot fomentations and friction; at the same time the penis should be supported with a broad piece of calico fastened round the body in such a manner as to comfortably suspend the injured organ therein, and if the constricted sheath becomes still tighter, relief may be afforded by effecting three or four incisions about half an inch deep with a sharp pair of scissors; this will have the effect of relieving the excessive turgescence of the parts, free hæmorrhage for a short time will probably conduce to the desired result; but should this continue too long then a stream of cold water should be allowed to play upon the parts until the bleeding stops; when the swelling subsides the exposed part of the penis should be well lubricated with carbolized sweet oil and an attempt made to return the organ within the sheath; the incisions made into that part should be carefully brought together and retained in position with a silken suture and thereafter a lotion $\mathrm{r}-6$ of Calendula $\theta$ applied two or three times a day until the healing is complete; if, however, a veterinary surgeon can by any means be secured it is distinctly advisable to incur any reasonable trouble to obtain his services under such circumstances, for the case may prove so hopeless as to necessitate the amputation of a portion of the penis, to determine which a professional opinion would be absolutely called for.

ORCHITIS or inflammation of the testicles is a disease little likely to affect a horse unless it be due to injury during an attempt at copulation; there is nevertheless the bare possibility of its existence from cold or undue exposure after being accustomed to warm surroundings; under such circumstances the swelling of the parts, which would also be very tender, would be attended by constitutional and febrile symptoms; the temperature would be exalted and the pulse more than usually rapid; the animal would be off his feed and generally give expression to feelings of malaise; under these circumstances a few preliminary doses of Aconite $3 x$ should be followed by Pulsatilla ix three times a day. If the horse has suffered from a blow and the testicles are contused thereby, the parts will require frequent fomenting witl hot 
water medicated with a ferw drops of Arnica $\theta$, and Arnica $3 x$ should be internally administered three or four times daily.

SATYRIASIS. - We use this term to convey the idea of excessive sexual excitement in the stallion; several cases have come under our notice of valuable thoroughbred horses which seemed to have developed a habit of self-abuse by continuously whacking the penis up against the abdomen until the excitement of the proceeding caused an emission of semen; unfortunately we were not professionally consulted in either of the instances referred to, and consequently cannot speak practically as to a cure; we see no reason however to doubt the possibility of such an occurrence, had the opportunity been placed at disposal and among the remedies that promise success under such conditions are Phosphorus, Nux vomica and Platina.

IMPOTENCE in the stallion we believe to be exceedingly rare, but that it may and does occasionally arise especially in the case of horses whose services are in great public demand there is no doubt, but our firm belief is that in the majority of cases where a mare proves barren the fault is on her side and not the horse's.

First, then, impotence may be due to an excessive demand upon the sexual functions. Under such circumstances it is of the first importance that the stallion should enjoy absolute rest for some months, during which time Phosphoric acid $\theta$ should be given twice a day and food rich in phosphates provided.

Second, the demand on the sexual powers of the horse may have been sufficient to produce atrophy or wasting of the testicles; this condition is still more serious; for such a state of affairs Conium and Baryta carbonica are recommended, but we cannot speak from experience as to the value of these remedies. 


\section{PARTURITION.}

\section{BEFORE, DURING AND AFTER THE ACT.}

But for the fact that there are included in the Homœopathic Pharmacopœia so many drugs which are entirely ignored or unacknowledged by the allopathist, whose special function seems to be to afford aid to the female during the periods of gestation and parturition (bearing and delivery), it rould be absolutely useless to attempt to compress into the pages of this book anything regarding this unusually wide subject that would be likely to be of the slightest use. Dr. Fleming in his text book on "Veterinary Obstetrics" has filled up over $75^{\circ}$ pages, and Dr. Guernsey in his valuable book on Human Obstetrics occupies close on Iooo pages in dealing with this all-important subject; it may, therefore, be asked what useful purpose can be served by attempting to present to laymen a few scattered thoughts, when the proper consideration of the subject by these two learned practitioners has occupied so much space. Well, our reply to such a critic, if such a one there be, is that a few crumbs to the starving are better than no food, and the few suggestions on this vitally important topic which can be compressed herein will, it is hoped, prove better than allowing breeders of horses to find nothing in this work regarding the subject which affects them from a financial standpoint in so marked a manner. Had we nothing more by.way of assistance at so critical a juncture than the allopathist can offer, we would feign let the subject pass, but as we can make suggestions for the comfort and safety of the "in-foal mare" before time of delivery, and further, can assist nature during the act of delivery, and, further still, help to restore nature to her normal equilibrium after the same has been upset diring the period of "foal birth" there is good reason to believe that we are warranted in the endeavor to place before those who are otherwise helpless a few leading suggestions for their adoption, and if the 
experience of the past stands for anything, these suggestions will be found worthy of careful consideration.

It is well known to all practical breeders that in the mare, as in all other animals, but probably in the mare more than any other, the fœtus during its development and growth in the uterus (romb) assumes all sorts of positions, some of which are normal and favorable to spontaneous and unaided birth, and many others which are abnormal and decidedly unfavorable to birth without the intervention of the surgeon; these positions are described as "presentations" according as the head, fore feet, hind feet, croup, etc., first presents itself to the hand of the exploring surgeon; the variety of these presentations is very numerous, and while the tissues of the womb, and the canal through which the fœtus has to pass during the act of being born, are extremely mobile and elastic, so much so that fœtuses in all sorts of abnormal positions have been brought into the world with more or less surgical force, there is a limit to the extent to which the parts will relax and for the good both of the mother and her offspring, it is of the first importance that this-under the most favorable circumstances-painful fulfillment of nature's demands should be carried out under the most favorable conditions, and although the allopathist, the orthodox practitioner as he delights to call himself, has not, with all his vaunted boasting, discovered anything to alleviate nature's pain at this critical period save the anæsthetic Chloroform, the much maligned homœopathist has found out that Pulsatilla is an agent in drug form capable not only of preparing the womb for the fulfillment of its natural functions under favorable and comparatively easy conditions, but that this valuable plant is capable of so influencing the maternal organs that in the event of a FALSE or COMPLICATED PRESENTATION the fotus will, under its influence, right itself sufficiently to be born without extraneous or surgical aid, and that without producing a permanent displacement of the womb which, in some instances, is the result of the rough usage and the violent methods resorted to when diffcult presentations occur. It may not be generally known to breeders, but it is a point they ought to be made aware of and to which they should give serious consideration, that operative obstetric surgery of the very crude and rough description to which so many mares are subjected, is responsible in quite a considerable 
number of cases for permanent DISPLACEMENT of the WOMB, and the subsequent BARRENNESS of valuable brood mares; the fact that so many mares miss being in foal after a satisfactory service, is too frequently attributed to the sterility or incapacity of the stallion, while the really responsible cause is that the womb of the mare through the violent measures adopted at her previous parturition (delivery) is displaced, and the os (or mouth) of the womb instead of being in a direct line with the genital canal is drawn on one side or the other so that the semen, when discharged in the act of copulation, cannot enter the womb but ultimately finds its way on to the floor of the canal, thereafter to be washed away on the first act of urination; and, of course, the mare proves not to be in foal and is a bitter disappointment to her owner; to render the act of parturition a normal and spontaneous one is of the first consequence to the breeder of horses, and to dispense with mechanical interference, especially the rough and tumble sort of work so often attempted by ignornant quacks and inexperienced, though well-intentioned stablemen, is no less important; the author does not wish it to be understood that obstetric surgery can always be dispensed with; there must of necessity be cases in which the presentations are so complicated and peculiar, either by reason of the distorted shape of the fotus or its excessive size, that nothing short of mechanical aid will effect delivery; but these cases should and might be much more rare than they are, and when mechanical aid is absolutely required it should be entrusted only to a skillful and experienced obstetric veterinary surgeon; indeed, we go so far as to state that an unqualified man who attempts to deliver a parturient animal should be amenable to the law for cruelty, as in so many cases is the attempt made by those who are absolutely ignorant of the anatomy of the animal.

By way of preparation for a safe and comparatively easy delivery the owner should see to it that the in-foal mare has ten drops of tincture of Pulsatilla $\mathrm{Ix}$ in a wineglass of water night and morning regularly for a month before the date she is due to foal on; and this should be given half an hour before both feeding and watering.

Space will not permit of dealing with the science of breeding nor of doing anything beyond offering a few suggestions as to treatment in cases of emergency; therefore it must be assumed 
that the owner has made satisfactory and suitable prorision for the comfort, general well-being and health of the mare, and that the due date of foaling has arrived; under the influence of Pulsatilla administered as hereinbefore explained, the mare will probably experience a spontaneous and normal delivery; but there may arise difficulties, which are amenable to the influence of drugs and which drugs will obviate without mechanical interference, concerning which some helpful suggestions may be offered. A contracted, hard, rigid condition of the OS UTERI (mouth of the womb) arises, and this quite independent of cancerous growths, termed cauliflorrer excrescences, which are sometimes the cause of this rigid condition; when this is the case it can of course only be positively recognized by manual exploration which should be carefully and gently attempted when delivery is delayed or the mare has made many ineffectual efforts to discharge the fœtus; before making the examination the person who undertakes the responsibility must strip off his clothes eren to the shirt, wash his hands and arms carefully with warm water, and then dress the arm that he is going to use in the examination with carbolized oil; this serves to facilitate the easy introduction of the arm into the vaginal canal and to prerent septic infection; if the os is found to be closed and very hard try the administration of tincture of Caulophyllum $\theta$ ten drops every hour for three doses, after which at the expiration of twelve hours from the first dose if the os is not dilated and the delirery effected professional aid should be obtained, but as a rule this drug remores the functional disturbance which caused the rigidity, the os relaxes and dilates and labor proceeds to a satisfactory termination. Another cause which sometimes accounts for delay in delivery is due to lack of nerre power in the walls of the womb, resulting in very spasmodic and irregular contraction in which case, if the mare seems to experience very violent pains while they last, and she gets irritable and probably neighs spitefully Chamomilla $3 \mathrm{x}$, ten drops to a dose every hour will be most suitable. In cases where no progress seems to be made and the mare bursts out into cold sweats especially about the neck and shoulders and every pain appears to exhaust her more and more Veratrum album $3 \mathrm{x}$ in the usual dose to be given every half hour until the cold sweats cease.

When the pulse is very weak, the body externally cold to the 
touch and dry, the mare extremely restless though apparently experiencing no real labor pains, give Camphor 30 every quarter of an hour, this will probably revive the natural heat and bring on the proper labor pains.

Should the vaginal canal be very dry and devoid of the natural lubricating fluids, and these parts with the os uteri are unbearably tender to pressure, the mare at the same time evincing great restlessness, groaning to herself in a sort of undertone, lying down with great care but almost immediately getting up again, tincture of Aconite Ix ten drops every half hour until more calm and the fluids of the vaginal canal begin to exude.

Again this dryness and tenderness of the vagina and os uteri may be present and the mare show signs of violence and knocking herself about when the labor pains come on; the whites of the eyes and the membrane lining the nose and mouth of a bright vermillion color; the pains come on very quickly, last but a short time and pass off as quickly; indeed there is every indication of the general system being as it were in a tumult, then give Belladonna $3 \mathrm{x}$ once an hour until the excitement has calmed down.

\section{SOME ACCIDENTS INCIDENTAL TO PARTURITION, RETENTION OF THE FCETAL MEMBRANES OR AF'TER-BIRTH.}

This is by no means an infrequent condition and calls for prompt treatment, as the consequences may and indeed do frequently prove serious and sometimes fatal; particularly is this the case when the retained membranes commence to decompose; as a rule there is not much difficulty in determining whether the afterbirth has come away because when retained either a portion of the umbilical cord or a mass of the membranes generally protrude from the vulva and hang down sometimes as low the hocks; in cases, however, where the membranes are enclosed in the womb other indications have to be relied upon to determine their presence; among these are the following: The mare will rest full upon her belly with knees and locks well under, occasionally straining, when the lips of the vulva will open and very frequently the mouth of the womb will be observed nearing the orifice each time she strains; at other times the mare will stand up and stanp first one foot and then the other at the same time angrily whisk- 
ing her tail, when all of a sudden she will posture herself as though about to micturate. If decomposition has set up, a darkcolored, sometimes bloody fluid discharge will continuously ooze away from the vagina, the stench from which is simply abominable; the discharge will at times come away in rushes accompanied by small broken up pieces of membrane when the mare strains in the standing position or passes water or dung; the period during which the after-birth may be retained varies considerably, we have known it go as long as nine days and then be spontaneously voided, but this is an undesirably long period. As a rule the membranes are voided spontaneously, but cases do occur where they have to be removed artificially; under homœopathic treatment this, however, is extremely seldom. Breeders of horses should be aware that while in cows retention of after-birth is rarely of much consequence, in the mare it is of first importance to be well assured that the membranes are expelled.

When a mare has been regularly having Pulsatilla as hereinbefore directed, it is a rare thing to find that the after-birth is retained; if, however, she should not have previously been taking this remedy, then Pulsatilla $3 x$, ten drops every four hours, will generally do the trick; if the mare has been under the preliminary Pulsatilla treatment and retains the placental membranes, then twenty-four hours after the birth of the foal commence giving Secale cornutum $3 \mathrm{x}$, a dose every four hours; this remedy is specially useful after protracted labor, and when the discharged blood is of a dark color and smells badly.

\section{POST-PARTUM HEMORRHAGE, OR FLOODING AFTER BIRTH OF FOAL OR ABORTION}

Is, in our experience, a very exceptional occurrence; still should it take place in a valuable brood blood mare-probably the most likely sort of animal in the world to be the subject of such a casualty-it is necessary to be armed with means for arresting a condition which must otherwise prove exceedingly debilitating to the general constitution if not absolutely fatal; flooding may commence either before or after the delivery of the after-birth.

The following remedies, with their indications, may be relied upon under the conditions specified:

Aconite 3x.-Mares of excitable, restless temperament, in high 
condition, with a profuse flow of ordinary-colored blood; frequently lying down and getting up, and when on their legs totter up against the side of the stall or box, as though giddy.

Belladonna 3x.--Extremely excitable, amounting to irritability, pulsation of the carotid arteries distinctly perceptible to the touch; a wild, bounding pulse; the discharge of the blood is very profuse and the color extremely bright, and very unusually hot to the feel; the whites of the eyes will be streaked with bright-red lines, and the pupils distinctly dilated; the mare strains, and in so doing presses out the walls of the vagina, which appear also of a brightred color.

Crocus 2x.- Very useful when the blood is of a dark color and comes away in long strings or stringy clots.

Hamamelis $\theta$ when the flow of dark-colored venous blood is slow and constant.

Ipecacuanha, $3 \mathrm{x}$ trituration, Io grains to a dose. The flow of bright-red blood is full and constant; this may be attended with an effort to vomit, although it is a recognized fact that horses rarely do vomit, and when they do, the ejecta pass through the nostrils and not the mouth, in consequence of a reil of mucous membrane which lies at the back of the mouth and at the entry to the cavity known as the pharynx. Nevertheless, cases have been known of horses vomiting, and hence the symptom, if present, should be noted, as it is an important indication for the selection of this drug in conjunction with the other symptoms specified.

Sabina $2 \mathrm{x}$ is a very important remedy in cases of hæmorrhage after delivery; its indications are blood dark in color; comes away in black clots, which float in a thin, watery-sort-of-colored fluid; the discharge is not constant and regular, but it comes away in spurts as the mare strains when the after-pains come on.

Secale cornutum $2 \mathrm{x}$. - Blood of a dark color and smells badly; the flow is constant but slow; mare apparently very weak, and takes little or no notice of what is going on around her; the bleeding is accompanied by very frequent after-pains, but these do not appear to affect the flow in any marked degree; the mare's external body temperature is low, and the expression of the countenance gives the impression that she is in constant pain.

Among the accidents which occasionally result from parturition are INVERSION (or turning inside out) of the womb and the 
vagina; these do not occur so frequently in the mare as in the cow, but sufficiently often to necessitate passing reference here; inversion of the bladder occasionally occurs at these times, and sometimes before parturition, and in the mare more often probably than any other of the domestic animals; it is therefore most desirable to be on guard at such times not to mistake one organ for another; in such cases as these it is of the first importance to secure the services of a trained reterinarian, as without doubt surgical methods take the first place here, and the administration of drugs can only be secondary thereto; the first step is to effect reposition of the organ and then to take the necessary measures for keeping it in situ; this being satisfactorily effected the most useful remedy that can be selected to assist in rendering the surgical operation a complete success is tincture of Arnica $3 \mathrm{x}$, a dose every hour for some time; should this not afford the necessary relief so far as the constitutional symptoms are concerned, one of the remedies referred to under the headings Retention of After-birth and Flooding may be tried according to the special symptoms indicated thereunder.

\section{DISEASED CONDITIONS INCIDENTAL TO PARTURITION.}

Some of the diseases incidental to foal-bearing in the mare have such a distinct bearing and influence upon the production of those two bugbears of the horse breeder, ABORTION and BARRENNESS, that, if for no other reason, it is most important to refer to them as fully as possible in order to show how such evil and peculiarly disastrous consequences may be avoided or at least materially lessened; the period of gestation in the mare is so long and the accidents incidental to pregnancy so numerous that as a matter of profit and loss, it becomes the horse breeder to exercise every available precaution so as to minimize the risks he has to contend with in this important branch of business; and especially does it behoove the breeders of high-class horses to do this, inasmuch as the better bred the animal is the more likely is she to fall a victim. 
VAGINITIS, INFLAMMATION OF THE LINING MEMBRANE OF THE VAGINA.

This form of inflammation may exist independently of the adjacent parts, but in the mare it is one of rare occurrence; and even assuming that for any period it has affected that part of the genital canal only, it speedily extends to the os of the womb and the internal lining membrane of that organ; when the origin of the inflammation is the vagina it usually arises as the result of protracted labor or the irritation set up by the use of instruments and ropes in effecting delivery mechanically; the more general seat of origin of this inflammatory condition is the womb when endo-metritis or inflammation of the lining membrane of the womb is present and extends therefrom to the vagina; a still more serious condition is that of metritis which includes an inflammation of the tissues of the walls of the womb as well as the lining membrane; this latter condition will be considered specially further on, as its consequences may be immediately serious; the more simple forms of inflammation, vaginitis and endo-metritis, are in themselves important and deserve notice, as their existence usually results in the production of a discharge commonly called leucorrhoea, which in its early stages is a secretion composed of mucus, and if this is not arrested by suitable remedial measures, both constitutional and topical, it rapidly assumes a graver character by the addition therewith of blood and pus. The consequences of this condition are serious to the breeder as to them may be traced the fact that so many mares prove barren, the secretion being of an acrid character destroys the active elements (spermatozoa) of the semen of the horse; this disease when originating in the uterus may be due to the same causes as those enumerated under simple vaginitis or to abortion or miscarriage; moreover if pregnancy is effected, notwithstanding the presence of this leucorrhoca, it may also result in abortion; it will therefore be quite clear that it is very important, especially in the case of valuable mares kept solely for breeding, to watch for the presence of this discharge before the time of CESTRUM (coming into use), otherwise it may be easily overlooked.

The first thing to observe in treatment is cleanliness, and the best method of ensuring this is to freely wash out the canal and womb with a tepid solution of Corrosive sublimate consisting of 
one part of the drug to one thousand of water; this can best be effected by using a large syringe with a long wooden nozzle; the injection should be continued until the solution returns per vulvam quite clear and free from any secretion; after that a lotion of Hydrastis $\theta$, one part to six of tepid water should be injected well into the womb and after quickly withdrawing the syringe hold the lips of the vulva firmly together in order to retain the lotion upon the parts for some two or three minutes; if after the first application the secretion is decidedly less the Corrosive sublimate solution washing need not be repeated, otherwise it should be; but the injection of the Hydrastis lotion must be repeated night and morning till a cure is effected; the internal administration night and morning of Hydrastis $\theta$, ten drops in a wineglass of water to a dose will much facilitate the cure.

\section{METRITIS, INFLAMMATION OF THE WOMB.}

This disease is sometimes described as parturient fever; when it occurs as a sequel to the birth of a foal it may very easily result in blood poisoning, if the surroundings of the box or stable are of an unsanitary character or if the dung pit is in close proximity; and in cases of protracted labor or when the uterus has been wounded by the careless use of instruments in effecting delivery, the septic infection gains entrance to the blood through this wound or abrasion. True metritis may be recognized by the exalted body temperature, it rapidly runs up to 105 degrees or even higher, and by the increased frequency of the pulse; from ninety to one hundred beats per minute being by no means infrequently observed, the respirations being proportinately increased in number. The mare will give distinct evidence of acute pain by turning her head first to one side and then the other in the region where the uterus is situated, and if the abdomen thereabouts is manipulated and also the loins she will generally flinch as though t:ie parts were very tender; she will lie down and rise again quickly and give evidence of great restlessness, hence the condition must not be mistaken for one of sinple colic; as the inflammation increases the mare will continue standing presumably because the act of lying down hurts her, the organ having become increasingly tender; considerable difficulty is generally experienced in evacuating the bladder and rectum. 
Aconite 3x.-It is generally safe to give this remedy in the first instance, especially when the pulse is hard, full and rapid, the temperature very high, skin hot and dry, abdomen very tender to the touch and accompanied by marked restlessness.

Belladonna $3 \mathrm{x}$.- Straining and pressure of the vagina outwards; the mucous membrane of the vagina very bright red; the urine flows involuntarily; mare is very violent, and the membranes of the nose and eyes are a bright red; mare will press the forehead against the wall as though suffering from headache; throbbing of carotid arteries.

Nux vomica $3 \mathrm{x}$. - This remedy is useful when there are frequent but ineffectual attempts at passing water or dung, or both; constipation.

Lachesis 30.- In cases of blood poisoning indicated by shivering; alternate heat and cold of body outwardly; suppression of urine and stool; stinking bloody discharge from the vagina; great uneasiness; the visible mucous membranes assume a dark hue and the temperature rises higher until the crisis, at which period if the change is not favorable, the temperature will drop down gradually until it is below the normal standard of 98.5 degrees, under which circumstances the termination is likely to be unfavorable.

In cases where convalescence is not established and the malady passes into the chronic form, which is by no means a rare occurrence, the discharge from the womb will continue and assume a putrid, stinking character; swellings and ulcers will appear on the external part of the vulva; relapses will take place and show themselves by alternate fits of heat and shivering cold; the appetite becomes irregular; the coat stares and the skin clings to the body, and will become covered with red spots and various eruptions; colicky pains and constipation will recur; the secretion of milk is entirely discontinued; for such conditions Secale cornutum $3 \mathrm{x}$ is the best remedy. Should this not complete the cure Sulphur $6 \mathrm{x}$ trituration, twenty grains dry on the tongue, norning and night for three days will often serve to arouse the system and render the action of the medicine that has previously been adninistered more effectual and so complete the cure.

Breeders of valuable horses, whether blood stock, trotters or cart horses cannot give too much attention to their brood mares at foaling time with a view to save them from the risk of any sort of 
infection; for parturition certainly predisposes to this, in consequence of the favorable condition of the parts, both genital canal and uterus, to come under the influence of septic (poisonous) material; and for this reason the most stringent measures should be adopted to ensure perfect cleanliness both in and around the box in which the mare foals; and further, it is a wise precaution to keep other in-foal mares, whose time for delivery is near at hand as far away from the mare that has just foaled as circumstances will permit, and that for a sufficient time to be satisfied that the mare has cleansed and is going on satisfactorily; and under no conditions should a man who has assisted in removing a decomposing cleansing be allowed to go near an in-foal mare until he has had a thorough good bath and disinfected his outer clothing; disregard of these precautions is only too often the chief factor in bringing about abortion or slipping foal; neither should any recently foaled mare be allowed to go into a pasture with other in-foal mares; all the litter in the box wherein the mare foaled should be burnt; and if the mare has been the subject of any of the foregoing maladies, the floor of the box should be thoroughly disinfected with quicklime before allowing another mare to occupy it.

\section{MAMMITIS, INFLAMMATION OF THE UDDER.}

Although this is a form of disease that rarely attacks the mare, no work on medicine would be complete without reference to it; moreover it is necessary for the horse breeder to be on his guard against any disorganization of this gland lest the milk should be altered in character or the secretion suppressed or only diminished, the consequence of which would fall on the sucking foal.

In the mare the gland is divided into two partitions thus differing from the cow, whose udder has four divisions. In the mare the whole gland is generally affected, while in the corv only one quarter is, as a rule, the seat of inflammation in the first instance or at one time.

Symptonis. - The gland is swollen, hard and shiny; the swelling extends along the abdomen, on the inside of the thighs and down the legs; the large veins on the under surface of the abdomen are distended and full; if the teats are squeezed a thick fluid mixed with blood is discharged; or if there is no blood the milk 
comes away in clots or flakes; febrile symptoms are present as indicated by the exalted temperature, the rapid full pulse, and the quickened breathing; constipation frequently persists, and the urine is high-colored and lessened in quantity; if pressure is brought to bear on the loins the mare evinces pain and stiffness, sometimes to the extent of lameness of one hind leg on the side the udder is most affected; where timely treatment is not resorted to the mare may lose the use of the udder through the organ becoming hardened and wasted.

TRFATMENT. - Aconite $3 \mathrm{x}$ when the inflammation is set up by a chill and high fever is present together with restless anxiety and great thirst.

Belladonna $3 \mathrm{x}$ when the bladder is very swollen and heavy, and the veins and arteries stand out prominently.

Phytolacca Ix. - This is as a rule the best remedy for this disease and in conjunction with Belladonna effects a satisfactory cure even when suppuration is established; it is specially indicated when the udder is very hard and the beats are painful and sensitive to manipulation.

Bryonia 2x when the parts are stony hard and lumpy; extremely hot, excessively painful and sensitive; great thirst and constipation the fæces being dry and burnt looking; moving seems to aggravate the pain.

Silicea $6 \mathrm{x}$ ten grains dry on tongue, night and morning, when suppuration is very advanced, and the udder discharges matter from broken ulcers.

As a rule properly selected remedies reduce the inflammation and avert suppuration, but in severe cases these internal remedial measures should be supplemented by

LOCAL, APPLICATIONS such as foinentations with hot water and poultices; with the latter a few drops of the mother tincture of the remedy which is being internally administered may usefully be applied; the poultice should consist of some soft agent like linseed meal or marshmallow; or, better still, "spent " lops; if difficulty is experienced in applying and keeping in place sucl a poultice then the udder should be well rubbed witl a cerate or ointment medicated with the remedy which is being internally administered: if, however, suppuration is established nothing short of a poultice will be of any use, and this must be continued until the abscess is 
discharged, after which the orifice should be gently plugged with cotton wool dressed over with Iodoform and repeated during the healing process so long as it will remain in place; this is to serve as a preventive against septic infection and blood poisoning.

\section{SORE TEATS.}

It may happen, especially in mares with a first foal, that the teats are very sore from cracks and fissures in their substance; and on some occasions they become so tender and sore that the mare not only absolutely refuses to allow the foal to suck, but when the latter is persistent in its efforts to obtain its nutriment, may go so far as to kick and perhaps permanently injure it; under such circumstances the teats require attention; the cracks may be brought on by cold or by the strong pulling of the foal in the act of sucking.

TREATMENT.-Thoroughly cleanse the teats with warm water; dress them with a lotion made up according to the following formula: Calendula $\theta$ one part, Glycerine two parts and water three parts. If possible the foal should not be allowed to suck for two or three days, which of course necessitates hand feeding with cows milk the while, and the use of the teat syphon to empty the glands must be resorted to; this little syphon must be obtained of a size to suit the mares teats; before introducing same the instrument should be dressed with carbolized oil; then holding the teat with one hand it should be gradually passed into the milk duct without any force and allowed to remain till the contents of the gland have drained off; this process together with the cleansing and the dressing should be repeated three times in twenty-four hours at least. The internal administration of trituration of Graphites, 6x, grains five to a dose, night and morning, will facilitate the cure.

\section{THE FOAL.}

It is impossible to lay down any general rule for the treatment of foals, but as these are frequently the subject of some infantile disorders, the work would not be anything like complete that did not refer to same; for instance, before the fotus is absolutely separated from the mother by severance of the umbilical cord, the same being born in the fotal membranes, it is quite evident it 
must be released therefrom or it will be suffocated; if the cord is not properly ruptured it should be ligatured (tied) with string or catgut in two places; the one about two inches from the body of the foal, and the other one inch from that again, and severed between the two; the membranes should be ruptured and carefully removed thereafter, leaving the mare to cleanse the body by licking; but if she shows any disinclination for this, sprinkle the body of the foal with a small quantity of salt or oatmeal in order to excite the attention of the dam and induce her to fulfill her maternal duties; it is desirable, also, to examine carefully the natural openings of the foal, such as the anus, mouth, vulva, etc., and if these do not exist, produce artificial ones by puncturing the parts with a sharp knife and keeping the orifice open by plugging same with medicated wool to prevent union of the parts. If the foal when born does not appear to have any life or animation, it is probable the act of breathing has not been properly established, but to induce this several experiments may be tried; for instance, some cold water poured on the top of the head; rubbing the limbs, with considerable friction; tickling the nostrils with a feather; remove the mucus from the mouth with a damp sponge, after which an attempt may be made to artificially inflate the lungs with air by means of a pair of bellows carefully passed up one nostril while the other is closed by pressure over the side of the nose. Should the mare refuse to cleanse the foal, it should be carefully washed with a warm sponge, dried with soft cloths, and thereafter kept warm, the milk of the mare being hand drawn and given to the foal; if by reason of temper or inexperience the foal is not allowed to suck, the mare must be put under restraint, and the foal be coaxed to utilize the teats, after which, as a rule, the foal will find the udder of its own accord and the mare takes kindly to it and fulfills her maternal functions without further compulsicn. Within a few hours of the birth, after the foal has partaken of its first meal of milk, it should have an abundant evacuation of the material collected in the intestines during its intra-uterine period of existence; should this not take place, and the anal orifice being quite certainly clear, then some remedial measures should be adopted or troublesome infantile constipation will ensue; probably the best remedy is a small dose of a mixture of liquid honey and castor oil in equal parts, in all amounting to a quarter of a pint; 
if, however, the constipation has become established other measures must be adopted, as purgatives or even mild laxatives only effect the desired object for the time, the constipation thereafter being more firmly established than ever; for treatment under such conditions reference must be made to the general article on constipation and the remedy selected according to the symptoms; the same remarks apply to cases of diarrhœea, as upon the subjects of constipation and diarrhœa special chapters are written; the treatment of the allopathic school under such conditions being so diametrically opposed to that of the homœopathic it is deemed advisable to devote special attention to the consideration and treatment of these two forms of common ailment.

After the foal is born it will sometimes exhibit signs of too much bleeding from the remains of the cord by which it was originally attached to its mother; under such circumstances it is best, if enough of the cord remains, to tie a piece of silk firmly round it, being careful that none of the intestines are inclosed; should, however, the remnant of the cord be too short to get sufficient hold for a ligature, then soak a piece of cotton, wool or lint with sesquichloride of iron and apply same firmly to the parts by means of a bandage over the loins, or if there is difficulty in maintaining this in position by reason of the restlessness of the foal, then obtain a stick of nitrate of silver and gently dress the orifice and surrounding parts with same until the bleeding is arrested.

In some countries it is no uncommon thing for foals to have a rupture, which may appear at birth or soon after, at the seat of the navel, and if not cured at the time it may prove very troublesome; this shows itself in the form of a round tumor into which the intestines drop, and it varies in size according to the amount of intestine that has descended, and how full the intestines are at the time; no measures need be taken for some little time beyond the administration of doses, night and morning, of Calcarea carbonica $6 \mathrm{x}$ grains five to a dose; should this not answer and an operation prove necessary, then resort must be had to a trained veterinary surgeon.

\section{ARTHRITIS.}

The heading of this chapter is the name given to a disease that affects the joints of foals; it is recognized in England under the 
term " joint ill;" we are of opinion that it is of scrofulous origin, and due in no small degree to imp-oper crossing of mares with horses, either the sire or the dam being the subject of some disease which interferes with their capability to reproduce healthy progeny; some attribute its development to improper systems of management or to giving the mare food deficient in those nutrient qualities which the requirements of the foal demand; while yet again it is considered that the milk of the dam is lacking in the proper proportion of mineral salts. Our own opinion is that each of these views has some bearing upon the condition known as arthritis, but that probably the digestive organs of the foal are more responsible than aught else for the disease in consequence of which the food is not thoroughly assimilated, and while the necessary constituents may be, and probably are, present in the food a large proportion of these pass through the systen of the foal without being appropriated as they should be; the principal tissue in the body of the foal to feel the effect of this resulting deficiency is the bone, and the epipheses or large ends of the bones of the legs, which together help to form the joints, not having the necessary amount of the mineral elements deposited in them become the seat of a disease which produces so much inconvenience and pain, and not infrequently results in consequences sufficiently important to influence the general constitution; in Homœopathy we have one remedy which has proved eminently satisfactory in overcoming this diseased condition and also its various complications; moreover, if it is given in the earlier developmental period, the more serious complications need not be anticipated; the earlier symptoms are swelling and heat of the joints, particularly those of the fetlocks, which on manipulation will be found exceptionally painful and tender to the touch and productive of considerable lameness; if the general constitutional symptoms give evidence of high fever a few doses of Aconite $3 \mathrm{x}$ ten drops may be administered with advantage, thereafter to be followed for some weeks by five-grain doses of Calcarea phosphorica $6 \mathrm{x}$ night and morning, and unless the arthritis beconnes complicated by the development of abscesses around the joints and among the tendons this remedy should complete the cure, but in the event of such complications five grains of Silicea $\mathrm{I} 2 \mathrm{x}$ three times a day must be substituted. 


\section{INDIGESTION.}

Among highly bred blood or trotting stock, which are bred specially for sport or sale, indigestion in the foal is a malady of rare occurrence because the little animal is never away from the mare and therefore takes its food at proper intervals; but in the case of the cart mare, working on the farm, the absence from the foal during the hours of labor necessitates the retention of milk in the udder until it probably becomes altered in constitution or on returning, the foal being ravenously hungry, engorges its stomach with fluid that is not now fit for it; the obvious method to be adopted to avoid this state of things is to allow the foal to suckle at more frequent intervals; indigestion may be due to the improper diet given to the mare or to the natural acidity of the secretions of the foal's stomach; if the former accounts for it the diet must be altered; if the latter, a few doses of Chamomilla $3 \mathrm{x}$ given to the youngster will generally put matters right; should the indigestion assume the lympanitic form when swelling of the abdomen is a leading symptom and much wind is passed per anus, Carbo vegetabilis $\mathrm{Ix}$, gr. $\mathrm{x}$, three times a day will afford relief.

We have now touched upon the several ailments to which the young foal is subject with the exception of two very common disorders, the one being the antithesis of the other, namely, constipation and diarrhoea; but these, as has been already intimated, will be dealt with under chapters specially devoted to these subjects; we therefore now revert to the mother once more and take up the consideration of that great curse to the breeder,

\section{ABORTION AND PREMATURE BIRTH.}

By the term abortion we desire to be understood that the fotus is expelled at a period anterior to that in which it could maintain a separate existence from its dam. Authorities on the subject are pretty well agreed that in the mare this period may be included any time before the three hundredth day of gestation, but it occurs more frequently during the first half of the period of pregnancy than the second half. Abortions occur under very varying conditions; some are due to accidents and take place in various parts of a country; while, yet again, quite a number of cases may arise on one estate, or in one township, or a large country district will be 
affected at one and the same time, and that without any recognized cause; this latter condition, however, is rarely experienced among studs of mares without the cause being capable of recognition, such as some particular description of food, as ergotism among rye grass, a species of rust in straw and a filthy water supply. Anything which is calculated to effect a sudden surprise such as a thunderstorm, may produce abortion, while contagion from decomposing cleansings or the discharges from mares that have already aborted is considered capable of bringing on miscarriage. Probably the most potent cause in the production of abortion is a diseased condition of the uterus and the vagina, or it may be traced occasionally to debility in the stallion in consequence of the horse's strength being enfeebled by being called on to serve too many mares during a season. With regard to the symptoms of abortion we cannot do better than to quote from Fleming's Veterinary Obstetrics, as therein they are clearly set forth, and though expressed in somewhat scientific terms they will probably assist the breeder to discover when a mare is likely to be visited with this mishap; it states as follows:

"Generally abortion takes place without any premonitory indications, and the animal may be as well and lively as usual up to the moment when the fœtus is expelled; and the expulsion itself is so sudden, so prompt and accomplished with so little visible effort or disturbance that the accident in most cases receives very little if any notice. It often occurs during the night and wonder is often expressed at finding in the morning the aborted fœetus, generally contained in its intact envelopes, lying behind an animal which, on the previous evening, looked perfectly well, and even now is so cheerful and unaltered and its functions so unimpaired, that it can scarcely be believed that it has been the subject of such a mishap. Even the sentiment of maternity, which is so strongly developed in animals, as Saint Cry justly remarks, is not awakened in favor of the expelled fotus, and the mother shows the utmost indifference to it as if it were in no way related to her. When this simple abortion has taken place during the day, it has been noted that the flanks fall in a little, the abdomen descends, the vulva and vagina siightly dilate and there escapes from them a glutinous, sometimes sanguinolent fluid, with which the fotus is passed, sometimes withont effort. We have said that the ovum or 
fotus is generally expelled in its intact membranes; this more frequently happens at an early stage of pregnancy. Sometimes, however, the amnion ruptures at the commencement of the abortion and the embryo or fœtus escapes with a small quantity of liquor amnii, the envelopes being rejected soon after, or in some instances they may be retained in the uterus, and thus constitute a source of danger, the animal not making any effort to get rid of them. This complicated abortion occurs more frequently at the later stages of pregnancy, and nore resembles normal birth than simple abortion, which is more often witnessed in the first half of gestation. Nevertheless we have the latter happen so late sometimes as the seventh or eighth month in the larger animals. It is observed more particularly in those which are debilitated from any cause; but at the same time animals which appear in the very best health are often the victims of simple abortion. So little disturbance does this kind of abortion cause that the animal can be treated in every way as if nothing had happened, though it is more judicious to give a little extra care for some hours at least. In what has been termed laborious, difficult or complicated abortion, which is often due to external causes such as injuries, the precursory symptoms are generally well marked, and vary somewhat according as the fœtus may be dead or alive. The animal suddenly appears dull, and peculiarly dejected; or it is restless, uneasy and continually moving about; if pregnancy is advanced and the fœtus is alive and strong, its movements are, on watching the abdomen attentively, perceived to be frequent, violent and disordered, but they soon become feeble and unfrequent and cease altogether when the fœtus has succumbed. The appetite is lost, and a plaintive neigh in the mare .... is emitted every now and again; the pulse is quick, small and hard as in hæmorrhage; progression is difficulty and unsteady; the physiognomy is anxious and respiration hurried. When the fœtus is alive there is perhaps less prostration, and with the mare there appears to be much abdominal pain. The animal often looks anxiously towards the flanks, paws with its fore feet and stamps with its hind ones, moves from side to side, perspires at the flank breast and elsewhere, lies down and gets up again, whisks the tail incessantly and exhibits every indication of increasing restlessness. At the same time the abdomen 
loses its round shape and drops; if the animal is in milk, the mammæ become soft and diminish in size more or less rapidly, while the secretion diminishes; but if it is not yielding milk then on the contrary they become enlarged and turgid; the vulva is tumefied, and from it escapes a tenacious mucus, serous or serosanguinolent and if the fotus is dead more or less fœtid fluid, according to the circumstances. Then follow symptoms analogous to those which characterize normal parturition; the uterus begins to contract, and the expiratory muscles act simultaneously with it; the expulsive efforts or 'labor pains' acting more or less ener. getically and continuously according to the suddenness of the abortion and the strength and health of the animal. The first result of this straining is the evacuation of the bladder and rectum; the next is the dilatation of the os uteri and protrusion of the membranes into the vagina, then through the vulva where they appear externally as the 'water bag;' this may rupture and the liquor amnii escape, and the pains becoming more powerful the fotus is at last expelled either nude or covered by the membranes. This act occupies a variable period, from a few to many hours, according to the strength of the animal, and it may even require human intervention to bring it to a successful termination. In other instances the fotus is not expelled immediately after it is dead, but after many of the premonitory symptoms just described have been manifested; with the cessation of the movements in the fœtus the animal regains its ordinary tranquility, appetite and liveliness, and all the symptoms disappear for one or more days when they again set in and the fotus may be rejected without any apparent effort or after much straining."

From a study of this graphic description of the circumstances arising out of and connected with a possible or actually realized abortion it will be possible, if discovered sufficiently early, to make an attempt to avert the fulfillment of the mishap involving such serious pecuniary loss; but before offering suggestions of a remedial character for the attainment of this object, we may just mention in passing that certain conditions of the uterus and its appendages may exist before pregnancy which are sufficiently serious to produce abortion and even to prevent conception and thus account for BARRENNESS; horsement are, as a rule, more inclined to attribute barrenness to the fault of the stallion than to the 
mare; but as the result of many years' experience during which time the opportunity of examining a large number of mares has arisen, we unhesitatingly affirm that with a considerable proportion of barren mares the stallion is not to blame, but the mare herself.

DISPLACENENTS OF THE UTERUS are frequent; the cause of these it is not necessary to go into, further than to affirm it as our belief that they are due in a large number of cases to unnecessarily rough obstetric surgery at a previous delivery, but whatever the cause may be, the fact remains, displacements of the uterus are frequently met with; to obviate this and procure conception it is necessary, in the first place, to allay all the inflammatory effects arising from the distortion of the organ, and thereafter to ensure the introduction of the male semen into the proper channel by means of an instrument, for the invention of which obstetric veterinary surgeons are indebted to American ingenuity. Mares that have once proved barren should be submitted to a careful manual examination without running the risk of losing another season, expending money in stallion's fees, or before raising any question as to the sterility of the horse; this last precaution serves two useful purposes; firstly, it obriates the risk of any legal or contentious proceedings on the part of the owner of the stallion for libelling his animal, and, secondly, it saves the owner of the mare from further disappointment should he have special reasons for availing of the cross with that particular animal; and yet, again, he has the satisfaction of tracing the absolute cause of the barrenness and may therefore know how to obviate it in the future; we have reason to speak confidently as to the practical utility of the OS DILATOR, having put it to the test with perfectly satisfactory results.

Other causes of abortion and barrenness are an inflammatory and ulcerated condition of the uterus; also of the neck and mouth of the uterus; this inflammatory condition of the uterus and adjoining parts results in the secretion of an unhealthy and fœtid discharge, occasionally of an acrid and acid character; if this is present when conception takes place it tends to render the development of the embryo very imperfect and usually results in abortion; and it may be added that the acridity of the secretion is frequently sufficient to destroy the vitality of the semen, prerent conception, and so prove the immediate cause of barrenness. The 
causes which may be accountable for abortion are so numerous that it is impossible to include within the limits now available anything like a detailed account of them, but we must in passing note one form, that which is said to be due to infection, when a number of animals abort one after another without any assignable reason; it is true that such a result is not frequently noticed among mares, but that is probably due to the fact that as a rule mares are not kept in such numbers as are cows $0^{\circ}$ : sheep; but there is no reason why such fatal consequences should not follow where mares are kept in any large number for breeding purposes; we are nevertheless firmly of opinion that under proper treatment and suitable conditions there is no reason why an epidemic of abortion ought not to be prevented, and mainly because of this faith do we propose to enter into the consideration of the administration of drugs as one means of averting the serious losses attendant upon the business of the breeder; the main symptoms have already been furnished in the language of Dr. Fleming, in his able work on Veterinary Obstetrics, and these must serve as the sign posts by the way to point the breeder to the destination he seeks to arrive at; with the hints there offered he will glean information that will enable him to determine if abortion is threatened, and when this is so, then from the symptoms given under the various drugs he will be able to select one that is suitable to the case, and, perchance, prevent the abortion; on the other hand, if one mare aborts then the time has arrived for watching closely all the other in-foal mares on the premises, in order that no time may be lost in treating them should symptoms of abortion supervene.

Arnica 3x. - In cases where a mare has sustained an injury, such as running against a fence or gate; or if she has fallen while galloping about and so experienced a shock to the system, a few doses of this remedy will serve to prevent untoward results.

Aletris far. $\theta$. - If a mare has aborted more than once this remedy should be administered in ten-drop doses every other day for a fortuight before the period of pregnancy to which she had attained on the previous occasion, and there is good reason to believe that it will serve to interrupt the habitual tendency to abortion.

Belladonna 3x. When a mare gives signs of uneasiness, and strains till the vagina presses outwards, with more or less discharge 
of blood, which feels very hot; the eyes bright red, and the carotid arteries throb under pressure; the slightest noise causes considerable excitement.

Calcarea carb. $6 \mathrm{x}$ is suitable for mares of heavy disposition with little or no life about them; ears, nose and legs more frequently cold than of a natural heat; the slightest abrasion of the mucous membrane brings on bleeding; if labor pains come on attended with giddiness and the before-mentioned susceptibilities are recognized as peculiar to the animal this remedy will suffice.

Caulophyllum $\theta$. - Where abortion is threatened but the uterine contractions are feeble and the loss of blood slight.

Chamomilla 3. when labor pains come on and the discharge of dark blood is attended with frequent attempts at passing water, the urine being profuse and of a pale, watery color; the mare will give distinct proof of excitability and irritableness, by continually lying down, getting up and moving about the box as though she did not know what to do with herself; moreover, if ordinarily quiet and inoffensive, she will viciously snap at her attendant as he passes her off his guard.

Cimicifuga $3 \mathrm{x}$ for mares that habitually abort and have at some time or other been the subjects of rheumatism; this has proved itself an invaluable remedy under the conditions indicated, and is one of the agents which under the most depressing conditions does such valiant service for the cause of Homœopathy, as it effects the cure of cases that entirely baffle the best efforts of Allopathy, probably because the latter fails to recognize the possible relation between two such diseases as abortion and rheumatism, and the bearing one has upon the other.

Crocus Ix.-The one indication for this remedy is the discharge of black blood in stringy clots; this is by no means an unusual condition when mares are about to abort, and if the symptom is presented no time should be lost in administering Crocus.

Gelsemium $\mathrm{IX}$ is an extremely valuable drug in those cases where the symptoms of abortion present themselves accompanied by the special indication "loss of control over movement."

Ipecacuanha $3 \mathrm{x}$. - It is seldom that horses ever give evidence of nausea by retching, inasmuch as they are unable to romit through the mouth by reason of a belt of mucous membrane that lies at the root of the tongue, being suspended from the roof of the throat; 
but occasionally under extreme aggravation, such as may very possibly take place with an in-foal mare, the desire to vomit overcomes every obstacle and the effort is repeatedly made; when this effort of nature accompanies other indications of abortion, and is attended by a profuse flow of bright red-blood per vulvam, Ipecacuanha will render good service and effect a most satisfactory cure.

Sabina Ix.-When abortion occurs at regular periods, more particularly the fifth month in mares and is accompanied by a profuse discharge, clotted and fluid blood, some dark, some red in color.

Viburnum $\mathrm{Ix}$. - When the pains are very severe and the blood is discharged entirely in clots, indicating threatened abortion.

The above-mentioned are all suggested as preventive remedies to be administered according to their special indications before abortion has taken place; we have now to consider what has to be done where abortion has already occurred first as regards the individual sufferer, and second as it affects or may affect other mares similarly placed. The mare that has aborted requires almost as much care and attention as one that has gone her full time and born a fully developed foal; she should be protected from exposure and generally nursed with light, easily digestible food for a few days; she should receive a few doses of Arnica Ix, and be watched for the complications attending an ordinary parturition, especially as regards the cleansing; at least twelve months should be allowed to elapse before permitting sexual intercourse, and meanwhile a manual exploration of the genital organs should be made by a qualified veterinarian to determine whether the parts are all in a healthy state, and if not, proper treatment should be adopted, both constitutional and local, if requisite. If there is reason to believe that the abortion is due to infection from a previous case, great care should be taken to isolate the animal that presents symptoms of abortion, and keep her far away from other pregnant mares; the attendant set apart to look after the one that has aborted should not be allowed to go near other pregnant mares until his clothes are properly disinfected; all the excreta of the patient should be covered with quick lime, the floor and drains clressed with a disinfectant, and thereafter thoroughly washed down with plenty of water, while the building 
itself should be disinfected by burning sulphur for some hours, and thereafter exposing it to a current of fresh air for a fortnight before allowing mares that are with foal to occupy the compartment.

When abortion can be traced to ergotized hay, rusty straw or other damaged fodder, the remedy is clear enough and it calls for no suggestion how to act. To those who have invested large sums in the purchase of valuable brood mares whose object it is to make breeding pay, or we would even say, who do not wish to lose money, we would impress upon such the importance of taking something like a scientific view of the position; mere hap-hazard chance will not do where vital processes, such as those associated with reproduction, are concerned, and bearing in mind the immense sums of money that have been lost for want of a more delicate appreciation of the requirements of nature under such conditions, we feel that we are only attempting to serve the cause we have at heart by issuing a warning note on this all-important subject to the breeders of the future: those who aim to realize profit at horse breeding, and who can conduct establishments on anything like an extensive scale should see to it that they secure the services of a qualified veterinarian who has made the subject his own in all its bearings, for certainly no lay horseman, however clever and observant, can properly undertake the responsibilities arising out of the care of a stud of brood mares, if the best possible is to be made out of them, and serious losses are to be obviated; for men, who are horsemen only, and have no practical knowledge of the subject of reproduction, the art of breeding must be a costly experiment, and if such think they can find among ordinary stud grooms or stablemen, those who can properly conduct a breeding establishment, we have no hesitation in stating that they will be disappointed in nine cases out of ten; it is not reasonable to expect anything else; it would be just as likely to answer, if a man was brought up to the business of a shoemaker to expect that he could conduct a large engineering works; every one knows what would be the consequence of such an appointment. It would be very easy to point to quite a number of horse breeders who seem to have done fairly well; but we never came across an instance yet where far better things might not have been realized had the business been in the hands of a man who knew how to deal with 
the subject of breeding from a scientific standpoint; the saving in mares alone would have shown a large profit on the gross capital invested; we are constrained to write very strongly upon this point, because so many men act as though the reproduction of the various classes of animals was a mechanical work; something like a clock which has to be wound up once a week to keep it regularly going; although necessarily compelled to blow one's own trumpet in showing how the business should be conducted, we are not slow to give a good, loud blast, as we are convinced that it will be for the ultimate benefit of those who have a hobby for breeding horses if they will but follow our suggestion, which is to rely upon a professional veterinarian in all that concerns the management of brood mares, always provided that he has made the subject a specialty。 


\section{THE NERVOUS SYSTEM.}

In order to properly, or even approximately, understand the tremendous influence which the nervous system exercises over all the other systems of the animal body in the regulation and maintenance of their varied functions, it is necessary to explain roughly the methods by which this marvelous combination of cause and effect is brought about; it is no uncommon thing for medical men and veterinarians when asked to account for certain morbid conditions, to attempt to disguise their own ignorance of the real cause by attributing the same to the mysterious influence of the nervous system, a procedure which doubtless serves to mystify the enquirer and may even leave the impression that the professional man is a singularly learned individual; it does not, however, make the matter any clearer, and therefore as passing reference has, here and there, through this book been made to the influence of the nerves or the nervous system in the production of certain morbid conditions, we desire as far as it is possible to clear up such vague generalities by a simple explanation of how these effects are brought about, and that before the special diseases affecting the different parts of the nervous system are considered. First then, of what does the nervous system consist? It may perhaps render the explanation more easy of comprehension, if we liken it to a large number of telegraphic offices, all of which are located under one roof and more or less intimately connected together; these are represented by the brain and spinal cord; and each of the respective offices is represented by what is commonly known as a nerve centre; each of the before-mentioned offices has a wire which conveys messages to it, and a wire that conveys messages from it; these wires are represented by what are known as nerves; for instance, an external impression is made upon some part of the skin, the nerve which receives such an impression conveys the message like a telegraph wire to the office or nerve centre in the spinal cord, and from thence it is conveyed by the 
other wire to some particular muscle which under its influence contracts: this is spoken of in physiology as reflexation; in other words an impulse is conveyed to a centre by a sensory nerve and is reflected from that centre through a motor nerve and through the latter produces a muscular contraction. There is further, an automatic action, the difference between which and reflex action, it is somewhat difficult to define, but perhaps the simplest explanation is this, that whereas so-called reflex action is due to some impulse effected from without the body, automatic action is due to impulses effected within the body, and without which life and the various functions of the body could not be maintained, such, for instance, as respiration, the pulsation of the heart, the movements of the alimentary canal, the control of the size of the blood vessels, etc.; at the same time the principle of conduction is much the same in both, the impulses being received at one place, conveyed therefrom by means of nerves to a centre and reconveyed by another nerve to the part to be acted upon; a very familiar illustration of this may be cited in the act of defæcation; the feeling of necessity for relief is brought about by the contact of the fæces with the mucous membrane of the lower intestine (the rectum); through the sensory nerves the impulse is conveyed to the nerve centre and from thence to the muscles of the rectum by the motor nerves, which produce contraction of said muscles and expulsion of fæces; this illustration, however, serves a double purpose, first to explain the meaning of automatic action, and second that some automatic actions are capable of restraint by exercise of the will; this is known as the inhibitory action. There are reflex actions other than those that affect the various complex movements referred to, which excite and set up the peculiar function of secretion in the glands, such, for instance, as the secretion of saliva, which is excited by some substance touching the tongue or through the action of the jaws in mastication. In attempting a simple description of the nerve centres, they were referred to as a number of telegraph offices all located under one roof and com1municating with one another, and that these are represented by the brain and spinal cord; some of these offices or nerve centres are located in the brain and some in the spinal cord; at the sane tine the inter-communication between these centres is maintained by what are called "paths of conduction" ' in the spinal cord; this may 
be proved by dividing the cord, when the parts that receive their nerve supply from the portion below or posterior to the division are paralyzed both as to feeling and the power to move, for the connection with the nerve centre which may either be located in the brain or in a part of the cord above the division is severed and the "path of conduction" is broken up; the same result transpires when through an injury the spinal cord is ruptured, as does occur sometimes to horses in the hunting field or while running in a steeplechase; the common method of testing the seat of injury to the spine is to prick the body and legs with a sharp pin; if the animal displays no sense of feeling in certain parts while it evinces pain in others, it is comparatively easy to determine approximately the seat of injury, as well as to come to an authoritative diagnosis with relation to its extent and serious consequences. Reference has already been made to the inhibitory or restraining action of some nerves and an illustration furnished; another instance may be mentioned of a similar kind of action, which has an interesting bearing upon the consideration of certain difficulties that beset the horse when called upon for a supreme effort of speed, namely, the power of restraining the beating of the heart which is effected when certain fibres of the pneumo-gastric nerve are unduly stimulated; now, it must be explained that the pneumo-gastric nerve is endowed with very complex functions; its centre is in the brain, and there it is very intimately associated with two other of the cranial nerves; among other functions, it presides over the processes of digestion in the stomach and intestines, which it serves to stimulate; but the branch that goes to the heart exercises the exactly opposite (the inhibitory) function, and according to the extent this branch is stimulated, it may either act usefully in preventing the heart from beating too frequently, or it may act prejudicially by arresting its action altogether; the point thereforewhich is of interest to the practical horseman is, that whereas the pneumo-gastric nerve is endowed with the power of producing two exactly opposite kinds of impulse, one branch going to and acting upon the digestive organs, while the other goes to the heart, an explanation is furnished of low some animals under peculiar circumstances are easily affected by careless feeding, or by calling upon them to perform work that demands special fitness at times when they are totally unfit to make anything like a violent effort. 
In contradistinction to the inhibitory or restraining action of some nerves there is also a provision in the nervous system for augmentation or increase of action in some nerve centres; this provision is evidently intended by an all-wise Creator to counteract difficulties that would, without it, otherwise arise in connection with the circulation of the blood, as the effect of such porver of augmentation is most noticeable by the way in which the calibre of blood vessels is regulated; without an extra stimulus, at times, the ordinary blood pressure in the vessels would be insufficient to keep up the necessary regularity in the normal blood supply to all parts; were this counteracting provision for regulating the blood pressure unprovided in all probability some parts would be overloaded and congested with blood, while others would be lacking and anæmic.

Both inhibition and augmentation in nerve action are conditions which may become unduly established; that is to say, each particular function after being brought into action may continue beyond the time or period in which it may be useful or necessary, and thus become a disease; the principle of the regulator of a watch somewhat explains the condition of affairs; when a timekeeper goes too fast and gains, the regulator may be moved too far in the contrary direction and the watch thereafter loses time; so long as the regulator is allowed to remain in this position the losing of time goes on; in like manner the nervous system may get out of order and require regulating; a study of the chapter on the diseases of the heart, its treatment, and the remedies which have a special affinity for that organ, will materially assist in overcoming the difficulties arising out of the irregularities in the nervous system just referred to, inasmuch as having discovered the totality of the symptoms and the drug peculiar to the same, the irregularity which has become established in certain nerve supplies will, under the action of such remedy, speedily be corrected and that frequently without the drug being included in the list of so-called nerve tonics, which is the kind of treatment generally resorted to by allopaths for these nervons disorders; the matter of chief importance for the practical horseman, who has to depend upon his own unaided powers of discrimination to discern conditions in an animal that are frequently most difficult of recognition, is to bear in mind that intimate relations exist between the various 
systems, and that unless these relations are recognized, and allowances made accordingly, it is not to be expected that treatment can be successful; the fact that injudicious feeding, both as to the quality of the food and the time of giving the same, may possibly exercise an unwarrantable demand upon the functions of the nervous system, which, in its turn, avenges itself upon the heart, and through that organ the lungs, points a moral and teaches a lesson which an intelligent horseman should not be slow to appreciate and put to practical application; fortunately for those who practice on homœopathic principles, it is not necessary to wait until every detail of the cause of disorder is discovered; the totality of the symptoms furnish the guide to a remedy, but among the symptoms must be included those that are observable through careful examination of the heart and how it performs its functions, bearing in mind when conducting such examination, the influence of the nervous system over that organ. There is still one other special action with which the nervous system is endowed, namely, co-ordination; to illustrate the meaning of this term it is only necessary to remind our readers of the loss of control which, under given conditions, horses occasionally experience over their powers of movement; as the attempt is made to walk the animal rolls from side to side, and in extreme cases is unable to retain its footing; this peculiar inability to control the movements may, sometimes be observed in the disease commonly called "staggers," of which there are two kinds, or at all events two kinds are described; one being considered due to the brain and the other to the stomach; however this may be, there is the fact that under these conditions the animal is unable to perform the complex muscular movements which the act of walking requires; other illustrations of co-ordination occur in the acts of swallowing and coughing, both of which acts call forth a regular succession of muscular contractions, one after the other, for their perfect performance; these complex movements are governed by certain nerve centres located in the spinal cord, where the co-ordinating impulses are developed. This brings us to the conclusion of the consideration of the physiological aspect of the nervous system; but for the fact that the subject has such an important bearing, alike upon health and disease, we should have refrained from any reference thereto; it seemed, however, desirable to attempt to show how the nervous system (albeit 
in a very imperfect manner) presides over and keeps going the other systems-circulatory, digestive, respiratory, etc. - and that without it the whole organism would come to a standstill; the impression undoubtedly prevails in the minds of leading veterinarians that primary disease of the brain, the spinal cord and the nerves, is comparatively rare in the horse, and probably this is so; seeing the difficulties in the way of recognizing the various morbid conditions in the human subject, and hence the greater difficulties that must of necessity beset the veterinarian to discern similar conditions among the lower animals, it is a matter of congratulation that diseases of the nervous system are comparatively rare among our patients; nevertheless we fully believe that the entire dependence of the other systems upon the nerves warrants the conviction that the study of the influence exerted by the nervous system as a factor in the cause of disease among horses and lower animals generally, demands far more serious consideration than it has yet received.

Before proceeding to the consideration of the diseases affecting the different parts of the nervous system, it is desirable for the sake of simplicity and the clearer appreciation of the same, that an explanation should be given of the parts that enter into the composition of this intricate and highly important division of animal life. The apparatus which provides, supplies and conveys all over the body that excitation which is requisite for the execution of all the acts and functions that are indispensable for the maintenance of life, is divided into two parts, namely: the cerebro-spinal axis, which consists of the brain and spinal cord, and the nerves, which are given off on either side of the central axis and therefrom distributed to all parts of the body. The brain and spinal cord are both enveloped, for the sake of protection, in a bony case called the cranial cavity (or skull) and the spinal canal (or vertebræ); in addition to these there are three membranes called the meninges, which serve to separate the soft nervous substance from this hard, bony case; the outer membrane serves as a lining to the bony case and is called the "dura mater;" the inner membrane, which is closely adherent to the outer surface of the cord and brain, is called the "pia mater;" while the middle membrane consists of two layers, one covering the outer portion of the pia mater and the other the inner part of the dura 
mater, which is known as the "arachnoid;" between the two layers of the arachnoid, and therefore intervening between the pia mater and the dura mater, a particular serous fluid is present; the object of this fluid is probably to diminish concussion and. generally to afford protection for the soft, delicate material of the brain and cord and prevent injury thereto that might otherwise attend the jar against the hard, bony case. In respect of the nerves, it may be stated broadly that they arise from certain recognized centres in the brain and spinal cord, and pass out of the cranial cavity and spinal canal in pairs through special openings (or foramina) and proceed therefrom to their particular destinations to be distributed over the whole body; of the cranial nerves there are twelve pairs; and the spinal nerves are estimated at fortytwo pairs. The three membranes already described as the dura mater, the arachnoid and the pia mater will in the future be referred to conjointly as the meninges, it not being necessary to differentiate between them when treating of them in the inflammatory conditions affecting them in the various forms of disease in which they are complicated; but it was deemed desirable to explain how and of what the meninges are composed, as they occupy a rather considerable and important position in some disease conditions affecting the brain and cord.

\section{INFLAMMATION OF BRAIN SUBSTANCES-CEREBRI- TIS-INFLAMMATION OF THE MENINGES- MENINGITIS.}

Although the true brain substance and the brain coverings may under certain conditions be independently the seat of inflammation it is rare to meet with a case in the horse where, either at the outset or as an ultimate development, both parts are not affected, and this is accounted for by the fact that the disease is generally due to a cause that necessitates their joint implication; injury as the result of external violence or some abnormal prominence in the cranial bones accounts most frequently for these cerebral inflammations; they may arise in some instances from exposure to the overpowering rays of a tropical sun, or in connection with a specific fever, but in the horse this is of rare occurrence. It will therefore be seen that whether the inflammation be due to violence from without or injury from within the cranial cavity as the result 
of an unduly prominent bone the effect will in the end be much the same; not only will the meninges participate in the damage, but the true brain substance also. The distinctive characteristics of the cerebral and meningeal structures under the influence of inflammation are set forth very clearly by the late Professor Robertson in his work entitled "Equine Medicine," in the following terms: "When the membranes are primarily affected there is suddenness in development of symptoms, local congestion, excitement with muscular spasms or convulsions, succeeded by subsidence or arrest of normal nervous activity. Invasion of the true cerebral structure, on the other hand, is less active in development of symptoms, is marked by no frenzy or excitement, but from the first exhibits lowered or depressed functional activity and impairment at the outset of some special nerve function. In the early stages of inflammation of the cerebral structures in all animals during which there is much mussular derangement, and particularly when the meninges seem more largely the seat of this morbid action there is very likely to be excitement, delirium or convulsions. The severity of these will be determined by the extent of tissue invaded. This hyperactivity of cerebral function is not constant or continuous, but paroxysmal in character, liable to be brought on or seriously augmented by any untorvard noise or disturbance to which the animal may be subject. The constitutional fever is well marked, the temperature raised, skin and mouth perceptibly hotter than natural; there seems pain in the head, which the animal cannot bear to have roughly handled; the eyes are staring and bloodshot, with pupils contracted; the pulse frequent and hard or sharp; respiration irregular and sometimes accompanied with a moan; bowels confined. The animal is restless and uneasy, moving from side to side or around his box, the body sometimes damp with perspiration. Occasionally muscular twitchings and general or local hyperæthesia are symptoms well marked. Succeeding this stage of increased nervous irritability and vascular excitement, which is generally short-lived, is that of nervous aberration and depression, indicative of more extensive involvement of the true nerve structures. The fever subsides, the temperature of the body is lower, the pulse dininishes in frequency, is less sharp or hard; the breathing becones stertorous, the delirium or excitability gradually declines, and special sensa- 
tion is lessened, until consciousness is lost in coma more or less perfect. With the subsidence of the restlessness the horse will, if capable of maintaining the standing posture, do so listlessly in one position, the head lowered, the eyes glassy, with pupils dilated, while control over voluntary movement is much disturbed. The disposition to preserve the position of the limbs as they may be placed is not unlike the condition which prevails in catalepsy. From the commencement the appetite is capricious and the discharge from kidneys and bowels less in amount than natural. The partial muscular twitchings or general convulsions are not present in every case and usually most attractive as the termination is approached. At this period the animal is almost certain, unless carefully watched, to do itself injury by violent and unconscious tossing."

Treatment. - Arnica Ix. - When the disease can be traced to external injuries this remedy should be administered four times a day at intervals of four hours; and compresses soaked in a lotion of the mother tincture, one part to four of distilled water, constantly applied.

\section{CEREBRO-SPINAL MENINGITIS.}

Nervous diseases affecting the horse are, we must admit, very obscure, so far as our knowledge of them is concerned; at the same time we are satisfied that however we may attempt to account for it, cases of this kind are far less numerous amcng the lower orders of animals than in the human subject, and under the circumstances there is cause for congratulation that it is so. The disease, which we now propose to consider is generally included in works upon equine medicine under the head of general disorders, but inasmuch as it owes it origin to and distinctly affects this group of organs, we feel justified in including it under the list of diseases of the nervous system proper. We believe we are correct in stating that some years ago an outbreak of what was described as cerebro-spinal fever took place in New York, and carried off quite a considerable number of animals, and it was at that time looked upon as a true specific fever; but we are not aware that any positive opinion was arrived at as to its precise pathology, nor were the actual relations between the severe symptoms exhibited and the changes which post mortem were observed 
in the brain and cord satisfactorily cleared up; this, however, is a matter of far less importance to the homœopathist than to the allopath, as he depends upon the symptoms a case presents during life rather than to any knowledge of changes that are going on as the result of the disease; for this cause we, as homøopaths, do not find ourselves beset with the same difficulties in attempting treatment of obscure diseases that the allopaths do. It is not at all clear what accounts for this form of fever, though by some it is attributed to dietetic errors, while others account for its presence by climatic disturbances; certainly the facts that frequently quite a number of horses are attacked at one and the same time, and that the outbreaks are only occasional, but when they do arise come suddenly, point rather to climatic influences than to dietetic errors; but whatever may be the cause it does not seem to us that this has much bearing upon the treatment. First we will deal with the Symptous presented: Suddenness is characteristic of the disease; the horse loses all power of control over his morements; falls to the ground without any apparent reason, intimation being given but a few moments prior to going down by giddiness and staggering; when down the horse struggles violently and makes frequent ineffectual attempts to rise; sweat breaks out over different parts of the body and literally pours off the animal; the pulse and respirations are rapid, urgent and irregular, there being no relation between one and the other, as there is in health and in many diseased conditions; the horse is extremely sensitive, and muscular spasms affect him in various parts of the body, contracting and relaxing with great apparent force; the eyes have a wild and staring look, and the animal throws its head about with great violence; the visible mucous membranes, especially of the eyes, are extremely red and injected. Unless the disease centres its force almost entirely on the brain, the horse cannot bear to have any pressure upon the spinal column. Constipation usually sets in early; the urine is passed with difficulty and at varying periods. The temperature changes remarkably; at one time of the day it will be found considerably elevated, at another almost down to the normal, nor is there any specified time when these alterations take place.

TrEatment. - In the first place it is important to have the animal placed in a quiet and roomy box, away from other horses, 
and apart from the attention of his nurse, should be allowed to remain as undisturbed as possible.

Actea racemosa IX is specially indicated for sharp muscular spasnis and great restlessness; and when the symptoms already referred to as affecting the eyes and the urine are present, these only confirm its usefulness; when a horse is in the condition which this remedy covers, it is a critical period, and to have a medicine at hand that is capable of alleviating these symptoms is a matter of the first importance.

Cicuta virosa $3 \mathrm{x}$. - This remedy goes farther in its effects than the previous one, as it not only meets those cases that have spasmodic twitchings, but also the paralytic symptoms; a horse is down and cannot rise in consequence of the paralyzed condition of hind quarters, give him this remedy and you will probably find that he is soon able to get up; in many cases that have died from this disease the post mortem examinations have revealed hyperæmia (excess of blood) of the brain and cord; the same condition presents itself in animals poisoned by this drug; to this extent, therefore, pathology and pathogenesy agree.

Cuprum aceticum $3 \mathrm{x}$ is a splendid remedy to steady muscles that have been the subjects of spasmodic twitchings, in addition to which paralysis, particularly when centred upon the right side and in the fore limb, is amenable in a remarkable manner to its action; this remedy exercises a potent influence upon the brain while at the same time a post-mortem examination reveals no organic mischief; a further indication of its usefulness in the disorder may be gleaned from the symptom already referred to of scanty urine.

Ipecacuanha $\theta .-$ Dr. Hughes, in his Pharmacodynamics, when referring to the action of this drug on the nervous system, states: "What amount of direct action Ipecacuanha exerts on the nervous system in health is uncertain. But it has found an occasional place in the treatment of neurotic affections in both schools of medicine, as may be seen in Dr. Imbert-Gourbeyre's collection. I can speak only of cerebro-spinal meningitis and of intermittent fever. In an epidemic of the former disease occurring at Avignon in 1846-7 Dr. Bachet was led to Ipecacuanha as the medicine most similar to the symptoms present, and he gave it (in the mother tincture) in every case with such great relative success that it was appropriated 
(of course without acknowledgement) by the practitioners of the old school in the place, and ranked as a specific."

Veratrum viride $3 \mathrm{x}$ is another agent which, after administration to the healthy in poisonous doses, produces hyperæmia of the brain and cord; among its chief symptoms are muscular spasms and contortions. Dr. Hale, of Chicago, esteems it highly under such conditions, and compares its action to those of Aconite and Belladonna conjoined. The pulse is a full, bounding one, and the tongue is coated with yellow fur at the sides, having a red streak down the middle.

\section{TETANUS-LOCKJAW}

Is a disease of the nervous system that is characterized by a continuous spasm of certain muscles, generally in the horse, those of the face; it certainly does at times affect other groups of muscles about the body, as in the case of the neck, when the head is drawn upward and backward; of the body generally when the tendency is to bend forwards; or of one side, when the effect is to draw the whole animal to one side.

The most recent studies of pathology have led the members of the old school to ascribe the disease to a specific organism; but as the larger number of cases in the horse seem to be the result of some mechanical injury, such as a prick in shoeing or a surgical operation, it is difficult for us to accept the microbe theory; our belief is, that these microbes are to be found in any and every form of disease, and our faith in their absolute powers of disease production receives a considerable shock when we come to try to account for the production of a disease which as a rule seems to depend on such a ca!sse as mechanical injury, like the one now under consideration, and the question at once arises in the mind, is this theory deserving of serious consideration in any form of disease? We find the other school of medicine admitting that symptoms similar to those of tetanus can be produced in the healthy animal by the administration of Strychnine-which is one of the remedies used by homœopathists to cure tetanus-therefore we agree that though microbes may be discovered in the blood of a tetanic subject, there are causes other than the microbe produces to account for the development of tetanus; and further, we are of opinion that whether recognized or not at the time, some injury, 
known or unknown, is invariably the fons et origo of all cases of tetanus; this may strike some as an illogical argument; we cannot help that; our faith remains the same, and it is rendered the more firm in this direction by the evident relation, pathogenetically and therapeutically, of certain drugs which have the power of producing on the healthy exactly similar symptoms to those presented in a true case of tetanus, and their capacity to cure the disease when it occurs in a patient.

Although the term tetanus may refer to spasm and rigidity of any of the voluntary muscles of the body, it is more generally applied to those of the face and neck of the horse, in which situation the morbid affection is mostly observed; through the rigidity of the muscles of the face, the jaws are closed, hence the characteristic term lockjaw. It would seem that a good warrant exists for the accepted idea that the muscles of deglutition are the first to experience an impression of a coining seizure, as one of the earliest symptoms observable is an irritable champing and grinding of the teeth, while at the same time saliva is rather profusely secreted, which drips from the corners of the mouth, the position of the head is almost invariably alike in all cases, the nose being poked out so that the angle of the jaw is a decidedly obtuse one; the muscles of the back of the neck become rigid, rendering the protrusion of the nose a more marked feature. Further, another essentially characteristic symptom is the spasmodic movement of the membrane, provided by nature to wipe the surface of the eyeball, termed the membrana nictitans; in ordinary health this fine membrane is never seen, being located beyond ordinary observation within the inner canthus of the eye, and only when a foreign substance alights upon the eye is it projected with great rapidity over the anterior surface for its removal; when, however, a horse is the subject of tetanus it frequently protrudes beyond its normal situation and flashes itself more or less frequently within the line of natural observation. The nostrils are very much dilated and the rate of breathing very much accelerated; the pulse and temperature are variously affected, one case exhibiting much greater sensibility than another; when the muscles of the body are affected those of the back will feel rigid and hard, while the tail goes through a continuous series of spasmodic twitchings; the animal stands with his legs mucin farther apart from one another 
than is usual in health, and can only move a few steps at a time with the greatest difficulty. From the character of the breathing and the general appearance of the countenance an impression is conveyed that the animal suffers acutely, a view that becomes confirmed when, as is often the case, perspiration is very profuse; if the animal is beyond the reach of relief, the pulse, which may in the earlier stages have been firm, as death draws near becomes more rapid and decidedly feeble, and overpowering exhaustion is but too plainly evident.

TREATMENT. - To prevent the administration of medicinal agents from being absolutely useless there is one precaution that must be observed most strictly; the more perfect the silence in the box or stable and the nore completely quiet prevails in the immediate precincts, the better for the patient; but it is absolutely a sine-qua-non that the man who attends the horse should move about in the quietest and most deliberate manner possible; the stable should be darkened; the door must be opened and shut without any noise, and strictly abstain from shouting or even talking, any deviation from this line of conduct is calculated to aggravate the spasms and paroxysnis of pain and thus retard a possible recovery. From a medicinal standpoint we have known many cases cured absolutely and alone by Aconite Ix, more especially in cases that can be distinctly traced to undue exposure to cold, or to sudden shock from a local injury; Henry Edgar, Essq., M. R. C. V. S., of Wanstead, in Essex, has reported several cases very successfully treated with Aconite; while we have personally had the satisfaction of seeing three very decided cases make excellent recoveries under the action of this remedy.

Strychnia $3 \mathrm{x}$. This powerful drug is credited with being thoroughly en rapport with tetanus when the same owes its origin to traumatic causes. Dr. Hughes affirms " the homœopathicity of Strychnia to tetanus needs no demonstration. It is one of those facts which go to prove the fundamental character of the law of similars, since we see nature herself making provision for its application. Now Dr. Stille cites (as I have mentioned) eight cases of the traumatic form of the disease in which its use was followed by cure." We liave relied more frequently upon this agent than any other, and, as a rule, though not invariably, with success.

Acid hydrocyanic $3 \mathrm{x}$; doses not to exceed five drops; if . Aconite 
fails this agent may usefully be employed, especially in the more acute cases, when the spasms are violent and attended by intervals of specially marked exhaustion. We are not able to offer any well-defined indications which will enable one to differentiate between these remedies.

In administering medicine the attendant must exercise great caution not to alarm or startle his patient, and must show unmistakeable forbearance and patience; if the horse is able to swallow, the homœopathic remedies, being capable of administration in small quantities of water as a vehicle, can be gently introduced to the back of the mouth by using a syringe for the purpose; or if that is not practicable the drops be mixed in a teaspoonful of glycerine and thence laid on the tongue; if this also is impracticable by reason of the close proximity of the teeth, then a rather larger dose, half as much again, must be injected well up the rectum.

The horse should, as a rule, be put into slings at the outset of the attack, unless there is reason to conclude from previous experience that it will annoy or irritate the animal.

Ice enclosed in muslin bags should be applied down the course of the spinal column and kept in position by means of long tapes tied round the abdomen, unless made sufficiently large to lie where placed without shaking off; when removed a soft horse cloth should be thrown loosely over the body to check a possible chill from the melted ice running over the sides. One of the chief diffculties that one has to contend with in a case of this sort is to induce the animal to take any nourishment; under no circumstances is food taken freely, therefore when presented it should be of a nourishing character and in concentrated form, such also as will check any tendency to constipation; eggs beaten up in new milk; beef tea, etc., etc.; if it is not partaken of voluntarily and the exercise of force to introduce it by the mouth is calculated to upset the horse, then an effort must be quietly and gently made by means of the enema pump to introduce a substantial quantity per rectum.

The frequency of the dose depends a good deal upon the severity of the attack, the intervals ranging from one to three hours; as infrequently as possible is our advice in order to avoid unnecessary disturbance. 


\section{CHOREA.}

The common and well-known term by which this form of disease is designated in the human subject is "St. Vitus' Dance," and although it is probable that while it is correct pathologically to speak of the nervous disturbances of the muscular system, which provoke the abnormal conditions known among horsemen as "shivering" and "stringhalt," among those classified under the general head chorea the symptoms are not identical with those observed either in man or dog. Whether it is the brain or the spinal cord that is principally affected, or which of these localities of the nervous system is the seat of the disturbance that produces these peculiar manifestations in the horse has not been definitely decided by pathologists, therefore we shall not attempt to discuss the question. In man and in dogs the choreic spasms, whatever limb or part of the body they may effect are as a rule fairly continuous, but in the horse that is a "shiverer" this is not the case; and for this reason there is the greater necessity, when buying a perfectly strange horse, to avail of every well known test to discover whether or no there is any tendency to this disease; this remark applies especially to horses of the heavier breeds, among which it is most commonly observed. Stringhalt, however, once developed is constant, and there need be little fear of deception from that source; with regard to its influence upon the usefulness of a horse there is a marked difference; a "shiverer" is to all intents and purposes a useless animal for draught work; the animal may be able to move forward fairly well, but when it comes to backing it is a different thing altogether; strange to say, however, though patent to the observation of the greatest novice, "stringhalt" does not seem to effect a horse's usefulness; we have known many horses that were the subjects of these peculiar muscular spasms, that worked regularly with, apparently, no difficulty; one case being that of a well known hunter whose owner rode him regularly every week to hounds and was as a rule among the first flight and that in a close country where the jumps were numerous and the fences frequently awkward. It is not necessary to make reference to the symptoms of stringhalt it is so well known, but some notice must be taken of those that indicate "shivering." 
Symptoms. - Among the muscles of the loins and thighs, occasional and sometimes constant twitching are observable; those muscles which enable the horse to raise its tail are effected when the animal is in the act of drinking. Very occasionally the muscles of the neck, shoulders and arms are affected.

When called upon to move the affected limbs are generaily lifted from the ground with an unusually sharp, snatchy action, while on putting them down greater caution is observed than by a healthy animal. If the horse is turned quickly from one side to the other, it seems to lose control temporarily over its movement; and if forced to back immobility will be very apparent either by a decided refusal to move, by helplessly dragging the affected limbs along without lifting from the ground at all, or by snatching them up very spasmodically and putting them down very cautiously; at the same time the tremulous twitching of the tail will be noticeable. Walking or trotting in a forward direction rarely discovers any peculiarity and avails nothing in an examination as to soundness.

TREATMENT of either of these forms of nervous disease is very uncertain and as a rule productive of little benefit; still, if one has a horse in his possession that develops either of these morbid conditions, it will be worth while to make an experiment with one or more remedies to be indicated.

Ignatia $\mathrm{Ix}$ in those cases wherein the symptoms are easily aggravated by being startled or frightened.

Agaricus muscarius $\theta$. - Twitchings cease when at rest.

Cuprum metallicum $3 x$. - Spasms extremely severe, indicating deep-seated disease-and structural change in the nerve centres.

Arsenicum album 3x.-Symptoms worse at night; restlessness, weakness; when brought on by work; comes on periodically; constitutionally impoverished.

Zinc sulphate 3x.-When produced by injury or is the sequel to some exhausting disease.

\section{PARALYSIS.}

This condition is somewhat rare in the horse, though there are several forms in which it is occasionally observed; on account of its infrequency we shall confine ourselves to a consideration of those particular forms of the disease which are met with the most 
often. We have to deal with cases of general paralysis wherein both fore and hind limbs are affected; with hemiplegia or onesided paralysis in which both fore and hind limbs of one side only are implicated; with paraplegia in which either the near fore and and off hind limbs or vice versa are affected, the result being that we have a bilateral disturbance to deal with; and local paralysis, a condition but rarely seen, but when it does occur, appears to affect the lips, facial muscles, larynx, penis, tail or rectum. When general paralysis takes place it seems to be due to an affection of the brain, such as might supervene upon injuries, as a fall in the hunting field or during a steeplechase. Hemiplegia or one-sided paralysis is probably the rarest form of the disease that occurs in the horse; but when it does arise the angle of the mouth appears to feel the full force of the attack; the lips on the affected side hang pendulous and the animal can neither take up food or water in consequence. When called upon to move the animal is inclined to bear towards the affected side, and if left to itself would soon walk in a circle, as going straight ahead seems to be out of the question; the limbs on the opposite side to the lesion of the brain are the ones that fail to do their duty.

Paraplegia, or transverse loss of power is the form most generally seen in the horse; among the causes to which it is due we have to enumerate injuries to the brain and spinal cord from fractures of the vertebræ or spicules of bone in the cranium; a diseased condition of the nerve substance of the cord; a lack of nutrition of the nerve centres through the blood; and reflex irritation from some foreign agent such as of worms, in the intestines.

Local paraly'sis is generally due to some direct injury upon the affected organ or part of the body-probably the most frequently observed development takes place in the muscles of the face, due as it is considered to some impairment of the functional powers of the portio dura nerve; the indications of the existence of this form of paralysis are observed in the lips and mouth generally, affecting not only the powers of prehension, but also those of mastication; the latter symptom distinguishes local paralysis from hemiplegia, so far as the muscles of the face are concerned.

TREATMENT.-Causticum Ix. In paralysis of the lips, face and larynx this remedy has acquired considerable reputation, not only among men, but animals also; as Dr. Huglies points out, a lead- 
ing symptom for this remedy is that of involuntary emission of urine when a paralytic patient coughs.

Conium $3 \mathrm{x}$ in paralysis of the penis due to excessive coitus, such as that which occasionally arises in stallions when they have served too many mares within a short period of time.

Argentum nitricum $3 \mathrm{x}$ in paraplegia due to a fall in the hunting field, the horse having pitched on to his head in landing over a big fence.

Belladonna $3 \mathrm{x}$ in paraplegia where the animal loses control over his movements; this remedy should be used in the early stages of the disease, especially when the whites of the eye are injected, red streaks appear thereupon, and the pupils are dilated; inability to hold water and considerable excitement are confirmatory symptoms.

\section{LAMENESS.}

The detection of the seat of lameness is not nearly so easy as many men who claim to have a fair knowledge of horses and their ailments seem to imagine; and while the scope and general objects of this work do not allow our dealing with the subject in anything like an adequate manner, it is necessary that a word of warning should be offered on the difficulties which are constantly presenting themselves to the amateur horseman in correctly determining the locality of the pain which causes a horse to go lame; for unless a man has some practical acquaintance with these diffculties and is prepared to recognize that they exist, it will prove of very little value for us to provide instructions as to treatment, which is, in fact, the primary object of this work. In the first place, it is essential that a correct opinion should be arrived at as to whether the horse is lame of a fore limb or a hind one; to determine this, the horse slould be run in hand, at a slow pace, both away from and towards the observer; in the case of a horse trotting from you, that is lame of one of the fore limbs, the dropping of the head gives a swaying motion to the body, which produces an up and down motion to the quarters, which might lead one inexperienced in testing such a case, to infer that the animal was lame of one of the hind limbs; but when the horse comes towards the observer it will be clear from the dropping of the head that it is in one of the fore limbs; on the contrary, when the lameness is 
in the hind limb the dropping of one quarter will be apparent as the horse goes from the observer, while in approaching him there is not so great a tendency to the counter-motion in front, and mistakes are not so liable to be made as when the opposite condition exists. Having then determined at which end of the body the lameness is to be found, the next matter for consideration and determination is in which particular limb the cause of pain is located; if a horse is lame of the off fore limb he drops the weight of the body upon the near fore and his head bobs and sways toward that side and vice versa; it may be also that the animal is unable to flex (or bend) one of the joints of the faulty limb, which necessitates its being carried forward stiffly and in a stilty fashion; such a coincidence furnishes still further proof of the particular limb that is affected; again, an animal may be lame of both fore limbs, as is frequently the case when a horse is the subject of navicular disease; under such conditions lameness will more often than not be overlooked by anyone other'than an experienced veterinary surgeon, as there will be no dropping, no bobbing of the head, and the general action will be fairly level; shady horse dealers frequently take advantage of this state of affairs to palm off an unsound animal as a perfectly sound one to the unwary purchaser; and, what is still worse, a horse that was considered to be suffering from an incurable lameness of one foot has had some foreign substance, such as a small piece of iron, inserted between the shoe and the sole of the sound foot, so as by pressure to produce tenderness and pain equivalent to that experienced in the diseased foot; in this way the sound limb was rendered as bad as the other, by which means the real lameness was temporarily obscured; it is of no use to rely upon the dropping gait to detect double lameness of this character; the way to discover it is to watch carefully the action, which under such circumstances is palpably short, stilty and cramped, accompanied by a distinct rolling of the body, as though the animal was afraid to bring any weight to bear on the feet, and no doubt this is the case. Cases of lameness in a hind limb are to be detected during motion from the dropping of the quarter on the side of the unaffected or sound limb, while the quarter of the affected limb is jumped at, as the animal, in course of progression, throws the weight of the body off the injured limb on to the sound one; the peculiar stiffness of gait already re- 
ferred to as being sometines observable in a fore limb is more frequently a marked peculiarity of lameness in a hind limb. So far we have been considering the methods of observation in detecting lameness from movement and action; it remains now to refer to those indications which may be observed when the horse is at rest; these are pointing with the injured or faulty limb; standing with one foot in advance of the other; standing with the knee bent or flexed and resting the leg on the point of the toe, the object of which is evidently to take the strain off the back tendons; in cases of severe shoulder lameness this flexed state of the knee joint is carried to such an extent that the tos, while barely to:tching the ground, rests lightly in a pendulous fashion behind the position occupied by the sound foot.

In cases of lameness of both fore feet, such as occurs in laminitis (inflammation of the sensitive portions of the feet), when the animal suffers acute pain by reason of the natural weight of the body brought to bear while standing, the horse advances both hind limbs well under the body, at the same time the fore feet will be alternately resting or well drawn under the body in proximity to the hind ones in order that they may be relieved as much as possible of the weight of the body; on the other hand, if the hind feet are affected in this way, they will still be advanced under the body, but the fore limbs will be placed perpendicularly, straight under the chest, the head being hung down and the body swayed towards the front with the object evidently of bringing the main body weight forwards and as much as possible on to the fore limbs.

Lameness of the hind limbs may be indicated during repose by a flexion of the fetlock joint, even to the extent of knuckling over; by continually resting the faulty limb, or, as is frequently seen, by standing with it completely elevated off the ground.

Having proceeded thus far and satisfied himself of which limb an animal is lame, it behooves the observer to complete lis examination, and by manipulation to determine the positive seat and cause of the lameness; in the majority of cases evidence is clear from the presence of heat, swelling and pain, while. in not a few neither of these objective conditions can be discovered, especially in cases where the deeply seated, sensitive structures of the foot are implicated, the bones of the limbs and feet, and the muscles whose 
function it is to enable the horse to flex and extend his limbs; under such conditions the evidence is rather of the negative order, and much reliance must be placed upon the peculiar character of the gait before the precise spot can be discovered, after which forcible manipulation in the case of an injured muscle will frequently cause the animal to reveal the seat of pain by flinching and drawing away from the person so examining it.

In proceeding to deal with the more general causes and seats of lameness, we shall only be able to touch the fringe of the subject: so much ground would have to be covered if it were dealt with exhaustively, and a whole volume might be written on this one division of our work; common ordinary causes of lameness will be merely mentioned en passant, believing as we do that this will be sufficient for all practical purposes to the majority of those who will patronize this book; but with some of the more obscure causes of lameness we shall attempt a fuller description in order that our methods of treatment may be the better applied and more satisfactory results be obtained.

\section{SPRAINS OF TENDONS, LIGAMENTS AND MUSCLES.}

The tendons and ligaments of both fore and hind limbs below the knees ancl hocks are frequently the seats of injury, from slips, either in the stable or out of it; from over-stretching produced by some violent effort, such as starting a heavily-loaded cart or wagon or jumping in the hunting field. A sprained ligament is generally more troublesome to deal with than a tendon; we may as well endeavor to explain the difference between tendons and ligaments; broadly and generally speaking, a tendon is a strong, thick and long piece of fibrous tissue attached at the upper end to a muscle, while inferiorly it is attached to a bone; its function being to enable a joint to be flexed or extended; a ligament is a short piece of fibrous tissue of very firm structure though of less substance and size than a tendon, which serves to keep the two ends of long bones approximated together to form joints; around each joint, of the limbs for instance, there are four or more ligaments: while both tendons and ligaments consist of what is described by the anatomist as fibrous tissue, a microscopical examination of their respective structures reveals a difference in their construction; but beyond the practical fact that the tendon 
is, generally speaking, softer, more elastic and yielding than the ligament it is not necessary to go more closely into these details. The muscles consist of a much more highly organized tissue than is the fibrous tissue of tendons and ligaments; muscular tissue is endowed with the power of contraction produced by a stimulus from the nervous system; by means of this power of contraction or shortening of the muscles the various phenomena associated with motion are effected. The composition of muscular tissue renders it much more amenable to the action and influence of drugs than are the tissues of either tendons or ligaments; for this reason cases of injury to the muscles, as a rule, are more easily and quickly cured than in those where the tendons and ligaments are damaged; moreover the lowly organized insensitive tissue of which tendons and ligaments consist requires severer methods of treatment than does muscular tissue, which fact will serve to make clear the absolute necessity, in bad cases of injury to ligaments for instance, for the use of the actual cautery or some irritant that will set up active inflammation for a time, a procedure which practical experience has shown is necessary before these lowly organized tissues can be restored to a sound and healthy condition. This, of course, is a very common style of treatment among allopathic veterinarians for all sorts of lameness, and it must be understood that we do not advocate its adoption as common or even ordinary practice, but only in very extreme and chronic cases; at the same time we are satisfied that the application of the actual cautery, inasmuch as it is used to set up inflammation in a given tissue, is distinctly homœopathic in principle; inflammation in the first instance was the cause of the morbid change that has taken place in a sprained tendon or ligament, and so caused lameness, to overcome this morbid condition and restore the tissue to its pristine condition, inflammation must sometimes be set up and allowed to subside naturally; without going into a detailed explanation of the various changes which take place under such treatment, it will suffice to state that as a rule satisfactory results follow its adoption, a thickened tendon or ligament thereafter assuming its normal size and usefulness.

In the first instance we invariably advocate the adoption of gentler measures, such as the application of a non-irritating lotion, and in all recent cases of sprains and injuries this method of pro- 
cedure suffices to effect a speedy cure. Heat, swelling and tenderness are pronounced characteristics of sprained tendons; in muscles the swelling is not so distinctly observable, but instead are soft and pulpy to the touch, and if not properly treated this condition is sometimes succeeded by an ahsolute loss of substance, hence the wasting which is at times observable in the muscles of the fore arms and thighs after violent injury; the fibrillæ or constituent elements of the muscle have in all probability been ruptured crosswise; inflammation being set up, a fluid exudate is, consequent thereupon, thrown out and degeneration of the elements follows which interferes with the function of contractility.

Lameness of the hind limbs from SPRAIN OF THE PSOAS MUSCLES is no uncommon condition among all classes of horses. The psoas muscles are situated internally, under the spinal column; they originate about opposite the last ribs and extend in a backward direction to be attached to the pelvis, one of their functions being to draw the hind legs forward; injury to either of these muscles renders it very difficult for a horse that is down to rise, hence the necessity of using slings for an animal in this condition to avoid the risk involved by allowing it to assume the recumbent position; a horse with such an injury can manage to stand without any fear of aggravation, but when very severe it is no uncommon thing for knuckling over at the fetlock joints to take place, furnishing additional reason for putting the animal into slings.

An animal suffering from injury to these muscles will stand with the hind legs wider apart than usual and, when cailed upon to walk, evinces considerable loss of power to bring either one or both legs forward, depending, of course, upon whether the muscles of both sides are affected; the animal is unable to properly lift its foot off the ground and drags it along in a helpless, uncertain manner, while there is a distinct tendency to knuckle over at the fetlock joint. Confirmation of the precise seat of the injury may be obtained by examining the parts, namely, per rectum; let the bare arm, which should first be lubricated with carbolized oil, be introduced as far as possible up the rectum, when heat, considerable tenderness and possibly some swelling will be detected; in very severe cases swelling is sonetimes observable externallyat the anus. The best treatment for these cases, after putting the horse in slings, is to apply hot fomentations to the loins by means 
of flannels wrung out of water as hot as the hand can bear, and thereafter applying a medicated (Arnica $\theta$ ) compress; the lotion, as usual, should be made of one part of tincture to six of water; this compress should be constantly applied for some few days; in addition two or three quarts of the lotion should be injected into the rectum by means of an enema pump t'iree times a day, and the usual dose of Arnica 3x administered per oram thrice daily. The diet should be of a slightly relaxing character, with plenty of slops, so as to render the fæces as soft as possible.

Another set of muscles involving lameness in the hind limbs that to an amateur horseman may prove obscure and somewhat perplexing is that portion of the quarters known as the crural muscles; they extend in a mass from somewhere about the hip joint to the patella or stifle; their function is to raise the thigh and bring it forward; when these muscles are injured the horse can neither straighten the stifle nor bend the hock, and when an effort is made to walk the leg is dragged along on the toe, the limb as a whole being, as it were, left behind; these are among the cases where there is a risk of some one or more of the muscles becoming wasted; when such is the case nothing short of a blister, repeated two or three times over a period of six or eight weeks, will serve to restore the wasted muscle to its normal state of health and usefulness. If the seat of lameness is discovered before wasting of the muscular tissue commences, hot fomentations and liberal hand friction with arnica lotion will generally serve to restore the animal to soundness, absolute rest being indispensable meanwhile.

One form of SHOULDER LAMENESS that frequently occurs among horses that are worked on the land during the ploughing operations is due to the sprain of certain muscles that serve to cover the shoulder blades, the points of the shoulders and the arms; also a long muscle which is attached superiorly each side of the head, passing down the lower part of the neck and helping to form the groove which exists down the course of the neck whence it passes over the point of each shoulder and is attached inferiorly to the inside of the fore arm, and that large mass of muscle which serves to cover the main bone of the arm as it lies in position, extending from the point of the shoulder forwards to the elbow backwards, together with the corresponding internal muscles known as the pectoral or muscles of the chest. Several of these 
muscles are very liable to waste if the injury is neglected, in which case stimulating remedies and long rest are absolutely necessary to effect a cure. The wasting, as a rule, takes place in those muscles that clothe the shoulder-blade, leaving a hollow space down the course of the bone which causes the prominent portion in the centre to stand out like a ridge.

The objective symptoms during motion, are marked dropping of the head, and the throwing out of the leg in a stiff, helpless fashion; when standing, the knee is flexed and the leg hangs just resting on the point of the toe. There will probably be some swelling and evident pain on pressure of the affected parts; a further test is to lift the leg from the ground, move it backwards, forwards and in a rotary manner, whereupon the animal will shrink from the proceeding and give evidence of considerable pain. When treatment is commenced early, it is rarely necessary to require anything more than that already indicated with Amica lotion, plenty of hand friction and hot fomentations; but should the horse have been at all susceptible to the rheumatic diathesis, and Arnica does not effect a satisfactory cure, resort may be had to the application of Rhus toxicodendron on similar lines, both externally and internally.

SHOULDER SLIP, by which is meant an apparent dislocation of the shoulder joint when the foot is planted on the ground, but which disappears when the foot is lifted from the ground, and ELBOW LAMENESS are both associated with the muscular injuries already described, háving symptoms very much a1ike, but discernible the one from the other by the marked sensitiveness on manipulation of the affected part. When we descend to the KNEE, the tissues affected are of the fibrous character, and we have to deal with ligaments and bones, as in inflammation of the knee joints, including those very fine membranes which serve to secrete the lubricating fluid, known as SYNovia, that is required to enable the bones forming joints to play smoothly one upon the other as the joints are flexed and extended; below the KNEE are found the FLEXOR TENDONS, or BACK SINEWS as they are rulgarly called, underneath which, in the groove of the canon bone, lie the susPENSORY LIGAMENTS bounded on either side by the small CANON BONEs; these exist in the hind as well as the fore limbs; the fibrous tissues of which these liganents are formed are of an in- 
elastic character and are frequently the seat of sprain among the heavier class of horses that are called upon to move heary loads; the lack of elasticity gives the horse the power to move a heary load, but when too much stress or force is laid upon the unyielding structures they give way, and a rupture of the individual fibres is the result; under such conditions nothing but long rest, in conjunction with ordinary treatment, is of any avail; time must be allowed for the fibres of the ligament to reunite and become firmly welded together before the animal can go sound or be fit for work of any sort. These remarks apply with equal force to the back sinews or flexor tendons, though we are of opinion that there is more elasticity in these than in the bulky ligaments just referred to; and inasmuch as the locality of these flexor tendons allows for more immediate application of lotions and liniments to them than is possible with the suspensory ligaments, treatment is generally more effective and satisfactory. The aforesaid suspensory ligament, on reaching the fetlock joint at the back, divides into two parts, is attached to two floating bones, called SESioIDs, which form part of the fetlock joint, and from thence the two divisions of the ligament pass downwards and ultimately blend with and become attached to the principal flexor tendon of the leg. We have gone thus fully into a description of this ligament and its attachments with a view to the production of a proper estimate of the damage that a sprain of the deeper situated tissues may effect; the examination of a weak or injured limb by amateur horsemen is, as a rule, so superficial that it becomes necessary to particularly point out one of the frequent seats of lameness affecting horses that have to move heavy loads or those that have to make violent efforts, as have steeplechasers and hunters in the act of jumping.

In the first instance all cases of injury affecting tendons and ligaments should be treated with hot fomentations, by standing the leg in a pail of hot water; occasionally adding a small quanity of boiling water to keep a uniform temperature; thereafter hand rubbing the affected part with Arnica lotion - I in 8-and then applying an Arnica lotion compress, which should be retained in position, with some pressure for several hours; when the compress is removed the legs should be firmly bandaged with a strong roll of dry linen, which should be kept in position for two hours, and the former process of fomentation, rubbing and compress re- 
peated; these two methods should be alternated for several days; meanwhile the horse should be kept quite still in the box; if these methods do not result in effecting a cure then the more severe measures must be adopted, such as blistering sharply or firing lightly; in the case of thickened tendons point or pin firing is the best, as by this means blemishing is avoided and a good deal of pain is saved.

Before leaving the upper part of the fore legs it is necessary to deal with a very common injury, namely BROKEN KNEES; the importance to be attached to this class of injury varies in degree according to the extent of the damage done; but so long as the sheath of the extensor tendon is not cut, nor the articulations between the rows of bones forming the knee penetrated, so as to allow the escape of synovia (or joint oil) no better treatment than the application of Calendula lotion, viz., one part of the mother tincture to three parts of water, can be adopted, the lotion may be satisfactorily applied by means of the spray diffuser, a method that has a decided advantage over the common practice of saturation of lint which is kept in position with a bandage, inasmuch as the formative material thrown out in the natural healing process is not removed by the immediate application of a resisting medium, moreover the horse is far more likely to stand quiet and not flex (or bend) the knee if the healing agent is applied in this almost imperceptible manner; it is quite true that in the first instance the applications require to be frequent, say once every hour; but the more speedy healing of the wound more than repays the slight extra trouble this method involves. In cases where JorNT orL. escapes either from the knee or the hock the measures it is necessary to take are tedious and sometimes involve many hours' persistent and unremitting attention; the continuous application of slacked lime, finely pulverized, sprinkling it on to the spot where the joint oil is escaping until such a time as the union of the oil and lime forms a plug and the further escape is arrested, is the best treatment; it is important to understand that once begun, this procedure must be continued without even one moment's intermission through day and night, if needs be; it is generally necessary to have a relay of at least three men who will keep up the sprinkling of the lime until the desired object is attained; once the flow of synovia is arrested the caked lime uutst be allowed to 
remain until it drops off, which it generally does when the wound is healed; it should be hardly necessary to add that when injuries of this kind are experienced, the horse must not be permitted to lie down, and in most instances it is necessary to put the animal into slings in order to afford it some rest.

SPLINTS or exostoses on the canon bone, particularly when they are located at the margins of the groove in which the suspensory ligament rests, are likely to be productive of lameness, not merely because of the tenderness arising from inflammation of the bone, but also by reason of the splint standing out so prominently that the back tendons ruo against it as the horse flexes and extends his leg in trotting and so produces extreme soreness; yet again, when a splint arises immediately underneath the joint of the knee, thus interfering with the true action of the articulation, it produces lameness. There are several methods of treating a splint: First, if the fine membrane which covers all bones, and necessarily extends over a splint when it forms, called the periosteum is cut, the splint will frequently disappear; this should be done with a fine periosteotomy scalpel by a veterinary surgeon. Second, a fine piece of hard steel, sharply pointed, about the size of a lady's ordinary stocking needle made red hot and plunged boldly into the splint will effect its reabsorption. Third, rub in an ointment consisting of one part of Biniodide of mercury, one part of Iodine and eight parts of lard once thoroughly; if after the effects have passed off, the splint, or any portion of it remains, a second or even a third application may be required, but in the end the absorption of the bony enlargement is effected.

SPRAIN OF FETLOCK JOINT is not of frequent occurrence, but when it does occur is productive of considerable trouble. Hunters and steeplechasers are more often the subjects of this form of lameness than any class of horse; indeed, fracture of the bone known as the suffraginis which enters into the composition of the fetlock, is not at all uncommon; if the fracture consists of a simple breakage in the long axis of the bone there is no reason why union should not take place and the horse be able to do light work; but when as is sometimes the case, the suffraginis is broken into splinters or in the transverse direction there is very little hope of effecting a satisfactory cure, and only in the case of a valuable brood mare should we recommend its being attempted; if, however, 
an attempt is to be made, we recommend in addition to the usual surgical appliances the internal administration of Symphytum $\theta$, a dose night and morning, as there is no doubt that this remedy aids the healthy union of fractured bones. In simple sprains, however, it is better to apply tow, cotton, wool or lint all round the fetlock joint, saturate the same with Arnica lotion and bind it on firmly with a cotton or linen bandage, taking care to keep the applications continuously moist with the lotion; a removal once in twenty-four hours would be essential; internal administration of Arnica 3x, a dose morning, noon and night, materially assists the action of the local application.

As we near the foot, the diseases of which will be dealt with at the close of this article, we have one very troublesome condition, which mostly affects the heavier class of horses, viz., RINGBONE; this consists of a bony growth which develops upon the upper and lower bones of the pastern, and as its name indicates forms a ring around the bone; the long bone of the pastern, already referred to as the suffraginis is the seat of the higher ringbone, and when very large it interferes with the free action of the ligaments which are attached to this bone; this form, however, is not frequently a source of trouble; the ringbone which gives the real trouble and produces such obstinate lameness is that which forms round the articulation of the suffraginis, or long bone of the pastern, and the corona, or short bone of the same, and may be felt as a prominent bony deposit round the upper margin of the hoof; the cause of a ringbone is attributed to strong inflanmation arising in the cancellated structure of the ends of the before named bones; as the result of the inflammation, lymph is thrown out, which, in the end, becomes organized and hard as bone; in a large number of cases, among heavy cart horses, this deposition of bony material goes on at the respective ends of these bones until an union is effected, and the joint becomes anchylosed or firmly joined together, so that the articulation cannot act freely, a fact which accounts for horses so affected going somewhat stiffly in their gait; prior to this union being completed, and while the inflanmation is actively proceeding, the horse experiences pain and consequent lameness ensues; this is the period for treatment, the object being to arrest the inflammation and the deposition of the formed and bony material that goes to make up the ringbone; if 
taken in time rery satisfactory results may be looked for from the application locally and internal administration of Symphytum $\theta$; locally by means of rubbing in a lotion and the application of a compress of the same; the lotion to consist of one part of the remedy to three of water, and internally the usual dose, in both cases using mother tincture. A horse with ringbone of the fore limbs puts his foot to the ground heel first, much like it does when suffering from laminitis or inflammation of the sensitive laminæ of the foot; but it may be distinguished from laminitis by the fact that the heat is confined to the upper part of the foot, whereas in laminitis the heat and pain are generally diffused orer the whole of the hoof; when the ringbone developes in the hind limbs the horse generally puts the toe to the ground first. In all such cases rest is imperative, and we strongly advocate the removal of all four shoes and allowing the horse to stand on a bed of saw dust or moss peat a foot thick.

We shall now turn our attention to lameness of the hind limbs other than those already dealt with, and will commence with the STIFLE; this joint is formed by the femur or thigh bone, the tibia or shank bone and the patella or knee cap of the human subject; inflammation of the ends and articular surfaces of these bones generally accounts for lameness of the stifle joint, and is very often due to what is described as the rheumatic diathesis; in other words the animal is susceptible to rheumatism, and this joint is a weak spot upon which the disease centres itself. In order to prevent as much as possible the articular surfaces of these bones from rubbing upon one another and so producing great pain, the horse stands with the leg flexed and resting on the toe; when the animal attempts to more, he drags the foot along on the point of the toe, and will not put the foot down flat if it can possibly be avoided; there is generally marked swelling and some heat in the region of the stifle joint.

One of the best remedies for this condition is Rhus toxicodendron $A$ in the usual proportions I-8 in the form of liniment, applied with plenty of friction, and internally administered in the third decimal attenuation; both being repeated at least three times a day.

The HOCK of the horse which corresponds with the ankle joint of the human subject, is by reason of its complexity the seat of 
several forms of lameness; the articulations formed by the approximation of various bones are frequently the seat of disease; strain and concussion are accountable for setting up inflammation in the bones, bony deposition follows, and the surfaces of the bonès cannot glide smoothly upon one another; when this takes place we have to deal with BONE SPAvin. Then in order that these various bones may be kept in proper relation, the one to the other, numerous ligaments or short bands of fibrous tissue are found; these become sprained, inflamed and thickened, causing lameness. One well marked form of lameness known as CURB, owes its development to sprain of the annular ligament of the hock in its posterior aspect; inflammation is set up, followed by thickening of this ligament together with a short ligament that is attached to one of the posterior bones of the hock and the long bone of the leg called the metatarsal bone, consequent upon which a slight prominence (a curb) is observable at the back of the hock in its lower aspect. Many practitioners, after reducing the inflammation with hot fomentations, fire for this condition; this practice we do not agree with; the remedy that we have found answer the best is a lotion consisting of one drachm of Perchloride of Mercury, dissolved in one pint of boiling water with just sufficient Hydrochloric acid added to keep the mercury in solution; with this the curb should be well rubbed twice daily until the parts are sore, after which apply a little sweet oil to the skin, and when the soreness has passed off recommence with the lotion orer another period till soreness is reproduced, and so on until the curb disappears entirely; the time that it takes to effect the complete absorption of an ordinary sized curb is one month under this form of treatment, which when properly carried out leaves no blemish behind.

Bog Spavin consists of a soft, fluctuating swelling on the inner portion of the front part of the hock joint; many liorses are the subjects of bog spavin, but never go lame; nevertheless they are unsightly and must at all times be looked upon with suspicion lest they should develop into a condition that produces lameness; when treatment is desired the same lotion and course of procedure should be adopted as has been already prescribed for curb.

Bone Spavin. - It is of the first importance that a horseman should be able to recognize when this form of bone disease is really present; even many professional men make mistakes and condenn 
horses for bone spavin when nothing more than big, coarse hocks are present; there is probably more uncertainty, among those who should know what a spavin really is, in determining the actual existence of the exostosis than in fixing upon any other defect to which a horse is liable; and from the great differences of opinion which have and do exist with reference to the fact that has to be frequently decided in courts of law, "is there or is there not a spavin," no little discredit has fallen upon the veterinary profession; we have repeatedly seen horses condemned as having spavins that had coarse and large boned hocks, while, on the other hand, a horse with undoubted spavins has been passed sound as though they were not present; we have found no difficulty in determiningthe presence or absence of spavins, and we consider that every veterinary surgeon of experience should be in a similar position. The question then arises: What is a bone spavin and how may it be detected? A bone spavin is a deposition of formed material, which ultimately calcifies and becomes hard and bone-like, on the inside of the hock at its lower point, and is due to an inflammation of the bones which go to form that part of the hock, viz., the cuneiform and the metatarsal; after the inflammation subsides and the formed material has become calcified the articulation formed by the before named bones is united, or as it is technically termed "anchylosed," and the spavin is plainly discernible to the eye and forms a distinct prominence of greater or less size that is readily capable of detection by means of touch; a hock that is free from spavin has a smooth surface, and the various bones that enter into its composition can be felt in proper apposition; the irregularities of surface which are present in a spavined hock cannot be discovered in a hock that is sound; the hocks of some horses are very full and the individual bones round and large, but when carefully examined the surface will be smooth and even; hence this normal fullness of the bones should not be mistaken for an abnormal and diseased condition; indeed, a horse with a large, bold or even coarse hock will stand far more work, strain and concussion than will the narrow, small joint. It has been asserted that if both hocks are alike in size and the action of the horse is good that spavins are not present, but we do not consider this a satisfactory proof either way, as both hocks may be spavined; again, some horses have one hock naturally larger than the other 
and still are sound. No! the proper thing is to be able to recognize when a spavin is present, and this we affirm every practitioner should be able to determine, and that without making a mistake. In dealing with spavins the most important matter for the owner to do is to watch for the first indications with a view to the prevention of further development; inflammation of the bones and their interosseous ligaments is the first process; an animal that is the subject of this inflammatory process must necessarily experience tenderness, heat and actual pain in the parts, which is exhibited either by positive lameness or a tendency to ease the hock by flexing it and resting the toe on the ground; when valuable young horses, between the ages of three and six years, are noticed frequently resting one leg in this way the hock should be carefully examined for palpable heat and the joint should be flexed and extended to determine if there is any tenderness; if these are present it would certainly be acting on the safe side to suspect an incipient spavin; the treatment should be the same as that already recommended for the early stages of coming exostosis, namely, hot fomentations and the application of a lotion of Symphytum by means of hand-rubbing and a compress, at the same time administering the remedy internally; there is good reason to believe that this line of treatment will allay the inflammatory action and arrest the formation of the spavin. In the case of a fully formed spavin that is the cause of lameness and requires treatment we strongly recommend pyro-puncture with a fine iron, great care being observed not to insert the instrument too near the articulation or serious and perhaps permanent damage would be effected.

There is one man in England who claims the possession of knowledge by which he is enabled to remove a spavin, but the process is a secret one, nor do we, in our ignorance, see how such a process can be affected without causing an unwarrantable amount of pain and long suffering.

THOROUGHPIN is another unsightly condition that frequently exists without producing lameness; it is due to the formation of an unnecessarily large quantity of fluid in the sheath of the flexor muscle of the foot, called the "perforans;" the fluid by pressure can be felt to move from inside to ontside of the hock, at the back part thereof, hence the designation "thoroughpin;" treatment such as that recommended for curb will generally serve to disperse 
the superabundance of fluid and thus effect a cure; some practitioners recommend the puncture of the swelling with an instrument to which a syphon is attached, thus enabling the fluid to be drawn off; but, inasmuch as it speedily reforms again and the swelling is again as large as before, this does not commend itself to us as a satisfactory procedure; it is a surgical operation to be sure, and with some that fact goes a long way and is preferred to any less ostentatious methods, even though it does not effect a cure; we, however, prefer the more tedious process herein recommended, as it goes to the root of the maiter and gets rid of the cause which produces the diseased condition.

CAPPED Hock as it generally arises, consists of the formation of a serous abscess between the tendon that passes over the point of the hock and the skin; a rarer form of capped hock is that which appears as a swelling on either side the point of the hock that is due to an inflammatory condition of the sheath of the tendon that passes down in that position; in consequence of this inflammation there is superfluous amount of synovia formed which fills the bursa to overflowing; the same preparation and treatment generally as that prescribed for curb will effect a cure; the ordinary allopathic treatment is to reduce the inflammation and then fire, putting on the while a high heeled shoe; even in our homœopathic practice this latter precaution is worthy of adoption as it throws the leg into a position that gives rest and ease to the parts, and in this way assists the treatment advocated.

All parts below the hock as far as the foot are liable to similar injuries, so far as tendons, ligaments and bones are affected, as those described in connection with the fore limbs and the treatment is the same.

We now pass on to the consideration of some of the chief points affecting the FOOT; we have no hesitation in affirming that by far the larger number of diseases to which the foot is prone are either due to or materially influenced by the barbarous practice of shoeing; we have satisfied ourselves by experiment and experience that for no class of horse is it necessary to put on a shoe of any sort whatever, provided the foot has never been manipulated by the shoeing smith, nor had a drawing knife used upon it; an intact foot is capable of bearing any wear whether on macadamized roads or paved streets that a horse can under fair and ordinary 
conditions give it; we have heard it argued that the heavy draught horse could not start and move such loads as are required of him without the aid of calkins and toe pieces; our reply to this objection is that any sound cart horse can start and move any load whatever that he can reasonably be expected to draw, as well or even better without shoes than with them, because in that state he will plant his foot on the ground naturally; toe pieces and calkins enable an animal to move a heavier load than he could do without them, provided he learns to stick his toes against the artificially laid street pavements; this leverage, however, enables the horse to put more force and power into his efforts than his natural strength warrants; hence sprained tendons and ligaments, ruptured diaphragms and such like injuries follow. On stone, wood or asphalt pavements, such as are laid down in large towns, the natural character of the horny sole and frog renders it specially adapted to the obtainment of a firm grip and foothold, whereas so far as the stone and asphalt pavements are concerned, it is well known an iron shoe renders foothold impossible.

To take another objection, it is said that carriage horses whose work lies mainly on country roads of the macadam type, on which are flint stones or sharp gravel, would soon wear away the horn, which would become abnormally thin; that the soles would not resist the bruising on round stones, and very shortly the animal would fall lame; this conclusion we affirm is hypothetical and incorrect; it is quite possible that the wall of the foot would, as it wore arvay, leave behind some fibres of incompletely worn horn; and that the foot would, if nothing worse came of it, look untidy; this objection is easily overruled; the frays of horn fibre could be rasped away; or if some sort of shoe must be worn for the sake of neatness and show, then the Charlier tips could be adopted, which are mere bands of steel, the width of the wall in a groove of which they are seated flush with the surface of the sole so that a full bearing is obtained upon the sole and frog; this is the nearest artificial approach to nature. Hunters, steeplechasers and flat racers, in which class we include also trotters, invariably get over the ground better and more safely with nature's foot than they do with the artificial provisions of the shoeing smith; moreover, the accidents and injuries due to jar, concussion and sprain are infinitely less numerous when the sole, bars and frog are left un- 
touched by the knife; we are quite aware that the promulgation of such ideas does not meet with a favorable reception even by those whom it most concerus, and very naturally meets with the active opposition of shoeing smiths; these are features in the discussion, however, which do not concern us; we have to advocate what we believe to be in the best interests of the horse and the horse owner, and fearlessly we affirm that horses generally would do far better without shoes, provided the foot has never been pared or cut with the drawing knife.

Among the diseases affecting the foot are ossification of the lateral cartilages known as SIDE BONES: NAVICULAR DISEASE, a very frequent cause of lameness among town-worked horses of the lighter class, due to inflammation of the small bone known as the "navicular," over which the tendon passes and plays like a pulley before it becomes inserted into the main bone of the foot; this condition can be recognized by contraction of the heels, and the short pottering style of action that subjects of this disease affect; it generally attacks both fore feet, and hence there is no dropping to indicate special lameness in a particular limb, a condition frequently availed of by ignorant or deceitful men to pronounce the animal sound; as the inflammation of the bone progresses, it ultimately results in an ulcerated, and consequently very sore, condition of the articulatory surface over which the perforans tendon plays; in this manner the diseased process extends to the tendon, the fibres of which become degenerated, and in the long run many of them are ruptured. When a horse is the subject of navicular disease, he may be observed, while in the stable, pointing first one foot and then the other; on coming out of the stable he will move like " a cat on hot bricks;" after going some distance and "getting warm," the worst features of the tenderness wear off, and the animal assumes a bolder style of action; let the horse, however, stand still for a time and get cool, and all the original cramped action recurs; further evidence of the existence of this diseased condition is presented by heat, tenderness and redness in the hollow of the heel, upon pressure being brought to bear on these parts; but the most conclusive evidence of its existence is obtained from the peculiar stiff gait and stilty action that characterizes the movement of an animal suffering therefrom. The treatment of old-standing cases of navicular disease is very 
unsatisfactory, and the prospects of success are extremely unpromising; if, however, it. can be detected in the earlier stages there is good reason to anticipate the realization of a successful outcome of the treatment we advocate; the most important matter for the owner to arrive at in the first instance is the detection of the incipient stage-that is, when the bone is becoming congested and before the inflammation has become thoroughly established. The question then arises, how is this point to be determined? The process of development is slow and insidious, a point certainly in favor of treatment, if it is recognized in the early stages; and we should certainly recommend an owner to allow his suspicions to be aroused if a horse was observed pointing either one or both feet when standing in the stable; further, if an animal, on being brought out, went slightly lame for a short distance, after which the lameness gradually wore off; if the natural action of the horse showed a tendency to shorten; if there be occasional heat, tenderness and redness in the hollow of the heel; if regular fast work seemed to intensify the tendency to temporary lameness; with these symptoms present we should certainly consider it wise to suspect incipient navicular disease, and especially so if there were neither splints nor corns present to affect the action of the horse. The treatment under such circumstances would involve a necessity for complete rest; the removal of the shoes; the horse should be compelled to stand in a bed of wet clay during the day, and at night be allowed a bed of moss peat; when taken out of the wet clay, the feet and legs should be carefully washed, the hollow of the heels be thoroughly rubbed with Arnica lotion, usual strength; afterwards the heels should be well padded with tow saturated with the Arnica lotion and surrounded with an ordinary compress to keep the tow moist; for internal medication give ten grains of Silicea $6 \mathbf{x}$, night and morning; this course of treatment should be continued regularly for a fortnight or three weeks; the horse should then be tried without shoes, and if the symptoms indicated as suspicious of navicular disease are discontinued and the animal goes somnd, gentle work might be resumed; if not, the treatment had better be continued for a further period; but under 110 circumstances should a horse that has once gone lame from this cause be shod with ordinary shoes; resort should be had to the Charlier shoe in order to bring pressure upon the sole and frog, or the concussion and jar 
experienced with the ordinary shoe will soon set up the diseased condition once again.

In well-established cases of navicular disease, where the horse is in all other respects a useful animal and the owner is reluctant to destroy it, a blister round the coronet might be tried, the best agent being the Biniodide of mercury ointment, and that because mercury has a specific action upon bony tissue; we have not much faith in this procedure, at the same time it might be put to the test; if this proves useless and the desire to retain the services of the horse is very strong, we should recommend that a veterinary surgeon be called in to perform the operation of neurotomy, as by this means the horse would be rendered insensible to pain and might, at all events, do slow work; before determining to have the operation performed it is well to remember that occasionally unfavorable results follow it, such as rupture of the tendon, fracture of the navicular bone and sloughing of the hoof; if an owner is prepared to run the slight risk of these possible untoward results, the operation will certainly enable the horse to move without pain, and so long as the bisected nerve remains disunited no indications of lameness will be observable.

LAMINITIS is probably one of the most painful diseases, while it lasts, to which a horse is subject; it is inflammation of the sensitive structures of the foot; a large proportion of these sensitive structures consist of laminæ or leaves surrounding the pedal bone, which fit into corresponding horny laminæ or leaves all round the horny wall; among these layers of leaves or laminæ an enormous number of blood vessels are situated; this fact accounts in a great measure for the agonizing pain experienced by a horse that is the subject of this disease, as the blood vessels become engorged with an excess of blood, which of necessity results in considerable swelling of the sensitive structures, and these being enclosed within the unyielding wall of horn, from which there is no escape, great pressure is brought to bear upon them, the congested vessels can obtain no relief, hence the extreme pain and agony. All practical horsemen know that when a horse has been the subject of a severe attack of inflammation of the foot it is no unusual thing for the animal to have what is called "dropped sole," and it may be interesting to know how this comes about; whenever blood-vessels are congested with an undue quantity of 
blood, a condition that precedes and attends inflammatory action in whatever part of the body it is present, an exudation of the fluid constituents of the blood takes place; this fluid, which escapes from the blood vessels must find room somewhere, and in laminitis it occupies the spaces between the sensitive and horny laminæ; this exudate or fluid, as it increases in quantity, ultimately presses upon the anterior portion of the os pedis (bone of the foot) and so forces it in a downward direction, at which point the bone presses upon the sole, which as time goes on loses its normal concave shape and becomes convex, assuming the characteristic bulging appearance and condition; the pressure which is thus brought to bear upon the sensitive sole interferes with its secretory powers and the horn becomes consequently degenerated and thin, ultimately resulting in protrusion of the pedal bone; a case that has gone to such extremes may fairly be looked upon as hopeless. Without, however, going to such an extreme, the inflammation by proper treatment may be induced to subside and the exudate which has been thrown out will become partially or entirely reabsorbed; but the most favorable cases and successful cures bear the distinguishing marks of laminitis by reason of an extension of the inflammation to the CORONARY BAND, the part where the horn is secreted and grows, something like the quick of the nail, as it is called, in the human subject; this inflammatory process of the coronary band gives rise to that ribbed or ringed condition of the horn frequently observed on the hoofs of horses; we do not wish to imply that all horses that have ringed hoofs have teen the subjects of laminitis, but when the rings are very prominent and noticeable there is some reason for suspicion, and a person before purchasing a horse with these marks should thoroughly satisfy himself that the animal is in this, as in all other respects, sound and in good health, and particularly note the condition of the soles, in order to be sure that they are of normal concave shape.

Laminitis owes its origin to several causes, most of which are preventable by the exercise of ordinary care on the part of the owner and stableman; among the various canses are: standing in constrained position for a great length of time on board ship or a railway train; over exertion in hot weather; partaking of large quantities of heating or improper food, such as wheat; drinking cold spring water in large quantities when overheated or much ex- 
hausted; exposure to a draught or chill of cold air; inflammation of the internal organs, such as the lungs and bowels, has been known to precede an attack of laminitis; sharp galloping on a hard road. Laminits may attack either the feet of the fore or the hind limbs, but it is rare for all four to be affected at one and the same time; the two fore feet are more frequently the seat of inflammation than the hind ones.

Symptoms. - The horse is exceedingly lame and hardly capable of moving; when located in the fore feet these are advanced and what pressure is brought to bear on them is confined to the heels; the hind feet are drawn forward and upon them, as much of the weight of the body as is possible is centred; the horse stands as it were "all of a heap;" when called upon to move the animal sways himself to and fro, rears up as it were on his hind legs, carrying the front legs forward with a swing and plants them on the ground very cautiously. When the hind feet are affected the horse stands with all four feet together under the median line of the abdomen. A horse with laminitis rarely stands long at a time if the opportunity is afforded him to lie down.

The pulse is rapid, 70 to 80 beats a minute; the respirations are quicker than usual, and with nostrils dilated he blows hard; the body temperature rises to 104 degrees or 105 degrees; the feet are exceedingly hot, and very tender to the touch when knocked.

Treatment.-Aconite $3 \mathrm{x}$, in the first place in hourly doses; indeed, except where complications arise, it is rarely requisite to give any other remedy while the fever lasts; we advocate the removal of the shoes, and putting the feet into hot water for a quarter of an hour, after which large poultices, consisting of equal parts of linseed meal and bran should be applied as hot as they can be born; outside the poultice, which should be rendered thoroughly moist and soft with plenty of hot water, a piece of waterproof material should be fastened to keep the application hot and moist; if two or three teaspoonfuls of the mother tincture of Aconite be adảed to the poultice where the same comes into apposition with the soft skin of the heel, much benefit will accrue; these poultices should be renewed, together with the fomentation of hot water three times in twelve hours. The bed upon which the horse stands when he does get on to his feet, should be some soft material like moss peat, and there should be plenty of it; but the ani- 
mal may be allowed with advantage to remain in a recumbent position as much as possible. After the fever and tenderness have passed away, and the horse is able to stand and move about, a jet or stream of cold water for half an hour at a stretch may with advantage be allowed to play upon the feet, and this procedure should be repeated twice a day. As soon as the temperature of the body has gone back to Ior degrees and the general febrile symptoms have commenced to abate, recourse should be had to the application of Arnica lotion, by hand-rubbing the coronets therewith, and keeping the pasterns, coronets, and hoofs clothed with some thick, soft material, which should be constantly saturated with Amica lotion; Amica 3x should also be administered internally three or four times a day, to favor the speedy resolution of the exudate already referred to. Some weeks must be allowed to elapse after convalescence before any attempt is made to put on the shoes, otherwise a relapse will probably take place, as the result of concussion which must be produced by nailing on.

SANDCRACKS, SEFDY TOE and CoRns usually call for some surgical interference which a layman could hardly be expected to undertake; but THRUSH, which consists of the discharge of a fœtid fluid from an unhealthy frog can best be cured by application of dry powdered Calomel and the internal administration of Arsenicum album $3 \mathrm{x}$ three times a day.

CANKER, or a diseased condition of the sensitive secretory laminæ of the sole, is a very intractible disorder that certainly demands surgical interference, which only a competent veterinary surgeon is capable of performing; by many it is considered an incurable disease; but very recently Mr. Malcolm, of Birmingham, published full particulars of a system of treatment which he had adopted with marked success among the horses under his care; very satisfactory confirmatory evidence having also been supplied by Mr. Edwin Faulkner, of Manchester, of the success which has followed his practice of this system; the details of this method appeared in the Joumal of Pathology and Therapentics, published by Professor Macfadyean, of the Royal Veterinary College, London; it would, however, serve no useful purpose for us to occupy space with describing the process, as the operation is entirely beyond the scope of an unprofessional man; if, however, the disease be detected in the early stages, it may be arrested by having the 
unhealthy horn carefully pared away, and the parts dressed with crude powdered white arsenic, and the administration internally, three times a day, of Arsenicum album 3x; it may be necessary to pare away the unhealthy horn every day and to redress with the white arsenic as frequently, in order to keep the agent well applied to the affected parts; pledgets of tow should be applied, and these may be kept in position by inserting crosswise strips of wood or iron and fixing same under the shoes; but this dressing must not be applied consecutively without intermission or it will destroy the secretive powers of the sensitive sole. Under such circumstances the animal need not remain idle, as some work is beneficial, exercise being advantageous; this, with good dry food and strict cleanliness in the stable, will contribute towards a satisfactory cure. So soon as the diseased process seems to be arrested, the sole should be dressed with tar, and pledgets of tow saturated also with tar, should be applied, so as to bring some pressure to bear upon the parts as the horse walks.

QUiTTORS are due to injuries of the feet internally, whereby inflammation, followed by suppuration, is set up; as the injury develops into suppuration, the matter which is unable to find an exit spreads, and small sinuses (or tubes) are formed, and extend until an abscess arises about the coronet; this bursts and leaves a little orifice out of which purulent and fœtid matter exudes; as a rule this description of wound requires the attention of a skilled surgeon, for unless it is probed to the very bottom, and the necessary applications are brought to act upon the whole course of the sinuses, whatever depth or direction they take, a cure is impossible; to effect this thoroughly it is sometimes-nay, very oftennecessary to lay them open with an instrument specially manufactured for the purpose; when the sinus has been probed to its bottom, and if necessary laid open, the best dressing to be applied is a strong solution of Bichloride of Mercury, one part to eight of water, but to keep this in solution will require the addition of some Hydrochloric acid.

A quittor is always productive of great pain and suffering, therefore complete rest is an absolute necessity.

This will complete our consideration of diseases affecting the foot of the horse, as being sufficient for the purposes of this work; we have dealt with those most frequently occurring and easily 
recognized by the amateur horseman, and we are of opinion that no good purpose would be served by attempting to treat of the more occult and less frequently presented forms of disease that are occasionallv the causes of lameness. 


\section{DISEASES OF THE EYES.}

These are not of frequent occurrence in the horse, but when they do present themselves are mainly limited to three causes, viz., injuries due to blows; the presence of a foreign body, such as hay seeds or portions of chaff; and cold. In byegone times horses were frequently the subjects of inflammation of one or both eyes by rison of the unhealthy condition of stables; but since owners have awoke to the necessity of studying the comfort and wellbeing of their animals by providing more light and more sanitary arrangements the occurrence of this disease is rare. OpHTHALMIA is a term generally used to define the presence of inflammation of the conjunctiva, a fine membrane that lines both the eyelids and the front of the eyeball; ophthalmia may arise as the result of any of the causes we have already referred to; in former times one form of this disease was described as periodic ophthalmia, owing to the fact that it frequently recurred, but this we attribute to the unsanitary conditions of the stables, and the cause that provoked the first attack was likewise accountable for those that followed, and the repeated recurrence of the attacks were responsible for the production of complete blindness in cases not a few.

Ophthalmia that is due to injuries-such, for instance, as the blow from a whip lash, or to the presence of a foreign body, is easily accounted for and with equal readiness successfully treated; the presence of a foreign body demands its careful removal, and once discovered, nothing answers better for this purpose than a bird's feather; after the removal is effected the organ should be fomented with hot water, and a weak lotion of Arnica, one in twenty, applied with a piece of sponge; when the inflammation is set up by a blow or an injury of any kind, frequent fomentations should be adopted and a compress of Amica lotion, about one in twelve, applied; the compress can be kept in position by a piece of linen cut to the shape of the head with holes to pass over the ears and tapes to tie round the jaw. 
Ophthalmia which is due to cold or some constitutional cause, as is sometimes the case, requires treating according to general symptoms, as follows:

Aconite $3 \mathrm{x}$ when the pulse is quick, the skin dry and the temperature at all higher than normal.

Belladonna 3x.-Evident pain, swelling and redness of the white parts; dryness of the membrane of the eyeball; intolerance of light.

Euphrasia Ix is par excellence the remedy when there is a profuse secretion of tears; great sensitiveness to light; a tendency to rub the eye, as though it itched or stung, and especially when the lachrymal secretion flows down the nostrils.

Argentum nitricum $3 \mathrm{x}$ for old-standing and chronic cases, when the lachrymal secretion is no longer thin, but has asumed a thick and purulent condition.

Mercurius corrosivus 3x. - In acute forms of the disease, when the animal has an evident dread of light, and when the glands between the jaws and around the throat are swollen.

Arsenicum album $3 \mathrm{x}$ for weak, emaciated animals, and when the inflammation is obstinate and intractable; the lachrymal secretion is acrid and as it were burns the skin over which it flows; light aggravates the condition and produces an increased flow of the secretion; the horse shakes his head every now and again as though it experienced paroxysms of stabbing pain in the eyeballs.

ACCESSORY MEASURES. - The eyes should always and regularly be fomented with warm water, any agglutinated secretion should be carefully washed away, and when Aconite, Belladonna and Euphrasia are indicated, a compress saturated with a lotion of the remedy-about one in twelve-should be applied to the eyes as before directed. In those cases where Argentum nitricum is indicated a solution made by dissolving two grains of Nitrate of Silver in an ounce of distilled water should be introduced over the eyeballs and under the eyelids, with a camel's-hair brush, night and morning.

PARASITES. - A worm is occasionally observed floating about in the humor of the eye, especially anong horses in India and Canada; the symptoms are those of inflammation, there is an intolerance of light and the eyelids are kept closed; it is prevalent among horses that are allowed to run loose in low, huninid situa- 
tions where stagnant water is found in abundance. The only satisfactory method of treatment in such cases is to puncture the eyeball and allow the parasite to escape with the aqueous humor; this operation, however, should not be attempted by a layman, or permanent injury to the organ would most probably be the result.

Fungus Hæinatodes is a form of disease that we have on several occasions met with; it consists of a dark vascular tumor, of a malignant character, that forms at the back of the eye, and unless arrested spreads until the whole of the eyeball and sometimes the bones $\pi$ hich help to form the socket of the eye are involved; the cases that have come under our notice were all so far advanced that we made no effort to treat them medicinally, but performed the operation of removal of the whole organ; and after the healing of the parts was completed one case was furnished with an artificial eye that answered the purpose of concealing the unsightly appearance which an empty socket presents.

Could the disease be discovered in its earlier stages, and before it had invaded the organ too far, we should think that Phosphorus $3 \mathrm{x}$ and Hydrastis Ix might be administered with some good prospect of arresting further development and so affecting a cure.

CATARACTS are opacities of the crystalline lens or its capsule, which prevent the rays of light from passing on to the retina and thus produce complete blindness or imperfect sight; it is under the latter condition that horses are rendered somerwhat dangerous, especially to inexperienced drivers, from the tendency to shy, a habit which is due to the inability of the animal to properly discern various objects on the road. In this country cataracts are attributed to frequent attacks of ophthalmia; whether this is correct or not we are unable to say; but we confess to being somewhat sceptical about it; on the other hand it is generally admitted that cataracts of one or both eyes develop independently of any preceding inflammation; it is hardly possible to positively diagnose the presence of cataracts without the aid of the ophthalmoscope; the majority of veterinary surgeons claims to be able to recognize the condition without the aid of this instrument, but for our own part we prefer to rely upon more positive evidence than is obtainable by trusting to our unaided sight. In the human subject cataract is said to be due to various causes, viz., to diabetes; to old age; in association with some established constitutional disease; 
to injury; to matters congenital dating from birth; and to defective nutrition. As a rule cataracts develop slowly and gradually and for some time the patient sees more or less distinctly; if, however, a horse that had not previously been guilty of the habit of shying when on the road takes to doing so, it would be wise to have the eyes carefully examined by an experienced veterinary oculist, and if in the opinion of such a practitioner a cataract is forming, medical treatment should be commenced; among ophthalmic specialists, as a rule, surgical measures only are relied upon; the idea of dissolving the cataract and clearing up the lens through the instrumentality of internal medication is scouted as ridiculous; but as the result of our own experience, we are satisfied that such a course of procedure is not only rational, but most hopeful; moreover, we have the experience of Dr. Burnett, of London, who has written a most interesting brochure upon the subject, that he has been instrumental in curing quite a number of well-established cases of cataract, and had we not had some success in this line among our own patients and had simply to rely upon the experience of Dr. Burnett we should unhesitatingly advise the practice he so ably propounds; such experience as we have had has been among dogs, but we see no reason why, if the opportunity offered, the same line of treatment should not suffice for horses. The late Sir David Brewster appears to have formed the opinion that a relationship existed between salinity of the lens and the origin of cataract; this is a most singular fact, as Dr. Burnett seems to have arrived at a similar conclusion; nay, more than that, he advocates strongly that persons with a tendency to cataract should discontinue taking salt with their food, in the belief that salt tends to produce cataract; moreover, Natrum muriaticum (which is the homœopathist's name for salt when prepared as a remedial agent), in high attenuation, is the remedy which Dr. Burnett prescribed for several of the cases of cataract that he succeeded in curing, and it was this drug that we prescribed for and cured several dogs that were the subjects of undoubted cataract. Dr. Burnett, however, with no uncertain sound, proclaims the absolute necessity of not relying upon any specific as a cure-all in different cases of cataract; he points out clearly, like the true honnoopath he is, that every case must be treated according to the totality of symptoms, not merely those that do exist, but those also that have existed 
years before; no doubt prescribing with such precision as this is all important in the human subject, while it is well.nigh impossible among the lower animals; still it is gratifying to know by experience that cases of this description do yield to medical treatment, because the surgical procedures now in vogue for the removal of cataract cannot possibly be resorted to among our patients, and even if they could, we should never be adequately remunerated for performing them.

TREATMENT. - Being satisfied that a horse is the subject of a cataract we should recommend the daily administration, first thing in the morning before any food or water are given, of Natrum muriaticum 12, twenty drops; continue this course of treatment for a week, and then discontinue for a week; alternating in this manner for one month; then have the eye examined by an independent oculist with a view to a report of the state of the eye, after which resume again; if at the end of two months no improvement is apparent, we should resort to Silicea 30 , twenty grains. once daily for similar periods. Other remedies that have been recommended for cataractous eyes are Belladonna after an attack of ophthalmia; Calcarea carb. when the animal is naturally emaciated and poor; Sulphur when chronic eruptions of the skin are present; Mercurius, Conium and Phosphorus, the selection depending of course upon any special symptoms to which these remedies are chiefly applicable in addition to those connected with the eyes more immediately. ENTROPIUM or inversion of the eyelids, and ECTROPIUM or eversion of the eyelids, are occasionally, but rarely, observed in the horse; when they do so occur, the services of an experienced veterinary surgeon should be called in to perform the necessary operation for alleviation of these respective conditions. 


\section{DISEASES OF THE EARS.}

We have never, in the course of our experience, come across a case of disease of the ear in the horse, and with the exception of occasional injuries, there would appear to be nothing calling for special treatment in the organs of hearing among the equine race. 


\section{OCCASIONAL DISEASES.}

PoLL EvIL is due to injury or violence brought to bear upon the top of the head; it may be caused by the willful act of some malicious person, or the horse itself may inflict an injury by suddenly throwing up the head and striking it against a cross beam; while by some it has been attributed to the habitual use of a Bearing rein. Whatever be the cause, the result is the same-namely, inflammation of the dense connective tissue which lies under the skin just behind the ears; as the consequence of the inflammation suppuration is established, a large swelling is formed that ultimately has to be opened or bursts spontaneously; in consequence of the lowly organized character of the dense tissues in and about this part of the head, and the tendency that suppuration has to go deeper and deeper among them rather than come to the surface, burst and discharge, it is always desirable, by means of hot fomentations and poultices to hasten on the maturation of the abscess and then open it with a free incision at the base of the swelling and thus allow the matter (pus) to escape. In some cases of long standing the natural tendency which pus has to burrow leads to the formation of deep-seated fistulous ulcers which take the form of tubular cavities about the size of a goose quill; therefore, when an abscess of this description has been freely laid open, it is still necessary to examine its base and sides with a vulcanite probe to discover if any of these sinuses exist; if so, they also must be laid open so that the imprisoned pus may obtain an exit and the whole of the walls of the sinuses be properly dressed. One good dressing of the solution of Bichloride of Mercury, the same strength as that used for quittor, will frequently serve to arrest the tendency to form pus and convert the whole into a healthy-looking wound; however, should the one dressing not suffice, it must be repeated at about half the strength, and should there remain any sinuses but incompletely laid open these should be carefully injected with the lotion by means of a glass syringe. 
Fistulous Withers are precisely the same sort of disease process as poll evil and resemble this morbid condition in all respects except the locality; the withers of some horses are so exceptionally prominent that unless a saddle be expressly made for a particular animal it fails to fit properly, and contused bruises are the natural consequence. Treatment on the same lines as for poll evil must be adopted; while in both diseases much benefit will accrue from the internal administration of Silicea $6 x$, three times daily until the wound is healed up. 


\section{DISEASES OF THE SKIN.}

We shall make no attempt to arrange these diseases into anything like the orders and distinctions which are observed by dermatologists for the reason that the study of these disorders takes a much more simple form among horses than it does in the human subject; moreover, such forms as the veterinarian has to deal with among his patients seem to yield more readily to treatment than do many of the varieties observed in man; so far as our experience goes, and. we can, without rendering ourselves chargeable with egotism, claim to have had a fairly extensive one in this direction, we have found that a very large majority of cases of skin diseases in the horse are due to parasitic mange; once this gets foothold in a stable there is no telling when it will be got rid of, unless an owner is willing to subject himself to an infinitude of trouble, so infectious is this disease and so readily is it conveyed from one animal to another; at the proper place, when mange comes under consideration, we shall offer our schedule of instructions, and provided they be carried out in their strict integrity, the disease may be eradicated from a stable but not without; one iota of omission will render all previous efforts fruitless and as though they had never been conducted.

In the first place, we shall refer to those forms of skin disease which owe their origin and development to constitutional causes, and are of a non-infectious character.

ERYTHEMA is an inflammatory redness of the skin of an uniform character always attended by heat, and occasionally by swelling and irritation; this form of disease is due generally to cold, wet, friction and undue pressure. Cold, wet and frost are frequently accountable for the development of an erythema that results in the long run in CRACKED HEELS and MUD FEVER; the former requires no further explanation, but in the latter, which usually comes out as the result of wet and frost, the skin of the legs, arms, thighs and surface of abdomen are considerably swol- 
len, the parts are irritable and tender; the flexures of the knees and hocks develop cracks, and occasionally a serous fluid exudes therefrom; these conditions are described commonly as MALLENDERS and SALLENDERS; under these circumstances constitutional symptoms are developed, as evidenced by an elevation of internal temperature and an abnormally rapid pulse, and until these febrile symptoms are relieved the local manifestations show no signs of abatement.

TREATMENT.-Aconite $3 \mathrm{x}$ when brought on through cold, chill and wet; when temperature is elevated; the skin dry and hot, attended with some irritation and considerable burning; in the early stages.

Rhus toxicodendron $3 \mathrm{x}$ for itching and burning, going on to vesicular eruptions; and by means of external application of same, consisting of one part mother tincture, two parts of glycerine and nine parts of water, gently dabbed on with a sponge and the operation repeated night and morning.

Graphites $3 \mathrm{X}$ for CRACKED HEELS, MALLENDERS and SALLENDERS when the surrounding parts are dry and harsh and the cracks exude an excoriating discharge.

Callendula $\theta$ one part, glycerine two parts and water three parts, to be locally applied to cracked heels, and the cracks in MALLENDERS and SALLENDERS; to be applied to the affected parts three or four times a day with a sponge.

URTICARIA is a form of skin disease not infrequently seen in the horse, consisting of various shaped swellings that form rapidly over any part of the body; the swellings vary in size from that of a pea to a walnut, having rather flat surfaces; the eruption is not unlike the wheals formed through the sting of a nettle, hence the common designation NETTLE RASH; it is accompanied by a tingling irritation which causes the animal to bite and rub itself; it is considered to arise as the cause of some stomach derangement; and being very capricious, sometimes departs as rapidly as it came; in those cases, however, that last on and demand treatment it is not unusual to find a very fine onter layer of the skin peeling off after the febrile symptoms are abated, and following upon this the hair falls out in patches.

Treaturent. - Apis $3 \mathrm{x}$ in simple cases due to a slight chill or exposure in the burning hot sun. 
Urtica urens $\theta$ applied locally as a lotion, one part of the drug to four parts each of methylated spirit and water,- and internally the usual dose of the third decimal attenuation; this in uncomplicated cases.

Antimonium crudum $3 \mathrm{x}$ when due to stomach derangement and the tongue is thickly coated with white fur.

Bryonia $3 \mathrm{x}$ in cases where the rash comes out quickly and departs as rapidly only to come out again in a short time; this is described as sudden retrocession.

Veratrum viride $\theta$ for outward application when the swellings or wheals are extremely tender and irritable; one part to four each of methylated spirit and water.

ACCESSORY MEASURES.-Much relief may be afforded by sponging the horse all over with hot water, as it soothes the irritation and renders the skin more amenable to the action of the local dressings. Exposure to sudden changes of temperature must, for a time at least, be avoided; great cleanliness in the body and general surroundings must be observed; moderate exercise must be given and no corn of a more stimulating character than oats is to be allowed,

SIMPLE ECZEMA-non-contagious and therefore non-parasitic-is characterized by more or less redness of a superficial kind, upon which small vesicles, abuut the size of a pin's head, form; these alternately burst, discharge a serous fluid, after which they seem to run together and over a more or less extended area crusts or scabs form and dry. Locally a good deal of heat and irritation prevails, and successive crops spring up. The chief point in the treatment is to commence as soon as the vesicles appear and before they burst and discharge. We have rarely found any remedy beyond Rhus toxicodendron necessary; so far as any drug can be a specific this is in simple eczema. Internal administration is, of course, a sine-quâ-non, but this must be supplemented by the outward application of a lotion consisting of one part of the mother tincture to eleven of water and be frequently dressed over the affected areas; should the disease have fully developed and crusts or scabs have formed, an ointment consisting of Vaseline eight parts, Glycerine two parts and Rhus. tox. one part should be thoroughly blended together and applied carefully twice daily.

ECZEMA IMPETIGINODES is a form of this eruption often seen 
in gross constitutioned cart horses that have much hair about their legs; it is commonly called GREASE; the disease generally originates in the heels and hollow of the fetlocks; in the first place vesicles form, these are rapidly followed by pustules, which burst and discharge a fœid, unhealthy pus; the hind limbs are generally the seat of the eruption, which as it develops sets up an inflammation in the connective tissue around the back tendons that produces considerable tenderness; here a further crop of pustules spring up, these discharge and the secretion irritates the skin over which it flows, producing superficial cracks and ulceration, until large fungoid growths are formed, commonly known as GRAPES; these fungoid excrescences are supposed to be due to the inflammation of the sebiparous (or sweat) glands, and ultimately -if unchecked or imperfectly treated-they become hard, rounded elevations. If through neglect this is allowed to go on and still further affect the leg, the fibrous tissue becomes alarmingly thickened until the legs are such a size that it is termed ELEPHANTIAsIs. Whether their presence is accidental or otherwise there is no doubt that in cases of grease of long standing there are always present large numbers of small parasites called acari, and before a cure can be effected some dressing must be applied, and that thoroughly, which is capable of destroying these parasites.

The exciting cause, in the first instance, is doubtless dirt and neglect, while sometimes improper food may have something to do with it; but we believe the main cause to which it may be attributed is constitutional tendency.

TREATMENT depends entirely upon the extent to which the disease has attained; in the first place, when from the offensive discharge, the heat and swelling, it is quite clear that the disease is thoroughly established, it is necessary to poultice the leg with boiled turnips; or with spent hops or linseed meal-anything, indeed, that has a tendency to soothe and soften the skin; after continuing this for a day or two the legs should be carefully washed with some non-irritating soap, thereafter dried as well as is possible and the long hairs cut off as closely as can be with a pair of scissors, after which an ointment of Benzoated zinc should be applied all orer the affected parts; while internally Kali bichromicum $3 x$ should be administered three times a day. If in a few day's this does not arrest the formation of the offensive discharge and induce the 
sores to heal, a lotion, consisting of Bichloride of Mercury, one drachm dissolved in sixteen fluid ounces of boiling water, to which when cool, should be added four fluid ounces of Glycerine, should be carefully applied three times a day with a soft piece of sponge; this will effectually destroy all the acari that may be on the legs in about two days; a small quantity only of this lotion must be applied at one dressing, just sufficient to cover the whole affected surface, but not more, lest the Mercury should become absorbed into the system. After the acari are destroyed the treatment externally may revert to the Benzoated zinc ointment; but if this does not seem to do the desired good, while the itching and irritation is very intense, an ointment of Bismuth nitrate, one part to eight of prepared lard, while internally Croton tiglium Ix should be administered three times a day. In old-standing chronic cases it will be better to give from the commencement Arsenicum album $3 \mathrm{x}$, three time a day, and bathe the legs with a lotion made by mixing Liquor arsenicalis (B. P.), one ounce in a pint of distilled water, and frequently applying same to the legs and that liberally.

If the case has developed into one of grapes it will be well to try dressing the legs with a lotion consisting of equal parts of Tincture of Iodine, Methylated spirit and water, and to administer internally Iodium $3 \mathrm{x}$ three times a day, after first cleansing the leg with poultices and washing for two or three days.

Occasionally, when the grapes are but small, Clematis $\theta$, internally, and externally as an ointment in the proportion of one part of the tincture to eight parts of vaseline, will be found effectual; it is hardly possible to say which of these various methods of treatment is the best; it is not easy to differentiate between the cases, the constitutional symptoms do not enable one to readily distinguish between them, nor do they render any aid in discriminating that which is most appropriate.

ACCESSORY MeAsURES. - Much aid to treatment can be obtained from careful dietary; during the summer the food should be confined to artificial grasses: but in the winter carrots, parsnips, turnips, or even mangold with sweet last season's hay chaff, and about one-fourth the ordinary allowance of corn (oats). Twice a week a mash consisting of boiled linseed, which has been gradually simmering for three or four hours, mixed with a suff- 
ciency of bran, and if necessary, to make it palatable, a small quantity of condiment like Thorley's food may be added. When the legs are washed soft water should be used. Out of door exercise is desirable when led by hand, but ordinary work should not be attempted. Great cleanliness must be observed in the stable, and if it can be obtained, moss peat should be used instead of straw for bedding.

\section{SCABIES-MANGE}

Is a contagious form of skin disease which is due to the presence of one of the minute microscopical animal parasites; of these there are three kinds which attack the horse; the SARCOPTES, which burrow under the epidermis into the substance of the skin; the SYMBIOTES which congregate in goodly numbers but only penetrate the superficial layers of the epidermis; and the DERMATODECTES that cling about the hairs and bite the skin; the result of the irritation set up by these parasites is the production of a serous fluid and it is supposed to be this serosity which the creatures live upon. The sarcoptes, from their habit of burrowing under the epidermis, render the methods of treatment more difficult, as the females lay their eggs in long channels or galleries, and unless the agent that is used for the destruction of the parasite penetrates to the depth of these galleries and dissolves the eggs, they will in all probability hatch out in three or four days and a fresh batch of parasites be raised; for this reason it is occasionally necessary to dress a horse a second or even a third time. With the two classes called symbiotes and dermatodectes the treatment is much more simple, and, as a rule, one dressing suffices. The dermatodectic scabies is considered by some writers to be more frequent than either of the other two classes; our experience does not agree with this; certainly eighty per cent. of the cases we have treated have been the sarcoptic scabies.

Symptoms.--The neck and shoulders, mane and tail are the favorite haunts of these parasites; their presence is indicated by small lumps forming in the skin which soon burst and discharge an acrid fluid; this serous fluid dries and forms a scab; in a short time the skin feels thicker to the hand and assumes a wrinkled appearance; wherever the exuded fluid tonches the surface of the skin, the hair falls off in considerable quantities; at all times the 
hair stands on end and gives the horse a very ill-favored appearance. These parasites may certainly be said to be prolific in their powers of reproduction; after sexual intercourse the female commences to burrow under the skin and is said to deposit one egg a day, the meanwhile boring her way under the epidermis; having formed a canal and deposited her ova, she dies; but the numerous eggs she has laid hatch out with the heat of the horse's body in about eight to ten days, and by five weeks these youthful parasites have attained sexual maturity and immediately commence the process of reproduction; from these facts it will be quite clear that only a comparatively short period elapses before a horse is covered with these troublesome guests; and it will also be apparent that if one sexually mature female is left behind after treatment, the whole process will have to be gone over once more, hence the imperative necessity for thoroughness. The parasites will live for some weeks apart from their natural host, located in brushes, on the sides of stalls and mangers, among harness and clothing, indeed, anywhere or in anything that the original has come in contact with during the period of the attack of the mange; the most diagnostic symptom of the sarcoptic variety is the presence on the neck and shoulders of the semi-circular wrinkles or furrows in the skin. Of course, it goes without saying, that the itching and irritation is intense, provoking the poor horse to rub and gnaw himself continually, and to stamp with his feet; indeed, at times it appears well nigh driven to distraction.

TREATMENT of the horse itself; thoroughly saturate the coat from head to tail with the following compound mange dressing, not leaving one hair without the application; allow the dressing to remain on three whole days and nights, after which the horse must be thoroughly washed with hot water and a non-irritating soap that lathers freely, once a day for three successive days.

Prescription, for mange dressing: Unguent Hydrarg. Fort., one ounce; Ol. Terebinth, eighteen ounces; Ol. Pics, ten ounces; Hellebore Alb. pulv, one ounce; Sulphur Flav. pulv., two pounds; Bolarmenia, two ounces; dissolve the Unguent Hydrarg. in the O1. Terebinth. carefully, and add sufficient O1. Lini to make up to seven pounds. This quantity is about sufficient for dressing one full-sized draught horse. The dressing should be constantly shaken while being applied to the patient. 
To treat the horse alone, however, will prove useless; all brushes and ciothing that have been used for and about the animal should be burned; the stable ought to be fumigated by burning powdered Sulphur over a charcoal fire; the windows, doors and apertures being thoroughly closed meanwhile; the fumigation should be kept constantly going for four or five hours; thereafter the walls, sides of stalls and mangers should be thoroughly washed down with a solution of Bichloride of Mercury, of the strength of one in five hundred; with this solution also the harness must be thoroughly washed, especially the collar and the saddle pads; also the shafts of the conveyance in which the animal may have been previously working; the clothing of the stableman who has been attending the horse, ought to be sent to the cleaners and properly treated, and under no circumstances should this man be allowed to touch other horses that are free from disease, until the patient is cured and his clothes are cleaned, for the contagion is readily conveyed through the medium of clothing. After the patient has been submitted to this course of treatment, it should be narrowly watched for two or three weeks, and in case of any symptoms of irritation remaining, the animal should again be subjected to a second course. Horses are occasionally troubled with LICE; there are three distinct varieties, but it is a very rare occurrence to find them upon the equine race unless they become infested through coming in too close contact with poultry, in which case no surer method of destroying the invaders can be suggested than a thorough dressing with the mange compound already given. A form of vegetable parasite of a contagious character, the TINEA TONSURANS, or RINGWORM, is not infrequently found among horses; it appears in the first instance in the form of small spots, which gradually increase and appear to run together or coalesce; ultimately a thin crust of oval or circular shape forms of a pale yellow color with raised edges. No little trouble is experienced to get rid of this disease, for it would appear that the development of the parasitic growth is fostered by constitutional tendencies, and it does not appear sufficient to simply use dressing that will destroy the fungus alone, the administration of internal remedies to render the soil less favorable to its growth is required. For local application nothing is better 
than blue Mercurial ointment; while internally, Arsenicum album, Sulphur and Calcarea carb. may be administered with advantage.

\section{INTERNAL PARASITES.}

According to the late Dr. Cobbold, a well-known teacher of Helminthology at the Royal Veterinary College, in London, the species of parasites that infest the horse are fairly numerous, but their importance in relation to disease is of less consequence than is the case with some other orders of domesticated animals. Tape worms are rarely found in the horse and are at all times comparatively small in size. The most commonly found parasites, are the Ascaris Megalocephala a long round worm, and the Oxyuris Curoula or maw worm; these, however, are with comparative ease got rid of; the former by a few doses of Aloes, followed by a course of Sulphate of Iron in moderately substantial doses-say half a drachm every other day mixed with the usual medical aromatics; or from one to three ounces-according to the size of the animal-of Oil of Turpentine mixed with linseed oil, from half a pint to a pint will generally serve to destroy numbers of these large parasites.

For the maw worm whose habitat is the rectum and colon, an enema of solution of Quassia three or four days in succession will generally dislodge these irritating little parasites, whose presence can always be determined, even though the worms are not observed among the fæces, by the whitish deposit round the fundament, the attention being first drawn to the horse continually endeavoring to rub his tail against the sides of the stall. The internal administration of Cina $3 \mathrm{x}$, night and morning, for a month consecutively has a very favorable influence on the constitution and doubtless produces such a healthy state of the mucous membrane lining the intestinal canal, that the locality becomes unfarorable to the life and existence of these parasites. There is one torm of parasite designated the STRONGyLuS Aruatus which gives rise in old horses to aneurisms of the mesenteric artery: but its presence is not easily diagnosed with any certainty even by specialists, so that no useful purpose would be served by attempting to suggest a prescription; were we to do so, seeing that it is included among the class of round worms, we should recommend a long course of Cina $3 \mathrm{x}$ on the principle already laid down. In 
the article upon the diseases of the eye passing reference was made to the occasional presence therein of a worm; this is designated the Filaria papillosa, and as already stated, the only method of disposing of this parasite is to remove it by operative surgery. Although it is almost universally deemed necessary to destroy the internal parasite by the administration of some drug that will destroy, there is in this course of procedure an invariable attendant risk of either poisoning the host or producing in it the pathogenetic action of the drug; and we are much more favorable to the slower and more tedious process of treating the host with a long course of medicine in a moderate homœopathic attenuation with a view to constitutional remedial action; as has already been said, to render the intestines or other locality an unfit place of habitation for the parasite, and so starve it out as it were, such a result we believe to be quite within the region of possibility, although the suggestion may make a considerable demand upon the credulity of most persons; it goes without saying, strong drugs cannot be administered for the destruction of worms without exercising some baneful influence upon the horse; for instance, although oil of turpentine will in all probability effectually destroy a large proportion of the worms present in the animal, there is a great risk of its setting up strangury. Aloes, in sufficient quantities and given often enough, will without doubt clear out the parasites, but its administration for this purpose is very likely to set up superpurgation or even inflammation of the intestines; it is therefore worthy of serious consideration of horse owners whether it is not worth a trial to dispose of these troublesome and undesirable guests by means of middle measures; as already indicated Cina $3 \mathrm{x}$ is a successful remedy; Spigelia $\mathrm{I} x$ might also be put to the test, especially if giddiness, colic, lassitude and itching at the anus are marked symptoms.

\section{INFLAMMATION.}

We propose to offer a few suggestions upon the nature and character of this process, because in the first place it is frequently referred to in the course of this work, and also because such indefinite ideas concerning it prevail in the minds of laymen generally, the term laymen being adopted to distinguish between 
those who have studied medicine and qualified and those who have not.

Inflammation, as used by horsemen, stablemen or even horse knackers, is applied in the most general and vague manner to any serious case of illness among animals that proves fatal; if you inquire of a man what a horse died of, the answer as a rule is "inflammation;" that word is used as a definition with which to conjure; it is referred to with awe-inspiring feelings, as though an animal that is once the victim of inflammation cannot possibly recover save by fire or at least a miracle. A horse dies, the carcass is removed to the slaughterers to be disposed of; on being opened it is discovered that the lungs are black in color, instead of a bright pink as in health; the blood vessels contain blood clots and the whole organ is otherwise surcharged with black-looking fluid; the slaughterman at once pronounces it inflammation, and the groom accordingly leaves to report this sage piece of information to the owner of the horse; he in his ignorance of this particular subject, is perfectly satisfied. All the while there was nothing like the semblance of inflammation affecting these organs; they were congested with an excessive quantity of blood it is true; it may be that during life congestion to a certain extent existed, but not in so pronounced a condition as was revealed at the autopsy; the large quantity of blood observed in the lungs was the result of post mortem effects; it had, in point of fact, gravitated there; had a precise examination been made, it is more than probable that the lung on that side of the animal upon which it lay when dying was far the blackest, and contained the greatest quantity of clotted blood and serum, the result really of gravitation and nothing more; there was, in point of fact, no inflammation, either local or general. Perhaps the reader will say, well! if this is not inflammation, pray what is inflammation, after all? So far as we can do so in plain, unconventional language, we will try to explain; because it is of importance that he who treats his own horse should clearly understand that the process is a definite and precise one and not a sort of generalized condition that serves to cover all the most serious complaints to which animals are subject in one comprehensive name. INFLAMUATION may be either GENERAL, winen tne entre system is implicater, or LOCAL, when some particular organ is the seat upon which is main force is 
concentrated. The exciting causes of inflammation are varions, among which the following are included: Mechanical injury, the result of a wound or bruise; chemical irritants, as when a cantharides blister is applied to the skin; excessive heat or cold, as when an animal is exposed to sudden and extreme changes of temperature; and the introduction into the system of deleterious animal products like bacteria.

We have already stated that inflammation may be either general or local; after we have attempted to explain the actual changes that take place as the result of inflammation, or rather that are dependent upon the condition known as inflammation, it will be seen why it is that inflammation of the local order occurs much more frequently than the general; by this we wish to be understood as meaning that special organs, as the lungs, kidneys, liver, et cetera, and very frequently only limited areas of these organs are more often the seat of the changes involved in the inflammatory process than the body generally. The changes which take place in the process called inflammation involves, Ist. The blood, the blood vessels and the circulation of the blood. $2 \mathrm{~d}$. The tissues through which the blood vessels so affected ramify and extend.

In the first place we must remind the student what the composition of the blood is; and in so doing shall refer only to its three principal constituents: (a) The liquor sanguinis or fluid portion; (b) the red corpuscles, and (c) the white corpuscles or leucocytes. The red corpuscles are circular, convex at the edges, and concave at the centres; they form about forty per cent. of the entire mass of the blood, and are the cause of its color and density. The white corpuscles are far less numerous than the red, and in comparative weight much lighter, evidence of which appears when blood coagulates or forms into a clot, the light colored portion always coming to the top; the shape of a white corpuscle varies considerably; if a single drop of blood is placed upon a glass slide, covered with a slip, and thereafter examined under a microscope, the red blood cells will be easily discerned by their shape and also by their movements, they keep up a continual strean, by rapidly passing from one end to another of the slide, while the white corpuscles adhere to the sides of the slicle

Whatever niay be the cause of inflannination its consequences 
are, as regards the blood vessels, arteries and veins, more or less dilatation, which gradually increases for some hours and then for awhile remains stationary. The circulation of the blood in the affected area is marked by increased rapidity in the early stages; after an excess of blood has flowed into the affected area a change takes place; the rate of flow slows down and ultimately this is followed by stagnation; an unusually large number of red corpuscles are crowded into the space so invaded; this is the state of affairs so far as the central area is concerned; just outside the affected zone there is an area in which the circulation is observable, though sluggish in character, while on the outside of all the current of blood keeps up a rapid circulation, as though to compensate for the sluggish and stagnant condition of the central portion. In the blood itself important changes are effected; the white corpuscles accumulate in the vessels, especially the veins, and consistent with their natural tendency, they adhere to the walls until layer after layer is formed and the lumen of the vessel is blocked up, thus bringing about a stoppage of the blood flow; after a time it would seem that they migrate and ultimately force their way through the walls of the blood vessels; their ability to effect this change of location is due doubtless in no light degree to their capacity of effecting an alteration in shape; as liberated white corpuscles they are known by the name of leucocytes, under which condition they wander about among the surrounding tissues; the red corpuscles are endowed with similar capacity to segregate together, and to effect a passage through the walls of the blood vessels, chiefly the capillaries, whose walls are of much more delicate fabrication than either arteries or veins; at the same time they do not migrate so freely as do the white corpuscles. The liquid portion of the blood (or at all events some of its consistent elements) exudes through the vessels and spreads itself over the surrounding tissues. Now! what about the tissues through which the blood vessels pass and among which the blood, that has wandered out of the vessels, has become distributed; passing reference must be made to the fact that muscle, skin, mucous and serous membranes, and all other tissues when reduced to their primary elements consist of cells; it is these cells that the inflammatory process acts upon, either destroying them entirely, or so interfering with their nutrition that they are starved and die; this fact 
will be better understood if we call to mind that the skin, over an inflamed sore, dies and peels off; this serves as an illustration of the result of inflammation when it proceeds to extremes or is not arrested by medical treatment. The foregoing is a rough and ready statement of what takes place during the development of inflammation; but when the process is arrested or stays its progress of its own accord, what becomes of the blood corpuscles, white and red, et cetera, which have got out of their normal channel and are hence nothing less than foreign products among the other tissues?

Something must be done with them; they must either be restored to their original locality or be disposed of in some way. The term resolution is applied to the change which has to take place in order that nature may be restored to her original state; resolution consists of a subsidence of the vascular disturbance; the absorption of the exuded elements; the corpuscles have to undergo a change, similar to fatty degeneration, to enable them to be reabsorbed into the blood vessels. The fluid portions of the exudation that are not resolved in the manner referred to may, according to their characteristics, remain among the tissues or collect into a given space; while these and the corpuscles also develop pus and bring about what is known as the suppurative process; the pus collects in carities, or invades the substance of tissues and organs, forming abscesses; while still further results of inflammation may be enumerated in softening and general destruction of affected tissues; thickening and induration of tissues; ulceration and death of the affected parts.

Whether we have succeeded in producing anything like an understandable explanation of what is involved in the inflammatory process or not, we trust that, at least, it is made plain that by inflammation of this organ or that, something more than a commonplace change has been effected, and that the term is not a mere vague expression without any definite characteristics of its own. 



\section{CODE OF COMMON SUGGESTIVE SYMPTOMS.}

Abscesses, internal.-Blood Poisoning, Pneumonia, Pharyngitis.

Abscesses on body.-Blood Poisoning.

Abscesses at root of tooth.-Caries.

Abdomen, enlarged and pendulous.-Dropsy.

Action when lifting legs sharp and jerky with very cautious putting down of the feet.-Shiverer.

Anxious countenance.-Congestion of Lungs, Asthma, Gastritis, Rupture of Stomach, Peritonitis.

Appetite capricious.-Chronic Glanders, Indigestion, Dropsy, Diabetes Insipidus.

Appetite, loss of.-Simple Fever, Bilious Fever, Errysipelas, Glanders, Weed, Lymphangitis, Purpura, Bronchitis, Pneumonia, Newmarket Fever, Possible Poisoning, Dysentery, Congestion of the Liver.

Blood dark, does not form clot.-Blood Poisoning, Purpura.

Blood spots, small on nasal membrane.-Purpura.

Blood oozes from swellings about body.-Purpura.

Blood drips continuously from swellings.-Purpura.

Body covered with patches of cold sweat.-Congestion of Lungs, Palpitation, Bowel Obstruction, Crebro-spinal Meningitis.

Bones of the face bulge out.-Advanced Nasal Gleet.

Breathing becomes weak with deep sighing.-Rupture of Stomach.

Breath drawn in easily and quickly.-Asthma.

Breath foul.-Bilious Fever, Erysipelas, Caries.

Breathing irregular. - Carditis, Meningitis, Cerebro-spinal Meningitis.

Breath expired with difficulty.-Asthma, Heart Disease.

Breathing rapid and distressed. - Pleurisy, Newwarket 
Fever, Palpitation, Carditis, Spasm of Diaphragm, Flatulent Colic, Lock-jaw.

Breathing quickened - Simple Fever, Bilious Fever, Strangles, Erysipelas, Glanders, Farcy, Anthrax. Rheumatism, Weed, Lymphangitis, Rabies, Purpura, Common Cold, Laryngitis, Bronchitis, Pneumonia, Newmarket Fever, Aneurism, Congestion of the Liver, Mammitis.

Champing and grinding of teeth.-Lock-jaw.

Cheeks swollen.-Calculus in Parotid Duct (see under Parotitis).

Choke, tendency to, from swelling around throat.-Purpura.

Constipated bowels.-Bilious Fever, Purpura, Pneumonia, Newmarket Fever, Enteritis, especially in Foals, Diabetes Insipidus, Cerebritis, Meningitis.

Constipation accompanied with dry cough - (See under Nitric Acid and Alumina article on Constipation).

Convulsive struggles.-Anthrax, Vegetable Poisoning.

Cough soft.-Strangles, Glanders, Common Cold, Broken wind.

Cough hard and dry.-Laryngitis.

Cough short and dry.-Bronchitis.

Cough moist.-Pneumonia.

Cough short and catchy.-Pneumonia.

Cough difficult and painful.--Pleurisy, Asthma.

Cough excited by exercise, eating or drinking.-Broken Wind.

Cough accompanied by passing of wind per anum.-Broken Wind.

Cough varied.-Sore Throat.

Delirium.-Anthrax.

Discharge of blood from natural outlets.-Anthrax.

Difficulty in swallowing.-Sore Throat.

Drink, constant desire to.-Temple Fever, Bilions Fever, Lymphangitis, Weed, Common Cold.

Dropsical swelling of legs and abdomen.-Dilatation of the Heart.

Drumlike state of abdomen.-Flatulent Colic.

Dropsical effusions in the breast.-Nephritis. 
Dropsical effusion of the penis.-Nephritis.

Dullness, lifelessness.-Chronic Glanders, Bronchitis, Pneumonia, Dropsy, Congestion of the Liver.

Emaciated condition.-Aneurism, Dysentery, Diabetes Insipidus.

Endeavors to balance itself on its back.-Enteritis.

Eructation of gas by the mouth.-Gastritis, Indigestion.

Eyes, watery discharges from. - Common Cold, Pneumonia.

Eyes, staring and bloodshot.-Cerebritis, Meningitis, Cerebro-spinal Meningitis.

Eyes, swollen and red.-Influenza, Common Cold, Congestion of Lungs, Pneumonia.

Eyelids, swollen and diffused.-Gastritis.

Exhaustion, indications of.-Blood Poisoning, Asthma.

Exhaustion and distress.-Carditis.

Fæcal evacuations very fœtid.-Dysentery.

Fæcal evacuations with blood.-Dysentery.

Fæces light-colored.-Bilious Fever.

Fore legs set wide apart.-Pneumonia, Palpitation, Lock-jaw.

Fore leg flexed and resting on toe.-Rheumatism.

Food not digested.-Bilious Fever.

Food imperfectly masticated dropped in manger.-Caries.

Frequent ineffectual attempts to lie down.-Colic, Flatulent Colic.

Giddiness.-Erysipelas.

Glands between back of jawbone and neck (parotid) swollen.-Parotitis.

Glands parotid, swollen.-Laryngitis.

Glands between jaws swollen and hard -Glanders, Nasal gleet.

Glands between jaws swollen and soft.-Strangles, Nasal Gleet, Laryngitis.

Great excitability.-Rabies.

Grunting on being turned round.-Pleurisy.

Gums swollen and tender.-Lampas.

Head turned (either side) pointing to region of uterus.Metritis.

Head, inability to move sideways.-Parotitis. 
Head turned to off side pointing to region of liver.-Congestion of Liver.

Head hanging down.-Congestion of Lungs.

Head leaning on manger.-Brain, Teeth, Caries.

Head pressed against wall.-Anthrax, Indigestion with stupor.

Head poked straight out.-Laryngitis, Pneumonia, Indigestion, Lock-jaw.

Heaving at the flanks. - Influenza, Pneumonia.

Hiccough.-Spasm of Diaphragm.

Hind limbs flexed and resting on toe.-Rheumatism.

Hind legs, stiffness of, dragging gait.-Nephritis, Shiverer.

Hind fetlock joints knuckle over.-Constipation, Strain of Psoas Muscle.

Hind quarters pressed against wall of stable.-Bowel Obstruction.

Impatient of pain.-Bowel Obstruction.

Inability to swallow.-Strangles, Laryngitis, Glossitis, Caustic Irritation, Lock-jaw.

Inability to open mouth.-Lock-jaw.

Joints swollen, hot and tender.-Rheumatism.

Jugular pulse.-Dilatation of the Heart, Carditis.

Leaden hue of mucous membrane of nostrils.-Glanders, Farcy.

Leg swollen.-Dropsy.

Legs and body deathly cold.-Congestion of Lungs.

Legs and ears very cold.-Pneumonia, Nerwmarket Fever, Dilatation of Heart, Enteritis, Congestion of the Liver.

Lips and cheeks swollen.-Lampas.

Liquid returns through nose while drinking.-Obstruction of Gullet.

Licking stable walls.-Gastritis, Indigestion.

Lies down for a few minutes only at a time.-Dropsy.

Lips on either side hang pendulous.-Hemiphlegia.

Loins and thighs, muscular spasms of. -Azoturia, Shiverer.

Loins tender on pressure.-Metritis, Mammitis.

Looking round at flanks.-Influenza, Gastritis, Bowel Obstruction, Nephritis.

Loss of condition.-Glanders, Farcy, Indigestion. 
Masticate, inability to.-Paralysis.

Makes a noise in breathing.-Roaring, Polypus.

Mare after foaling rests full upon belly, knees, and hocks well under.-Retention of After-birth.

Mare stamps her feet, swishes tail, and postures to urinate.-Retention of After-birth.

Membrana nictitans of eye moves spasmodically.-Lockjaw.

Mouth đry and hot.-Enteritis.

Mouth and tongue cold and clammy.-Rupture of Stomach.

Movements of hind legs cannot be controlled.-Azoturia.

Mouth hot and clammy.-Erysipelas.

Movements cannot be controlled.-Influenza, Anthrax, Rabies, Cerebro-spinal Meningitis, Shiverer.

Muscular spasms in various parts of the body.-Cerebrospinal Meningitis.

Muscles hard and unyielding.-Rabies, Lock-jaw.

Nasal membrane red and dry.-Common Cold, Bronchitis.

Nasal discharge thick and viscid.-Chronic Glanders.

Nasal discharge rusty colored.-Pneumonia.

Nostrils dilated.-Influenza, Pneumonia, Lock-jaw.

Nose rested on seat of pain.-Bowel Obstruction.

Nose mucus discharge clotted.-Nasal Gleet.

Nose discharge mixed with blood.-Nasal Gleet.

Nose elevated.-Laryngitis.

Nose discharge yellow.-Newmarket Fever.

Noise creates excitement.-Rabies.

Paddling with the hind feet.-Traumatic Peritonitis, Cystitis.

Pain, paroxysms of.-Colic.

Pain and great uneasiness.-Rupture of Stomach, Bowel Ohstruction.

Pain in abdomen, constant.-Enteritis, Peritonitis.

Persistent pawing of fore leg but does not roll.-Gastritis, Indigestion, Mineral Poisoning, Colic, Trammatic Peritonitis.

Penis, sheath of, excessively swollen-cannot protrude when urinating.-Phimosis. 
Penis protrudes beyond sheath, cannot retract.--Paraphimosis.

Pointing with nose to seat of pain.-Weed, Peritonitis.

Prostration.-Influenza, Erysipelas, Carditis, Dysentery.

Protrusion of the anus.-Bowel Obstruction.

Pulse rapid.-Simple Fever, Bilious Fever, Strangles, Influenza, Erysipelas, Rabies, Glanders, Farcy, Rheumatism, Blood Poisoning, Weed, Lymphangitis, Purpura, Common Cold, Laryngitis, Bronchitis, Pneumonia, Newmarket Fever, Dysentery, Congestion of the Liver, Nephritis, Azoturia, Mammitis.

Pulse rapid, but weak. - Anthrax.

Pulse rapid and hard.-Pleurisy, Cerebritis, Meningitis, Cerebro-spinal Meningitis.

Pulse rapid and full.-Carditis, Metritis.

Pulse rapid, small, and wiry.-Pneumonia, Gastritis, Bowel Obstruction, Enteritis, Peritonitis.

Pulse rapid, small, and weak.-Congestion of Lungs.

Pulse soft and weak.-Diabetes Insipidus.

Pulse weak and intermittent.-Dropsy.

Pulse quick and thready.-Peritonitis.

Pulse intermittent and irregular.--Palpitation, Dilatation of the Heart, Carditis, Aneurism.

Pulse tumultuous.-Palpitation, Spasm of Diaphragm.

Refuses to be handled about mouth.-Lampas.

Region of liver just behind last rib, tenderness on pres. sure.-Congestion of Liver, Nephritis.

Respirations thoracic.-Influenza, Flatulent Colic, Peritonitis, Dropsy.

Resting on breast bone.-Indigestion.

Restlessness and uneasiness.-Cerebritis, Colic, Meningitis, Nephritis, Peritonitis.

Rolling and stretching.-Enteritis.

Roof of mouth swollen.-Lampas.

Rolls frequently.-Indigestion, Bowel Obstruction.

Running at the nose and eyes.-Strangles, Influenza.

Saliva dripping from mouth.-Anthrax, Caustic Glossitis, Influenza, Lampas, Lock-jaw, Foreign Substances in Gullet, Gastritis, Mercurial Poisoning, Rabies, Parotitis, Strangles.

Sediment in urine.-Rheumatism. 
Shaking.-Anthrax, Gastritis.

Shivering fits.-Simple Fever, Bilious Fever, Congestion of Lungs, Carditis, Dysentery, Enteritis, Peritonitis, Pleurisy, Pneumonia.

Staring coat.-Simple Fever, Bilious Fever, Influenza, Erysipelas, Glanders, Farcy, Common Cold, Nasal Gleet, Bronchitis, Congestion of Lungs, Indigestion, Dropsy, Diabetes Insipidus.

Standing position persistently maintained.- Carditis, Gastritis, Hemiplegia, Metritis, Pneumonia.

Stiff gait.-Rheumatism.

Stiffness in turning.-Aneurism.

Stupor with partial unconsciousness.-Indigestion.

Stiffness and soreness.-Influenza.

Straining to evacuate.-Bowel Obstruction.

Swelling of head, nostrils and lips.-Purpura.

Swelling or distension down groove of neck.-Gullet.

Swelling of legs.-Errysipelas, Aneurism, Influenza, Weed, Rheumatism.

Swelling about legs and body with exudation of fluid and blood.-Erysipelas, Weed, Purpura.

Swelling underneath abdomen that pits on pressure.Dropsy.

Swelling of abdomen with exudation of blood.-Anthrax.

Swelling of hind legs, high up extending downwards.Lymphangitis.

Sweating.-Anthrax, Carditis.

Swelling of skin, tense, bright red and shining.-Erysipelas, Weed.

Swishing of the tail.-Cystitis.

Temperature below normal.-Diabetes Insipidus, Mineral Poisoning.

Tail, jerky twitching of.-LLock-jaw.

Temperature heightened.-Bilious Fever, Simple Fever, Weed. Strangles, Influenza, Rabies, Erysipelas, Glanders, Farcy, Lymphangitis, Rheumatism, Blood Poisoning, Purpura, Common Cold, Laryngitis, Bronchitis, Pneumonia, Newmarket Fever, Pharyngitis, Enteritis, Dysentery, Peritonitis, Nephritis, Azoturia, Metritis, Mammitis, Cerebritis, Meningitis.

Tenderness over region of liver.-Bilious Fever. 
Tenderness on pressure over the loins.-Aneurism, Nephritis.

Tenderness on pressure of abdomen.-Enteritis, Peritonitis.

Testicles shrunken in size.-Impotence.

Thirst very great.-Bilious Fever, Simple Fever, LymphanThroat swollen.-Laryngitis.

Throat sore.-Common cold.

Tires quickly with little work.-Indigestion, Nasal Gleet.

Tongue dry and brown.-Primary Glossitis.

Tongue swollen and protruding.--Primary Glossitis.

Tongue swollen and whitish.-Caustic Irritation. gitis, Weed, Common Cold, Bronchitis, Dysentery.

Turning constantly to one side in walking.-Hemiplegia.

Udder swollen, hard and shining, the swelling extending along abdomen.-Mammitis.

Ulcers on legs.-Farcy.

Unconsciousness.-Anthrax.

Urine, inability to pass.-Colic, Metritis.

Urination, posing for.-Colic, Renal Congestion, Nephritis.

Urine, suppression of.-Renal Congestion, Nephritis.

Urine, high-colored.-Simple Fever, Bilious Ferer, Influenza, Purpura, Pneumonia, Carditis, Indigestion, Dropsy, Mammitis.

Urine diminished in quantity. - Simple Fever, Bilious Ferer, Influenza, Pneumonia, Carditis, Indigestion, Dropsy, Mammitis.

Urine increased in quantity.-Glanders, Farcy.

Urine coffee colored.-Azoturia.

Urine pale in color.-Glanders, Farcy.

Urine watery constituents excessive.-Diabetes Insipidus. Urine mixed with blood constantly dribbles from vagina.Cystitis.

Variable action of the bowels. - Indigestion.

Visible mucous membranes greyish-blue color.-Diabetes Insipidus.

Visible mucous membranes pallid.-Rupture of Stomach, Dropsy.

Visible mucous membranes yellow.-Congestion of the Liver.

Visible mucous membranes red and injected.-Cerebrospinal Meningitis. 
Vomition.-Ruptured Stomach.

Wasting of muscles.-Diabetes Insipidus.

Womb, mouth of, closed.-(See under Parturition.)

Yellow appearance of mucous membranes.-Bilious Fever, Influenza. 



\section{GENERAL INDEX.}

A

Abdominal Breathing, Character of . . . . . . 26

Abortion . . . . 238, 240, 250

Acari ........ . 3 35

After-birth . . . . . 237

Air, Ingress of . . . . . . 16

Air, Egress of . . . . . . 16

Allopathy and Homœopathy, Their Distinction. . .

Allopathy Has no Guiding Principle..........

Allopathists, How They Prescribe . . . . . . . . xi

Allopathic Prescribing Uncertain . . . . . . xii

Allopathic Prescribing Is Not

Precise .. . . . . . . xii

Allopathic Prescribing, Why it

Fails ........ . xii

Anthrax ...... . . 72

Aneurism ....... . I46

Antidotes ........ I65

Aorta . . . . . . . . . I 35

Artery and Vein, How to Distinguish ...... 24

Arteries . . . . 9 92, I35, I46

Arthritis . . . . . . 248

Asthma . . . . . . . I 26

Ascites . . . . . . . . 197

Astringents . . . . . 207

Ascaris Megalocephala . . . 320

Atrophy . . . . . . . . I46

Attenuation, The Meaning of . 35

Attenuation, The Advantages of ........ . 35

Attenuation, Processes of . . . 35
Attenuation, Action of Drugs

Developed by ..... 36

Attenuation, Comparative Strength of Drugs Developed After . . . . . . 38

Attenuation, Physiological Activity Produced by . . . 40

Attenuation, Drugs Rendered

More Active by . . . . . . 4I

A uscultation of Chest . . 27, II9, I42

Auscultate, How to . . . . 27

Auscultation Practice on

Healthy Animals Desirable, 27

Auto-inoculation . . . . 69

Azoturia . . . . . . 227

B

Bacillus Anthracis . . . . 73

Balling Instrument . . . . . I54

Barrenness ..... 240, 253

Back Sinews . . . . . 286

Belching Up Wind . . . . I73

Bladder, Inversion of . . . . 226

Blowing ....... 25

Blood Poisoning ...... $\mathrm{S}_{2}$

Bone Sparin . . . . . . 29r

Bog Spavin . . . . . 29I

Bronclitis ..... I 10

Brain . . . . . . . . 32

Breathing Rapid, an Indication of Coming Illness . . . . 25

Breathing, Differences in Character of . . . . . . 26

Breathing, Different Sounds of . 27

Breathing, Modifications of . . 27

Brokell Wind . . . . . I 26

Broken Wind, How Indicated . 26 
Broken Knees . . . . . . 287

Broncho-pneumonia ..... . II5

\section{C}

Cataract . . . . . 306

Canker ....... 301

Calculus . . . . I I79, I80, 227

Calculus, Possible Presence of . 32

Calculus, Symptoms Suggestive of . . . . . . . 32

Capped Hock . . . . . . . . . 294

Catarrh . . . . . . . . 97

Capillaries . . . . . . I I33

Carditis . . . . . . I40

Caries . . . . . . . I53

Canula ......... . I 88

Canon Bones. . . . . . 285

Centicimal Scale . . . . 36

Cerebritis . . . . 266

Cerebro-spinal Meningitis . . 268

Chyle ......... 89

Chorea .. . . . . . . . 275

Chorde Tendinæ . . . . . I42

Circulatory System. . . . . I32

Cleanliness of Stable, Reasons for and Importance of . . . I6

Cleanliness, Danger Where Neglected . . . . . . I6

Code of Symptoms . . . . 327

Coryza . . . . . . . . . . 96

Corona .. . . . . . . 289

Common Cold . . . . 96, III

Corns . . . . . . 30I

Coma . . . . . . . . . I64

Coronary Band. . . . . . 299

Congestion of Kidneys . . . . 217

Congestion of the Liver . . . . 2II

Constipation . . . . . I98

Constipation, Not Necessary to

Purge for . . . . 32

Co-ordination . . . . . 264

Colic ... . . . . . I $\mathrm{I}_{3}$

Colic, Horse Should be Allowed to Roll When Suffering from . . . . . . . 32

Cracked Heels . . . . . . 3I2
Crural Muscles . . . . . . 284

Crib-biter ....... 173

Curb . . . . . . 29r

Cystitis ....... 225

$\mathrm{D}$

Dermatodectes .. . . . 3 3 I7

Decimal Scale . . . . . 36

Decayed Teeth....... I53

Disinfection, Necessary,

$$
48,62,63,72,76,379
$$

Diseases, Arrangement of . . 43

Diseases, Classification of . . . 43

Diseases not all Cured by Drugs, I2

Diagnosis . . . . . . . . $2 I$

Diaphragm, Spasms of . . . 148

Digestive System . . . . . . 149

Diarrhœa . . . . . . . 205

Diabetes ........ . 223

Diabetés Mellitus . . . . . 223

Diabetes Insipidus . . . . . 223

Dose, The . . . . . . . . 34

Dose, General Quantity for a : $\quad 39$

Dose, Repetition of the . . . 39

Dosage . . . . . . . 34

Doors, Their Use . . . . . I6

Drainage of Stable . . . . I I7

Droptsole . . . . . . 298

Dropsy ....... . I24, I97

Drugs, The Strength of . . . . 34

Drugs When Given in Crude

Form . . . . . 38

Drugs, Strength of in Various

Forms of Disease . . . 38

Dyspepsia . . . . . . I67

Dysentery ....... I 192

\section{$\mathrm{E}$}

Ears, Diseases of . . . . 309

Eczema . . . . . 3 314

Eczema Impetiginodes . . . 3 I4

Ectropium . . . . . 308

Elbow Lameness . . . . . 285

Elephantiasis . . . . . 3 I5

Embolism . . . . . . I 46

Emphysema ...... I 28 
Entropium . . . . . . 308

Endo-metritis . . . . 24I

Enema Pump . . . . . . I82

Endo-carditis ...... . I I

Enteritis . . . . . . I90

Erysipelas . . . . . 58

Erythema . . . . . 3I2

Exostoses . . . . . . 288

Exposure . . . . . . 80

Experimental Inculation . . . 74

Eyes ... . . . . . 304

$\mathrm{F}$

Farcy . . . . . . . 6I

Fatigue .. . . . . . 80

Fetlock Joint, Sprain of . . . . 288

Fever, Low Type Produced by Want of Cleanliness . . . 18

Fever, Simple . . . . . 45

Fever, Bilious . . . . . . 46

Fireplaces in Stables Advantagous . . . . . . . . I7

Fistulous Withers .... 3 $\mathrm{II}$

Filaria Papillosa . . . . 32I

Flooding After Birth . . . . . 238

Flatulent Colic . . . . . . I 86

Flexor Tendons . . . . . 285

Foot, The ........ 294

IFoal, The ....... 246

Fœtal Membranes . . . . 237

Fracture of Suffraginis . . . 288

Fungus Hæmatodes . . . . . . 306

G

Gastritis . . . . . . 162

Generative Organs, Diseases of $2 \mathrm{I} 4$

General Diseases . . . . . 45

Glanclers. . . . . . . 6 r

Glanders, Chronic . . . . 66

Glands . . . . . . . S8

Glossitis . . . . . . I56

Gonorrhœea...... 230

Grapes . . . . . . 315

Gravel ...... . 227

Grunter . . . . . . IO4
Grease . . . . . . 3I5

Gullet . . . . . I49, I6I

$\mathrm{H}$

Hæmorrhoids . . . . . 201, 204

Hæmorrhage Post Partum. . . 238

Hepatitis . . . . . . 212

Health, Preservation of . . . 15

Heart Beats, How to Count . . 23

Heart Valves . . . . . . . 78

Heartburn . . . . . . . 169

Heart . . . . . . . . 88, 132

Heart, Dilatation of . . . . I 38

Heart, Fatty Degeneration of . 146

Hemiplegia . . . . . . . 277

Hernia Umbilical . . . . . . I82

Hernia Scrotal . . . . . I 182

Hernia Strangulated . . . . I82

Hiccough . . . . . . . . $\mathrm{I} 48$

Homœopathic Principle Unaf-

fected by Dose..... . 34

Homœopathy and Allopathy, their Distinction ... . . vii

Homøoopathy, What is it . . . viii

Hom œopathic I aw . . . . . . xi

How to Determine What is the

Matter . . . . . 2I

Hock, the . . . . . . 290

Hygieue, Principles of ... I5

Hypertrophy of Heart . . . ${ }_{13} 8$

I

Impotence . . . . . . 232

Importance of Drug Symptoms $\mathbf{x}$

Internal Parasites . . . . . 320

Intestinal Obstruction . . . 176

Influenza . . . . . . 50

Introduction . . . . . . $\mathrm{ii}^{\mathrm{i}}$

Indigestion . . . . . . . I 67

Indigestion in Foals . . . 250

Intestines, the $\quad . \quad . \quad . \quad 174$

Inflammation . . . . . 32 I

Inflannuation of Lungs . . . 115

Inflan1111ation of Heart . . . 140

Inflammation of Arteries . . 147 
Inflammation of Veins . . . I47

Inflammation of Tongue . . 156

Inflammation of Parotid Glands 157

Inflammation of Pharynx . . $\quad$ I59

Inflammation of Stomach . . . I62

Inflammation of Intestines . . I90

Inflammation of Peritoneum . I95

Inflammation of Liver . . . 2I 2

Inflammation of Kidneys . . 219

Inflammation of Bladder . . . 225

Inflammation of Uretha. . . 229

Inflammation of Testicles . . 23I

Inflammation of Vagina . . 24I

Inflammation of Uterus . . . 24I

Inflammation of the Womb . . 242

Inflammation of the Udder . . 244

Inflammation of Brain . . . 266

Inflammation of Meninges . . 266

Inflammation of Foot . . . 296

Inflammation of Conjunctiva . 304

Intersusception . . . . I 76

Incarceration . . . . . . I 17

Invagination . . . . . I I77.

Isolation . . . . . . . 62

$\mathrm{J}$

Joints . . . . . . 77

Joint Ill . . . . . . . 249

Joint Oil . . . . . . 287

Jugular Veins . . . . . . I39

$\mathrm{K}$

Kidneys, Congestion of . . . 217

Knee. . . . . . . . . 285

\section{I}

Lamminitis . . . . 228, 298

Lampas . . . . . . . I54

Laryngitis . . . . . . . IOI

Lameness . . . . . . . 278

Leucorrhœa . . . . . 24

Ligament . . . . . . . 77

Ligament, Sprains of . . . . 2SI

Liver ......... 2IO
Light From Stable Roof, Its Advantage and Disadvantage . . . . . . . I I7

Light, Importance of, to Preserve Eyesight . . . . . I7

Lice . . . . . . . . . 3 I9

Local Paralysis...... . 277

Lock-jaw . . . . . . 27r

Lungs . . . . . . . . I09

Lungs, Congestion of . . . II 5

Lymphangitis . . . . . 58,87

Lymphatic Vessels . . . 6I, 88

\section{M}

Mallein ..... . 63,64,68

Mammitis ...... 244

Mallanders ....... $3 \mathrm{I} 3$

Mange . . . . . . . $3 \mathrm{I} 7$

Maw Worm . . . . . 320

Medicine, How it Enters the Body... . . . . 37

Medicine, Not Necessarily Required Strong for Animals . 38

Medicine, Best Vehicles for Administering . . . . . 39

Medicine, How to Administer . 39

Membrana Nickitans . . . 272

Meningitis . . . . . 266

Metritis . . . . . . 242

Mesentery . . . . . . I76

Miscarriage . . . . 250

Monday Morning Disease . . $\mathrm{S}_{7}$

Moisture . . . . . . . . . Sa

Mortification . . . . . . IgI

Mud Fever....... 3I2

Muscles ......... 77

Muscles, Sprains of the ... $28 \mathrm{I}$

Musicians . . . . . . I I I

\section{$\mathrm{N}$}

Nasal Gleet . . . . . . 97

Navicular Disease. . . . . 296

Nephritis . . . . . . 219

Newmarket Fever . . 83, I06, I 29

Nervous System . . . . . 260 
Neurotomy . . . . . . . 298

Nettlerash ........ $3 \mathrm{I}_{3}$

$\mathrm{O}$

CEstrum . . . . . . . $24 \mathrm{I}$

Essophagus ........ . . I6I

Opthalmia ....... . 304

Orchitis ........ 231

Os Uteri . . . . . . . . 236

Os Dilator . . . . . . . . 254

Oxygen Gas . . . . . . . 55, 76

Oxyuris Curvula .. . . . 320

$\mathrm{P}$

Parasites ....... 305, 315

Parasites, Internal . . . . 320

Pathological Names Unreliable xiii

Pain, Locality of, How Indicated... . . . . . $3 I$

Paraplegia . . . . . . 277

Palpation... . . . . . I 35

Palpitation ....... . . 136

Paraphimosis .. . . . . . 230

Parturient Fever . . . . . . 242

Parotid Glands .. . . . . IOI, IO5

Parotitis . . . . . . . . . I57

Parotid Glands, Inflammation of I57

Parturition . . . . . . . 233

Parturition, Diseased Condition

Incidental to . . . . . 240

Paralysis, General . . . . 276

Peritonitis . . . . . . . I95

Percussion ....... . . 95

Pericarditis . . . . . . . 138

Periosteum . . . . . . 288

Phlebitis . . . . . . . . I55

Pharynx .. . . . . . I49, I59

Phimosis . . . . . . . 230

Pharyngitis ....... . . 168

Piles... . . . . . 201, 204

Pleura......... . 95, I10

Pleuro-pneumonia . . . . II5

Pleuro-pneumonia Septic . . I.30

Pleurisy . . . . . . . 123

Pneumonia . . . . . . . II6
Potencies . . . . . . . 34

Potencies, Varieties of . . . 35

Poll Evil ....... 30, 310

Polypus .......... . 105

Presentations .. . . . . . 234

Presentations, False .. . . 234

Probang . . . . . . . . . I62

Prolapsus Ani . . . . . . . . I94

Preservation of Health . . . xiii

Premature Birth .. . . . 250

Protrusion of Bowels . . . . I94

Psoas Muscle. . . . . . . . 283

Pulsations, Normal Numbers of 23

Pulsations, Variations of . . . 23

Purpura Hæmorrhagica . . . . 92

Pulse, the Character of the . . 23

Pulse, Practice the Taking of . 24

Pulse, Special Points in Taking

Pulse, Where to Take it . . . . 24

Pulse, Variations of, What They suggest. . . . . . . . 24

Pulse, Value Diagnosis of . . . 25

Pulse and Respirations, Relationship Between . . . . 26

Pulse, Uniformity with Temperature and Respiration not Absolute .. . . . . 27

Pyæmia ......... 82

\section{Q}

Quidding . . . . . . . . I53

Quittors . . . . . . . 302

R

Rabies . . . . . . . . . $S_{5}$

Renal Congestion .. . . 2 I7

Respiratory Organs . . . . . 95

Remedies, Sensitiveness of Hon1œopatilic....... . 40

Restlessness . . . . . . . So

Respiration . . . . . . 25

Respirations, Normal Number of 26

Respirations, How to Observe . 26

Respirations and Pulse, Rela-

tiouship betwee1 . . . . 26 
Respirations, Uniformity with Pulse and Temperature not Absolute

Respiratory Murmurs . . . . 27

Retention of Fœtal Membranes 237

Rheumatism ...... . 77

Ringbone . . . . . . . 289

Ringworm ........ . 3 I9

Roaring . . . . . . . . . IO3

Rolling, to Prevent, in Colic is

Erroneous ..... 32

Roof, best for Ventilation . . . 16

Rupture . . . . . . . . . I80

Rupture of Intestinal Walls . . I88

S

Sanitation, Principles of . . . I I5

Satyriasis . . . . . . 232

Sandcrack . . . . . 30I

Sallanders ....... . 3 33

Sarcoptis . . . . . . . 317

Scabies ...... . 3 $\mathrm{I} 7$

Septicamia . . . . . . 82

Seedy Toes . . . . . . 30I

Shiverer . . . . . . 275

Shivering . . . . . . 275

Shoulder Lameness . . . . 284

Shoulder Slip . . . . . . 285

Sirle Bones. . . . . . . . 296

Sighing. . . . . . . . I73

Skin, Diseases of the... . 3 12

Sore Teats....... . 246

Sore Throat ....... I59

Speculum. . . . . . I05

Sprains. . . . . . . 28I

Splints . . . . . . . . 288

Strongulus Tetracanthus. . . 206

Strongyulus Armatus . . . . 320

Stringhalt . . . . . . 275

Stethoscope. . . . . . . . 135

Stamping Out. . . . . 68

St. Vitus' Dance. . . . . . . 275

Strangles. . . . . . . 47

Staggers . . . . . . . . . 264

Stomach, Rupture of . . . . I70
Stomach Staggers. . . . . . I68

Stupor . . . . . . . . . . I I64

Stifle. . . . . . . . 290

Stable, Construction of . . . I5

Stable, Drainage of . . . . I5

Stable, Lighting of . . . . . I6

Stable, Importance of Site, Soil and Aspect . . . . . . I6

Suffraginis . . . . . . 288

Super-purgation. . . . . . 207

Suspensory Ligaments. . . . . 285

Swollen Glands (see Strangles) . 47

Symbiotes . . . . . . 3 37

Synovia. . . . . . . 285

Symptoms, How Expressed by Animals . . . . . . xi

Symptoms, Totality of Necessary ......... xii

Symptoms, How to Recognize Totality ....... 29

Symptoms, How to Observe in Various Organs . . . . . . . 29

Symptoms, Objective. . . 29

Symptoms, Subjective. . . . 30

Symptoms, Same in Different

Maladies . . . . . 43

\section{$\mathrm{T}$}

Tape Worm. . . . . . . \$20

Teats, Sore . . . . . . 246

Teeth. . . . . . . . I52

Temperature, Normal in Horse . 22

Temperature, Importance of

Determining . . . . . 22

Temperature of Stables. . . I6

Temperature, Best in Building . 17

Temperature in Relation to

Pulse and Respiration .. . 25

Temperature, Uniformity with Pulse and Respiration not

Absolute ....... 25

Temperature an Important

Guide ....... 29

Tetanus ....... . 27 I

Tendons . . . . . . 77 
Tendons, Sprains of .... 28I

Thermometer, its Value and Use . . . . . . . . 22

'Thermometer, When to Use . . 22

Thermometer, Varied Registration of.

Time Best for Watering Horse .

Time to be Allowed Between Watering and Feeding . . 20

Thrush

Thoroughpin . . . . . . 293

Thick Wind ..... II3, I22

Totality of Synıptoms . . . . $\mathrm{x}$

Tonsils ........ . . I59

Trachea ...... I06, I09

Tracheotomy ... . . . . 93

Trituation, Advantages of . . 36

Treatment, How to Determine . 21

Treatment, Local Combined with Internal . . . . 30

Trochar . . . . . . . I 188

Trephining ........ 99

Twist . . . . . I79, I8I

U

Ulcers . . . . . . . 6I

Urinary Organs, Diseases of, 214, 229

Urticaria . . . . . . 3 13

Urethra . . . . . . . 229

Uterus, Inversion of . . . 239

Uterus, Displacement of . . 254
V

Valvulitis . . . . . I 40

Vaginitis ....... . 24I

Venous Pulse ....... I 142

Veins . . . 88, I33

Ventilation of Stable . . . I5

Ventilation, a System of . . . 16

Virus .. . . . . . 6I

Vomiting ..... 170

\section{W}

Warmth of Body, How Best Maintained .. . . . . 16

Water, Service of . . . . . I9

Water, Hard to be Boiled I9

Water, Influence on Digestive organs ......... . 19

Water, Purity of Supply Tested, 76

Watering Horse, Reasons for

Special Time . . . . 20

Weed . . . . . . . $S_{7}$

White, Fibrous Tissue . . . 77

Whistler ........ . I04

Windpipe ...... 106, 109

Windows, Their Use ... r6

Wind Sucker. . . . . . 169

Womb, Inversion of . . . 239

Womb, Displacement of . . . 235

Womb, Inflammation of . . . 242

Wool Sorters' Disease . . . . 74 



\section{CATALOGUE OF}

\section{Popular Homeopathic}

\section{AND OTHER WORKS}

PUBLISHED BY

BOERICKE \& TAFEL,

HOMGOPATHIC PHARMACISTS, IMPORTERS AND PUBLISHERS.

Philadelphia: 1011 Arch St. and 111 S. 13th St.

New York: 145 Grand St. and 15 W. $42 d$ St.

Chicago: 44 E. Madison St.

Pittsburgh : 627 Smithfield St.

Baltimore: 228 North Howard St.

Business Established in 1835.

Cincinnati: 204 W. 4 th St.

Boericke \& Dewey, Drs. The Twelve Tissue Remedies. Schüssler. Third edition. Revised and enlarged. 384 pages. 8 vo. Cloth, $\$ 2.50$ net. By mail, \$2.68.

The only complete work published in English, on The Truelve Tissue Remedies, or the "biochemic" treatment of disease.

Bradford, Dr. T. L. The Life and Letters of Dr. Samuel Hahnemann. 5I 3 pages. 8vo. Cloth, \$2.50 net. By mail, $\$ 2.75$.

Near half a century elapsed after the death of the greatest of medical reformers before his life was written. But it is now well written. A book of great interest and permanent value.

Custis, Dr. M. A. The Practice of Medicine. A condensed manual. 360 pages. Flexible leather. Gilt edges and round corners. $\$ 2.00$. By mail, $\$ 2.07$. 
The best condensation of the practice of medicine, with therapeutics, ever written. It names, describes and gives the treatment of every known disease. Especially adapted for all students of medicine.

Dewey, Dr. W. A. Essentials of Homceopathic Materia Medica. Second edition. 294 pages. Cloth, \$1.50. By mail, \$r.58.

-Essentials of Homœopathic Therapeutics. 266 pages. Cloth, \$I.5O. By mail, \$I.58.

These two works are designed for those who want to get an insight into the subjects treated.

Ellis, Dr. John Avoidable Causes of Disease, Insanity and Deformity. 396 pages. Cloth, \$I.5O. Mailed post-paid on receipt of price.

Dr. Ellis is the well-known temperance writer and this book has been a favorite for many years.

Gallavardin, Dr. The Homoepathic Treatment of Alcoholism. I 38 pages. Cloth, 50 cts. By mail, 56 cts.

A work by the famous French psychopathist and homœopathist, who is known throughout France for his wonderful cures.

Guernsey, Dr. E. Homoepathic Domestic Practice. Ioth edition. 653 pages. 8vo. Half morocco, \$2.50. Mailed post-paid on receipt of price.

A favorite domestic work.

Hahnemann. Organon. 244 pages 8vo. Cloth, $\$$ I.75. Mailed post-paid on receipt of price.

This book is the philosophical corner-stone of Homœopathy. It is highly interesting reading.

Helmuth, Dr. W. T. With the "Pousse Cafe." I4 I pages. \$I.00 net. By mail, \$ro8.

Dr. Helmuth's verses are one of the social land-marks of Homœopathy.

Hensel, Julius. Macrobiotic, or our Diseases and our Remedies. Translated from the German. 20I pages. 8vo.

Cloth, \$I.50 net. By mail, \$I.62.

Not homœopathic but physiologic.

Hering, Dr. C. The Homoopathic Domestic Physician. $45^{8}$ pages. 8 vo. Cloth, $\$ 2.50$. Mailed post-paid on receipt of price.

No man did more for Homœopathy in the United States than Constantine Hering. His "domestic" is one of the best. 
Holcombe, Dr. W. H. How I Became a Homceopath. 28 pages. Paper, I 5 cents. By mail I 7 cents.

-What is Homoopathy' 28 pages. Paper, Ij cents. By mail, I 7 cents.

- The Truth About Homoopathy. 43 pages. Cloth, $2.5 \mathrm{cts}$. net. By mail, 28 cents.

Three as good little "missionary" works as were ever printed. The last one is Dr. Holcombe's final word; the MSS. was found in his desk after his death.

Jones. Dr. S. A. The Grounds of a Homceopath's

Faith. 92 pages. Cloth, 30 cents. Mailed post-paid on receipt of price.

Three brilliant addresses with which Dr. Jones faced, demoralized and routed the whole faculty and students of an Allopathic college.

Jones, Dr. Stacy. The Medical Genius. A guide to the Cure. 320 pages. 8vo. Cloth, \$2.00. By mail, \$2. I I.

An immensely popular book. Gives homœopathic and also other treatments-the simple, yet practical, treatments of experience.

-The Bee-Line Repertory. 2 Io pages. Flexible leather. Gilt edges, round corners. \$I.00 net. By mail, \$I.03.

A very popular homœopathic repertory.

Laurie \& $\mathrm{McClatchey,} \mathrm{Drs.} \mathrm{The} \mathrm{Homoeopathic} \mathrm{Do-}$ mestic Medicine. 1044 pages. 8vo. Half morocco, \$5.00. Mailed post-paid on receipt of price. The oldest, largest and completest work on domestic practice published.

Johnson, Dr. I. D. A Guide to Homoepathic Practice. 494 pages. 8vo. Cloth, \$2.00. Mailed post-paid on receipt of price.

A very popular work on account of its extreme clearness and simplicity.

Lutze, Dr. A. A Manual of Homocopathic Theory and

Practice. Translated from the sixtieth thousand German edition. 750 pages. 8vo. Half morocco, \$2.50. Mailed post-paid on receipt of price.

It is the book in Germany, the home of Honnœopathy, for the people.

Manual of Homoopathic Veterinary Practice. Second edition. 684 pages. 8vo. Half morocco, \$5.00. Mailed post-paid on receipt of price.

The completest work on Homceopathic Veterinary Practice. Includes treatment of all chmestic animals. 
Morgan, Dr. S. Text-book of Domestic Practice. I9I pages. Cloth, 50 cents. Mailed post-paid on receipt of price. Our smallest "domestic."

Poultry Doctor. 85 pages. Cloth, 50 cents. Mailed post-paid on receipt of price.

The only homœopathic work on the diseases of the feathered creation.

Ruddock, Dr. E. H. Stepping-stone to Homoepathy and Health. Latest revised American edition, by Wm. Boericke, M. D. 256 pages. Cloth, \$I.oo. Mailed postpaid on receipt of price.

A very satisfying little work and one well adapted for individuals and families.

Safety in Cholera Times. 63 pages. Cloth, 50 cents net. By mail, 54 cents.

A book you need when cholera approaches.

Sharp's Tracts on Homoopathy. 232 pages. 8vo. Cloth, 75 cents net. By mail, 87 cents.

These tracts have probably made more converts to Homœopathy than any other publication of a similar nature.

Small, Dr. A. E. A Manual of Homoepathic Practice for the Use of Families. Fifteenth edition. 83I pages. Half morocco, \$2.50. Mailed post-paid on receipt of price.

A fine old work and the favorite of many.

Sexual Ills and Diseases. I6o pages. Flexible leather.

Gilt edges and round corners. \$1.00. By mail, \$105.

The best book on the subject ever written for the public. Clear, practical and helpful to young and old, married and unmarried. Gives proper medical treatment for all sexual troubles. Verdi, Dr. T. S. Maternity. 450 pages. Cloth, $\$ 2.00$. Mailed post-paid on receipt of price.

A wholesome book for young wives about to become mothers. -Mothers and Daughters. 287 pages. Cloth, \$I.5O. Mailed post-paid on receipt of price.

A book instructing the mother as to the care of her daughters from infancy to marriage.

-Home Treatment of Disease, for Popular Use. 579 pages. 8vo. Cloth, \$3.50. Mailed post-paid on receipt of price.

The latest work on domestic practice published, and a most excellent one.

Complete Catalogue of Books Mailed on Application. 






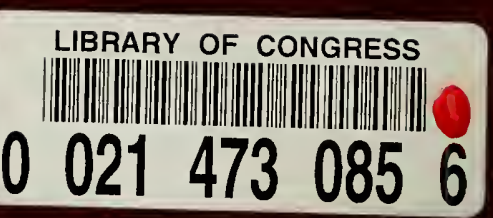

